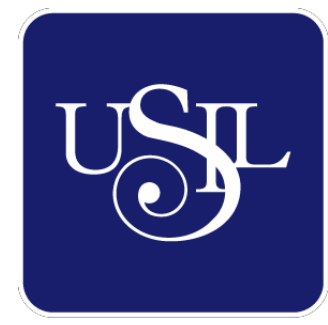

UNIVERSIDAD

SAN IGNACIO

DE LOYOLA

ESCUELA DE POSTGRADO

\title{
PLAN DE NEGOCIOS PARA UNA EMPRESA QUE AYUDE A FINANCIAR IDEAS DE NEGOCIO EN LA CIUDAD DE AREQUIPA
}

Trabajo de Investigación para optar el grado de:

CESAR BOBADILLA MEDINA

Maestro en Ciencias Empresariales con Mención en Gestión de Proyectos

YENNZY PAOLA VARGAS AMARO

Maestro en Ciencias Empresariales con Mención en Gestión de Proyectos

Asesor:

Dr. Edmundo Rafael Casavilca Maldonado

Lima - Perú

2019 


\section{Resumen Ejecutivo}

La creatividad y el emprendimiento son las mayores virtudes del poblador peruano, siendo este el espíritu que domina los negocios del país. Las pequeñas y microempresas desempeñan un papel fundamental en la economía peruana: contribuyen a la creación del empleo, disminuyen la pobreza e incrementa el Producto Bruto Interno. Sin embargo, son muchas las ocasiones en las que una buena idea de negocio no puede ser desarrollado porque no cuenta con los medios económicos necesarios, en contraparte hay personas que poseen un capital y buscan la forma de cómo invertirlo.

En conclusión se tiene dos grupos de personas: las que poseen capital y buscan la forma de cómo invertirlo y las personas que no acceden a los financiamientos tradicionales, este distanciamiento se profundiza por las carencias de métodos para unirlos, teniendo como consecuencia una incorrecta inclusión financiera.

El presente plan de negocio propone la creación de IDeltas S.A.C, una empresa cuya finalidad es ayudar a contactar a inversores que buscan obtener rentabilidad por su capital y a personas que necesitan financiación para sus emprendimientos o negocios. Para ello se ha valido de estrategias de Crowdfunding, que es un mecanismo de financiamiento colectivo.

En cuanto al sector, este método es nuevo en nuestro país, pero a nivel mundial el crowdfunding ha mostrado gran potencial.

IDeltas ofrecerá el servicio de asesoramiento, contando con los siguientes productos: Venta por adelantado, licitación de préstamos, servicios especiales y capacitación. El servicio consiste en una atención personalizada, a través de las oficinas y plataforma web, los cuales son el punto de encuentro entre los clientes, buscando cumplir sus expectativas y necesidades, en contraparte IDelta hará el cobro de comisiones por la prestación de dichos 
servicios. Cabe resaltar que IDelta no efectuará intermediación financiera y que tampoco tiene decisión sobre el destino del dinero ni lo hace suyo, solo se encargará de canalizarlo de los inversores hacia los que buscan un financiamiento. IDeltas se encargará de recopilar información de los clientes que deseen hacer uso de nuestros servicios, tanto inversionistas como de los que buscan financiamiento, con la finalidad de armar un perfil y validar la información, como por ejemplo evaluar el historial crediticio del cliente.

El segmento de mercado al que va dirigido es a personas entre los 25 y 55 años de edad, pertenecientes al PEA (población económicamente activa) que radiquen en la ciudad de Arequipa.

En cuanto a la inversión, se requerirá de US\$ 41,754 donde el 100\% será capital social.

El costo de oportunidad (COK o Ke) del proyecto asciende a 9.74\%, considerando que el proyecto no cuenta con apalancamiento financiero, el Costo promedio ponderado de Capital (WACC) será el mismo.

El VAN del proyecto asciende a US\$26,074 con una TIR de $31 \%$, por tanto podemos concluir que la propuesta es rentable.

Finalmente, es a través de este plan de negocio para IDeltas S.A.C. que se busca ser el punto de encuentro entre inversores y prestatarios, a través de nuestras instalaciones y plataforma, facilitando y ayudando a ambas partes a satisfacer sus necesidades de una forma sencilla, ágil y sobre todo transparente, donde los clientes deben tener a su alcance oportunidades a través de nuevas estrategias de financiación y tecnología. 


\section{ÍNDICE}

Introducción $\quad 8$

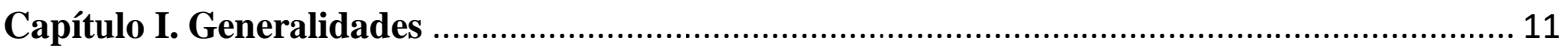

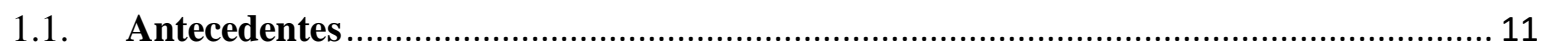

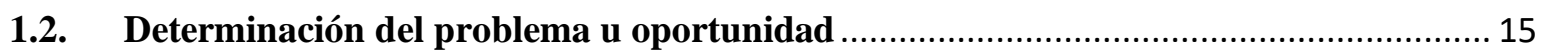

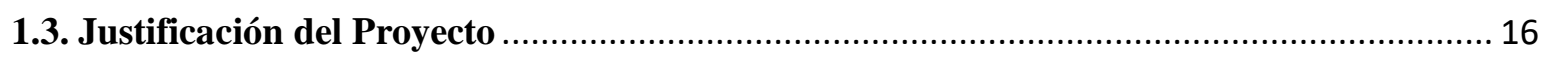

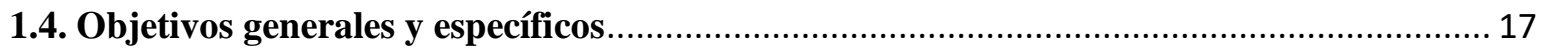

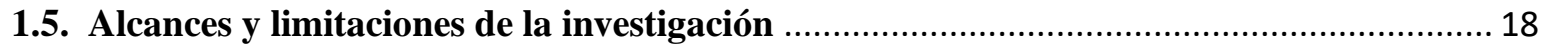

Capítulo II. Estructura Económica del Sector .......................................................................... 20

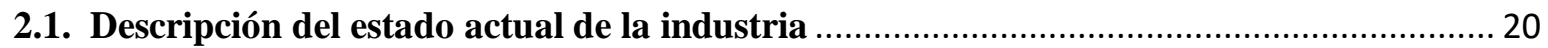

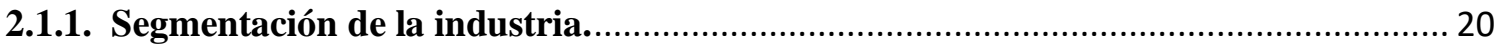

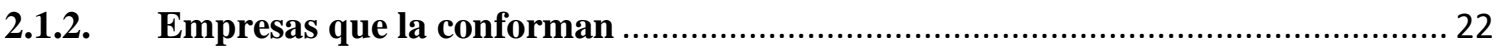

2.2. Tendencias de la industria (crecimiento, inversiones) ..................................................... 27

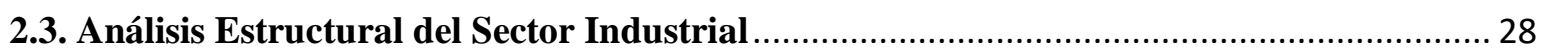

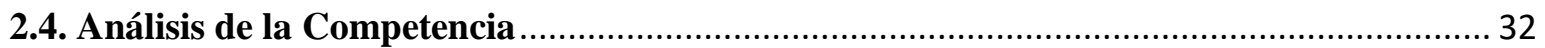

2.4.1. Empresas que ofrecen el mismo producto o servicio (indicando las semejanzas y diferencias que tienen con el proyecto de empresa) ............................................................ 33

2.4.2. Participación de mercado de cada uno de ellos........................................................ 34

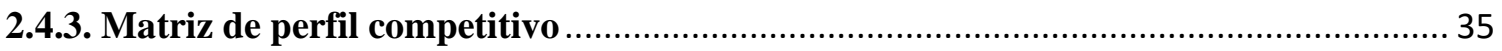

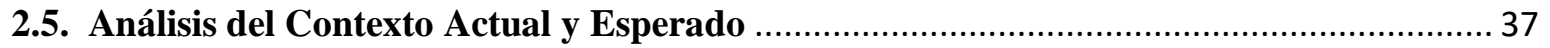

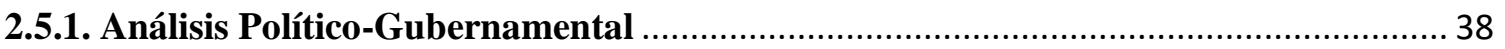

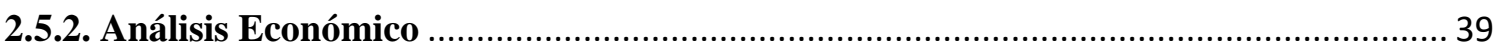

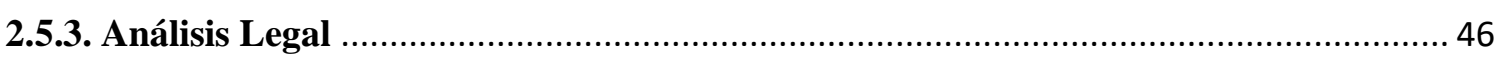

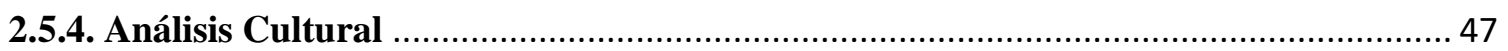

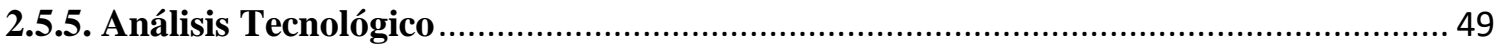

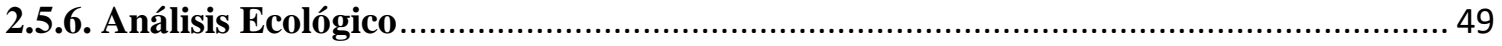

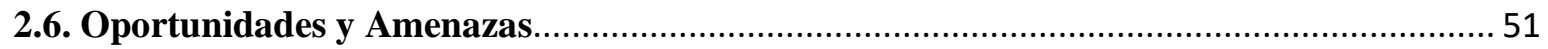

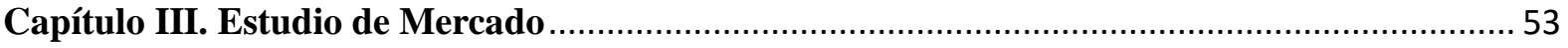

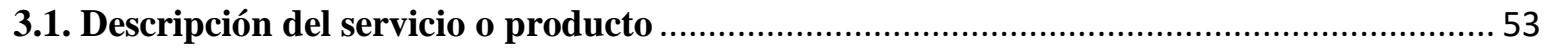

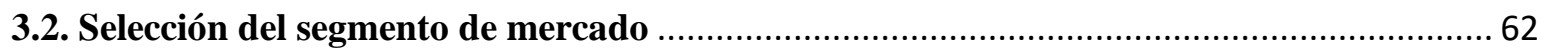

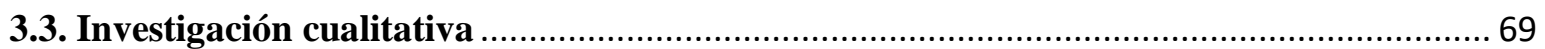

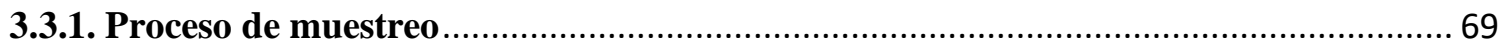




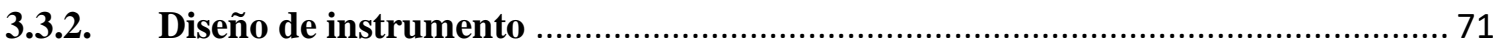

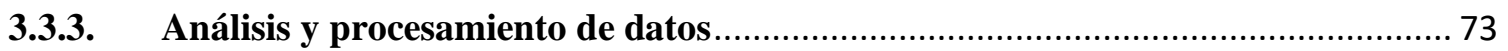

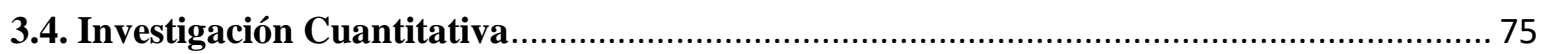

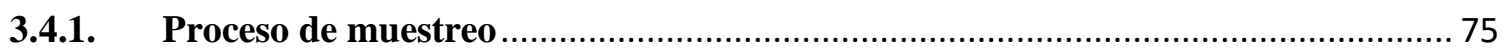

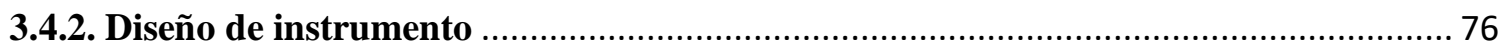

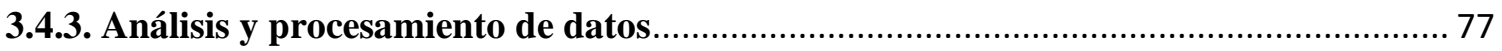

3.5. Conclusiones y recomendaciones del Estudio Cualitativo y Cuantitativo........................... 90

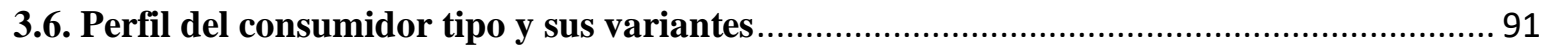

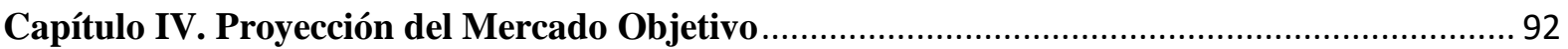

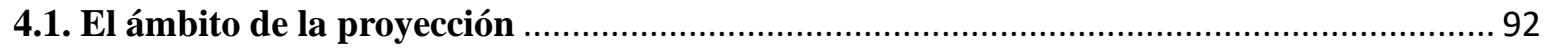

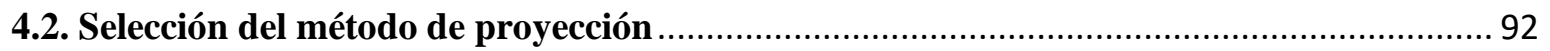

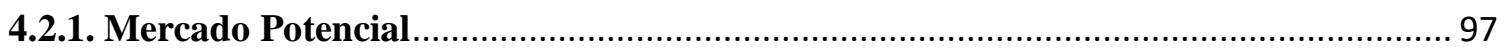

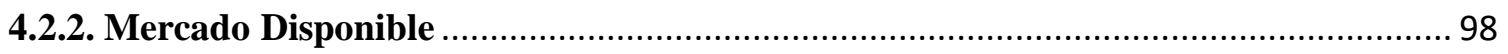

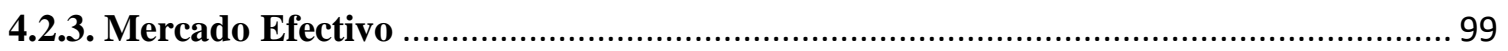

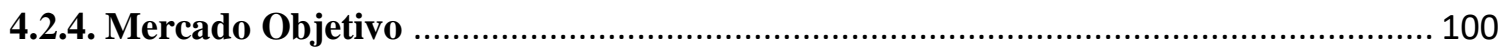

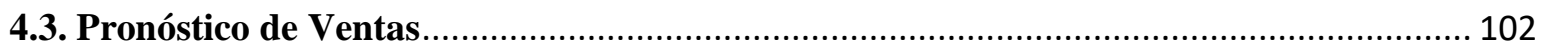

4.4. Aspectos críticos que impactan el pronóstico de ventas ................................................... 105

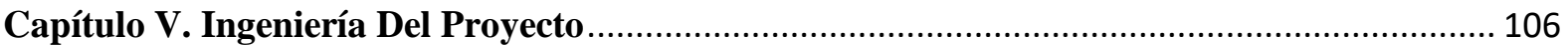

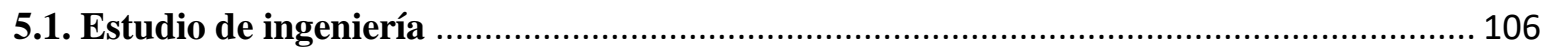

5.1.1. Modelamiento y selección de procesos productivos .................................................. 107

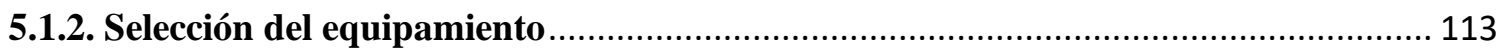

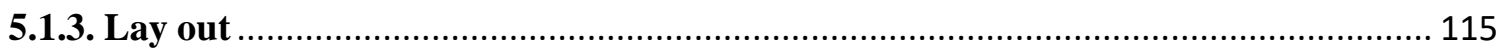

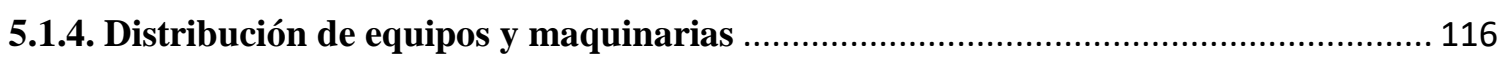

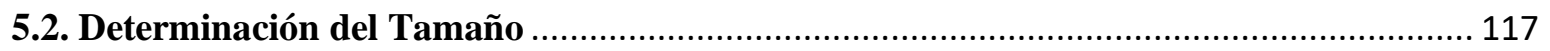

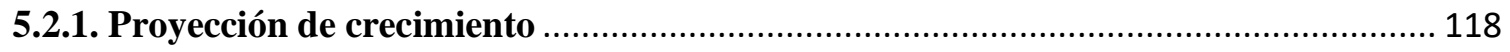

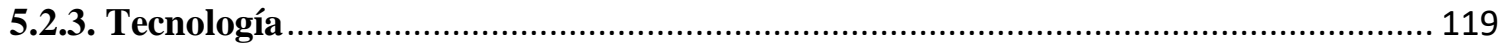

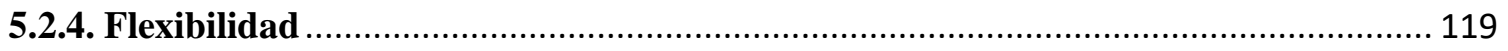

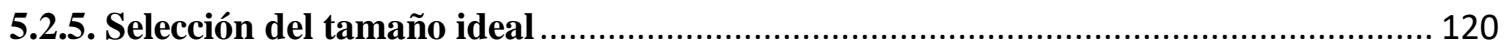

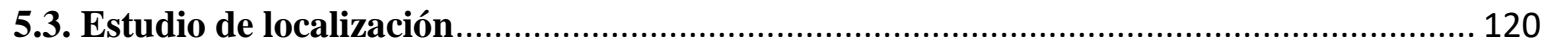

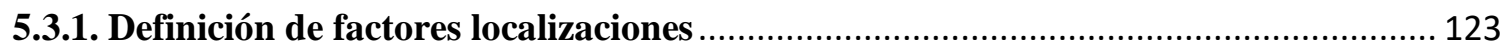

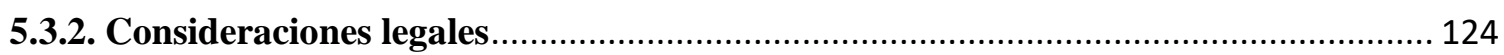

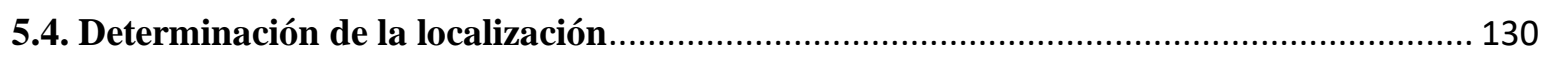

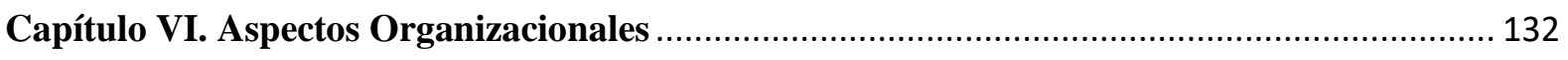

6.1. Caracterización de la cultura organizacional deseada ................................................. 132 
6.1.1. Visión

6.1.2. Misión

6.1.3. Principios

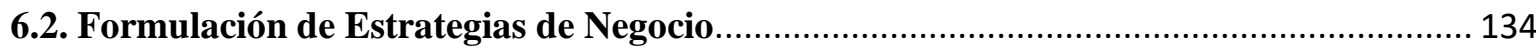

6.3. Determinación de las ventajas competitivas críticas .................................................... 140

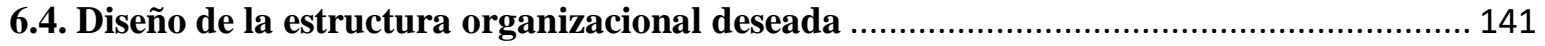

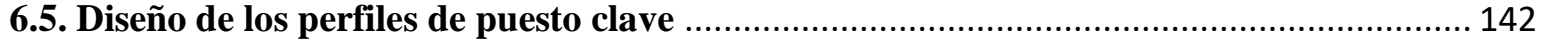

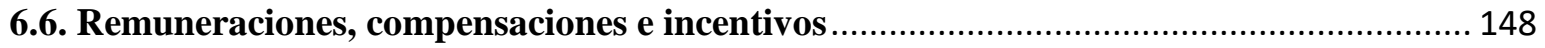

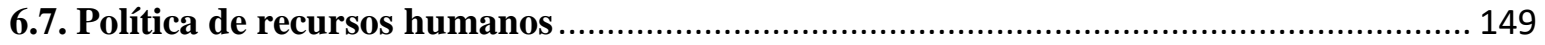

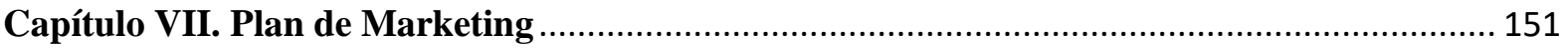

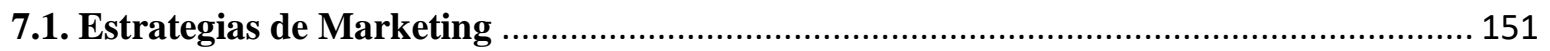

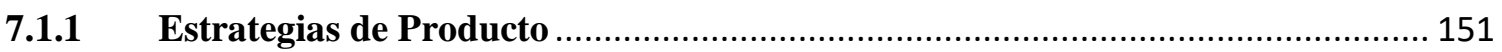

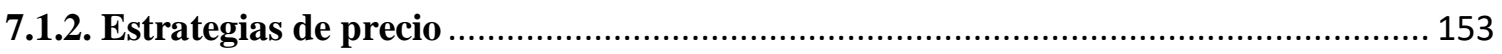

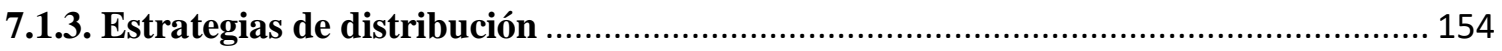

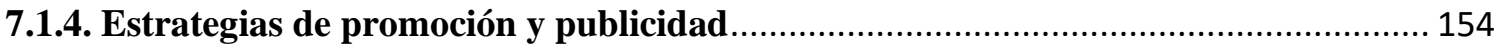

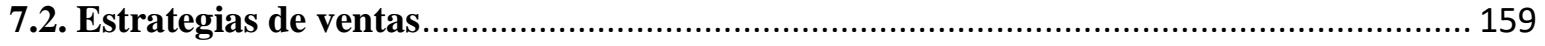

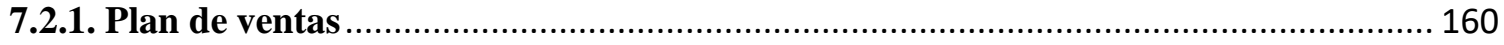

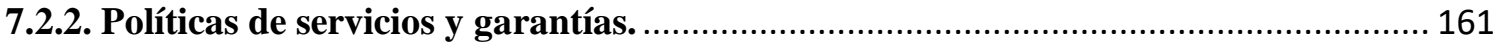

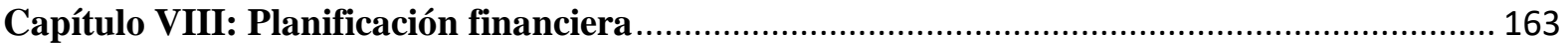

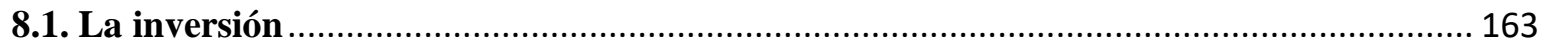

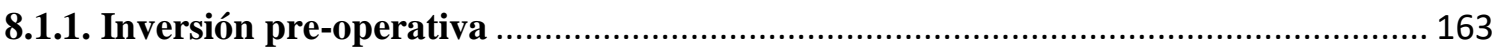

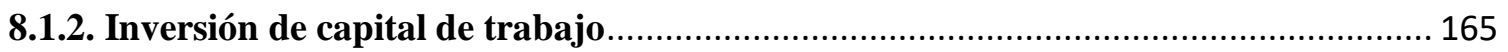

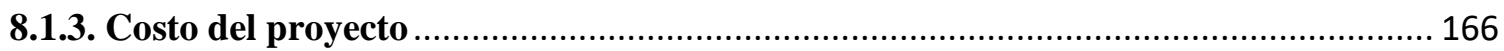

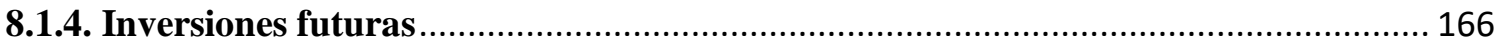

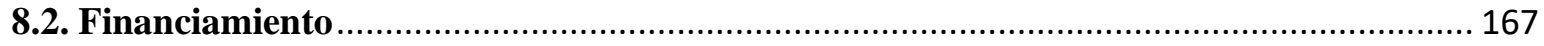

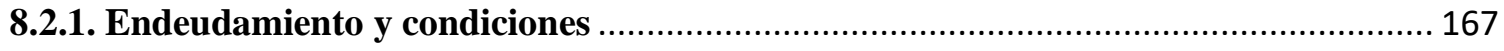

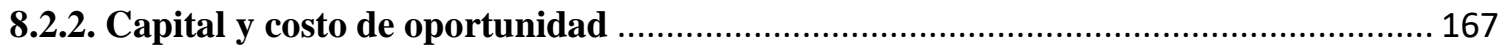

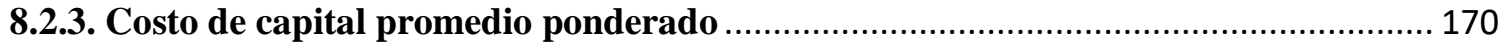

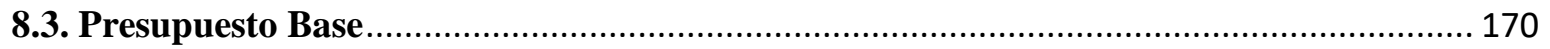

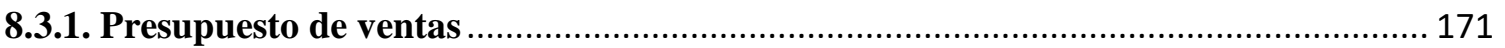

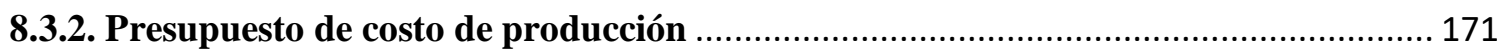

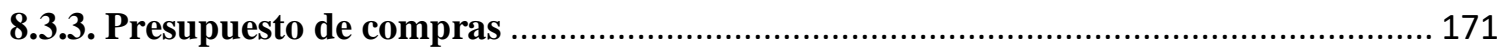

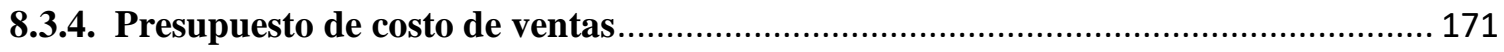

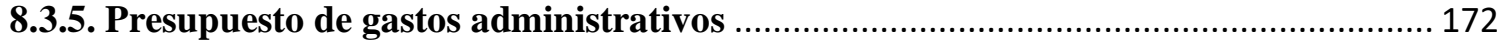


8.3.6. Presupuesto de marketing y ventas.

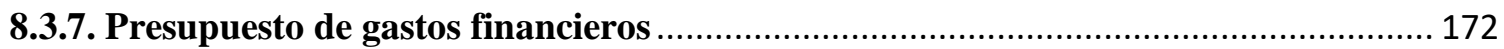

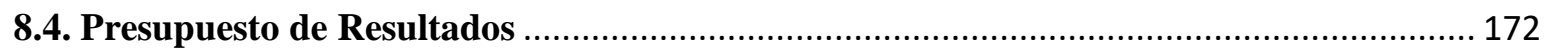

8.4.1. Estado de Ganancias y Pérdidas Proyectado …..................................................... 172

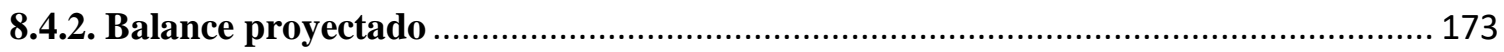

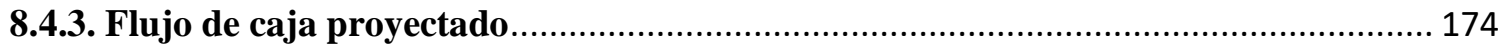

Capítulo IX. Evaluación Económica Financiera ….................................................................. 176

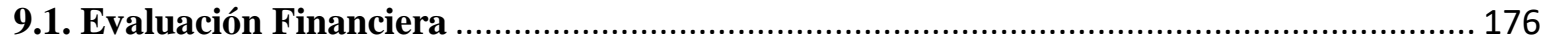

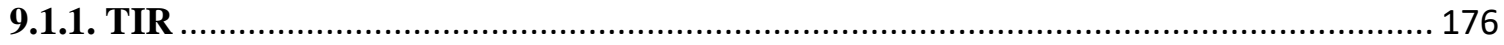

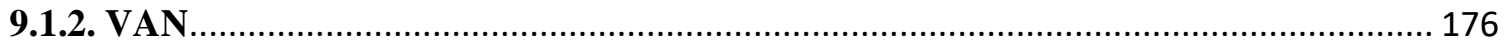

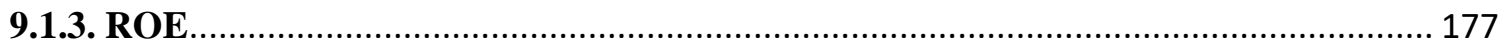

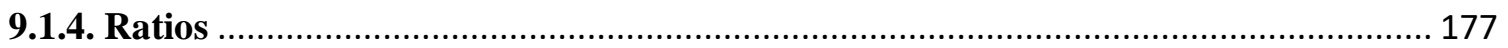

9.2. Análisis de Riesgo

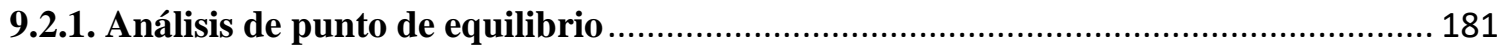

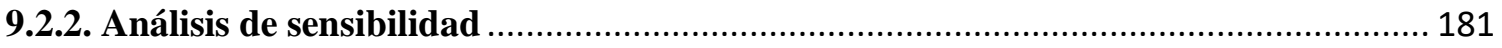

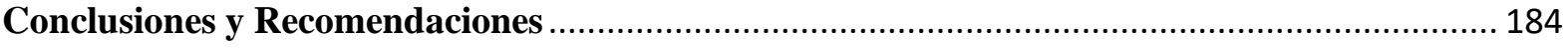

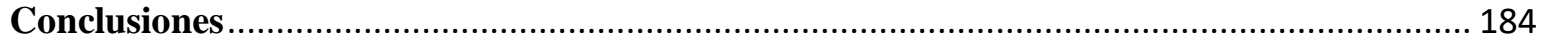

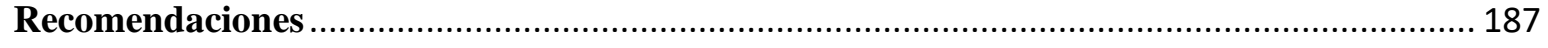

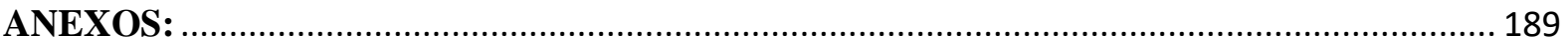

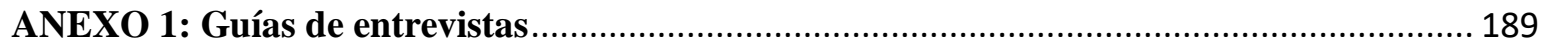

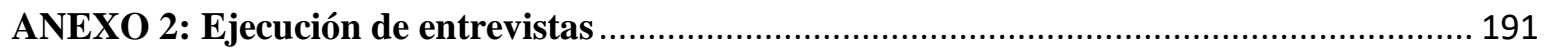

ANEXO 3: Entrevistas en grupos de enfoque sobre oportunidades y/o alternativas de

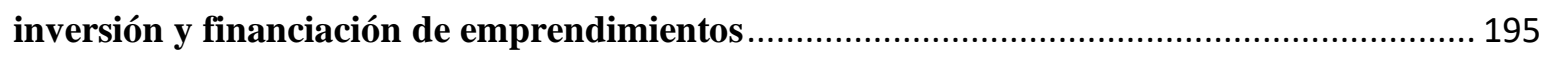

ANEXO 4: Encuesta: Oportunidades y/o alternativas de inversión y de financiación de

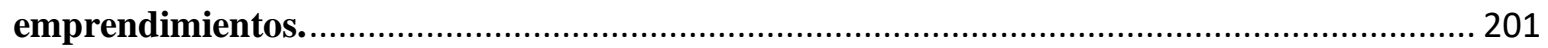

ANEXO 5: Análisis Complementario al Análisis Cuantitativo …......................................... 207

ANEXO 6: Rivalidad entre competidores. Factoring y Confirming …................................. 209

ANEXO 7: Términos y Condiciones IDelta S.A.C................................................................... 216

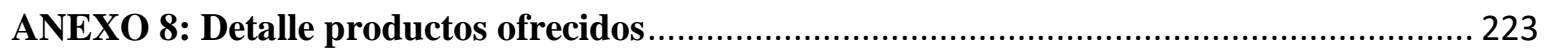

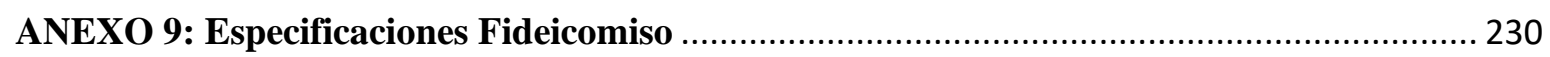

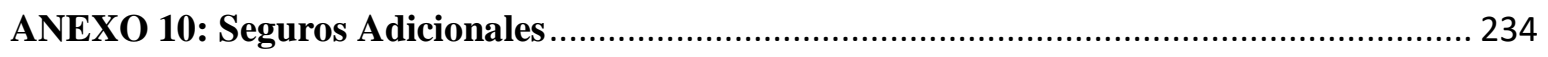

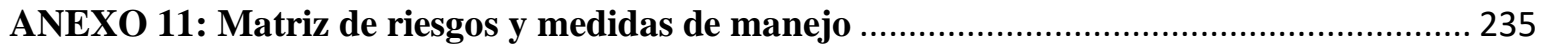

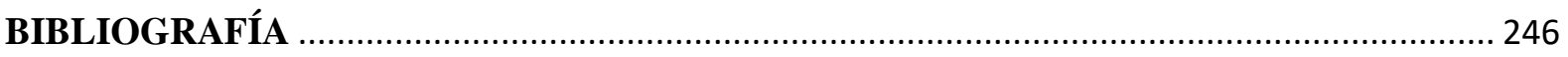

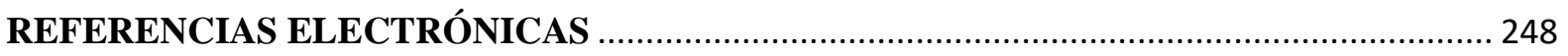

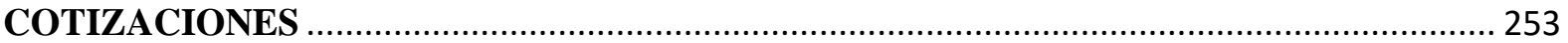




\section{Introducción}

La financiación alternativa, a nivel mundial, ha mostrado altos niveles de crecimiento y un gran potencial, como se puede ver en informes recientes se muestra que en el 2015 el crowdfunding ascendió a USD\$34.4 billones, el doble del valor registrado en el 2014 (National Crowdfunding \& Fintech Association NCFA, 2015). Entre las causas que motivan el traslado de las actividades tradicionalmente bancarias a actividades no bancarias, como es el Crowdfunding, están aquellos que necesitan de un financiamiento pero no califican porque significa un riesgo para la entidad financiera.

El crowdfunding (financiación colectiva) consiste en la financiación a personas, proyectos o negocios por numerosos inversores. Modelo innovador, que en una de sus formas, permite poner en contacto a personas que buscan financiamiento con inversores que quieren obtener mayor rentabilidad para sus ahorros, sin acudir a los servicios de una entidad financiera.

El crowdfunding tiene muchos beneficios, entre ellos se tiene: No hay intermediarios, ni bancos. Conexión directa entre prestatarios e inversores, proporcionando financiación asequible y mayor rentabilidad a los inversores. Reducción de costos de los préstamos.

La oportunidad de negocio surge por los siguientes motivos:

- Escasa inclusión financiera.

- Alta desconfianza en las entidades financieras, como resultado de la escasa formación financiera y la presencia de la economía informal en el país.

- El gran desarrollo de la tecnología informática redes sociales y comunidades de internet.

- El espíritu innovador y constante en la creación de microproyectos y emprendimientos. 
Para ello se considera desarrollar una empresa que ayude a emprendedores a acceder a fuentes de financiamiento utilizando estrategias de crowdfunding así como figuras legales amparadas y utilizadas en el código civil peruano, ofreciendo de este modo un modelo de negocio que brinde asesoría, capacitación y procesos necesarios para convertir su emprendimiento en un caso de éxito.

Los temas desarrollados en la presente tesis son:

El capítulo I inicia definiendo el ámbito de evaluación del proyecto, realizando una descripción general del servicio y el medio en el que se va a desarrollar, sustentando el problema y la propuesta que se tienen para resolverlo, junto a la justificación y objetivos a los que se quiere llegar con esta nueva propuesta a nivel de la ciudad de Arequipa; el capítulo II se da más detalle del ambiente donde se desarrollara el negocio, mostrando el estado actual de la industria y su tendencia, con el apoyo del modelo de las cinco fuerzas de Porter y el Análisis del contexto actual y esperado en lo político, económico, legal, cultural, tecnológico y ecológico, lo cual permite determinar tanto las oportunidades como las amenazas.

En el capítulo III se realiza el estudio de mercado, iniciando con la descripción del servicio a dar, ubicación y a quienes está dirigido, realizándose una investigación cualitativa realizando una investigación exploratoria con preguntas abiertas, no estructuradas a través de grupos de enfoque y entrevistas a expertos, y para la investigación cuantitativa se realizaron encuestas el objetivo es determinar la existencia de un mercado potencial que haga posible la introducción del presente proyecto. Se determinan, posteriormente, los sistemas de comercialización y distribución, política de precios y productos sustitutos.

Con los resultados obtenidos del capítulo III, en el capítulo IV se realiza las proyecciones haciendo uso de datos históricos así como los resultados de las encuestas 
realizadas, determinando el mercado disponible, efectivo y el mercado objetivo, que es el mercado meta, así como el pronóstico de ventas según el comportamiento del mercado.

Posteriormente en el capítulo V se desarrolla la Ingeniería del Proyecto, donde se realiza la descripción del proceso productivo de la empresa, ilustrando brevemente las diversas fases del proceso, sus características propias, tamaño y localización.

En el capítulo VI se ve las características de la cultura organizacional (misión, visión y principios) y estructura organizacional de la empresa, la formulación de la estrategia del negocio y la estructura organizacional de la empresa con cada uno de los perfiles de puestos

Luego en el capítulo VII se desarrolla las diferentes estrategias de marketing, utilizadas para llegar a clientes así como el demostrar los beneficios del negocio y las estrategias de ventas que nos permita alcanzar los objetivos de venta.

En capítulo VIII se realizará la planificación financiera, la cual muestra el plan presupuestal necesario, es decir cuánto dinero se necesita para llevar adelante el proyecto y cómo viabilizar esta realidad; esto consiste en la inversión y los presupuestos; lo que permitirá reflejar el costo general del proyecto, los ingresos y gastos totales de operación.

Por último, en el capítulo IX se efectúa la evaluación financiera y el análisis de riesgo, a fin de evaluar una decisión de inicio de operaciones, para esto se emplea indicadores (VAN, TIR, ROE, etc.) lo que permitirá analizar la rentabilidad del proyecto. 


\section{Capítulo I. Generalidades}

\subsection{Antecedentes}

En términos generales las fuentes de financiación según González Rodríguez (citado en Schwienbacher y Larralde, 2012) se pueden clasificar en dos grandes grupos: capital y deuda, el primero se da cuando se invierte directamente en el capital de la empresa (reinversión de utilidades, venta de activos, incremento de capital entre otros) donde los inversores reciben acciones y tienen un cierto control de la empresa y a la vez asumen riesgos; y por otro lado la deuda que proviene del financiamiento de una entidad externa (créditos bancarios, bonos u otros títulos financieros) sólo se encuentra vinculada a la empresa a través de un contrato, corren menos riesgos y no dependen del rendimiento de la empresa. A pesar de ello muchas empresas emprendedoras y en crecimiento no cuentan con la solvencia ni la garantía para acceder a una financiación por deuda.

Ante esta realidad la globalización ha permitido nuevas estrategias tecnológicas que combinan el concepto de financiación a través de capitalización por medio de fuentes de financiamiento externa, sin que esto signifique generar deuda en la compañía.

Entre los mecanismos más exitosos, actualmente usados se encuentra el crowdsourcing, este término fue utilizado por primera vez en el año 2006 en un artículo publicado por Jeff Howe en la revista "Wired", realizando una convocatoria abierta a un amplio e indefinido grupo de personas. El mecanismo conseguiría unir el talento y conocimiento que se encuentra disperso entre los seres humanos, junto aquellos que lo necesiten, reduciendo de este modo la brecha entre necesidades puntuales y capacidades; este mecanismo, no es exclusivo de nuestra época, es novedoso por el papel preponderante que tiene la Tecnología de la Información y la Comunicación (TIC) con su constante desarrollo (Lara, 2014). Actualmente el crowdsourcing es un potente instrumento para descubrir 
talentos, impulsar proyectos o solucionar problemas que cuentan con medios y recursos insuficientes (Dobrecky, 2012).

El crowdsourcing presenta diversos tipos de clasificación, según Enrique EstellésArolas y Fernando González-Ladrón-De-Guevara (Biblios - University of Pittsburgh, 2016), proponen: a) crowdcasting: se publica el planteamiento de un problema o tarea y el primero de los receptores que lo resuelva es premiado; b) crowdcollaboration: donde individuos aportan conocimiento para resolver problemas o plantearlos en forma colaborativa; c) crowdcontent, donde el público aporta su mano de obra y conocimiento para crear, mejorar o encontrar contenido de diversa naturaleza; d) crowdfunding, búsqueda de financiación por parte de la multitud a cambio de una retribución; e) crowdopinion, donde se intenta conocer la opinión de los usuarios sobre un tema o producto; f) crowdlending, o P2Plending es un tipo de crowdfunding que consiste en pequeños préstamos a empresas o personas particulares por parte de muchas personas que desean invertir.

Lara afirma que los tipos de crowdsourcing: coworking o crowdworking han alcanzado gran nivel de madurez (compartir lugares de trabajo en espacios colectivos) y el crowdfunding, donde el colaborador se convierte en socio, inversor, donante o mecenas (Biblios - University of Pittsburgh, 2016).

En el ámbito empresarial, podríamos mencionar el caso de la compañía Lego (Lego Ideas, 2016) quien lanza una campaña donde el público participa presentando su propio diseño. Y si es suficientemente votado, pasa a revisión y posteriormente se fabrica la producción para la venta. El instituto Smithsonian (2016) impulsa un programa de voluntarios denominados "Digital Volunteers: transcription Center", el cual busca contribuir a la transcripción de documentos históricos y datos de biodiversidad. A nivel local, casos como "Uber" en Lima, son retroalimentados por la gente, del mismo modo casos como "Limacoworking" son casos de éxito del crowdsourcing. En este contexto, es importante 
pensar en el crowdsourcing como una oportunidad para proveer a los individuos caminos significativos para comprometerse y contribuir a la memoria pública.

Es acerca del crowdfunding, de donde se extrae algunas de sus estrategias las cuales se propone implementar en el presente plan de tesis. En términos simples, crowdfunding es la financiación de un proyecto o un emprendimiento por un grupo de individuos en lugar de financiamientos externos (como los bancos, accionistas, inversionistas, prestamistas, etc.). Inicialmente se limitaba a modelos de donación o recompensa de iniciativas sociales o artísticas, así como por horas de trabajo de apoyo en redes sociales, etc., pero luego se desarrollaron esquemas financieros, específicamente de préstamos, tanto a personas como a empresas, y de valores especialmente de acciones (equity crowdfunding) con el fin de conseguir el objetivo de financiación o viabilización del proyecto o emprendimiento a financiar; caso similar se da con el mecanismo de ventas por adelantado, donde se realiza una venta a futuro, siendo el cliente beneficiado por el descuento que esto genera y el productor beneficiado también por el capital de trabajo que recibe para impulsar su emprendimiento (Unidad de Proyección Normativa y Estudios de Regulación Financiera, 2016).

El sistema de Crowdfunding cuenta con cuatro alternativas de financiamiento: (a) Donaciones, que como su nombre indica son aportes voluntarios por los que no hay devolución, pero que sí dan la posibilidad de ver concretado el proyecto y, en algunos casos, el de recibir una mención por el apoyo; (b) Pre venta o Premios o venta por adelantado, que consiste en la posibilidad de recibir algún regalo por el aporte o un descuento en los productos una vez que estos salgan al mercado; (c) los Préstamos, una de las modalidades más populares, son similares a los del sistema tradicional. El inversor recibirá la devolución 
de su aporte más el pago de intereses; y (d) Equity, consiste en aportar capitales que permiten al inversor ser socio del proyecto.

Otro ejemplo de ello se tiene a nivel nacional, un proyecto dirigido por el licenciado y profesor Javier Salinas, de la Universidad Pacífico, con la empresa Kapital Zocial S.A. ubicada en la Ciudad de Lima, Santiago de Surco.

A nivel mundial la industria del crowdfunding ha demostrado gran potencial; de acuerdo con IOSCO (2014) la financiación a través del esquema de préstamo alcanzó un volumen de USD\$6.4 billones en 2013, concentrado especialmente en Estados Unidos, China y el Reino Unido. Informes más recientes, muestran que en 2015 el saldo total de crowdfunding ascendió a USD \$34.4 billones, el doble del valor registrado en 2014. Se estima que sólo el volumen de préstamos podría ascender a USD \$70 billones en 2019 y hasta USD \$150 billones en 2025 (Unidad de Proyección Normativa y Estudios de Regulación Financiera, 2016).

\section{Monto crowdfunding financiero (USD\$ Billones)}

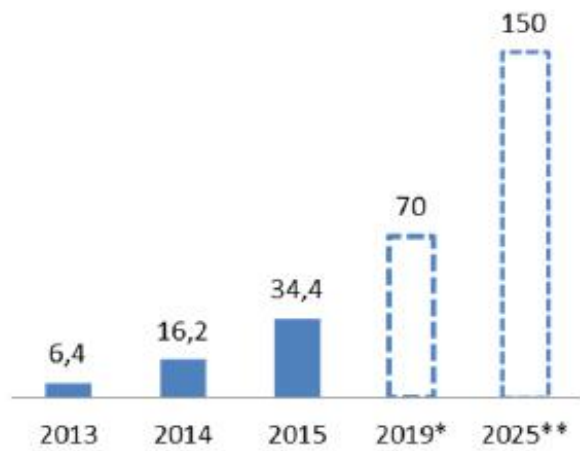

\section{Distribución geográfica crowdfunding financiero (2013)}

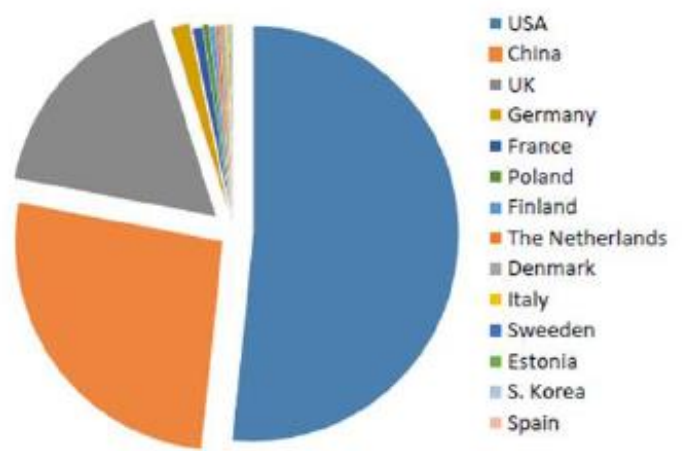

Fuente: NCFA (2015), *IOSCO (2014) y **PWC (2015). Cálculos propios.

Figura 1. Tamaño de la industria de crowdfunding en el mundo. Tomado de Alternativas de regulación del crowdfunding, 2016. Recuperado de http://www.urf.gov.co/urf/ShowProperty?nodeId=\%2FOCS\%2FP_MHCP_WCC$\underline{049581 \% 2 \mathrm{~F} \% 2 \mathrm{FidcPrimary} F i l e \& r e v i s i o n=l a t e s t r e l e a s e d}$ 
Un ejemplo de esta categoría es el caso de Doublefine, una empresa que en 2012 lanzó una campaña a través de la plataforma Kickstarter en Estados Unidos para financiar la creación de un videojuego llamado Broken Age. La meta era recolectar USD\$400.000 en 32 días y como recompensa se ofrecía la entrega temprana de una copia del juego. Doublefine alcanzó la meta en ocho horas y al finalizar los 32 días recaudó un monto de USD \$3.3 millones de más de 80 mil donantes con aportes de USD\$40 en promedio (Kickstarter, 2016).

Entre otros sistemas de financiación no tradicionales están:

Los Business Angels que son inversores privados y/o públicos que aportan capital, conocimientos y experiencia a emprendedores, a cambio obtienen una participación en la empresa que luego venden para obtener beneficios.

Las Empresas de Capital Riesgo son entidades que financian capital a empresas, su participación al igual que los Business Angels y es temporal suele de los tres a los siete años.

Las Start up en sí, son una forma de obtener financiamiento, pues son empresas de una creación que presentan grandes posibilidades de crecimiento.

Private Equity que es un tipo de actividad financiera mediante la cual una entidad de Private Equity adquiere parte o totalidad de una empresa la cual no está cotizada en fase de crecimiento-madurez. Un subtipo de este es el Venture Capital, pues son entidades que invierten en empresas para venderlas en un futuro próximo.

\subsection{Determinación del problema u oportunidad}

En el Perú existe una gran demanda de préstamos y del mismo modo inversiones por parte de personas y/o empresas con capital, teniendo así dos grupos de personas las que poseen capital y buscan la forma de cómo invertirlo, y por otro lado las personas que no acceden a los financiamientos tradicionales y que necesitan ese dinero para sus emprendimientos; esta distancia entre quienes buscan un préstamo y quienes desean invertir, se profundiza por la carencias de métodos para unirlos, señala Sánchez director ejecutivo de 
Prestaclub (Gestión, 2014), y el problema de acceso a estos servicios financieros, lleva a una incorrecta "inclusión financiera".

De otro lado la legislación peruana prohíbe otros tipos de financiamiento que han crecido y ha generado oportunidades en el mundo como es el crowdfunding asociado a deuda o acciones.

Esta situación genera una oportunidad que precisa de nuevos mecanismos que permitan gestionar el problema existente, acercando al inversionista hacia el prestatario.

\subsection{Justificación del Proyecto}

De lo visto en el punto anterior, surgen las siguientes inquietudes, desde el punto de vista del prestatario: ¿De dónde obtener dinero para poder llevar a cabo un emprendimiento y/o proyecto? ¿Si hay el sustento de demostrar ingresos a través de boletas de pago, contrato, nombramiento o similar?, ¿y si estos pueden cubrir las cuotas de pago ante una eventual quiebra del proyecto o emprendimiento?, ¿Como persona natural podría acceder a un monto, suficiente para poder llevar a cabo el proyecto o emprendimiento?

Por otro lado, desde el punto de vista del inversor: ¿Dónde podría invertir en este momento si se contara con un excedente económico? ¿Un banco a depósito fijo, en fondos mutuos o mercado financiero, acciones, bonos, instrumentos financieros en el extranjero? Existiendo un alto riesgo o el de obtener bajos intereses y sin poder mover el dinero.

El informe de Estrategia Nacional de Inclusión Financiera (Comisión Multisectorial de Inclusión Financiera, 2015) muestra la escasa inclusión financiera que hay en el país: (a) está conformada por la mayoría de los ciudadanos (alrededor del 29\% de los adultos); (b) es indispensable que el Estado mejore sus estrategias para impulsar inclusión financiera; (c) la población rural es la más excluida y lo que se ofrece no va de acuerdo a sus necesidades; (d) la alta desconfianza en las entidades financieras, a consecuencia de la escasa formación 
financiera y la presencia de la economía informal en el Perú; (e) es necesario encontrar nuevas vías y sistemas de financiación para poder ofrecer a la población nuevas alternativas de financiamiento e inversión.

Siendo estos motivos los que impulsan el crear nuevos canales y alternativas de financiamiento e inversión que sean más asequibles y que estén dirigidas a sus necesidades, generando mayor competencia a la población.

\subsection{Objetivos generales y específicos}

Elaborar un plan de negocios en la empresa IDeltas S.A.C. que busque promover el acceso y uso responsable de servicios financieros no tradicionales como alternativas económicas que sean confiables, eficientes, innovadores y adecuados a las necesidades de los 
diversos segmentos de la población que cuente con un negocio o emprendimiento en la ciudad de Arequipa y para quienes desean invertir y obtener mejor rentabilidad de su dinero. Objetivos Específicos:

- Realizar el análisis del micro y macro entorno de la industria.

- Realizar el estudio de mercado para el proyecto justificando la cantidad de servicios u ofertas financieras a brindar y la mejor forma para comercializar, a través de un estudio de investigación cualitativo y cuantitativo.

- Realizar la ingeniería del proyecto, determinando la estrategia para brindar calidad superior al de los rivales, costos más bajos, alternativas más atractivas y obtener una satisfacción más elevada.

- Realizar un plan de marketing, identificando los canales o medios óptimos de contacto con los clientes, basados en la identificación de las necesidades y tendencias de los clientes.

- Analizar la rentabilidad o viabilidad financiera del proyecto.

\subsection{Alcances y limitaciones de la investigación}

El plan de negocios se centra inicialmente en la ciudad de Arequipa, en ideas de negocio y/o comercios que ya tengan productos, producción, clientes y precisen acceder a montos menores para poder apalancarse financieramente a cambio de obtener tasas bajas de interés proveniente directamente de inversionistas.

Los montos a negociarse no serían mayores a 100 mil soles en su primera etapa.

La empresa propuesta no tiene decisión sobre el destino del dinero ni tampoco lo hace suyo, solo se encargará de canalizar el dinero de los inversores hacia los que buscan un 
financiamiento y el adecuado asesoramiento en cuanto a nuevas formas de financiamiento e inversión.

Existen limitaciones por falta o ausencia de información del sector, considerando en especial que el presente modelo no tiene parecido a nivel nacional.

Otra limitación es la no disponibilidad de mayor capital para poder iniciar el presente modelo en un plan nacional a nivel sur en una primera etapa y en un modo consistente y sólido. 


\section{Capítulo II. Estructura Económica del Sector}

\subsection{Descripción del estado actual de la industria}

Para la ejecución de todo negocio se requiere de recursos financieros y poder desarrollar actividades, ya sean nuevas ideas de negocio o ampliar las existentes, lo que conlleva a la búsqueda de fuentes o formas de financiamiento para la provisión de recursos. Siendo ese uno de los más grande obstáculos que tienen las PYMES y emprendedores, el acceder a financiamiento.

El entorno actual de desempeño donde se desarrolla , teniéndose así una propuesta alternativa al de los productos que se ofrecen en el campo financiero tradicional, más simplificada, con costos más bajos y mejores beneficio y a la vez de brindar asesoramiento.

\subsubsection{Segmentación de la industria.}

La actividades de asesoramiento y mediación entre clientes en el Perú se encuentra en constante crecimiento como se puede ver en la lista de actividades de la Clasificación Industrial Internacional Uniforme (CIIU, [2016]) adaptada por el Instituto Nacional de Estadística e Informática (INEI), donde encontramos actividades como agentes comerciales, agentes de aduanas, agentes de valores, agentes y corredores de seguros, corredores inmobiliarios, comisionistas, intermediarios de exportación e importación, en la industria de viajes y turismo como las agencias de viaje, etc., los cuales se relacionan estrechamente con el desarrollo económico del país generando mayor oferta y demanda.

En la actualidad existen oportunidades para los partícipes de este tipo de actividad, sin embargo, a la vez se presentan importantes desafíos, debido a la fuerte competencia que se experimenta en el mercado y la desaceleración de la economía peruana. Como se puede ver en el corretaje inmobiliario que durante los años 2011 y 2013 llegó a su mayor crecimiento producto del auge de la construcción, y aunque ha disminuido la venta de viviendas a causa 
de la desaceleración de la economía peruana, esta no ha llegado a los niveles que se tenía antes del 2011, esta situación ha permitido que tanto las agencias como los corredores, planteen nuevas estrategias para mejorar la comercialización y hacer más atractivos los productos (inmuebles) hacia la demanda, abarcando nuevos segmentos (El Comercio, 2015).

En cuanto a los agentes de bolsa de valores, está presente la Sociedad Agente de Bolsa (SAB) que es la única intermediaria del mercado bursátil permitida y supervisada por la Superintendencia del Mercado de Valores (SMV), quienes se encargan de realizar las operaciones de compra y venta que los inversionistas les solicitan; a cambio de una comisión. Las SAB también prestan otros servicios, como resguardar los valores (custodia), administrar cartera, ofrecer asesoría, mostrando a los inversionistas las diferentes opciones que brinda el mercado de valores a fin de que elijan la mejor opción de inversión (Bolsa de Valores de Lima, 2016). Los canales de distribución que emplean son: plataforma web, central telefónica, boletines electrónicos, atención personalizada.

Por otro lado el corretaje de seguros es una actividad especializada en la asesoría e intermediación de pólizas de seguros. Los corredores de seguros por lo general no reciben comisiones por parte de sus clientes, ya que sus ingresos resultan de las comisiones y bonos que son fijadas por las Compañías de Seguros que emiten las pólizas. Entre los canales de distribución que emplean se tiene: telemarketing, atención telefónica, atención personalizada, a través de una plataforma vía web (Gómez, Govea del Valle \& Zagal, 2016).

Otro tipo de intermediación son las actividades realizadas por el agente de Aduana que comprende todas las fases del traslado de la mercancía comercializada y cuenta con las facultades encomendadas por el dueño, consignante o consignatario de la mercancía. Como contraprestación por el servicio, el consignatario le pagará por concepto de comisión un porcentaje del valor de la mercancía despachada, es decir, bajo la misma modalidad de cómo 
se paga a un comerciante, por ejemplo un comisionista (Asociación de Agentes de Aduana del Perú, 2016).

En cuanto a las empresas que otorgan el servicio de asesoría empresarial, en el Perú existen entre las promovidas por el estado como el de Servicios de Desarrollo Empresarial del Ministerio de la Producción diseñadas para promover la competitividad de las micro, pequeña y mediana empresa a través de la implementación de mecanismos e instrumentos para el desarrollo y fortalecimiento empresarial; también están las Cámaras de Comercio que brindan el servicio de asesoría tributaria, laboral y administrativa, información empresarial, oportunidades de negocio, capacitaciones, arbitraje, etc.

\subsubsection{Empresas que la conforman}

Se considera que está conformado por todas aquellas empresas que se encuentran dentro del mercado comercial, participando en las actividades de asesoramiento empresarial y sirviendo como mecanismo de mediación entre personas que desean invertir y personas que buscan de un capital para un negocio. Por lo que se muestra cómo está conformado el mercado de asesoramiento y el mercado financiero tradicional, este último se toma como referencia ya que proporciona datos que muestran el volumen de participantes tanto prestatarios como inversionistas.

En cuanto a la actividad de asesoramiento y mecanismos de enlace o mediación entre personas o empresas, están las siguientes empresas o entidades:

Corredores Inmobiliarios, en la actualidad, las dos asociaciones que agrupan y representan a los corredores inmobiliarios tienen registrados cerca de 7,000 integrantes; el Ministerio de Vivienda, Construcción y Saneamiento (MVCS) maneja un registro de 5,967 personas naturales cumpliendo dicha función (El Comercio, 2015). 
Agentes de Bolsa, en la Bolsa de Valores de Lima (BVL) se encuentran inscritas 25 sociedades agentes de bolsa, instituciones que son monitoreadas por la Superintendencia del Mercado de Valores (SMV). Actualmente operan en el mercado nacional, 14 compañías de seguros, 11 de las cuales venden seguros para personas, nueve ofrecen seguros de Vida, y 13 comercializan seguros de Riesgos Generales y de Accidentes y Enfermedades. Además, existen 11 Corredores de Reaseguros, la mayoría de ellos vinculados a corredores de seguros que operan en el mercado local.

La Asociación de Agentes de Aduana del Perú es la institución que representa a los agentes de aduana, que en la actualidad cuenta con 117 integrantes (Asociación de Agentes de Aduana del Perú, 2016).

En cuanto a las entidades financieras tradicionales:

Muchas empresas financieras han tenido que adaptar sus procesos o adecuarse a la idiosincrasia local introduciendo diferentes tipos de financiamiento (como crear créditos para comercios informales), en base a las ventajas y desventajas que puedan ofrecer.

Entre las empresas que brindan servicios financieros al sector al cual se pretende atender se tiene:

Tabla 1

Sistema Financiero en la Región Arequipa

\begin{tabular}{lc}
\hline Diciembre 2015 & $\begin{array}{c}\text { Número de } \\
\text { Empresas }\end{array}$ \\
\hline Banca Múltiple & 13 \\
Empresas Financieras & 8 \\
Cajas municipales (CM) & 7 \\
Cajas rurales de ahorro y crédito (CRAC) & 2 \\
Entidades de Desarrollo de la Pequeña y Microempresa & 3 \\
(EDPYME) & 1 \\
Banco de la Nación & \\
Nota: Adaptado de la "Carpeta de Información del Sistema Financiero, Cuadros Estadísticos" \\
por Superintendencia de Banca y Seguros y AFP, 2015. Recuperado de \\
http://www.sbs.gob.pe/app/stats/EstadisticaBoletinEstadistico.asp?p=14\#
\end{tabular}


En la Tabla 2 se muestran los tipos de créditos directos, dados por las diferentes entidades financieras.

Tabla 2

Créditos del Sistema Financiero por tipo de crédito en la Región de Arequipa

\begin{tabular}{llr}
\hline Tipo de crédito & Tipo de empresa del sistema financiero & $\begin{array}{r}\text { Total de } \\
\text { crédito directo }\end{array}$ \\
\hline Medianas empresas & Banca Múltiple & $786,427.09$ \\
& Empresas Financieras & $3,772.94$ \\
& Cajas Municipales & $75,156.85$ \\
& Cajas Rurales de Ahorro y Crédito & 963.33 \\
& Edpyme & 65.01 \\
Pequeñas empresas & Banca Múltiple & $333,316.19$ \\
& Empresas Financieras & $132,714.94$ \\
& Cajas Municipales & $239,903.62$ \\
& Cajas Rurales de Ahorro y Crédito & $13,729.60$ \\
Microempresas & Edpyme & $7,064.87$ \\
& Banca Múltiple & $36,836.02$ \\
& Empresas Financieras & $80,651.70$ \\
& Cajas Municipales & $86,315.05$ \\
& Cajas Rurales de Ahorro y Crédito & $6,478.96$ \\
& Edpyme & $4,648.47$
\end{tabular}

Nota: En miles de Soles. Adaptado de la "Carpeta de Información del Sistema Financiero, Cuadros Estadísticos" por Superintendencia de Banca y Seguros y AFP, 2015. Recuperado de http://www.sbs.gob.pe/app/stats/EstadisticaBoletinEstadistico.asp?p=14\#

En la Figura 2, se puede apreciar los créditos dados para las actividades empresariales por Sector Económico a nivel nacional, estando el comercio, la industria manufacturera, actividades inmobiliarias, transporte y almacenamiento, agricultura y ganadería, entre las cinco actividades con mayor solicitud de créditos. 


\begin{tabular}{|c|c|c|c|c|c|c|c|c|}
\hline \multicolumn{9}{|c|}{$\begin{array}{c}\text { Créditos para Actividades Empresariales }{ }^{1 /} \text { por Sector } \\
\text { y Tipo de Empresa del Sistema Financiero } \\
\text { Al } \mathbf{3 1} \text { de December de } \mathbf{2 0 1 5} \\
\text { (En miles de Soles) }\end{array}$} \\
\hline Sector Económico & 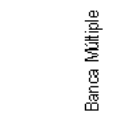 & 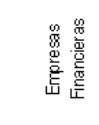 & 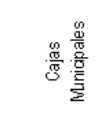 & 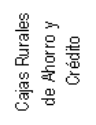 & $\begin{array}{l}\text { 崖 } \\
\text { 咅 } \\
\text { 岁 }\end{array}$ & 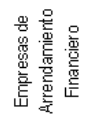 & 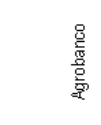 & 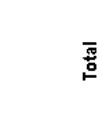 \\
\hline Agricultura, Ganadería, Caza y Silvicutura & $6,160,804$ & 472,295 & 842,893 & 120,445 & 63,233 & 16,982 & $1,513,023$ & $9,189,674$ \\
\hline Pesca & $1,301,610$ & 40,654 & 93,941 & 1,817 & 9,354 & 11,822 & 6,277 & $1,465,475$ \\
\hline Mnería & $8,015,286$ & 14,826 & 24,924 & 758 & 6,991 & 19,955 & - & $8,082,741$ \\
\hline Industria Manufacturera & $34,387,858$ & 383,328 & 662,737 & 26,887 & 55,867 & 67,550 & 59,369 & $35,643,595$ \\
\hline Eledricidad, Gasy Agua & $8,631,419$ & 6,850 & 8,827 & 43 & 394 & - & - & $8,647,533$ \\
\hline Contruoción & $5,337,603$ & 157,587 & 333,367 & 8,266 & 16,844 & 27,246 & - & $5,880,914$ \\
\hline Comercio & $34,507,531$ & $2,284,657$ & $4,778,775$ & 133,157 & 269,532 & 52,377 & 4,639 & $42,030,669$ \\
\hline Hoteles y Resaur antes & $3,299,235$ & 214,566 & 586,213 & 12,817 & 30,411 & 12,871 & - & $4,156,113$ \\
\hline Transporte, Almacenamiento y Comunicaciones & $10,281,578$ & 524,899 & $1,507,832$ & 44,676 & 170,308 & 153,855 & - & $12,683,148$ \\
\hline Intermediación Financiera & $7,948,036$ & 34,324 & 309,650 & 10,297 & 259 & 181 & 312 & $8,303,059$ \\
\hline Adividades Inmobiliarias, Enpresariales y de Alquiler & $18,030,607$ & 355,177 & 906,044 & 17,496 & 38,745 & 86,370 & 4,338 & $19,438,776$ \\
\hline Administración Pública y de Defensa & 492,919 & 8,983 & 22,646 & 1,389 & 578 & - & 10,516 & 537,030 \\
\hline Enseñanza & $2,606,588$ & 18,228 & 128,313 & 1,508 & 1,795 & 46 & - & $2,756,479$ \\
\hline Servicios Sociales y de Salud & $1,094,275$ & 26,894 & 79,943 & 1,241 & 3,374 & 2,388 & - & $1,208,116$ \\
\hline Otras Actividades de Servicios Comunitarios & $6,845,260$ & 160,502 & 583,724 & 19,613 & 50,630 & 9,906 & 5,669 & $7,675,303$ \\
\hline Hogares Privados c/Serv. Doméstion y Organos Extraterritoriales & $1,477,857$ & 390,889 & 113,043 & 11,807 & 73,611 & - & - & $2,067,207$ \\
\hline Créditos Corporativos, a Grandes, Medianas, Pequeñas y Microempresas & $150,418,465$ & $5,094,659$ & $10,982,872$ & 412,218 & 791,927 & 461,550 & $1,604,143$ & $169,765,833$ \\
\hline
\end{tabular}

Figura 2. Créditos para Actividades Empresariales por Sector Económico a nivel nacional. Tomado de la "Carpeta de Información del Sistema Financiero, Cuadros Estadísticos" por Superintendencia de Banca y Seguros y AFP, 2015. Recuperado de http://www.sbs.gob.pe/app/stats/EstadisticaBoletinEstadistico.asp?p=14\#

Como se verá más adelante en el estudio de mercado, existe un gran porcentaje de empresas en los rubros expuestos que constituyen el mercado potencial a dónde se dirigirá la empresa propuesta, es decir micro y pequeña empresa, para ello se identificará el tipo de empresas o sector económico con mayor dinamismo en la región Arequipa.

El estudio elaborado por la empresa Aurum (2015) muestra los sectores económicos que se desarrollan en la región Arequipa así como la productividad por sector (ver figuras 3 y 4), de donde se concluye que la construcción, telecomunicaciones, minería, el comercio y otros servicios son los sectores con mayor crecimiento económico en Arequipa, no dejando 
de lado al sector de alojamiento, restaurantes, mantenimiento y servicios que también resaltan en su desarrollo en este periodo.

Haciendo una comparación entre las actividades empresariales que solicitan o requieren un crédito (Figura 2) y los sectores que se desarrollan en nuestra región indica que existe un mercado al cual puede dirigirse el presente proyecto.

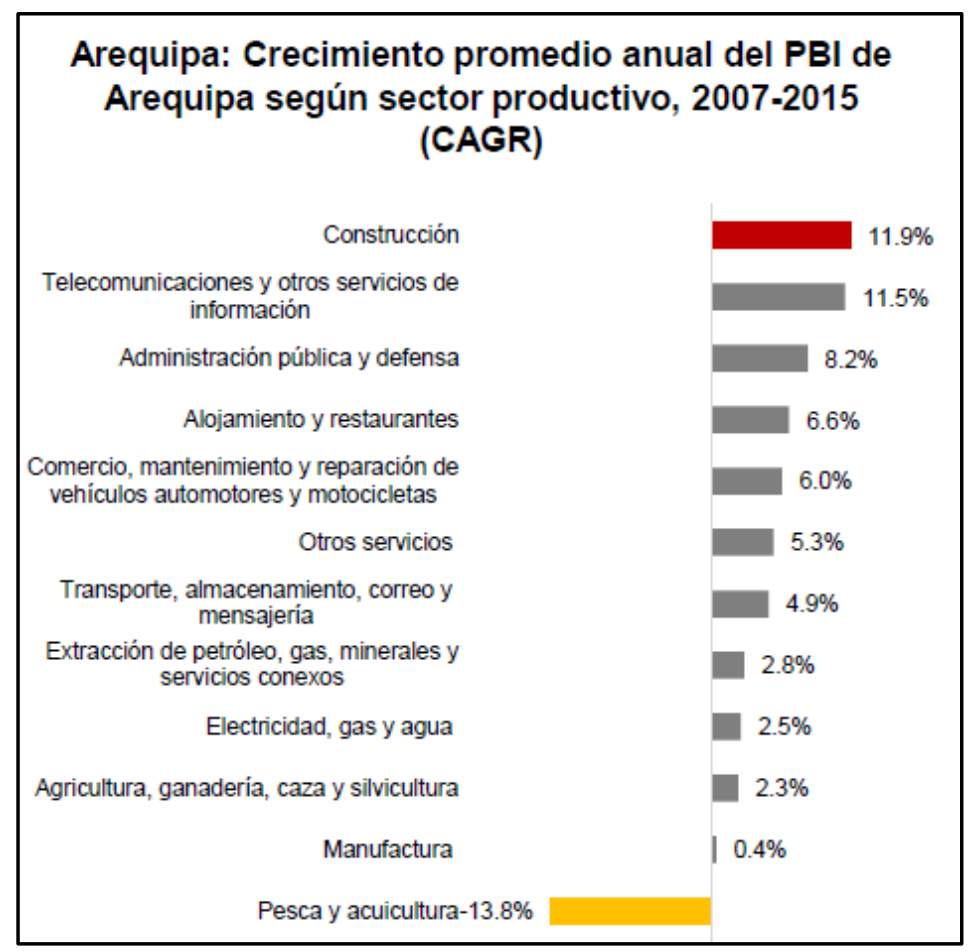

Figura 3. Crecimiento promedio anual del PBI de Arequipa según sector productivo, 20072015 (CAGR). Tomado de "Informe Perspectivas Económicas 2017, Región Arequipa" por AURUM consultoría \& Mercado, 2017. Recuperado de http://mercadosyregiones.com/informes/Aurum\%20\%20Informe\%20Perspectivas\%20Economicas\%20-\%202017.pdf 


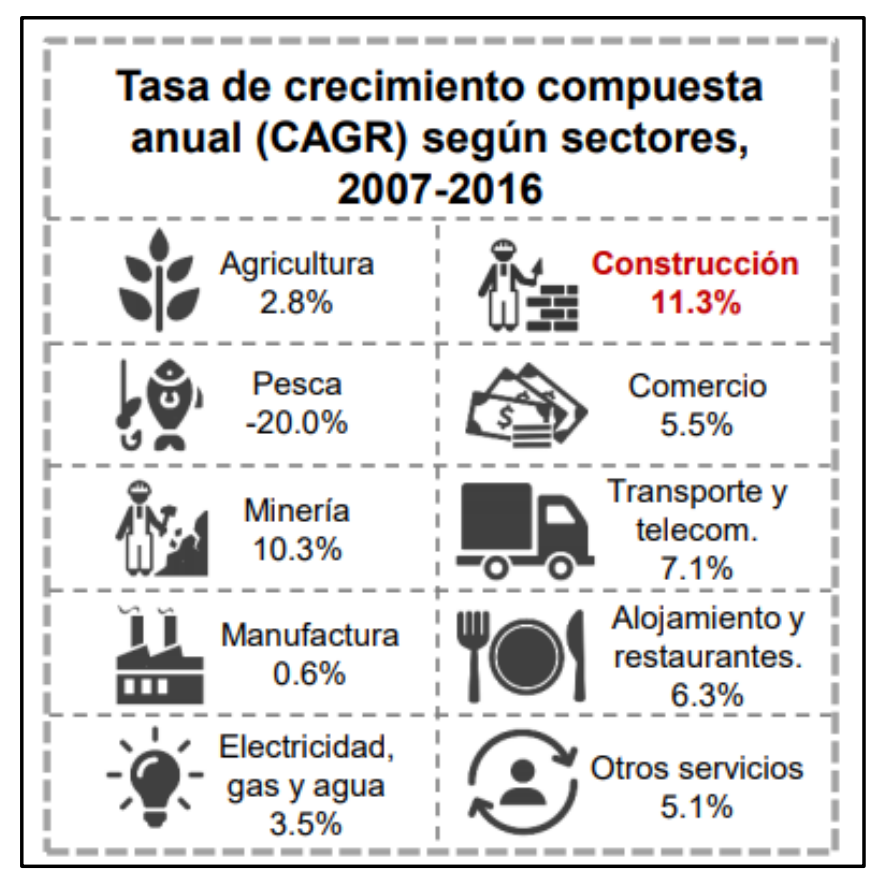

Figura 4. Tasa de crecimiento compuesta anual según sectores, 2007-2016. Tomado de "Informe Perspectivas Económicas 2018, Región Arequipa" por AURUM consultoría \& Mercado, 2018. Recuperado de http://mercadosyregiones.com/wpcontent/uploads/2018/04/Aurum-Informe-Perspectivas-Econ\%C3\%B3micas-2018.pdf

\subsection{Tendencias de la industria (crecimiento, inversiones)}

En la actualidad el mercado de asesoramiento y mediación se encuentra en constante crecimiento y participación en el desarrollo económico del país, como por ejemplo tenemos:

En la industria de viaje y turismo se tiene a las agencias de viajes como canalizadoras del servicio, quienes siguen creciendo en el Perú gracias a los cambios y mejoras en los servicios, la ejecución de eventos internacionales en el país y la creciente uso del Internet, donde se puede ofrecer mayores opciones de compra y reservas online a los turistas. Como lo indica un reciente informe de la consultora Euromonitor International, en el 2015 hubo un crecimiento de $10 \%$ en la performance de la intermediación de viajes en el mercado peruano, cifra que superó al nueve por ciento registrado en el 2014. También se estima, que existen más de 5,000 agencias de viajes en Perú, colocándose como una de las principales actividades intermediarias del mercado, responsables de un importante porcentaje de las transacciones comerciales (Portal de Turismo, 2016). 
En el sector inmobiliario la directora gerente de Perú Sotheby’s International Realty, Nella Ponce Odría, señaló que en el último año la empresa de bienes raíces ha mejorado su performance, en la oferta de proyectos inmobiliarios en Lima. De otro lado, en lo que le espera al sector inmobiliario para este año, Ponce refiere cierta lentitud en el sector por efectos del año, así como la continua alza del dólar que ha hecho que cambie la perspectiva y los movimientos en la compra de viviendas (Gestión, 2016).

En el sector financiero se ha visto la disminución de la solicitud de préstamos por parte de las pequeñas y microempresas ha ocasionado la desaceleración de los créditos; en los últimos cinco años el microfinanciamiento a las PYME ha sufrido un descenso, así las empresas especializadas como son las cajas, EDPYME y algunas financieras de tener una tasa de crecimiento anual de $21 \%$ han disminuido a un $6 \%$, y las no especializadas han sufrido una caída de un 33\% a un 4\% anual. Lo que ha ocasionado el retiro de algunas entidades del rubro. María Belén Effio gerente general de Microrate para América Latina, sostiene que el exceso de ofertas de créditos para las PYME trajo como consecuencia un alto endeudamiento de las mismas, lo que junto a la desaceleración de la economía, ocasionó que no haya suficiente mercado para las entidades financieras, especialmente en las zonas urbanas y periurbanas. La actual situación muestra la necesidad de un mayor afianzamiento de las empresas financieras, debido a los altos costos que demanda; según Jorge Arias, gerente general de la Asociación de Microfinanzas "Esto se ha vuelto un negocio de mayores volúmenes y eficiencia” (Diario El Comercio, 2015).

\subsection{Análisis Estructural del Sector Industrial}

El modelo de las cinco fuerzas de Porter (Figura 5) ayudará al análisis del sector y es utilizado para desarrollar estrategias. Para ello se debe reconocer los elementos clave de cada una de las fuerzas competitivas que afectan a la empresa, evaluarlos y según el resultado de 
la fuerza conjunta de todos los elementos se debe decidir si para la empresa valdría la pena entrar o permanecer en la industria (David, 2013).

Dentro del entorno donde se desarrollara la empresa, se encuentran como principales actores o competidores las empresas del sistema financiero tradicional (bancas, cajas, EDPYMES, etc.) e inclusive el sector informal. Si bien la empresa propuesta no está dentro del sector financiero, esta se encuentra dirigida a las personas que buscan financiamiento o que deseen invertir, siendo la empresa propuesta el canal o mediador que los conecte, sin tener que quedarse con el dinero ni tomar decisiones sobre él.

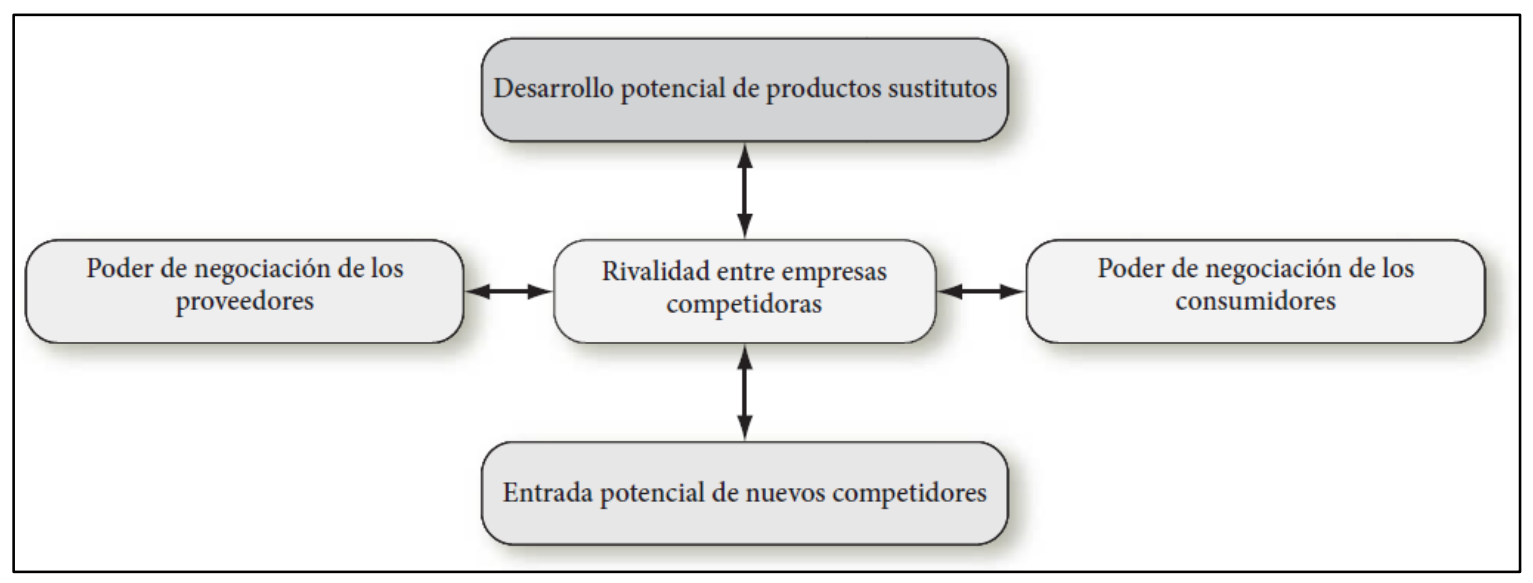

Figura 5. Modelo de las cinco fuerzas de Porter. Tomado de Conceptos de Administración Estratégica (p. 76), por F. David, 2013, Neucalpan de Juárez, México: Pearson Education. Copyright 2013

Amenaza de nuevos competidores: Existen barreras que limitan el ingreso a nuevos competidores, como es la confianza a nuevos métodos financieros acompañado de la tecnología informática. La confianza y el nivel de educación financiera juegan un factor importante ya que al introducir nuevos modelos financieros, que ya existen en otros lugares del mundo y que son un éxito, sumado a ello el alcance limitado de la tecnología a las zonas rurales, así como la falta de que estos se adecuen a sus necesidades, todo ello se convierte en el principal obstáculo para los competidores, siendo una fortaleza para el presente proyecto. 
- Economía de Escala - Disminución de costos de servicio

- Diferenciación de Producto - Se trata de ofrecer un servicio con nueva metodología de financiación.

- Tecnología - Este servicio hace uso de la tecnología informática y uso de software.

- Rentabilidad de la Industria. - Resulta rentable por el gran de número de clientes al que va dirigido.

- Incertidumbre en la industria y riesgos de negocio - El ingreso de nuevos competidores genera poca confianza, más aún cuando se trata de dinero.

Se concluye que las barreras consideradas ofrecen un entorno atractivo debido a las restricciones que causa la diferenciación del producto, frente al sistema tradicional financiero. Con el fin de seguir adelante a pesar del panorama, se tiene el reto de posicionar la marca y diferenciar el producto, de modo que sea fácil de entender, vender, controlar y personalizar.

Rivalidad entre competidores: El grado de rivalidad de la competencia dependerá de la cantidad de competidores y tamaño de estos, entre ellos se tiene a las entidades financieras que otorgan crédito y microcréditos (banca, cajas municipales y rurales, EDPYME), el sector informal (prestamistas, agiotistas, casas de empeño, etc.), otros intermediarios como los de corretaje de créditos. A nivel nacional, existen cinco bancos principales, el BCP, BBVA Banco Continental, Scotiabank Perú, Interbank. Ante esta realidad, la principal competencia de bancos se da entre BCP y BBVA Banco Continental, BCP tiene el 33\% de mayor participación, y estos dos bancos se dirigen a casi los mismos clientes y con productos muy parecidos (Equilibrium Clasificadora de Riesgos S.A., 2016). Las cajas Municipales y Rurales, presentan ventaja también con sus préstamos fáciles y rápidos a personas naturales y pequeñas empresas, lo que está asociado a los requisitos de dichas entidades, como por ejemplo para obtener un crédito bancario es necesario contar con un ingreso estable, lo cual 
no es exigido por las cajas municipales, debido a que muchas personas tienen un trabajo independiente o son emprendedores (Gestión, 2016), y es a ese mercado es donde se desea llegar.

Amenaza de sustitución (productos sustitutos): Posibilidad de que clientes y consumidores emplean productos sustitutos a los producidos por el sector industrial. El producto sustitutivo hay que analizarlo igualmente desde la perspectiva de los dos clientes del presente proyecto: desde la perspectiva del cliente buscador de financiamiento el producto sustitutivo sería principalmente la financiación bancaria, y desde la perspectiva del cliente financiador serían todas aquellas posibilidades de ahorro (depósito a plazo fijo, fondos de inversión, etc.), frente a esto el modelo de negocio propuesto ofrece como elementos positivos una mejor rentabilidad y el cobro del capital e intereses de forma mensual, mientras que al hacer un depósito fijo o invertir en un fondo mutuo el cobro del capital no sucede hasta el final o el riesgo es alto, respectivamente.

Poder de negociación de los consumidores: El poder de negociación con los clientes financiadores es alto, por lo que su atención es fundamental, para poder contar con clientes frecuentes y buenos financiadores que puedan sentir la confianza de trabajar con la empresa propuesta, por lo que se necesita prestar un servicio diferenciado, transparente que haga que el cliente se sienta más cómodo y seguro al invertir su dinero. En cuanto a nuestros clientes buscadores de financiamiento, es necesario captarlos, brindando un trato personalizado de acuerdo a sus necesidades, orientándolo para acceder a un financiamiento.

Poder de negociación de los proveedores: Proveedores de materiales e infraestructura, hardware, software, proveedores de equipos, diseñadores de la plataforma y su soporte que garantice el buen funcionamiento y seguridad. Existe en el mercado varios proveedores de estos servicios es que se puede obtener un buen poder de negocio. 


\subsection{Análisis de la Competencia}

En este punto se refiere a la estrategia actual, objetivos, fortalezas y debilidades a quienes se consideran parte del grupo estratégico: Banca, Organismos no gubernamentales (ONG), EDPYME, entre otros.

En el 2015, las entidades bancarias otorgaron créditos a los diferentes segmentos del mercado de forma creciente y continua, mostrándose más favorable frente a la coyuntura económica por la que pasa el país, creando nuevos tipos de créditos según las necesidades de la población, así al cierre del año 2015 la cartera de crédito otorgado alcanzo la suma de S/. 226,000 millones, lo que representa un crecimiento del $10 \%$ respecto al 2014. Por otro lado, también se encontró un ligero aumento en el ratio de morosidad, hecho que tiene que ver con el descenso en el crecimiento de la economía, que afecta negativamente en la actividad productiva de algunos segmentos del mercado, como medianas y pequeñas empresas, afectando así su capacidad de pago. A pesar del crecimiento financiero visto, aun se presenta los bajos niveles de inclusión financiera (Asociación de Bancos del Perú [ASBANC], 2015).

Por otro lado las cajas, las EDPYME y algunas financieras han desacelerado su tasa de crecimiento de $21 \%$ a $6 \%$, y en otros casos de un $33 \%$ a un $4 \%$ anual, lo que ha generado que algunas entidades con menos experiencia desaparezcan, ocasionado, al igual que las bancas, por el descenso de la economía y el crecimiento del endeudamiento de las empresas y microempresas por exceso de sobre ofertas de créditos (El Comercio, 2015).

También se tiene aquellas entidades o personas que ofrecen créditos informales, los cuales ocupan el mercado no atendido por el crédito formal, y donde el prestatario está dispuesto a pagar tasas elevadas, esto debido a los requisitos y tiempo que demora en acceder al crédito por parte de las entidades bancarias. El negocio del prestamista informal está en vender las garantías, lo cual no sucede con los bancos y cajas, por lo que nunca pierden (Gestión, 2013). 


\subsubsection{Empresas que ofrecen el mismo producto o servicio (indicando las semejanzas y diferencias que tienen con el proyecto de empresa)}

Entre las empresas que ofrecen un producto y/o servicio similar, ya que hasta el momento no hay empresa que realice el mismo servicio, se considerarán a las entidades financieras, casas de empeño o de préstamo, comisionistas, asesores comerciales, comisionistas, entidades de servicio de desarrollo empresarial, entre otras.

La entidades financieras como las cajas municipales, cajas rurales, EDPYME, también ofrecen el servicio de financiamiento, pero mayormente dirigido a los segmentos Pequeñas Empresas y Microempresas, a la vez ofrecen tasas más atractivas que la banca a los ahorros.

Las casas de empeño otorgan créditos a cambio de una prenda valor como aseguramiento de la paga del préstamo. Por otro lado se tiene a los prestamistas informales que como se mencionó antes ofrecen crédito inmediatos si tantos requisitos pero con elevadas tasas.

La empresa propuesta IDeltas SAC se encargará de brindar un servicio que tiene dos opciones, la de financiamiento y la de inversión. Entre la diferencias esta que IDeltas SAC no actuara como un intermediario financiero tal como las entidades tradicionales, sino que brindará el servicio de asesoramiento y canalización del dinero de los inversionistas hacia los que buscan un financiamiento, no quedándose con el dinero ni tomando decisiones acerca del él, serán los inversionistas quienes decidan dónde invertir su dinero o a quien financiar; así mismo la empresa brindará la información y la evaluación necesaria tanto a los inversionistas como a los solicitantes de financiamiento, ofreciendo un servicio seguro y de calidad. 


\subsubsection{Participación de mercado de cada uno de ellos}

Según el Reporte de Estabilidad Financiera del Banco Central de Reserva del Perú ([BCRP], 2016), el sistema financiero en general, conserva una estado financiero estable. Donde el índice de fortaleza financiera (IFF) de la banca presenta una posición "solvente", las financieras y las cajas municipales una posición "moderadamente solvente" y las cajas rurales se encuentran en una situación "menos solvente". En cuanto a la participación del mercado podemos ver en la siguiente figura:

\begin{tabular}{|c|c|c|c|c|c|}
\hline \multicolumn{6}{|c|}{$\begin{array}{l}\text { ACTIVOS FINANCIEROS Y PARTICIPACIÓN DE MERCADO } \\
\text { (A marzo de 2016. Millones de S/) }\end{array}$} \\
\hline & \multirow[t]{2}{*}{ Activos } & \multicolumn{3}{|c|}{ Participación (\%) } & \multirow{2}{*}{$\begin{array}{l}\text { Número de } \\
\text { Entidades }\end{array}$} \\
\hline & & Activos & Créditos & Depósitos & \\
\hline Total & 392680 & 100,0 & 100,0 & 100,0 & 59 \\
\hline 1. Banca & 359560 & 91,6 & 89,5 & 91,5 & 17 \\
\hline 2. No Banca & 33121 & 8,4 & 10,5 & 8,5 & 42 \\
\hline - Financieras & 11407 & 2,9 & 3,7 & 2,1 & 11 \\
\hline - Cajas Municipales & 18921 & 4,8 & 5,9 & 6,1 & 12 \\
\hline - Cajas Rurales & 641 & 0,2 & 0,2 & 0,2 & 7 \\
\hline - Edpymes & 2151 & 0,5 & 0,7 & 0,0 & 12 \\
\hline
\end{tabular}

Figura 6. Activos financieros y participación de Mercado. Tomado de "Reporte de Estabilidad Financiera”, por el Banco Central de Reserva del Perú (BCRP), 2016. Recuperado de http://www.bcrp.gob.pe/docs/Publicaciones/Reporte-EstabilidadFinanciera/ref-mayo-2016.pdf

Acerca del Mercado del Crédito Informal en el Perú, según el informe del Instituto Peruano de Economía ([IPE], 2012), se entiende que es aquel crédito que no está supervisado o regulado por la SBS u otra autoridad competente. El crédito informal usualmente ocupa el mercado no atendido por el crédito formal.

En los últimos años se ha dado un gran desarrollo de instituciones microfinancieras, esto implicaría un posible desplazamiento del Crédito Informal, pues se estaría reduciendo su ámbito de acción. 
Según la encuesta realizada por el IPE, en su informe de Crédito Informal en el Perú, se determinó origen de los créditos con instituciones informales.

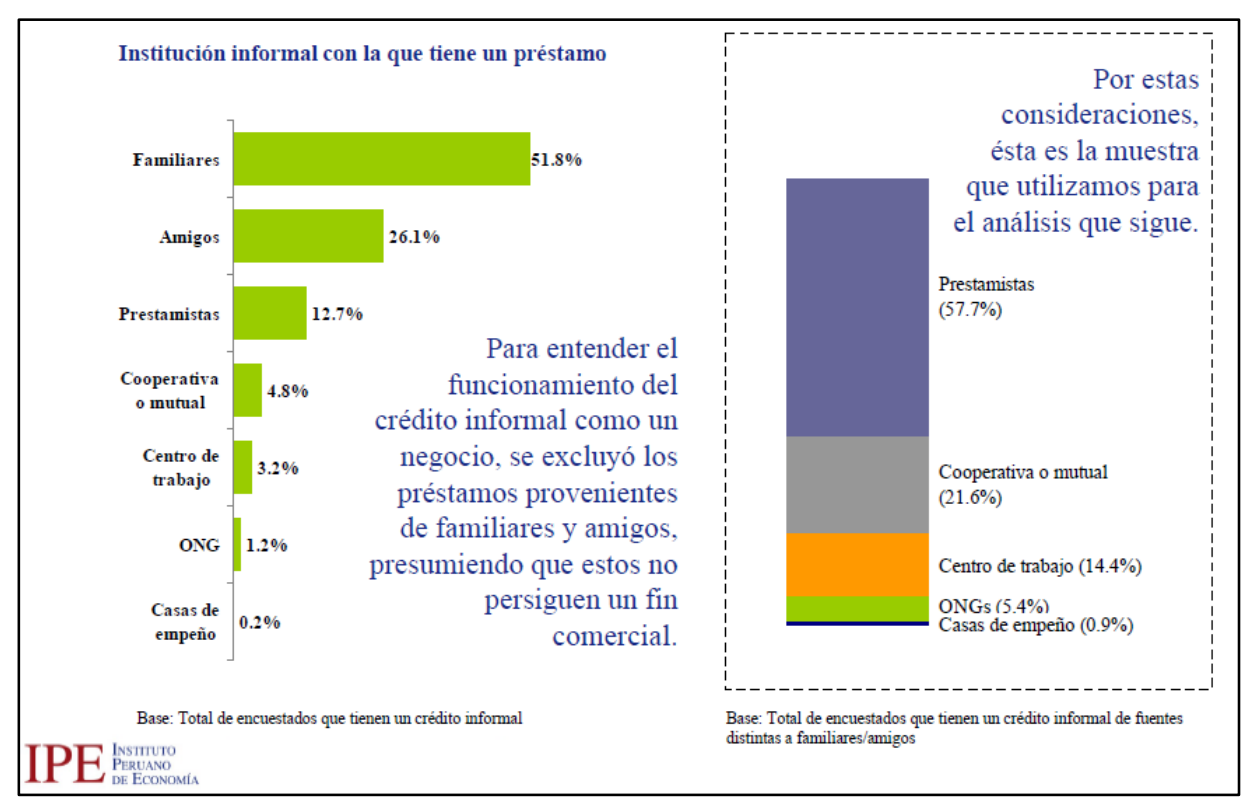

Figura 7. Instituciones Informales con las que se tiene préstamos. Tomado de "Crédito Informal en el Perú", por el Instituto Peruano de Economía (IPC), 2012. Recuperado de http://ipe.org.pe/documentos/el-credito-informal-en-el-peru

\subsubsection{Matriz de perfil competitivo}

La matriz de perfil competitivo (MPC) identifica los principales competidores de la compañía, así como sus fortalezas y debilidades. Acorde a esto los factores críticos de éxito en una MPC considera el criterio de 4 = principal fortaleza, $3=$ fortaleza menor, $2=$ debilidad menor, 1 = principal debilidad. De igual manera la matriz MPC permite utilizar las calificaciones y puntuaciones totales para comparar compañías rivales hacia la propuesta del presente proyecto. La matriz elaborada acorde a David (2013), y según el análisis hecho (ver Tabla 3), nos hallamos en una situación de fortaleza respecto a la de los competidores, con un total 2.75 (el cual es mayor a 2.5) mostrando que se tiene mayores fortalezas que debilidades. 
En cuanto a la participación en el mercado: se trata de una nueva propuesta de acceso a financiamiento e inversión, según las encuestas realizadas (preguntas 10 y 11, ver Anexo) se obtiene un $76 \%$ y $70 \%$ respectivamente de aceptación a esta nueva alternativa, sin embargo el resultado obtenido de las entrevistas hechas dan como resultado un temor considerable a los riesgos de pérdida de invertir en métodos alternativos. Por lo que al tratarse de la introducción de este nuevo producto se le da una calificación mínima de 1.0.

La competitividad en precios muestra una ventaja debido a que es una de las ventajas que se propone frente a los métodos tradicionales, ya que los precios son de menor costo.

En cuanto a la posición financiera de la empresa propuesta, se cuenta con un VAN de US\$26,074 y un TIR 31\% es cual es mayor al valor de Ke $9.74 \%$ indicando la viabilidad del proyecto, pero al tratarse de un proyecto con características nuevas e innovadoras de adquirir financiamiento es que se ha considerado como una fortaleza menor, dándole el valor de 2.

La calidad del producto es una de las mayores fortalezas debido a que está dirigido a según las necesidades del cliente, con la finalidad de hacer de los servicios de la empresa la primera opción para los clientes y afianzar su fidelidad. 
Tabla 3:

Matriz de perfil competitivo

\begin{tabular}{|c|c|c|c|c|c|c|c|}
\hline \multirow{2}{*}{$\begin{array}{l}\text { Factores } \\
\text { Críticos para el } \\
\text { éxito }\end{array}$} & \multirow[b]{2}{*}{ Peso } & \multicolumn{2}{|c|}{ Empresa propuesta } & \multicolumn{2}{|c|}{ Entidad Informal } & \multicolumn{2}{|c|}{ Caja Arequipa } \\
\hline & & $\begin{array}{c}\text { Califica } \\
\text { ción }\end{array}$ & $\begin{array}{c}\text { Peso } \\
\text { Ponderado }\end{array}$ & $\begin{array}{c}\text { Califica } \\
\text { ción }\end{array}$ & $\begin{array}{c}\text { Peso } \\
\text { Ponderado }\end{array}$ & $\begin{array}{c}\text { Califica } \\
\text { ción }\end{array}$ & $\begin{array}{c}\text { Peso } \\
\text { Ponderado }\end{array}$ \\
\hline $\begin{array}{l}\text { Participación en } \\
\text { el mercado }\end{array}$ & 0.15 & 1.0 & 0.15 & 2.0 & 0.3 & 4.0 & 0.6 \\
\hline $\begin{array}{l}\text { Competitividad } \\
\text { de precios }\end{array}$ & 0.25 & 4.0 & 1.0 & 1.0 & 0.25 & 3.0 & 0.75 \\
\hline $\begin{array}{l}\text { Posición } \\
\text { financiera }\end{array}$ & 0.15 & 2.0 & 0.3 & 3.0 & 0.45 & 2.0 & 0.3 \\
\hline $\begin{array}{l}\text { Calidad del } \\
\text { producto }\end{array}$ & 0.2 & 4.0 & 0.8 & 1.0 & 0.2 & 2.0 & 0.4 \\
\hline $\begin{array}{l}\text { Lealtad del } \\
\text { cliente }\end{array}$ & 0.25 & 2.0 & 0.5 & 2.0 & 0.5 & 3.0 & 0.75 \\
\hline Total & 1.0 & & 2.75 & & 1.9 & & 2.8 \\
\hline
\end{tabular}

Nota: (1) Los valores de las calificaciones son: 1 = debilidad importante, $2=$ debilidad menor, 3 = fortaleza menor, 4 = fortaleza importante. (2) Sólo se considera cinco factores críticos para el éxito, para simplificar un poco la realidad. Adaptado de "Matriz de perfil competitivo" por F. David, 2013, Conceptos de Administración Estratégica p. 83, Neucalpan de Juárez, México: Pearson Education. Copyright 2013

\subsection{Análisis del Contexto Actual y Esperado}

El presente análisis es una herramienta que permite conocer las fuerza externas que interactúan en el sector financiero, que pueden condicionar el desempeño, identificándose las Oportunidades y Amenazas que podrían impactar en la Empresa que se propone. Estos factores son: 


\subsubsection{Análisis Político-Gubernamental}

En el análisis político, según el plan del gobierno entrante, tiene como objetivo general el retomar el crecimiento económico y lograr una tasa de 5\% por año a partir de 2018, impulsando al mismo tiempo la formalización de millones de trabajadores.

Este hecho, es importante debido a que afecta directamente los intereses de la empresa propuesta, además menciona que alentará la inversión. Para ello se simplificará el Impuesto a la Renta para las empresas que no estén en el régimen de PYMES, permitiendo un crédito tributario equivalente a los costos de reinversión de utilidades. Pensamos que aparejada con el proyecto de destrabar trámites, esta medida le dará un fuerte impulso a la inversión y nuevos proyectos de las empresas industriales, comerciales, mineras, turísticas, agrícolas, logísticas y otras. Los cuatro grandes objetivos del Plan de Gobierno son: Seguridad ciudadana, Recuperar el dinamismo económico, Lucha contra la corrupción e Inversión social (Plan de Gobierno Peruanos por el Kambio, 2016).

Según el estudio realizado por Semana Económica e Ipsos Perú: Informalidad $360^{\circ}$. Cuando se pregunta a los encuestados cuáles son las tres principales características del Estado peruano, las respuestas son muy preocupantes; y a su vez al preguntarles si confían o no en el Estado peruano, los encuestados responden que no confían o desconfían mucho (Cámara de Comercio de Arequipa, 2016,Agosto). 


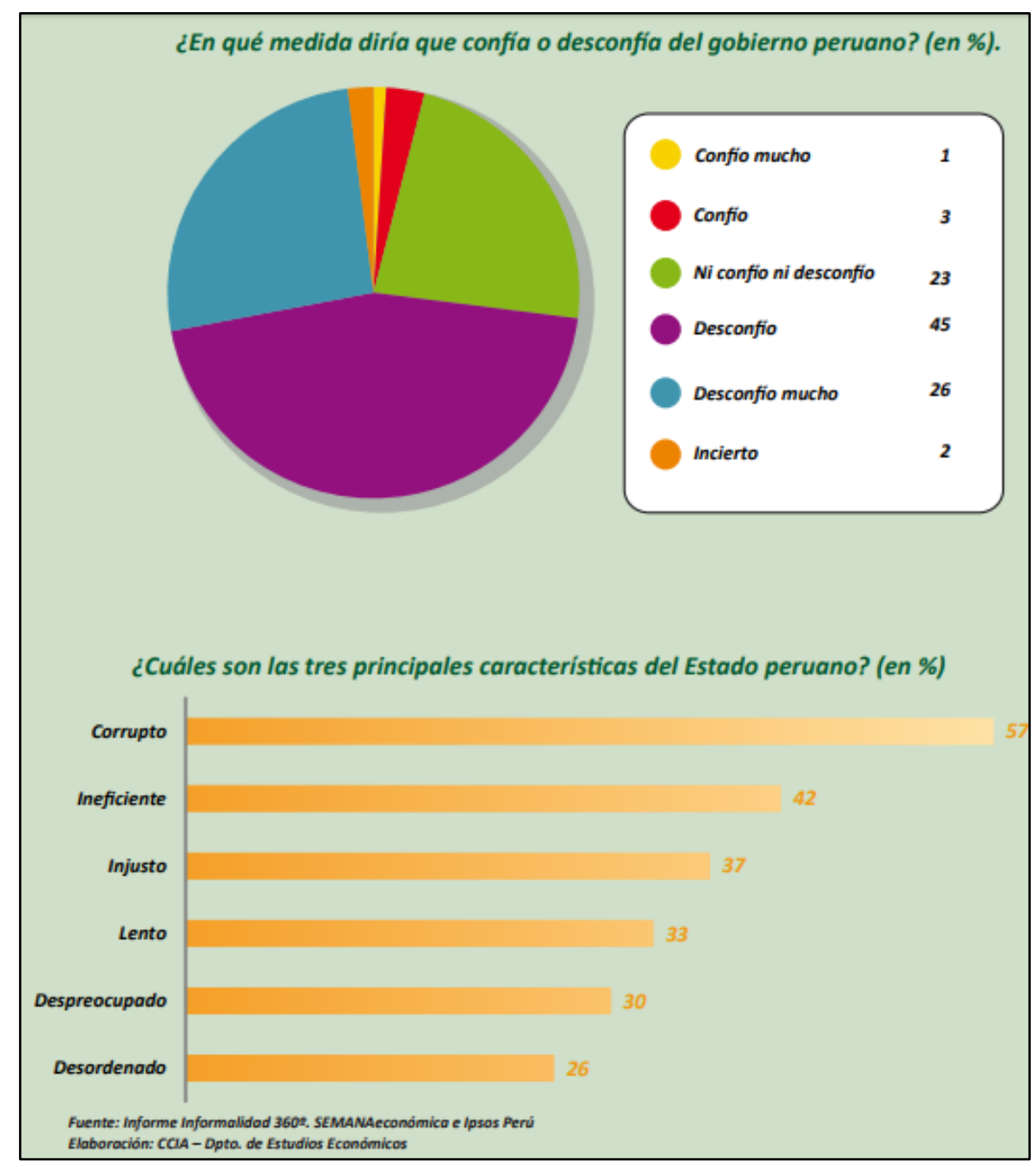

Figura 8. Informalidad y Legitimidad del Estado, por Cámara de Comercio de Arequipa, 2016. Recuperado de http://www.camaraarequipa.org.pe/sites/default/files/publicaciones/informe_de_coyuntura__economia_informal_y_productividad._agosto_2016.pdf

\subsubsection{Análisis Económico}

Este punto está relacionado con el comportamiento de la economía, el flujo de dinero, bienes y servicios tanto a nivel nacional como internacional, que tienen consecuencia directa en el posible atractivo de diversas estrategias.

Según el Marco Macroeconómico Multianual 2017-2019 (2016), en el 2016 la economía consolidará el proceso de recuperación iniciado durante el 2015 y crecerá 3.8\%, dentro de un rango de 3.5\% - 4.0\%. El entorno macroeconómico del 2016 está caracterizado por: (a) caídas de los precios de exportación y lento crecimiento de nuestros socios 
comerciales; (b) la entrada de nuevos proyectos mineros; (c) una política fiscal moderadamente expansiva, liderada por la inversión pública; y (d) un incremento gradual de la tasa de interés de referencia del BCRP como respuesta a presiones depreciatorias que impulsan al alza la inflación. En este contexto los motores de crecimiento del 2016, serán: una mayor producción minera; el gasto en infraestructura (privado y público); y el gasto público, excluyendo grandes megaproyectos de infraestructura.

Así mismo la economía China causa impactos sobre la economía peruana como se puede ver en las exportaciones de materia prima que se han visto afectados por la caída de sus precios, por ejemplo el cobre y el oro cuyas cotizaciones han caído $24 \%$ y $11.3 \%$, respectivamente. El efecto negativo sobre la inversión privada con commodities a precios más bajos, los proyectos mineros se hace menos atractivos y se decide aplazarlos. La inversión privada ha caído 9\% en el segundo trimestre del 2015 y esto, a su vez, implica menos generación de empleo. Además, los proyectos mineros en funcionamiento obtienen menos utilidades. En un escenario con menos inversiones y menores utilidades, las empresas pagan menos Impuesto a la Renta (Diario Gestión, 2015).

A nivel regional, tal y como se puede ver en el estudio realizado por la Universidad San Pablo en junio del 2014, se tiene que la mayor demanda de mano de obra se ubica en el procesamiento y servicios de alimentos, lo cual da un indicador a considerar en el rubro a centrarse finalmente, se adjunta un artículo publicado por "Aurum Consultoría y Mercado” sobre el índice de confianza del consumidor en Arequipa, en el cual muestra que a pesar de la reducción del dinamismo económico, se mantiene un nivel de confianza en el consumidor de Arequipa (Semana Económica, 2015).

Disponibilidad de crédito, este punto se refiere a la existencia o no de fuentes de financiamiento para la ejecución de proyectos. Se considera entonces a la Banca y no Banca (Financieras, Cajas Municipales, Cajas Rurales, EDPYMES, entre otros), en los cuales tienen 
una participación crediticia de $89.5 \%$ y $10.5 \%$ respectivamente (Banco Central de Reserva del Perú, 2016). Pero este crédito muchas veces se da con altas tasas de interés a través del sistema bancario, hacia las Pymes, por ser calificadas como empresas de alto riesgo crediticio.

El endeudamiento en el Sistema Financiero, (Cámara de Comercio de Arequipa, 2016), entre los posibles determinantes de los altos niveles de endeudamiento tanto de familias como de empresas, se tiene:

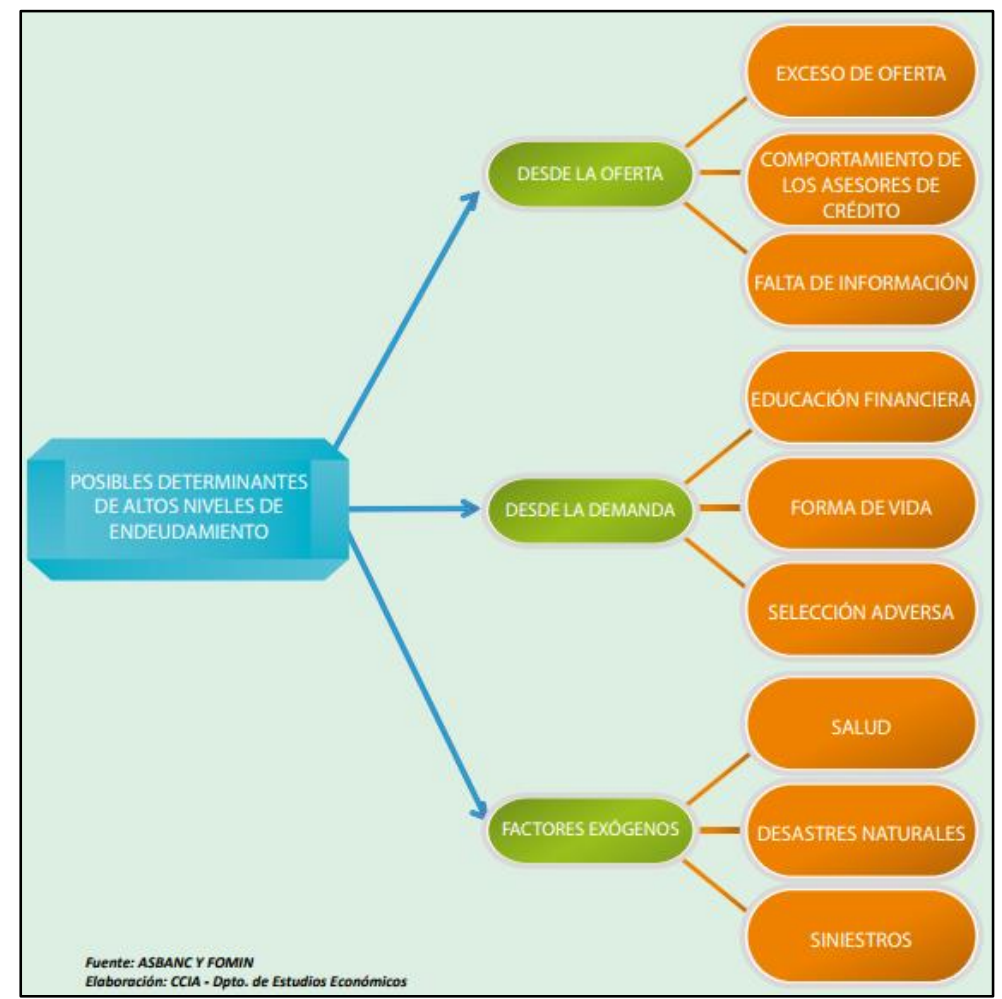

Figura 9. Endeudamiento en el Sistema Financiero, por Cámara de Comercio de Arequipa, 2016. Recuperado de http://www.camaraarequipa.org.pe/sites/default/files/publicaciones/informe_de_coyuntura_noviembre_2016.pdf

Una de las causas es la escasa educación financiera que limita a la persona a tomar una decisión racional en base a su nivel de ingresos y a su capacidad de pago de obligaciones. Otra causa es el tipo de vida del consumidor, quien ha hecho las deudas parte de su vida, y se ha habituado a estar siempre endeudado y destinar gran parte de su ingreso al pago de éstas. 
A agosto del 2016 en el Perú, los créditos Corporativos tienen la mayor participación, constituyendo el $22.1 \%$; seguido de los créditos de Consumo que representan el 18.8\%; mientras que los créditos dados a las Micro y Pequeñas empresas (MYPEs), son solo el $12.4 \%$ del total de la cartera. Sin embargo, en Arequipa ocurre lo contrario, tienen mayor presencia los créditos dados a las Micro y Pequeñas empresas con un 31.6\%; seguido de los créditos de Consumo con el 21.3\%; y los créditos Corporativos con solo el 5.7\% del total de la cartera. En Arequipa, en agosto del 2016, el crédito para empresas (crédito Corporativo, crédito a la Gran Empresa, crédito a la Mediana Empresa, crédito a la Pequeña Empresa y crédito a la Microempresa), registra una tasa de crecimiento de $17.8 \%$, con respecto al periodo anterior donde registraba un crecimiento de $6.7 \%$.

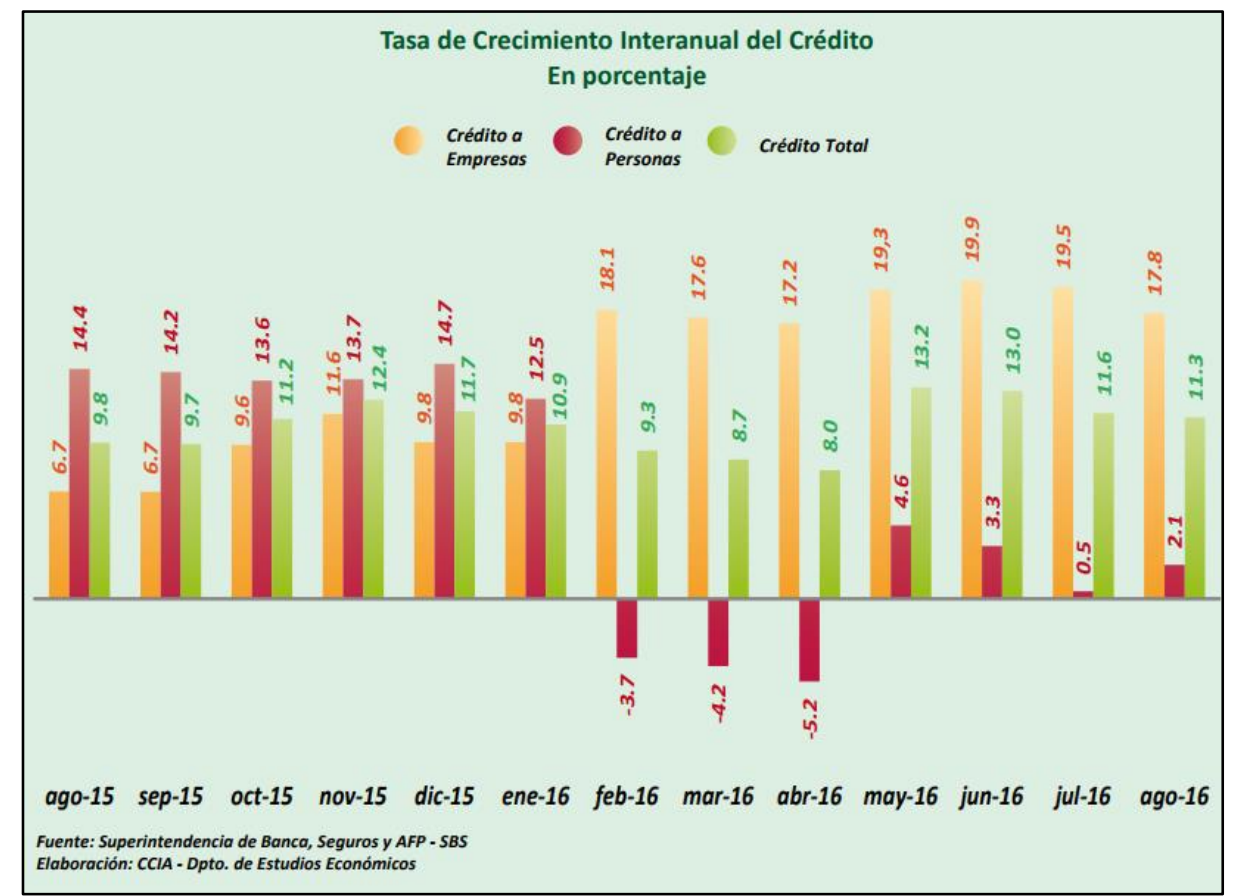

Figura 10. Comportamiento de los tipos de crédito en Arequipa, por Cámara de Comercio de Arequipa, 2016. Recuperado de http://www.camaraarequipa.org.pe/sites/default/files/publicaciones/informe_de_coyuntura_noviembre_2016.pdf

De otra parte, la población económicamente activa (PEA) a nivel de Arequipa alcanzó el 71.5\% de la población en edad de trabajar; mientras que a nivel nacional, esta cifra alcanzó 
el 72.3\% de la población en edad para trabajar (PET). La edad base para trabajar de la población en Arequipa oscila entre 25 y 59 años, representando el 59.3\%; mientras tanto a nivel nacional, las personas que se encuentran en este rango de edades representan el 59\%. Es importante lograr que tanto jóvenes y adultos se empleen adecuadamente y así fomentar el desarrollo económico del país (Cámara de Comercio de Arequipa, 2016).

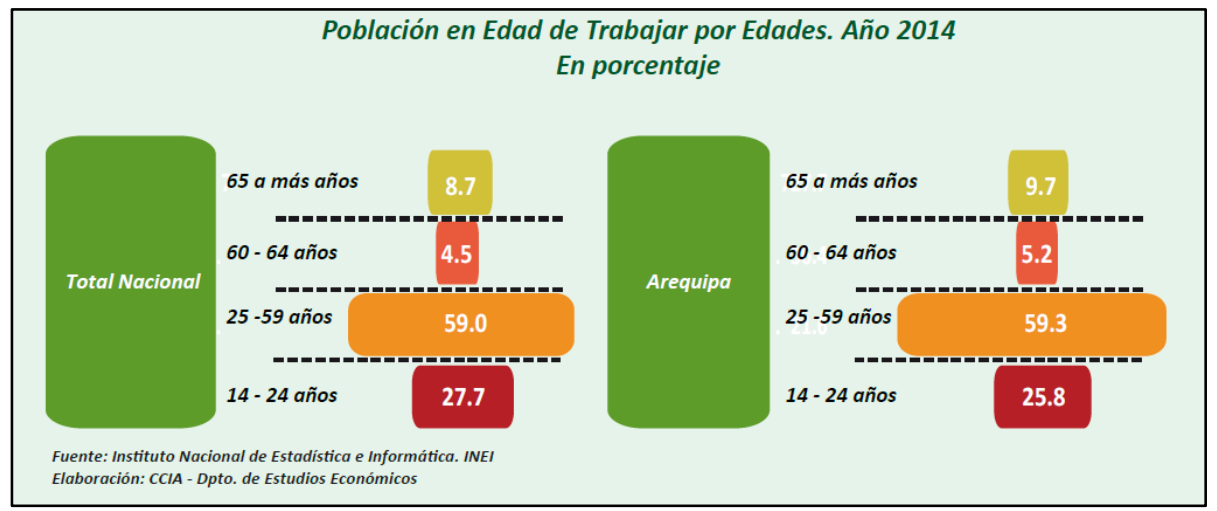

Figura 11. Población en Edad de Trabajar según edades, por Cámara de Comercio de Arequipa, 2016. Recuperado de http://www.camaraarequipa.org.pe/sites/default/files/publicaciones/informe_de_coyuntura_la_dinamica_de_la_pea_en_arequipa._junio_2016.pdf

En cuanto a la PEA ocupada en Arequipa, se incrementó en un cinco por ciento entre los años 2004 y 2015, ello debido al crecimiento económico suscitado en la región, lo que permitió que el empleo crezca ininterrumpidamente durante muchos años, situación que no sucedió en la gran mayoría de regiones del país. 


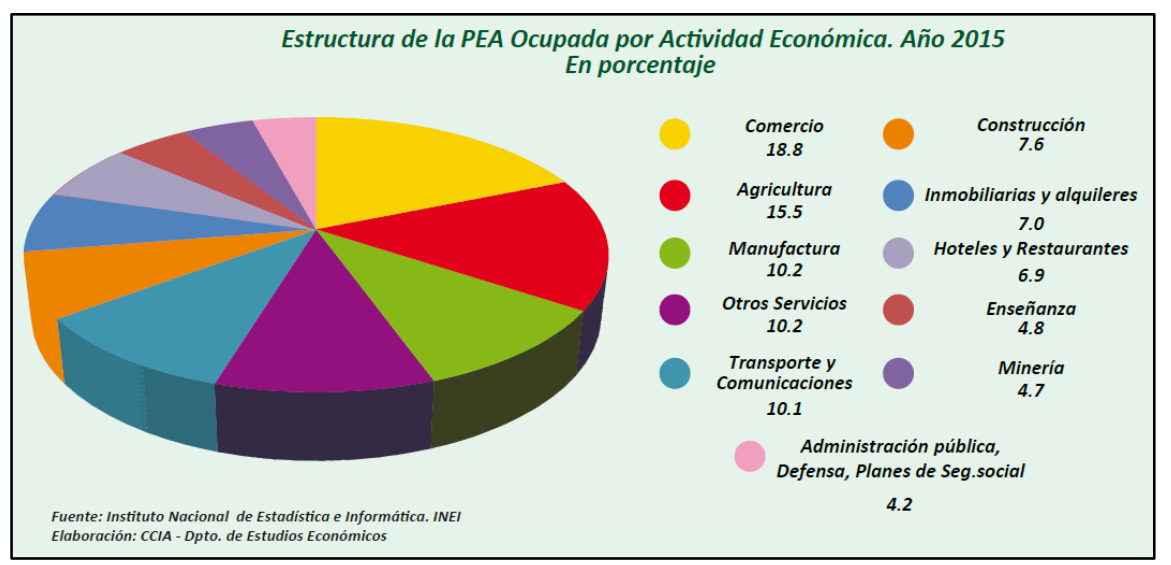

Figura 12. PEA ocupada según actividad económica, por Cámara de Comercio de Arequipa, 2016. Recuperado de http://www.camaraarequipa.org.pe/sites/default/files/publicaciones/informe_de_coyuntura__la_dinamica_de_la_pea_en_arequipa._junio_2016.pdf

El nivel de subempleo en Arequipa alcanza el 32.9\% de la PEA de la región, inferior en 14 puntos con respecto al promedio nacional. Se define como subempleo a la ocupación por tiempo parcial, con una remuneración por debajo del salario mínimo, no aprovechándose las capacidades del trabajador. Según el INEI, la tasa de desempleo en Arequipa disminuyó de $8.7 \%$ en el 2004 a $3.9 \%$ en el 2015 . Arequipa ocupa el onceavo lugar a nivel nacional de desempleo juvenil urbano alcanzando el $10 \%$, por debajo del promedio nacional de $11.2 \%$; y por encima de regiones como Apurímac (6.3\%), Moquegua (8.8\%), Cusco (8.9\%), la Libertad (9.0\%), entre algunas otras (Cámara de Comercio de Arequipa, 2016). 


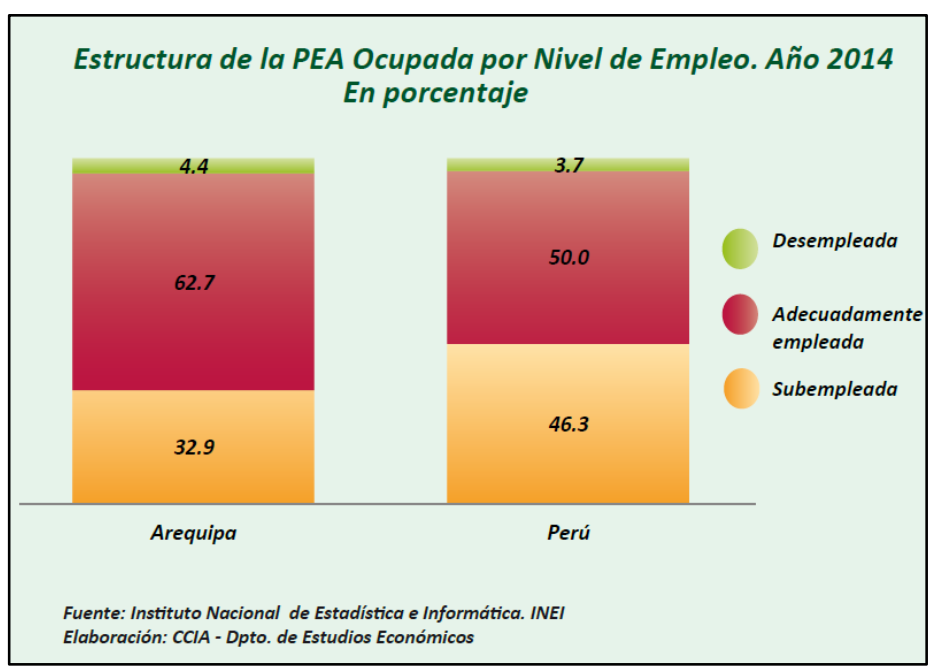

Figura 13. Nivel de Subempleo en la PEA, por Cámara de Comercio de Arequipa, 2016. Recuperado de http://www.camaraarequipa.org.pe/sites/default/files/publicaciones/informe_de_coyuntura__la_dinamica_de_la_pea_en_arequipa._junio_2016.pdf

En cuanto a las empresas arequipeñas, se puede apreciar en la gráfica los principales obstáculos que se presentan (ver Figura 14), destacando la incertidumbre en cuanto al panorama económico después de asumir el poder un nuevo gobierno y la caída en cuanto a la demanda del mercado, seguido por la alta competencia y la débil demanda del mercado.

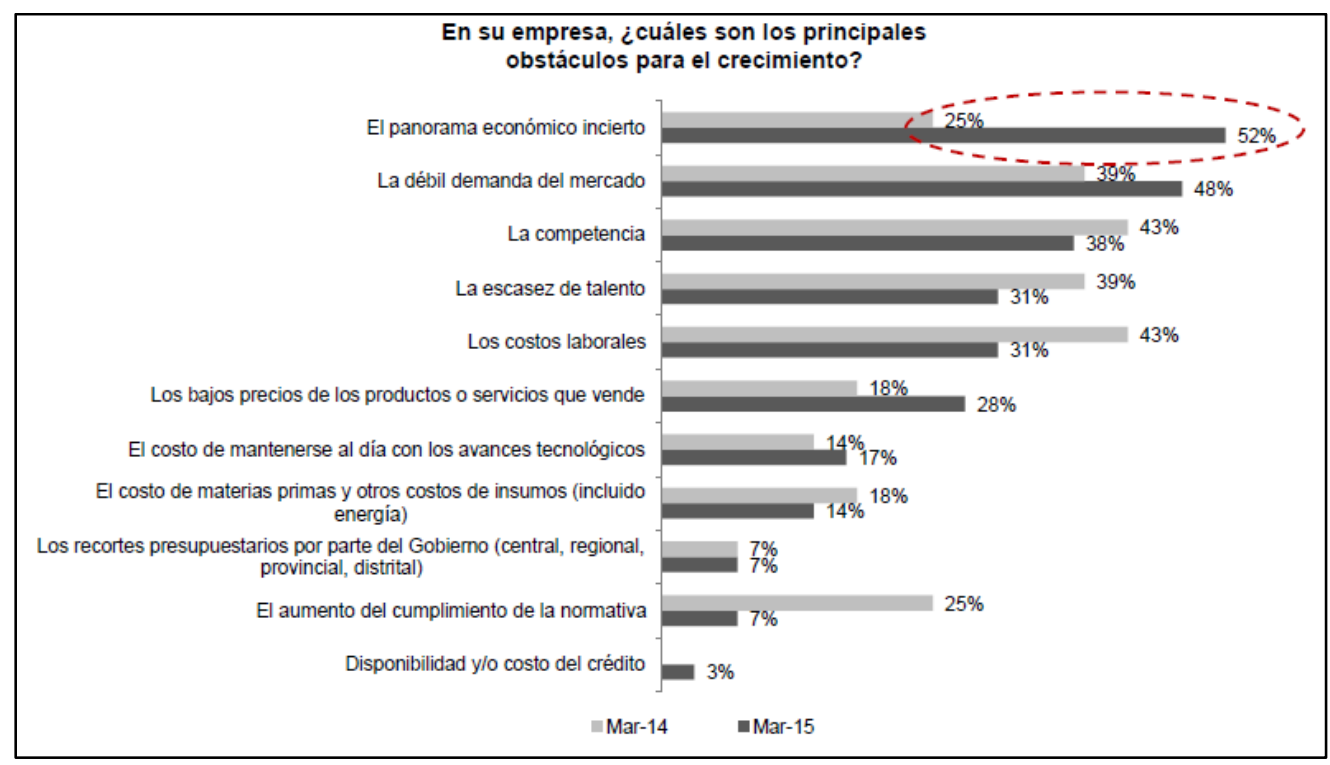

Figura 14. Principales obstáculos en una empresa para su crecimiento, por AURUM, 2015. Recuperado de http://ucsp.edu.pe/cegob/wp-content/uploads/2015/04/AURUM_InformePerspectivas-Econ\%C3\%B3micas-2015-Regi\%C3\%B3n-Arequipa_Abril-2015.pdf 
El Sector Informal, según el estudio de avance investigación No. 8, 2016 de la CEPLAN (Centro Nacional de Planeamiento Estratégico) la economía informal prevalece en muchos contextos, apareciendo de diferentes maneras. En una economía informal no solo existen empresas o unidades productivas informales sino, también, trabajadores que laboran en condiciones de informalidad; por ello se expresa generalmente en términos de producción informal y empleo informal. A pesar del crecimiento económico sostenido, la informalidad persiste y no ha desaparecido, adoptando nuevas formas.

\subsubsection{Análisis Legal}

En este punto se analiza sobre el desarrollo legislativo que pudiera afectar a la empresa propuesta. Se tiene:

1. El Art. 59 de la Constitución establece que el Estado promueve la creación de riqueza y garantiza la libertad de trabajo y la libertad de empresa, comercio e industria.

2. Marco de Regulación y supervisión dado por la Superintendencia de Banca, Seguros y AFP (SBS) que es el organismo encargado de la regulación y supervisión de los sistemas financieros, de seguros y del Sistema Privado de Pensiones (SPP), así como de prevenir y detectar el lavado de activos.

3. Ley Marco de Ciencia, Tecnología e Innovación Tecnológica, Nro. 28303, así como el D.S. 027-2007-PCM, donde se establece las Políticas Nacionales con referencia a la Ciencia, Tecnología, Innovación y Competitividad.

4. Ley $\mathrm{N}^{\mathrm{o}} 28976$, Ley Marco de Licencia de Funcionamiento y su modificatoria Ley $\mathrm{N}^{\mathrm{o}}$ 30230, Ley que establece medidas tributarias, simplificación de procedimientos y permisos para la promoción y dinamización de la inversión en el país. 
5. Los emprendimientos estarían dentro del denominado sector de Micro y Pequeña Empresa, de acuerdo a lo que contempla la Ley No 28015 (Ley de Promoción y Formalización de la Micro y Pequeña Empresa).

6. Ley 30056 (Ley de Impulso al Desarrollo Productivo y Crecimiento Empresarial) esta ley va dirigido a los problemas de las MYPES, como la informalidad, la falta de capital humano capacitado, los altos costos para innovar.

7. Ley 29733 (Ley de protección de datos personales) Se busca garantizar el derecho fundamental a la protección de datos personales.

8. Ley 30096 (Ley de delitos informáticos) Se busca prevenir conductas ilícitas que afecten sistemas y datos informáticos.

9. NTP-ISO/IEC 27001:2008 EDI. Tecnologías de la Información. Técnica de Seguridad. Sistemas de Gestión de Seguridad de la Información. Requisitos.

Por otro lado para Samuel Gleiser, presidente de la Cámara de Comercio de Lima, el alto nivel de la informalidad no disminuye porque más allá de los discursos no hay una política de Estado que haga atractiva la formalidad y que simplifique toda la normativa. "Persisten las trabas burocráticas y un sistema tributario y laboral que no apoya el crecimiento de la pequeña empresa, sino que hace que esta se estanque", sostiene (El Comercio, 2014).

\subsubsection{Análisis Cultural}

El Perú es un país con una población muy diversa, por razones culturales y sociales; productos y servicios financieros que reflejan los hábitos y cultura de la población: De acuerdo a información publicada por la SBS y Asociación de Bancos (ASBANC) Sólo el $29,5 \%$ de la población está en el sistema financiero formal y un 23,3\% no ahorra. El 35,4\% de personas ahorra en su hogar. El 6,9\% prefiere ahorrar en las juntas (agrupación de 
personas que se comprometen a realizar aportes en una determinada frecuencia), todo esto dependiendo del grado de educación financiera de las personas y cuan conservador sea.

Educación: El director general de Educación Básica Alternativa (EBA) del Ministerio de Educación, Luis Vásquez, indicó que en el Perú hay un millón 300 personas analfabetas. El 75\% de ellas son adultos mayores (más de 65 años) y el resto son jóvenes con edades entre los 15 y 20 años. En Arequipa, el 60\% de la PEA no tiene formación educativa superior, ya sea universitaria o técnica, tan sólo el 21\% de la PEA tienen educación universitaria, y el 19\% posee educación superior no universitaria (Cámara de Comercio de Arequipa, 2016).

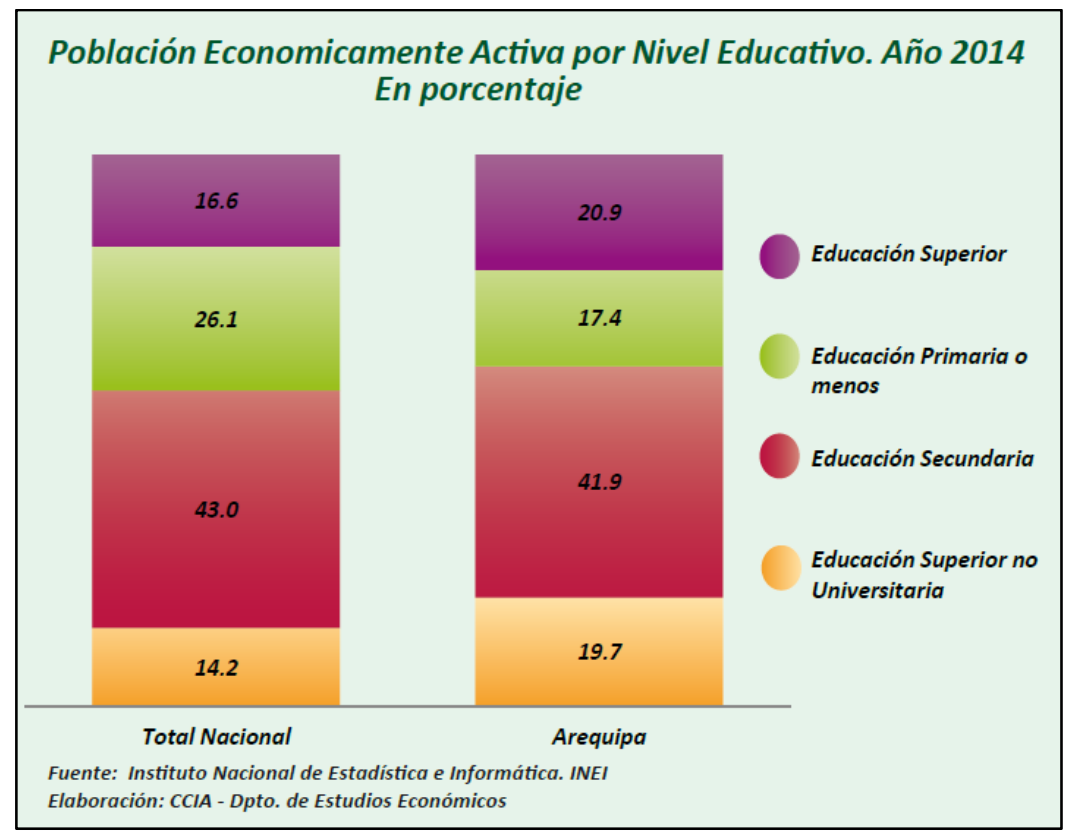

Figura 15. Población en Edad de Trabajar según edades, por Cámara de Comercio de Arequipa, 2016. Recuperado de http://www.camaraarequipa.org.pe/sites/default/files/publicaciones/informe_de_coyuntura_la_dinamica_de_la_pea_en_arequipa.jjunio_2016.pdf

Demografía: En el Perú, al 30 de junio de 2015, según proyección del Instituto Nacional de Estadística e Informática - INEI, la población alcanzó los 31 millones 151 mil 643 personas. Del total de la población peruana, el 50.1\% son hombres y el 49,9\% son mujeres; asimismo, la población urbana alcanza el 76,7\% con 23 millones 893 mil 654 habitantes y la rural el 23,3\% con una población de 7 millones 257 mil 989 mil. 
Las lenguas oficiales son el español y el quechua, que es hablado por $84,1 \%$ y $13 \%$ de la población, respectivamente. Existiendo lenguas no oficiales (3\%), entre ellas: el ashaninka, las lenguas amazónicas y otras.

La expectativa de vida, estimada al 2012, en hombres: 70.78 años, mientras que en mujeres: 74.76 años.

\subsubsection{Análisis Tecnológico}

La Industria se ha visto afectada sustancialmente por los cambios en la tecnología, en algunos casos los cambios han sido muy positivos incrementado de forma considerable la competitividad de las empresas, pero en otros, las empresas se han visto muy afectadas e incluso quebrado por la incapacidad de adecuarse a estos cambios tecnológicos.

En cuanto a la Tecnología de información y Comunicación, la telefonía móvil es la que tiene mayor grado de acceso en los hogares del país, presentando un continuo crecimiento. De cada 100 hogares 80 tiene al menos un televisor y un aparato de radio. Aumentan en 5,4 puntos porcentuales hogares rurales que tienen televisión, al pasar de 44,2\% a 49,6\%, también se incrementa los que tienen un aparato de radio transmisor de 77,9\% a 79,4\%. (Fuente: INEIencuesta nacional de hogares)

Otro avance importante en el país es la consolidación del Programa Nacional de Innovación para la Competitividad y Productividad del Ministerio de la Producción, organizado para atender problemas específicos de las empresas manufactureras y de los nuevos emprendimientos (Ministerio de la Producción, 2014).

\subsubsection{Análisis Ecológico}

En el caso del Perú, se concentra un gran patrimonio natural y una riqueza biológica reconocida, pero cuyas dimensiones reales hasta el momento han sido difíciles de determinar. 
En términos económicos, la diversidad biológica del Perú es un pilar de la economía nacional. El 99\% de la pesquería depende de los recursos hidrobiológicos, por lo menos el $65 \%$ de la producción agrícola se basa en recursos genéticos nativos, el 95\% de la ganadería recurre a los pastos naturales nativos y el $99 \%$ de la industria forestal emplea bosques y especies nativas.

Mediante D.S. N 014-2011-MINAM se implementó el Plan Nacional de Acción Ambiental - PLANAA (2011-2021), que es un instrumento de planificación nacional de largo plazo, formulado sobre la base de la Política Nacional del Ambiente, el cual contiene metas prioritarias que contribuyen con la conservación y el aprovechamiento sostenible de los recursos naturales, la mejora en la calidad ambiental; y por tanto, a mejorar la calidad de vida de la población (Legislación Ambiental, 2015).

Existe una gran preocupación por el impacto de la producción que puede ocasionar a las condiciones actuales del planeta.

Por otro lado también está la presencia de las MYPES que se dedican a actividades productivas que implican la transformación de insumos y uso de energía, usualmente reportan mayores riesgos a la salud humana y al medio inmediato. Este es especialmente el caso de las MYPES comprendidas en los rubros de: a) industria textil, b) curtiembre, c) galvanoplastia, d) metalmecánica y e) elaboración de alimentos. Por lo general, los daños a la salud humana y al ambiente que de estas se originan, no se aprecian en el corto plazo y afectan no sólo a los conductores de los negocios y a sus trabajadores, sino también al vecindario. En muchos casos, las MYPES disponen de equipamiento e infraestructura obsoletos, invierten poco en la reingeniería de sus procesos y generalmente no disponen de los recursos para realizar las inversiones que la adecuación ambiental demanda 


\subsection{Oportunidades y Amenazas}

Del presente análisis realizado en la sección anterior se pudo determinar las fuerzas externas que intervendrán en el desarrollo de la futura empresa propuesta, encontrándose 34 oportunidades y 36 amenazas (ver Figura 16); los cuales serán evaluados cuantitativamente en la Matriz de Evaluación de Factores Externos (EFE), desarrollado en la sección 6.2 Formulación de Estrategias de negocio.

El desarrollo de nuevos productos con la finalidad de poder atender a nuevos clientes, en nuevos segmentos de mercados a menor riesgo, puede ser muy bien aprovechado al utilizar las oportunidades externas con las estrategias adecuadas. 


\begin{tabular}{|c|c|c|c|}
\hline \multicolumn{2}{|c|}{ Oporturidades } & \multicolumn{2}{|c|}{ Amenazas } \\
\hline 01 & Actual crecimiento económico en el Peri & Al & Nuevo gobierno: ine stabilid ad politica e incertidumbre \\
\hline $\mathrm{O} 2$ & Inchusion social y desc entralización & A.2 & Inestabilidad social \\
\hline 03 & Desarrollo sostenible & A3 & Exceso de procesos burocráticos \\
\hline O4 & Altas tas as de interes a través del sistema bancario. & A4 & Tipo de cambio de la moneda extranjera. \\
\hline 05 & Desconfianza y desconocimiento por parte de los emprendedores. & A.5 & Agravamiento de conflictos en Medio Oriente. \\
\hline 06 & $\begin{array}{l}\text { Los retrasos en la implementación de los programas de inver sión pública y } \\
\text { privada. }\end{array}$ & A6 & Volatilidad financiera, as ocia do al ajuste monetario de Estados Unidos \\
\hline 07 & $\begin{array}{l}\text { Bajos intereses ofrecidos para los ahorros por el sistema financiero } \\
\text { interme diación indirecta (bancas). }\end{array}$ & A.7 & Reducción en los precios de los commodities, el petróleo y otros insumos. \\
\hline 08 & $\begin{array}{l}\text { Necesidades insatis fechas (pers onas naturales y microempresas) en zonas } \\
\text { no atendidas con productos y servicios financieros. }\end{array}$ & A8 & Menor optimis mo de empresarios. \\
\hline 09 & $\begin{array}{l}\text { Los retos del próximo gobierno para incrementar la productividady } \\
\text { competitividad nacional. }\end{array}$ & A9 & Aumento de la morosidad crediticia \\
\hline 010 & Tratado de Libre Comercio & A.10 & Bajos niveles de ahorro de pers onas y empresas \\
\hline 011 & Fomento a la PYME & All & Desaceleración de la economia China. \\
\hline 012 & Inchusion financiera & A.12 & Disminución de la inversión privada. \\
\hline 013 & Politicas laborales más flexibles con un nuevo gobierno. & A.13 & Marco legislativo negativo \\
\hline 014 & Leyes antimonopolio. & A.14 & Leyes de impuestos, Sistema Tributario \\
\hline 015 & $\begin{array}{l}\text { Ley de Promoción y Formalización de la Micro y Pequeña Empresa Ley } \\
N^{0} 28015\end{array}$ & A.15 & Ordenanzas municipales sobre licencias de actridad \\
\hline 016 & Ley Marc o de Ciencia, Tecnologia e Innovaciön Tecnológica, Nro. 28303. & A.6 & $\begin{array}{l}\text { Restricciones y pocos beneficios presentados en la Ley MYPE Ley No } \\
28015 \text {. }\end{array}$ \\
\hline 017 & $\begin{array}{l}\text { Ley } 30056 \text {, Ley de Impulso al Desarrollo Productivo y Crecimiento } \\
\text { Empresarial } \\
\text { Ley } N^{0} 28976 \text {, Ley Marco de Licencia de Funcion armiento y su }\end{array}$ & A.7 & Bajo nivel educativo y poca educación financiera \\
\hline 018 & $\begin{array}{l}\text { modfic atoria Ley } N^{0} 30230 \text {, generación de dinamismo de la inver sión en el } \\
\text { pais. }\end{array}$ & A18 & Inseguridad cirdadana \\
\hline 019 & Decreto Ley $\mathrm{N}^{\circ} 728$, Ley de Formacion y Promo ción Laboral & A19 & $\begin{array}{l}\text { Conflictos por huelgas, terrorismo o desastre natural afectan do la inversion } \\
\text { privada. }\end{array}$ \\
\hline $\mathrm{O} 20$ & Economia Informal & A20 & $\begin{array}{l}\text { Exchsión geográfica, que imposibilita o reduce el acc eso a servicios } \\
\text { básic os y financieros. }\end{array}$ \\
\hline $\mathrm{O} 21$ & Efecto que causa la emigracion & A.21 & Falta de adaptación a las innovaciones te cnologic as. \\
\hline 022 & Crecimiento poblacional & A22 & $\begin{array}{l}\text { Cambios y modernización constante en la tecnologia, hace que la que se } \\
\text { tiene se vuelva obs oleta. }\end{array}$ \\
\hline $\mathrm{O} 23$ & Reduccion del nivel de analfabetizmo. & A.23 & Al impacto del Fenómeno de El Nifio en la economia real. \\
\hline $\mathrm{O} 24$ & Reducción del tiempo para alcanzar los difer entes destinos. & A.24 & La escasez de agua. \\
\hline 025 & $\begin{array}{l}\text { Los cambios tecnológicos hacen más eficientes y competitivas a las } \\
\text { empres as (producción, manejo, distribuciön, informaciön, logistic a, etc.) }\end{array}$ & A25 & Calentamiento global. \\
\hline 026 & La diver sidad biológica de1 Peni & A26 & Baja conciencia ambiental y poco conocimiento. \\
\hline $\mathrm{O} 27$ & Plan Nacional de Acción Ambiental & A27 & $\begin{array}{l}\text { Actividades de MYPES que pueden contribuir con el deterioro significativo } \\
\text { del ambiente }\end{array}$ \\
\hline $\mathrm{O} 28$ & No existe competidor directo. & A.28 & $\begin{array}{l}\text { Desc onocimiento en los temas básicos de higiene, salud y seguridad en el } \\
\text { trabajo por parte de microempres arios. }\end{array}$ \\
\hline 029 & Microempresarios vinculados a la informalidad. & A.29 & La experiencia de la competencia. \\
\hline 030 & Altas tasas de interès por un fin anciamiento informal. & A30 & Alto recurso financiero de las empresas competidoras. \\
\hline 031 & Numerosos proveedores en el mercado. & A31 & Mayor participación de mercado de nuestro competidor \\
\hline 032 & Inn ovación y empren dimiento. & A32 & Canales de distribución de la competencia. \\
\hline $\mathrm{O} 33$ & Aphicar una nueva estrategia basada en Crowdfiunding. & A33 & Cre dito Informal, prestamistas informales. \\
\hline $\mathrm{O} 34$ & Menor rie sgo hacia las inversiones. & $\begin{array}{l}\text { A34 } \\
\text { A35 } \\
\text { A36 }\end{array}$ & $\begin{array}{l}\text { Ingre so de otras entidades financieras. } \\
\text { Deficiencia o incumplimiento en la prestación de los servicios. } \\
\text { Alto nivel de morosidad e incumplimiento }\end{array}$ \\
\hline
\end{tabular}

Figura 16: Análisis del contexto actual y esperado: Oportunidades y Amenazas 


\section{Capítulo III. Estudio de Mercado}

\subsection{Descripción del servicio o producto}

En este punto se define las características generales del bien o servicio que se ofrecerá; IDeltas S.A.C. tiene como finalidad el de contribuir a solucionar o disminuir el problema de acceso al financiamiento de las personas, se encuentra localizado en el entorno servicios, específicamente "Actividades de Asesoramiento Empresarial” con CIIU: 74145 y tiene por finalidad ser de nexo, canal o mediación entre las personas que buscan un financiamiento con las personas que deseen otorgarlo, con la finalidad de obtener un beneficio; y también el de brindar servicios de asesoría empresarial en materia de nuevos métodos de conseguir financiamiento; a cambio de ello IDeltas S.A.C. realizar el cobro de comisiones asignado a los clientes por el servicio y gestión ofrecido, siempre y cuando se ejecute.

La empresa IDeltas S.A.C. no efectuará intermediación financiera, por lo que no se encuentra regulado por SBS como indica la ley General del Sistema Financiero No. 20702.

Los clientes del presente proyecto son:

Clientes financiadores/benefactor: se caracterizan por beneficiarse en una venta por adelantado; o ser participantes en el financiamiento de algún proyecto o emprendimiento, serán quienes decidan dónde invertir su dinero o a quien de los solicitantes financiar, todo bajo el amparo del código civil peruano (contrato de mutuo).

Clientes buscadores de financiamiento/ beneficiario, conformado por personas emprendedoras, personas o empresas que cuenten con un negocio en crecimiento, proyectos creativos, artísticos, tecnológicos, sociales, entre otros, que mediante una alternativa de financiación distinta a la bancaria, desean emprender un negocio o ampliar el que tienen. 
IDeltas S.A.C.se encargara de recopilar información tanto de los inversionistas como de los que buscan financiamiento y armar un perfil de cada cliente: identidad, perfil crediticio (ej. historial crediticio de la PYME rentabilidad en los últimos años), como obtienen sus ingresos, lugar donde labora; para luego hacer un análisis frente a base de datos de organismos gubernamentales y empresas privadas especializadas, y validar la información.

De este modo se pretende brindar una alternativa considerable a una gran demanda de préstamos y por otro lado a inversionistas en busca de mejores rentabilidades sin tener que enfrentar mayores riesgos (Figura 17). La empresa contará con una oficina donde se realizarán todas las actividades del servicio así como también se contará con una plataforma online en donde se podrá encontrar toda la información de los servicios y de cómo funciona el sistema, también la publicación de solicitudes de financiamiento, servicio de chat en línea y de mensajería.

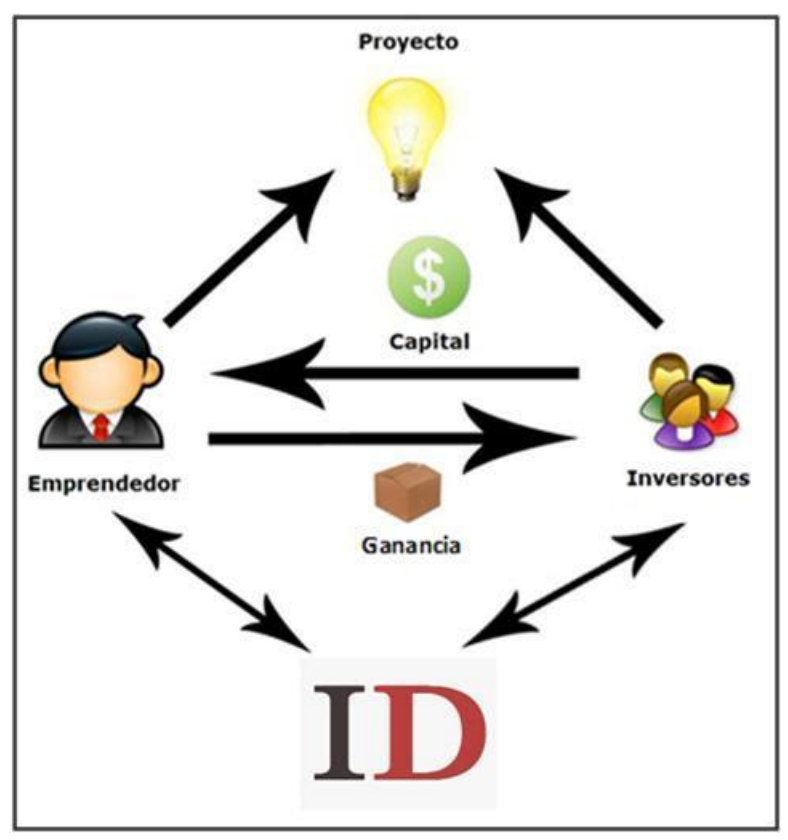

Figura 17. Descripción del modelo alternativo de financiamiento en IDeltas SAC 
La forma de funcionamiento de esta propuesta alternativa es como sigue:

- Se inicia con el registro de los inversores y quienes buscan de un financiamiento. En ambos casos y por cuestiones de garantía, se hace una evaluación, en el caso de los inversionistas se busca el cómo obtienen su dinero con la finalidad de prevenir el lavado de activos, para ello solo se operará con clientes que perciben o mantienen cuentas dentro del sistema financiero, por lo que han sido evaluados por las entidades financieras donde tienen sus cuentas. En el caso de una persona natural este no debe superar los tres mil soles, y en el caso de empresas estas deben sustentar su rentabilidad obtenida en los últimos años.

- En el caso de los que buscan financiamiento se evalúa su historial crediticio, pasando por una exhaustiva evaluación (puede ser a través de Infocorp, Equifax, Sentinel, Reporte de deudas SBS), su grado de estabilidad y la del negocio y las actividades laborales o comerciales que realiza, además de los mencionados en párrafos adelante.

- Una vez que los solicitantes aprueben la evaluación puede acceder a su solicitud de préstamo, para ello debe describir su proyecto de financiación, indicando el monto necesario, como se utilizaran los recursos y el tiempo de recaudación. Con la información recaudada del proyecto se procede a su publicación en el sitio web, para la presentación a los financiadores y un eventual otorgamiento de préstamo. El importe máximo de captación de fondos por proyecto de financiación participativa no podrá ser superior a los 100 mil soles.

- Se efectúa un contrato de mutuo amparado por el Código Civil peruano entre el inversionista y el solicitante del financiamiento.

- Una vez recaudado el dinero de los inversionistas, interesados en financiar, se hace una transferencia a la cuenta bancaria del solicitante. Mensualmente se realizará el cobro de las cuotas de la misma cuenta, devolviéndose luego a los inversores que participaron (esto aplica al producto de Financiamiento). 
- Toda la suma de dinero de los financiadores es depositada en una cuenta bancaria, la que se denominará Cuenta de Fideicomiso IDelta, cuyos fondos serán administrados por una Fiduciaria, en donde se transferirá en dominio fiduciario los desembolsos que se reciben de los financiadores y los buscadores de préstamo y garantizar la oportuna canalización

Entre los productos u oportunidades de inversión que se ofrecen tenemos:

1. Ventas por adelantado, en el crowdfunding existe este beneficio de pronto pago, tras un modelo de ventas por adelantado (crowdfunding de recompensa), tanto para productos como servicios, del mismo modo, se da en diferentes rubros, manejando el concepto de ventas por adelantado así como donaciones (Acconcia, 2015).

Este producto consiste en recibir el pago por adelantado (financiamiento), directamente del cliente inversor a través de la cuenta de fideicomiso, para ejecutar la producción en masa de productos con la condición de que una vez concluida la producción en un tiempo pactado este sea entregado al inversor a un precio menor del que se vendería al público en general y/o distribuidores. En esta modalidad, los emprendedores (clientes que buscan financiamiento o también beneficiario) se acogen a brindar una oferta de venta de un volumen de producción que permita obtener un descuento que sea atractivo para el financista negociante (benefactor), consiguiendo de este modo el beneficio principal de recepción de capital de trabajo a menor costo que los modelos tradicionales y pago de este capital con el producto prometido al financista, quien se beneficia por la adquisición de una mercadería con un descuento mayor al del promedio del mercado. Finalmente para poder garantizar la entrega de productos en forma, tiempo y calidad pactados inicialmente, el receptor de capital entrega una prenda valor en garantía, la cual es devuelta una vez se dé por exitosa la transacción entre el comprador y el vendedor. 
Entre otras posibilidades en que es útil y resulte benéfico a los clientes este producto de ventas por adelantado, tenemos:

\section{Caso de beneficiario}

- $\quad$ Acceso a una opción de capitalización no considerada

- Podría recibir donaciones de mecenas interesados en apoyar el emprendimiento y/o proyecto, podría incluso motivar donaciones a cambio de una retribución significativa como un agradecimiento en la página web oficial del proyecto, mención honrosa en la placa de inauguración, envió de tarjeta autografiada, entre otros, esto podría aplicarse a proyectos con un entorno social, artístico, musical y otros similares.

- $\quad$ Podría lanzar un nuevo producto utilizando nuestra red de contactos, con el respaldo de nuestros mecanismos transparentes que bajan los índices de riesgo entre el ofertante y el o los clientes, recibiendo además observaciones por parte de los clientes antes del lanzamiento, recibiendo nuevas ideas y logrando un acercamiento más alto de las empresas y/o autónomos para con sus clientes.

\section{Caso de benefactor}

- $\quad$ Acceso a una opción de una posible oportunidad de inversión por el descuento y/o costo de oportunidad asociado.

- Ser parte de la financiación de proyectos de innovación, con el beneficio de obtener el producto.

- $\quad$ En el caso de las empresas que deseen participar como donador, además de poder utilizar los productos de estas donaciones, también puede convertirse en un poderoso 
potenciador de branding para la creación de una identidad en la imagen de la marca del producto al generar una asociación conceptual, emocional y de identidad como sponsor.

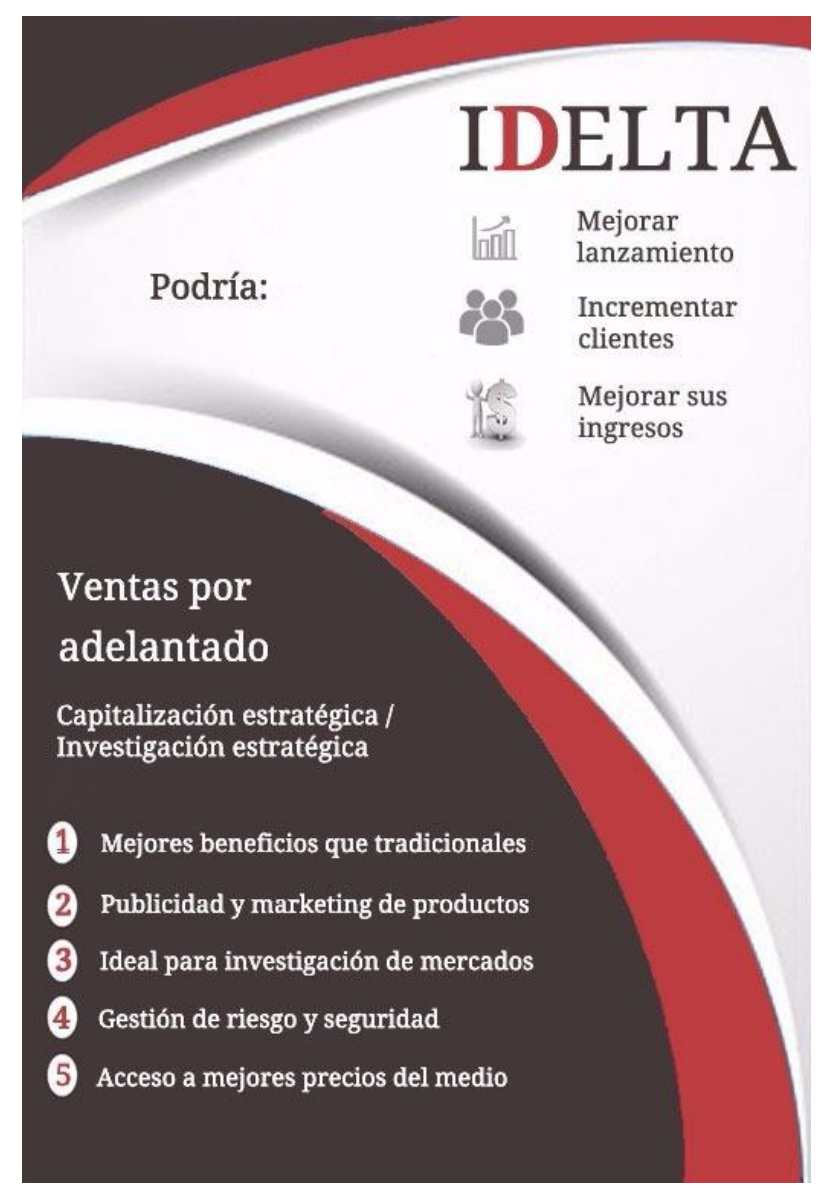

Figura 18. Descripción del producto de Ventas por adelantado ofrecido por IDeltas SAC

2. Financiamiento. Licitación de préstamo, se da cuando los clientes solicitan un financiamiento indicando el monto y plazo, el o los clientes interesados en invertir deciden cuánto desean aportar y el tipo de interés al que quieren prestar. Esta actividad se realiza a modo de subasta, terminado este periodo de subasta, los inversionistas que hayan ofertado un menor tipo de interés serán los que participen en dicho préstamo, saliendo beneficiado el solicitante del préstamo al obtener mejores tasas de interés (Grow.ly,2016). Este mecanismo es ejecutado a través de la plataforma web. Al usuario interesado en participar como solicitante de un préstamo o en financiar alguno se le aplica ciertos filtros y procedimiento 
para la validación de datos y del proyecto que desea ejecutar, los cuales se detallan en el capítulo cinco sección 5.1.1.

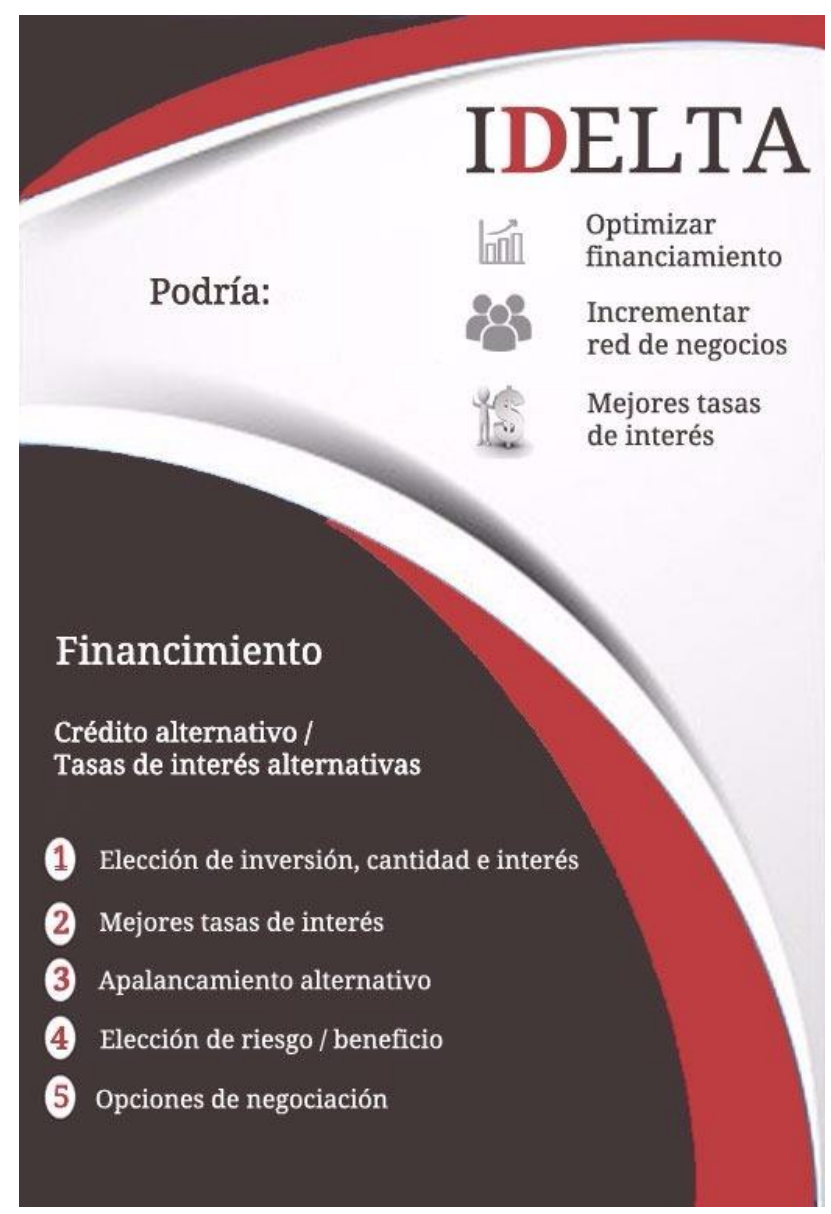

Figura 19. Descripción del producto de Financiamiento ofrecido por IDeltas SAC

3. Servicios Especiales. Refiere a venta de derechos, este se efectúa cuando los clientes inversionistas que son participantes de financiamientos, desean vender dicha participación, debiendo estar con sus pagos al día. El sistema de funcionamiento de esta operación es a través de subastas directas entre inversionistas, la mejor oferta gana los derechos de cobro de los préstamos de la cartera (Afluenta, 2016). Las participaciones de financiamiento se encuentran agrupadas en carteras, y deben tener un tiempo funcionando, por ejemplo de ventas por adelantado u otras que anteriormente se estaban realizando. 
El unir estos diferentes conceptos, llevándolo a la realidad local, genera el concepto de apalancamiento financiero que se propone en el presente plan de negocio, el cual se busca viabilizar minimizando el grado de endeudamiento por una responsabilidad a cumplir, ofreciendo un costo de oportunidad al inversionista.

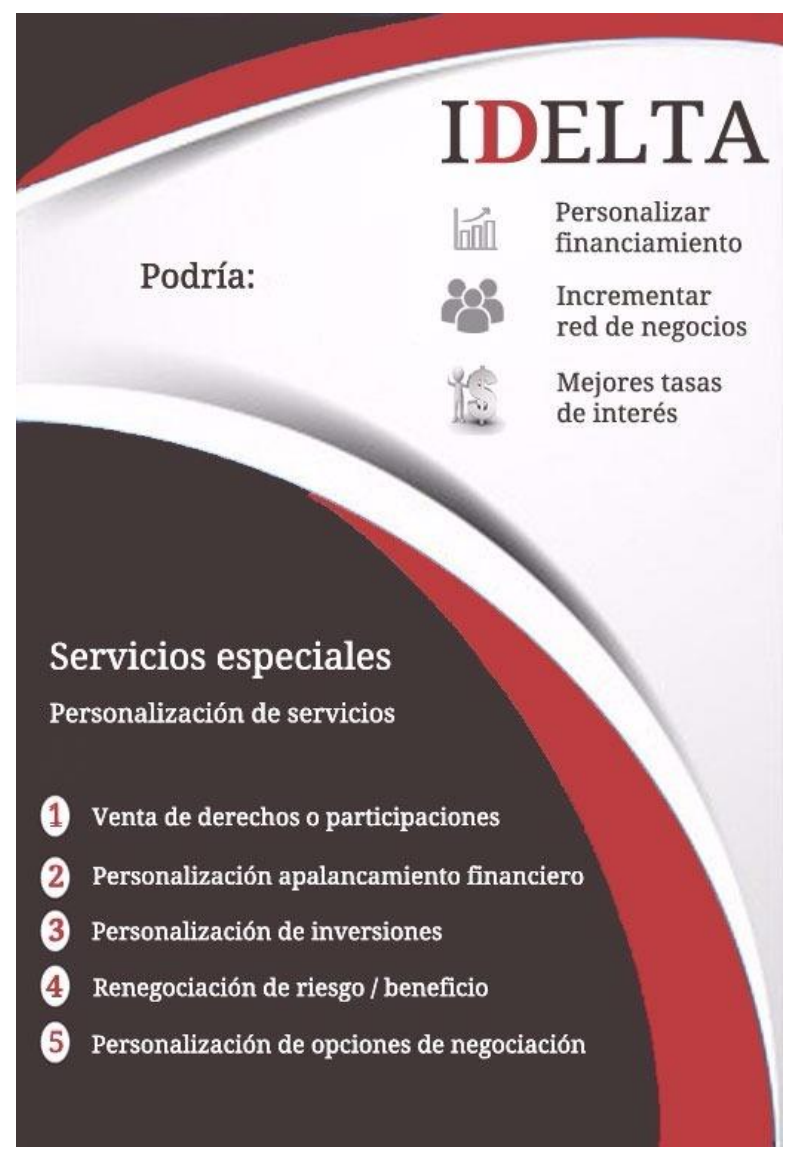

Figura 20. Descripción del producto de Servicios Especiales ofrecido por IDeltas SAC

4. Asesoramiento y capacitación, en relación a conocer nuevas formas de adquirir un apalancamiento financiero con nuevos mecanismos. Las asesorías que se ofrece pueden ser permanentes o solo dadas por horas, así también los cursos o capacitación que se imparte serán dirigidas de acuerdo a las necesidades de los clientes. 


\section{IDELTA}

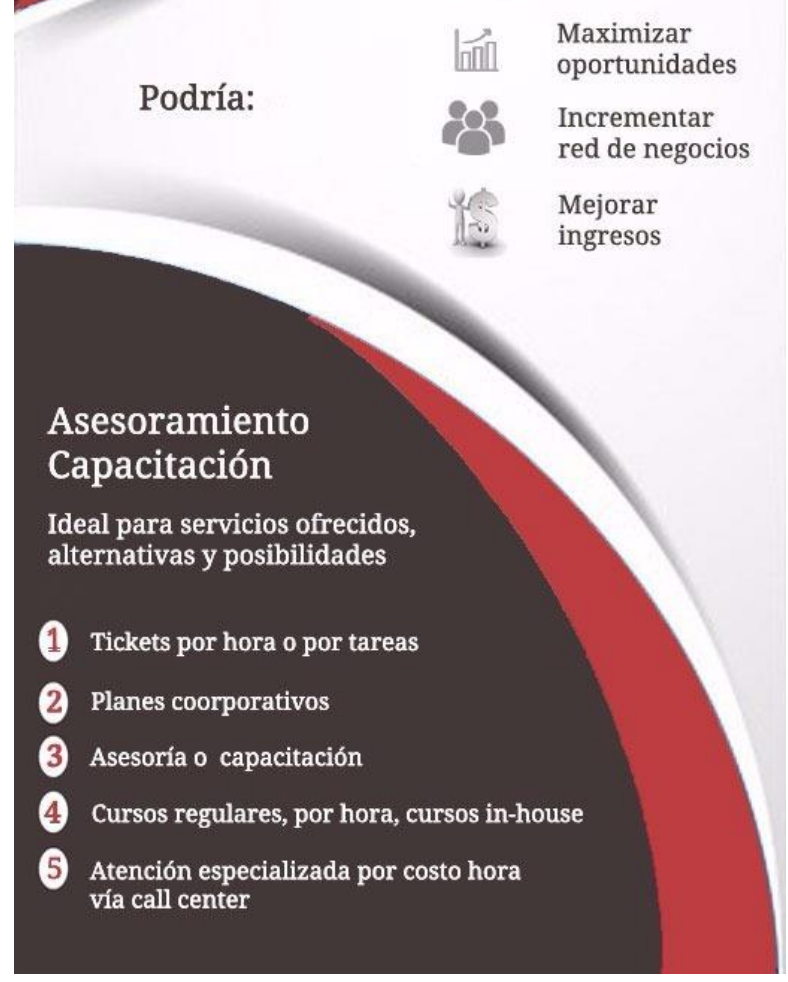

Figura 21. Descripción del producto de Asesoramiento y Capacitación ofrecido por IDeltas SAC

Considerando los productos que se ofrecerán, se precisa plantear un estudio de mercado que permita saber puntualmente donde se encuentra la mayor densidad demográfica del público objetivo, del mismo modo el grado de aceptación y/o interés por parte del público objetivo para con el concepto de opciones de inversión y financiamiento escuchando acerca de alternativas, y finalmente conocer acerca de los canales de distribución más aceptados o considerados por parte de nuestro público objetivo. Sintetizando lo expuesto con tres objetivos generales: Conocimiento de características de las personas que buscan financiamiento/inversión y productos/servicios, Características de Demandantes por estratos y Canales de distribución. 
1. Conocimiento de características de las personas que buscan financiamiento/inversión y Productos/Servicios: Desde el punto de vista del inversor y del vendedor/cliente/prestatario.

a) Financiamiento/inversión: Disposición de adquisición y disposición de sustitución por nuevas alternativas (cuantos usarían o necesitarían); Como podría afianzar la confianza, quienes son adversos al riesgo.

b) Productos/Servicios: ¿Cantidad de Tipos/variedades suficiente?, ¿Qué podría innovar?; nivel de comodidad con las características del producto/servicio (Accesibilidad, precio, viabilidad); formas que se ofrecen son suficientes, ¿Se debería considerar una plataforma informática como medio principal?

2. Características de Demandantes por estratos: Desde el punto de vista del inversor y del vendedor/cliente/prestatario. Cantidad de demandantes y características generales por estratos (ubicación geográfica, rubro de interés para el negocio, analizar el enfoque de los dos tipos de cliente).

3. Canales de distribución; la mejor forma de llegar al cliente.

Para llegar a resolver los objetivos de la investigación propuesta por el estudio, se usarán herramientas de investigación cualitativa y cuantitativa, dado que con la investigación cualitativa logramos entender de mejor manera la realidad en investigación, enseguida se utiliza la investigación cuantitativa, logrando de este modo tener un sustento lógico de nuestros objetivos de investigación. Los objetivos de la investigación se repartirán o complementaran entonces en la investigación cuantitativa así como cualitativa.

\subsection{Selección del segmento de mercado}

Para poder llegar a este punto, se ha considerado el servicio que se pretende ofertar, analizando las materias primas a requerir en el proceso productivo, considerando el estudio de las empresas que forman parte de la industria en la que se ejecutará el proyecto, 
comprensión de las características del medio externo o internacional que puedan influir en el desempeño del proyecto. Para poder finalmente concluir en el segmento de mercado, se intentarán agrupar a los consumidores que puedan responder de manera similar a un conjunto dado de actividades (Kotler \& Amstrong, 2012), se delimitará el área geográfica que va ha ser atendido por el proyecto, así como una caracterización sobre el usuario y/o consumidor potencial del producto, considerando factores económicos, socioculturales, demográficos, tecnológicos, competitivos y político-legales del macroentorno, y del mismo modo considerando las actividades a desarrollar en el futuro próximo.

Entonces se elige a un grupo de clientes, el cual está relacionado con la amplitud de la línea de productos, tipos de clientes, alcance geográfico y las áreas de la cadena de valor agregado en las cuales la empresa decida participar. Más adelante se buscará comprender las actitudes y preferencias de los clientes, así como de los beneficios que se buscan.

Considerando las características del cliente, se toman estos factores tanto para la investigación cuantitativa como también para herramientas consideradas en la metodología cualitativa.

Entre los procesos de segmentación se tiene:

a) Geográfica: En este punto se considera a los clientes según el lugar donde desarrollan sus actividades laborales o donde viven y cómo esto se correlaciona con otras variables. En este punto se toma en cuenta los factores de alcance y las medidas geográficas de mercado, así: los factores de alcance de mercado, incluyen una estipulación del lugar en que se localizarían los mercados a ser atendido, que en este caso podrían ser Arequipa ciudad, Arequipa periurbana o Arequipa provincia; las medidas geográficas de mercado, incluyen análisis de densidad de la población y clientes potenciales, de modo que se pueda estandarizar áreas de mercado. 


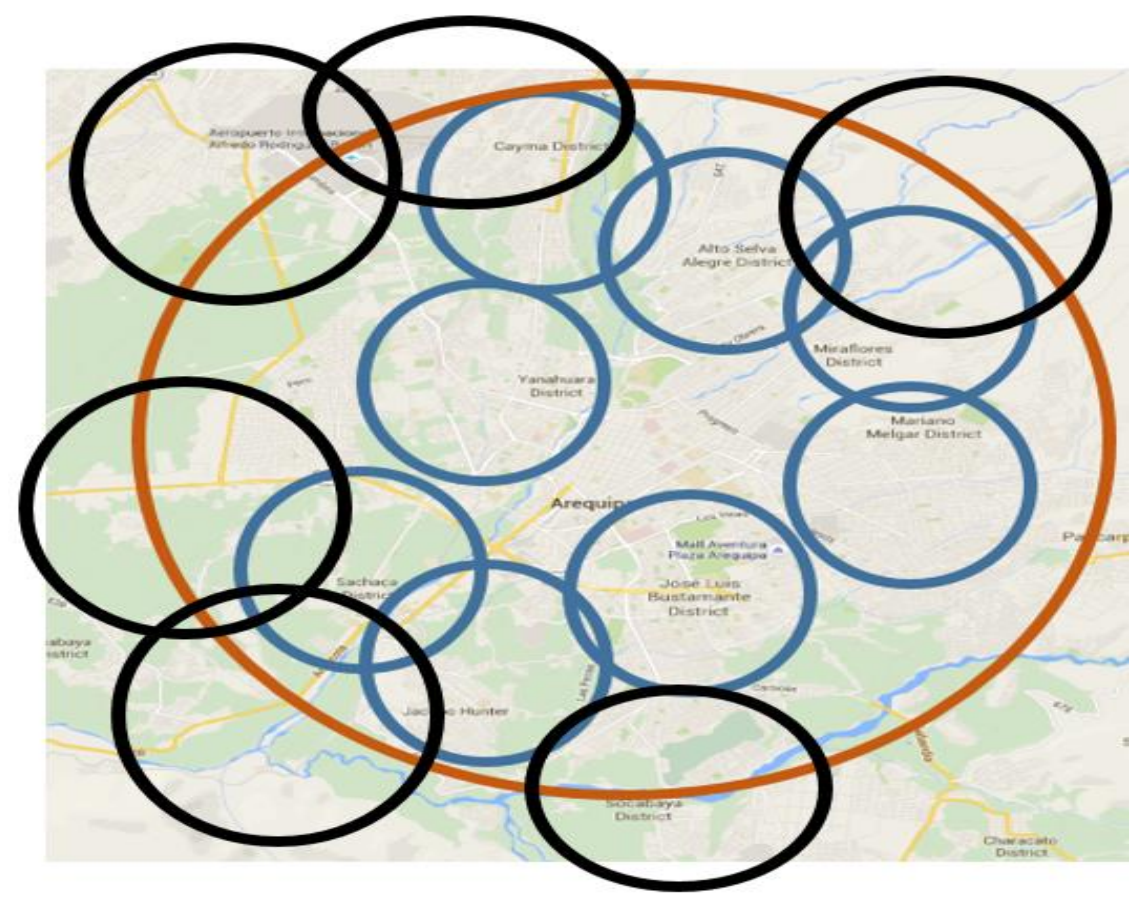

Figura 22. Detalle segmentación geográfica Arequipa urbana, periurbana y provincia. Adaptado de Google Maps, 2016. Recuperado de https://www.google.com.pe/maps

La propuesta del plan de negocios, se centra en la ubicación del estudio de mercado la cual será en el departamento de Arequipa, provincia de Arequipa y en la ciudad de Arequipa.

Por tal motivo se propone validar una densidad de mercado en Arequipa ciudad, considerando de este modo a los distritos de Alto Selva Alegre, Cayma, Cerro Colorado, Jacobo Hunter, Mariano Melgar, Miraflores, Sachaca, Yanahuara, José Luis Bustamante y Rivero, Cercado. De este modo: 
Tabla 4

Distribución población por distrito

\begin{tabular}{lc}
\hline Distrito & Población \\
\hline Arequipa & 59,095 \\
Alto Selva Alegre & 82,412 \\
Cayma & 91,802 \\
Cerro Colorado & 148,164 \\
Jacobo D. Hunter & 48,326 \\
Mariano Melgar & 52,667 \\
Miraflores & 48,677 \\
Sachaca & 19,581 \\
Yanahuara & 25,483 \\
JLByR & 76,711 \\
Total & 647,918 \\
\hline
\end{tabular}

Nota. Adaptado de Instituto Nacional de Estadística e Informática (INEI). Recuperado de http://proyectos.inei.gob.pe/web/poblacion/

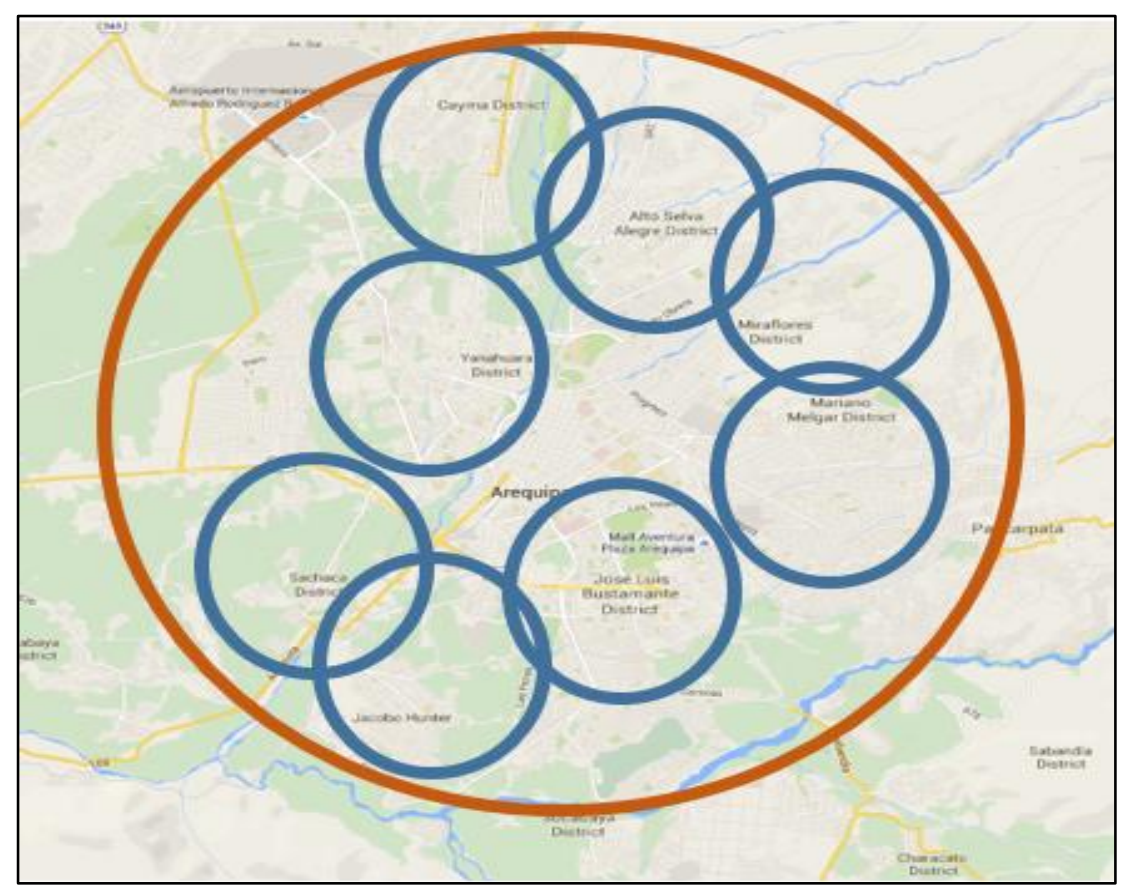

Figura 23. Segmentación Geográfica Arequipa urbana. Adaptado de Google Maps, 2016. Recuperado de https://www.google.com.pe/maps 
Se tiene un total del segmento el cual proviene de los 10 distritos que rodean al cercado de la ciudad de 647,918 personas según los datos de INEI.

b) Demográficas y factores: Se incluye como factor la edad. Las variables socioeconómicas, también se consideran, como nivel educativo y estado civil. Del mismo modo al punto A a nivel geográfico, ahora se considera que el mercado debe estar entre 25 y 55 años.

\begin{tabular}{|c|c|c|c|c|c|c|c|c|c|c|c|c|c|c|c|c|c|c|c|}
\hline \multirow{2}{*}{ DISTRITOS } & \multirow{2}{*}{ Total } & \multicolumn{18}{|c|}{ GRUPOS QUINQUENALES DE EDAD } \\
\hline & & 0.4 & $5 \cdot 9$ & $10-14$ & $15 \cdot 19$ & $20-24$ & $25-29$ & $30-34$ & $35-39$ & $40-44$ & $45-49$ & $50-54$ & $55 \cdot 59$ & $60-64$ & $65-69$ & $70-74$ & $75 \cdot 79$ & $\begin{array}{l}80 \mathrm{y} \\
\text { más }\end{array}$ & $25 \cdot 55$ \\
\hline AREQUIPA & 54,095 & 2,735 & 2,823 & 3,016 & 4,518 & 4,816 & 4,344 & 3,819 & 3,715 & 3,592 & 3,819 & 3,771 & 3,221 & 2,642 & 2,179 & 1,783 & 1,471 & 1,831 & 23,060 \\
\hline ALTO SELVA ALEGRE & 82,412 & 6,111 & 6,428 & 7,034 & 8,235 & 7,899 & 6,950 & 6,220 & 6,292 & 5,842 & 5,486 & 4,538 & 3,295 & 2,410 & 1,843 & 1,458 & 1,179 & $1,192^{\prime}$ & 35,328 \\
\hline CAYMA & 91,802 & 7,217 & 7,452 & 8,025 & 9,769 & 9,367 & 7,812 & 6,931 & 6,679 & 6,004 & 5,619 & 4,756 & 3,537 & 2,829 & 1,924 & 1,441 & 1,164 & 1,276 & 37,801 \\
\hline CERRO COLORADO & 148,164 & 12,993 & 13,147 & 12,694 & 13,550 & 13,586 & 13,404 & 12,581 & 11,442 & 9,743 & 8,118 & 7,194 & 5,863 & 4,431 & 3,332 & 2,474 & 1,794 & 1,818 & 62,482 \\
\hline JACOBO HUNTER & 48,326 & 3,783 & 3,640 & 3,883 & 4,347 & 4,691 & 4,316 & 4,095 & 3,772 & 3,097 & 3,012 & 2,507 & 2,104 & 1,611 & 1,172 & 953 & 686 & $657^{\circ}$ & 20,799 \\
\hline MARIANO MELGAR & 52,667 & 4,117 & 3,987 & 4,135 & 4,728 & 4,657 & 4,424 & 4,265 & 3,978 & 3,479 & 3,275 & 2,938 & 2,347 & 1,743 & 1,427 & 1,158 & 921 & 1,088 & 22,359 \\
\hline MIRAFLORES & 48,677 & 3,358 & 3,599 & 3,640 & 4,350 & 4,386 & 4,233 & 3,853 & 3,691 & 3,411 & 3,016 & 2,761 & 2,137 & 1,806 & 1,414 & 1,157 & 938 & 927 & 20,965 \\
\hline SACHACA & 19,581 & 1,547 & 1,629 & 1,746 & 1,854 & 1,715 & 1,548 & 1,522 & 1,480 & 1,307 & 1,253 & 1,084 & 840 & 664 & 498 & 352 & 248 & $294^{\prime}$ & 8,194 \\
\hline YANAHUARA & 25,483 & 1,270 & 1,432 & 1,556 & 2,211 & 2,146 & 1,892 & 1,791 & 1,845 & 1,806 & 1,761 & 1,812 & 1,496 & 1,337 & 998 & 848 & 618 & $664^{\prime}$ & 10,907 \\
\hline JOSE LUIS BUSTAMANTE Y R. & 76,711 & 5,069 & 5,082 & 5,126 & 6,415 & 6,838 & 6,274 & 6,167 & 5,811 & 5,148 & 4,992 & 4,628 & 4,115 & 3,558 & 2,731 & 1,962 & 1,412 & $1,383^{\prime}$ & 33,020 \\
\hline TOTAL & 647,918 & & & & & & & & & & & & & & & & & & 274,915 \\
\hline
\end{tabular}

Figura 24. Segmentación de la población de Arequipa por edades. Adaptado de "Población total al 30 de junio, por grupos quinquenales de edad, según departamento, provincia y distrito," por INEI, 2015. Recuperado de https://www.inei.gob.pe/media/MenuRecursivo/indices_tematicos/cuadro001_1.xls

De la figura anterior se tiene un total 274,915 , que pertenecen al segmento demográfico que se encuentra entre los 25 y 55 años.

c) Psicográfica: En este punto se analiza el comportamiento de las personas y de sus modos de vida. Tratando de investigar las características y actitudes respecto a sus consumos habituales los cuales están relacionados con lo que se oferta.

Ahora se filtra el número de personas que se tiene en el segmento seleccionado y filtrado por su ubicación (variable geográfica), por su edad (variable demográfica), se segmenta en base a la PEA, para eso, se utiliza datos de la población de Arequipa y se 
enfrenta con el porcentaje de población económicamente activa para sacar una proporción que permita segmentar más el mercado meta.

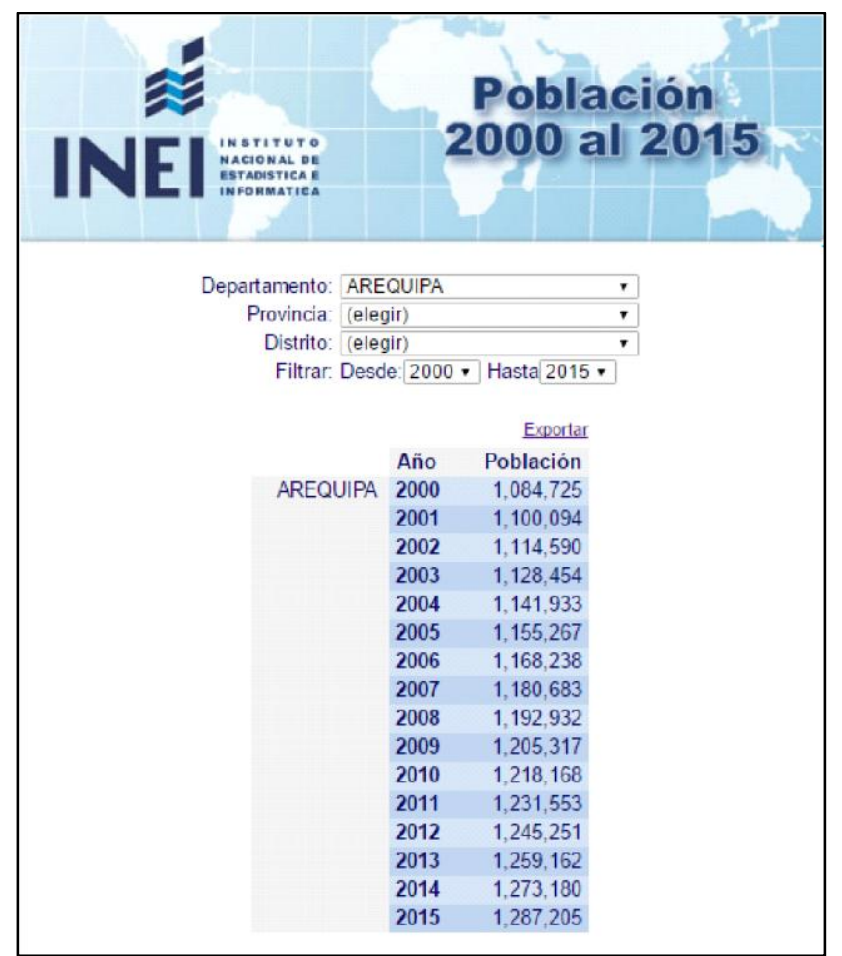

Figura 25. Tomado de Instituto Nacional de Estadística e Informática (INEI), 2015. Recuperado de http://proyectos.inei.gob.pe/web/poblacion/

De este gráfico adjunto se toma el número de habitantes al 2015, es decir 1’283,205 habitantes, ahora se toman los datos del informe brindado por Aurum Consultoría y Mercado, donde la población económicamente activa (PEA) es de 660 mil 706 (Diario el Correo, 2014).

Entonces con estos dos datos (1'283,205 y 660,706), se calcula el factor de la PEA, obteniendo el $51.49 \%$ de la población.

Entonces de nuestras 274,915 personas calculadas anteriormente, se toma el $51.49 \%$, lo cual da 141,554 personas.

Finalmente se llega al mercado meta a través del índice de personas que pertenecen a los segmentos A, B, C+. Para llegar a esto, se precisa elaborar otro factor que filtre el 
porcentaje de personas que pertenecen al mercado meta; para elaborar este factor se toma de la publicación realizada por Aurum Consultoría y Mercado, donde se puede apreciar la cantidad de personas que trabajan en la microempresa, pequeña empresa, así como mediana y gran empresa en una muestra de 76,685 personas que corresponden a la PEA.

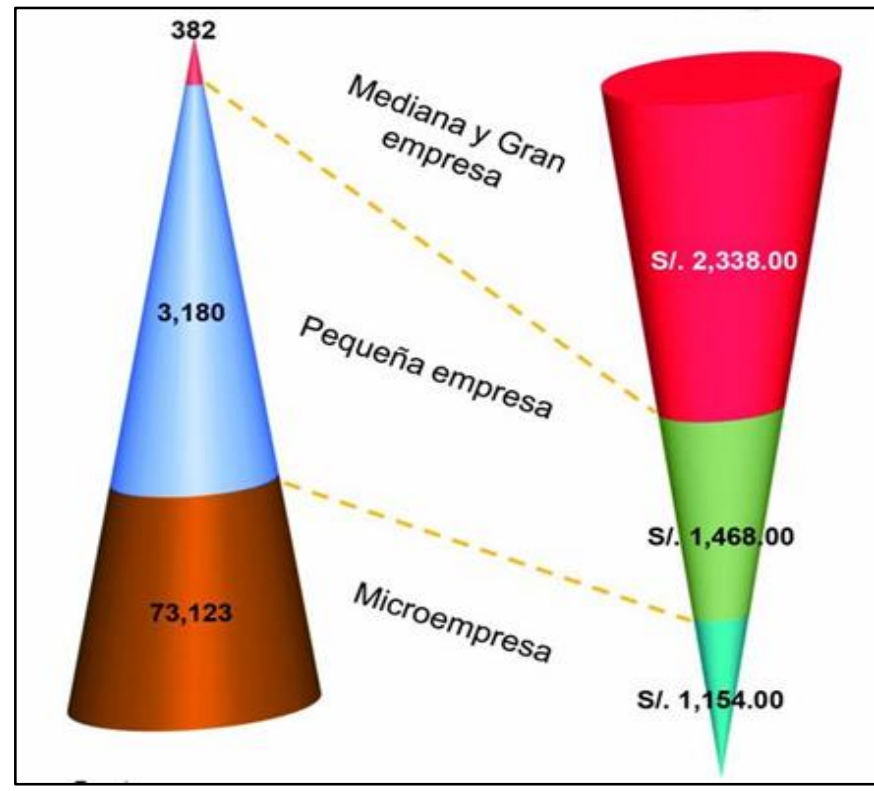

Figura 26 Tomado de Perspectivas Económicas de la Región Arequipa, por AURUM, 2015. Recuperado de http://diariocorreo.pe/ciudad/pea-de-arequipa-es-de-660-mil-35401/

Como se puede apreciar en el gráfico, de las 76,685 personas 73,123 trabajan en microempresas que pertenecen al mercado propuesto a validar. De estos valores se calcula el factor correspondiendo al $95.4 \%$ de la muestra. Entonces del mercado segmentado por variables geográficas (localización geográfica) y dos variables demográficas (edad y por nivel socioeconómico, trabajo con poder adquisitivo), se extrae 141,554 personas, a este número se aplica el factor final 95.4\%, de donde se obtiene 135,043.

En el presente estudio se considera sondear la realidad de 135,043 personas, las cuales trabajan en microempresas, son dueños o socios. 


\subsection{Investigación cualitativa}

Acorde a Hair, Bush y Ortinau (2010), el objetivo de utilizar la investigación cualitativa es el poder adquirir conocimientos preliminares de los problemas de investigación; tratando de descubrir nuevas ideas, tendencias, conceptos, pensamientos, impresiones, conocimientos, etc. que permitan comprender a los participantes en la investigación.

Este tipo de investigación es exploratoria, dadas a corto plazo, donde las preguntas son del tipo abierto, no estructurado.

Las técnicas a emplear son: grupos de enfoque (conocido también como focus grup o enfoque grupal) y entrevistas exhaustivas, esta última dirigida a expertos en el tema tanto inversionistas como emprendedores.

La investigación cualitativa, tienen como objetivo:

- Conocer las características que los clientes (inversionistas y emprendedores) consideran para la adquisición de financiamiento o el invertir a partir de métodos alternativos.

- Obtener características de demandantes por estratos, ubicación, rubro de interés para el negocio.

- Determinar los canales de distribución.

\subsubsection{Proceso de muestreo}

Las entrevistas exhaustivas, en donde un entrevistador competente realiza un conjunto de preguntas semiestructuradas a un entrevistado, lo cual se puede ejecutar en persona, pudiéndose combinar con entrevistas vía telefónica.

Los fines de realizar una entrevista exhaustiva son: Adquirir información preliminar sobre lo que opina o piensa un entrevistado acerca del tema, obtener comentarios libres y 
detallados que sirvan para entender mejor las ideas de un entrevistado y sus motivaciones y conseguir los conocimientos y conductas acerca de un objeto o tema (Hair, Bush \& Ortinau, 2010).

Las entrevistas están dirigidas a personas que cumplan con el perfil de estar en la segmentación geográfica, sociográfica, así como psicográfica inicial además de ello, ser emprendedor con ideas de negocio o ser inversionistas, ambos que cuenten con trayectoria en los negocios y finanzas. Las entrevistas serán de dos tipos, dependiendo a quien se dirige: si es un inversor o emprendedor con negocio o quiera iniciar uno.

Así también se realizará entrevistas a expertos con experiencia comprobada (dos años), quienes deben cumplir el siguiente perfil:

- Pertenecer al ámbito comercial, empresarial, cámaras, al sector público e incluso la cooperación internacional.

- Personas conocedoras de la realidad de las MYPE y/o proyectos.

- Que tengan manejo de temas asociados a la inclusión, economía nacional y el uso de tecnologías informáticas.

- Las entrevistas serán individuales y se realizarán en una sola sesión por experto. El grupo de enfoque, (Kotler \& Amstrong, 2012) es una entrevista de tipo personal en la que se invitan de seis a diez personas a hablar con un moderador, quien promueve un debate libre acerca de un producto, un servicio o una organización.

En este tipo de investigación se busca generar sinergia entre los participantes a partir de la respuesta de una persona que incite los comentarios de otras, lo que permite extraer cuantas ideas, actitudes, experiencias y lo que piensan las personas acerca del tema de interés (Hair, Bush \& Ortinau, 2010). 
Para elegir a los participantes en el grupo de enfoque se consideran a personas que cumplan el siguiente perfil: que además de estar en la segmentación geográfica (ciudad de Arequipa), sociográfica (25 a 55 años), así como psicográfica (pertenecientes a la PEA), que sean personas con ideas de negocio o que hayan emprendido uno, o inversionistas que cuenten con trayectoria en los negocios y finanzas

Con este tipo de investigación se busca identificar necesidades específicas del cliente, como sus necesidades, deseos, actitudes, sentimientos, conductas, percepciones y motivaciones, temores al riesgo con respecto a servicios y productos de estas nuevas alternativas propuestas; el poder entender mejor los resultados de los estudios cuantitativos y generar nuevas ideas sobre canales de distribución, servicios o métodos de entrega.

\subsubsection{Diseño de instrumento}

Las entrevistas seguirán una guía de preguntas semi-estructuradas, directas y flexibles, cada guía consta de siete preguntas abiertas. Estas entrevistas serán de dos tipos: uno dirigido al participante con características de inversor y otro dirigido al participante con un negocio o ideas de negocio.

De acuerdo al tipo de pregunta según Mertens (Hernández, Fernández \& Baptista, 2010) se incluyen preguntas de los tipos de opinión, de conocimientos, de antecedentes y de simulación. Por ejemplo

De conocimiento: ¿Qué factores considera importantes para poder determinar dónde colocar sus inversiones?, ¿Qué factores considera importantes para poder determinar de dónde obtener financiamiento para su negocio o emprender uno?

De opinión: ¿De emprender en algún negocio, cuál es el rubro de este negocio que cree que tiene mayor expectativa? 
De antecedentes: ¿Qué sistema o alternativa de inversión uso últimamente (por ejemplo en una entidad financiera o como capitalista en un negocio, etc)?

De simulación: ¿Qué políticas, metodologías, condiciones y/o acciones le daría más confianza ante una entidad que le brinde nuevas alternativas de financiación? ¿Qué recomendaciones daría?

En cuanto a la entrevista de enfoque grupal, se realizó una sesión de grupo con preguntas semiestructuradas, con un tiempo de duración de aproximadamente de dos horas 
dirigida a un grupo de seis personas que cumplan el perfil. La estructura para la entrevista en grupos de enfoque está dada a través de una guía de pautas y consta de las siguientes partes:

\section{A. Objetivos de Investigación}

B. Perfil del participante

C. Guía del moderador para la sesión de entrevistas en grupos de enfoque

- Introducción: bienvenida, reconocimiento de participantes, explicación de las reglas básicas para la reunión.

- Calentamiento: se realiza se una dinámica del grupo.

- Presentación del primer tema: donde se realiza preguntas de introducción.

- Segundo tema importante: Conformado por preguntas críticas.

- Elementos concretos de diseño

- Cierre de la sesión con sugerencias e ideas finales: Conformado por preguntas conclusivas.

- Fin de la sesión de enfoque: A. Agradecimiento a los participantes por su cooperación y aportaciones, entrega de presentes.

- Sugerencias e ideas finales

- Fin de sesión de enfoque

En cada una de estas etapas se incluyen sondeos.

\subsubsection{Análisis y procesamiento de datos}

Los resultados aquí recopilados fueron diseñados para explorar qué opinan los entrevistados y cómo se comportan, ellos constituyen una muestra pequeña y no representan el universo, además ello ayuda a poder entender mejor los resultados cuantitativos.

A continuación, se analiza las respuestas obtenidas clasificándolas por temas y de acuerdo a los objetivos. 
- Características que los clientes (inversionistas y emprendedor/solicitante de préstamo) consideran para la adquisición de financiamiento o la inversión a partir de métodos alternativos: Los resultados cualitativos muestran optimismo e interés sobre el tener métodos alternativos frente a los tradicionales. Para el caso de quienes buscan un financiamiento de sus negocios el poder acceder a un crédito en el corto tiempo a menores tasas, que le permita crecer o conseguir una mejor tecnología, lo cual no lo obtienen con la banca tradicional. En el caso de los inversionistas, muestran confianza con el sistema tradicional, aunque no muy satisfechos con las ganancias que obtienen por sus ahorros o inversiones, muestran optimismo y curiosidad por métodos alternativos y nuevos productos de inversión, con cierto temor a los riesgos, pero con el interés de conocer y recibir alguna garantía si se trata de invertir en un negocio o emprendimiento con buena rentabilidad y que sea sostenible.

- Obtener características de demandantes por estratos, ubicación, rubro de interés para el negocio: Los resultados del estudio indican que el tipo de negocio más atrayente es el comercio (venta de productos, servicios) en la ciudad de Arequipa, seguido por inversión en la ganadería y la agricultura.

- Determinar los canales de distribución, la mejor forma llegar a los clientes: Recomiendan tener servicios personalizados de acuerdo a la necesidad del cliente (en el caso de los prestatarios), el poder contar con un servicio de asesoramiento y educación financiera y entender de nuevas formas de financiamiento e inversión. 
Contar con un servicio de calidad y confiable, que vaya acorde a la tendencia actualidad y que minimice los riesgos.

\subsection{Investigación Cuantitativa}

Según Hair, Bush y Ortinau (2010), se utiliza la investigación cuantitativa para realizar pruebas de mercado, con el análisis estadístico de la demanda. Se diseña encuestas empleando preguntas formales y opciones de respuesta predeterminadas en cuestionarios aplicados a muchos entrevistados, trabajando sobre problemas de investigación específicos y bien definidos. En este punto se busca hacer predicciones atinadas sobre las relaciones entre factores de mercado y conductas, del mismo modo, profundizar en el conocimiento de esas relaciones, validando estimaciones e hipótesis.

\subsubsection{Proceso de muestreo}

Acorde a Hair, Bush y Ortinau (2010), las técnicas de muestreo pueden clasificarse en probabilístico y no probabilístico. La técnica probabilística, es aquella que está conformada por una población elegida al azar, por otro lado está la técnica no probabilística, la cual será la que se va emplear en el presente estudio, es aquella que está conformada por una población que no ha sido elegida al azar; estos muestreos pueden ser por conveniencia, por juicio, por cuotas o por bola de nieve. Se tomó un muestreo por cuotas en dos etapas, en la primera etapa se desarrollan las características e control de los elementos de la población, dirigida a la población meta y en la segunda etapa se selecciona los elementos de muestra con base a la conveniencia o juicio. Así para el presente estudio la encuesta tiene como primera etapa el determinar la población que cumpla las características de control, estas son: estar en la segmentación geográfica, sociográfica así como psicográfica inicial; y la segunda 
seleccionar en base al juicio a aquellas personas con interés en actividades emprendedoras en ideas de negocio y/o inversiones.

Para calcular la cantidad estimada de muestra que se debe considerar se tiene 135,043 personas las cuales trabajan en microempresas, son dueños o socios. Se tiene entonces:

$$
n=\frac{N^{*} Z^{2} * p^{*} q}{(N-1) * e^{2}+Z^{2} * p^{*} q}
$$

\section{Donde}

$$
\begin{array}{lll}
\mathrm{n} & = & \text { Tamaño de la muestra } \\
\mathrm{N} & = & \text { Población a investigar }(135,043) \\
\mathrm{Z} & = & \text { Margen de confiabilidad 95\% (correspondiente a } 1.96 \text { desviaciones estándar) } \\
\mathrm{p} & = & \text { Probabilidad que el evento ocurra }(0.5) \\
\mathrm{q} & = & \text { Probabilidad que el evento no ocurra }(1-\mathrm{p}=0.05) \\
\mathrm{e} & = & \text { Error de estimación }(0.05)
\end{array}
$$

$$
\begin{gathered}
n=\frac{(135,043) *\left(1.96^{2}\right) *(0.5) *(0.5)}{(135,043-1) *(0.05)^{2}+(1.96)^{2} *(0.5) *(0.5)} \\
n=384
\end{gathered}
$$

El tamaño de la muestra de la población es de 384 personas. Con un nivel de confianza del $95 \%$ y una estimación de error de $5 \%$.

\subsubsection{Diseño de instrumento}


Se considera en este punto aplicar encuestas las cuales se realizarán por: Aplicación directa o personal; vía telefónica o por internet. Se han considerado utilizar tipos de pregunta estructuradas y cerradas (Hair, et al., 2010).

Consideraciones específicas: Preguntas claras, breves, precisas y comprensibles para los encuestado, considerando no incomodar a la persona encuestada ni que las preguntas puedan ser percibidas como amenazantes y nunca sentir que se enjuicia al encuestado; considerando un solo aspecto o relación lógica; preguntas sin inducir las respuestas; preguntas sin contextos racistas o sexistas que ofendan a los participantes.

La estructura de la encuesta está dada por:

Un conjunto de catorce preguntas diseñadas para generar datos primarios, de las cuales trece son preguntas estructuradas y una no estructurada (uno). Dentro de las preguntas estructuradas tenemos una pregunta dicotómica (dos y siete). Dos preguntas dicotómicas más que posteriormente según la respuesta se pide elegir dentro un abanico de respuestas (diez y

once). Se formulan dos preguntas de valoración (doce y catorce), cuatro preguntas con respuesta única (tres, cuatro, cinco y seis), dos preguntas con respuestas que pueden ser más de una (ocho y trece) y una pregunta socio-demográfica (nueve).

\subsubsection{Análisis y procesamiento de datos}

Se procederá al análisis de los resultados obtenidos de cada una de las preguntas: 
Pregunta: 1 ¿Podría indicar su edad?

\begin{tabular}{|l|r|r|r|r|}
\hline \multicolumn{1}{|c|}{ Edades } & Frecuencia & Porcentaje & $\begin{array}{c}\text { Porcentaje } \\
\text { válido }\end{array}$ & $\begin{array}{l}\text { Porcentaje } \\
\text { acumulado }\end{array}$ \\
\hline $25-29$ & 62 & 16.1 & 16.1 & 16.1 \\
$30-34$ & 61 & 15.9 & 15.9 & 32.0 \\
$35-39$ & 67 & 17.4 & 17.4 & 49.5 \\
$40-44$ & 69 & 18.0 & 18.0 & 67.4 \\
$45-49$ & 53 & 13.8 & 13.8 & 81.3 \\
$50-55$ & 72 & 18.8 & 18.8 & 100.0 \\
Total & 384 & 100 & & \\
\hline
\end{tabular}

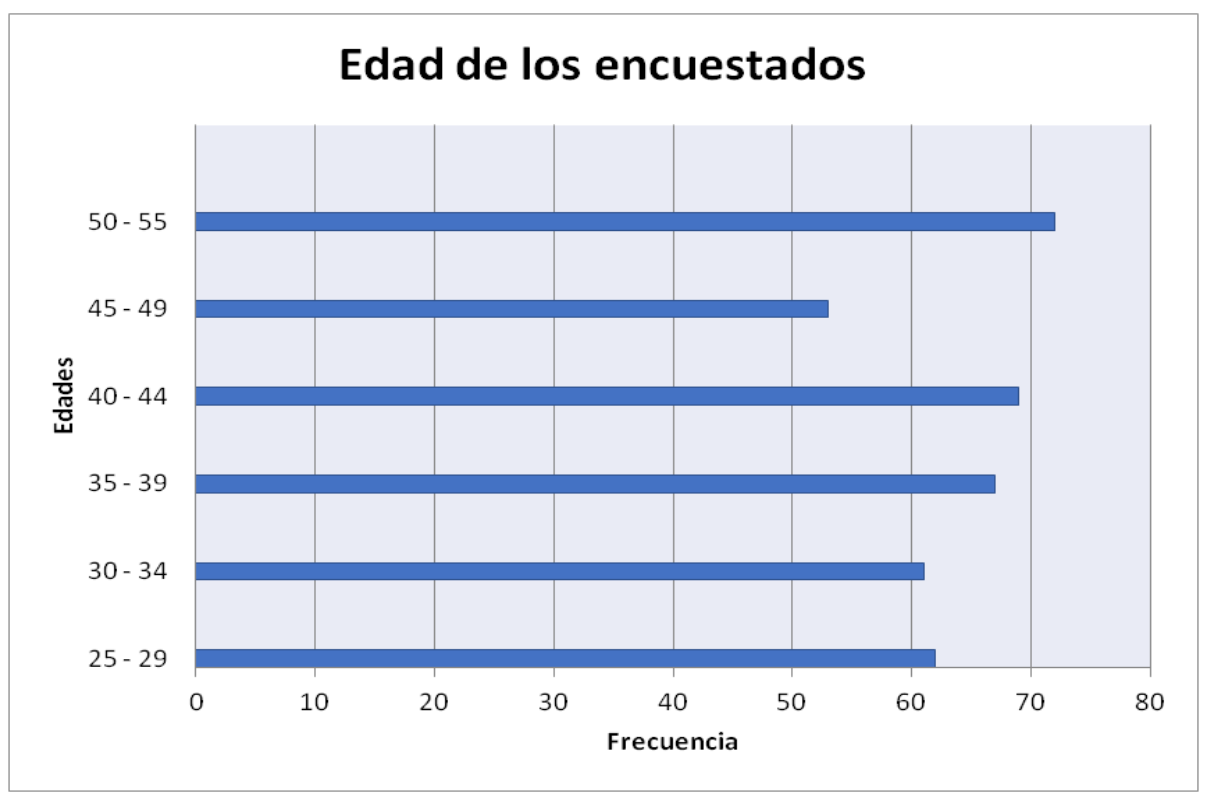

Figura 27. Información obtenida de encuestas de trabajo de campo.

El segmento de personas a las que fue dirigida la encuesta está en el rango de 25 a 55 años de edad. 
Pregunta: 2 Mujeres y Varones encuestados

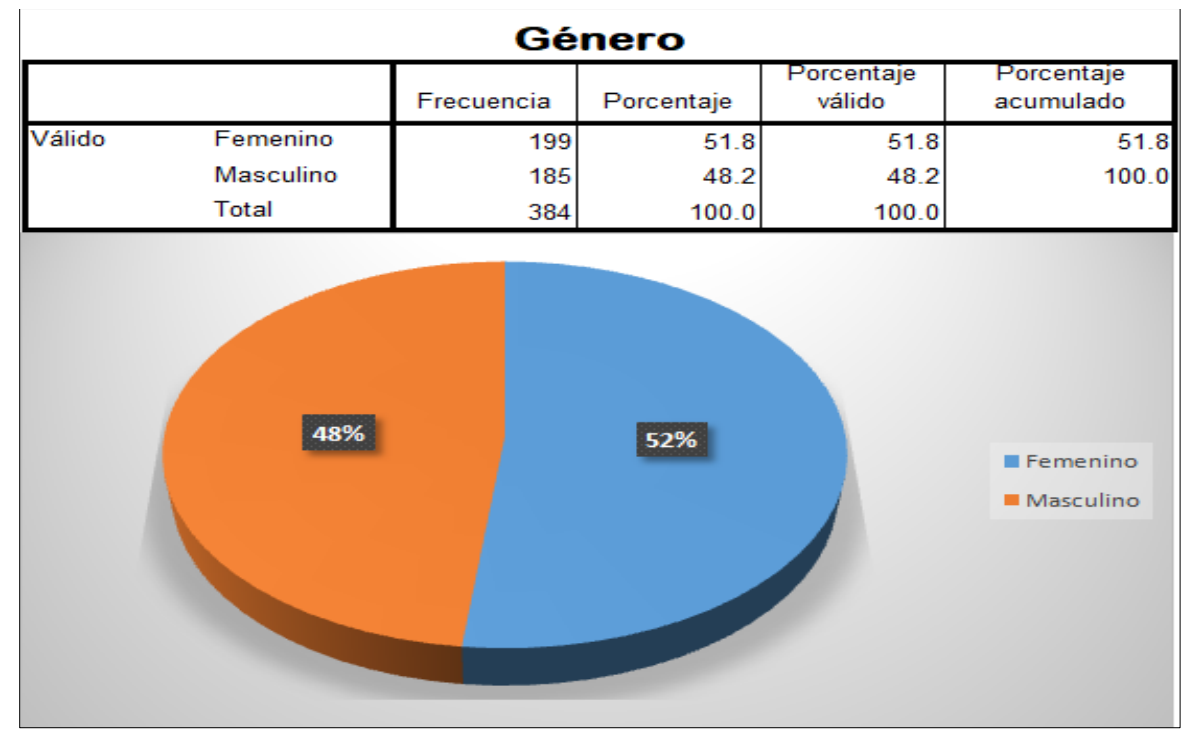

Figura 28. Información obtenida de encuestas de trabajo de campo.

Del grupo encuestado $52 \%$ fueron mujeres y $48 \%$ varones.

Pregunta:3 Cuál es su estado civil?

\begin{tabular}{|c|c|c|c|c|c|}
\hline \multicolumn{6}{|c|}{ Estado Civil } \\
\hline & & Frecuencia & Porcentaje & $\begin{array}{c}\text { Porcentaje } \\
\text { válido }\end{array}$ & $\begin{array}{l}\text { Porcentaje } \\
\text { acumulado }\end{array}$ \\
\hline \multirow[t]{6}{*}{ Válido } & Casado & 139 & 36.2 & 36.2 & 36.2 \\
\hline & Divorciado & 8 & 2.1 & 2.1 & 38.3 \\
\hline & Conviviente & 105 & 27.3 & 27.3 & 65.6 \\
\hline & Viuda & 10 & 2.6 & 2.6 & 68.2 \\
\hline & Soltero & 122 & 31.8 & 31.8 & 100.0 \\
\hline & Total & 384 & 100.0 & 100.0 & \\
\hline
\end{tabular}

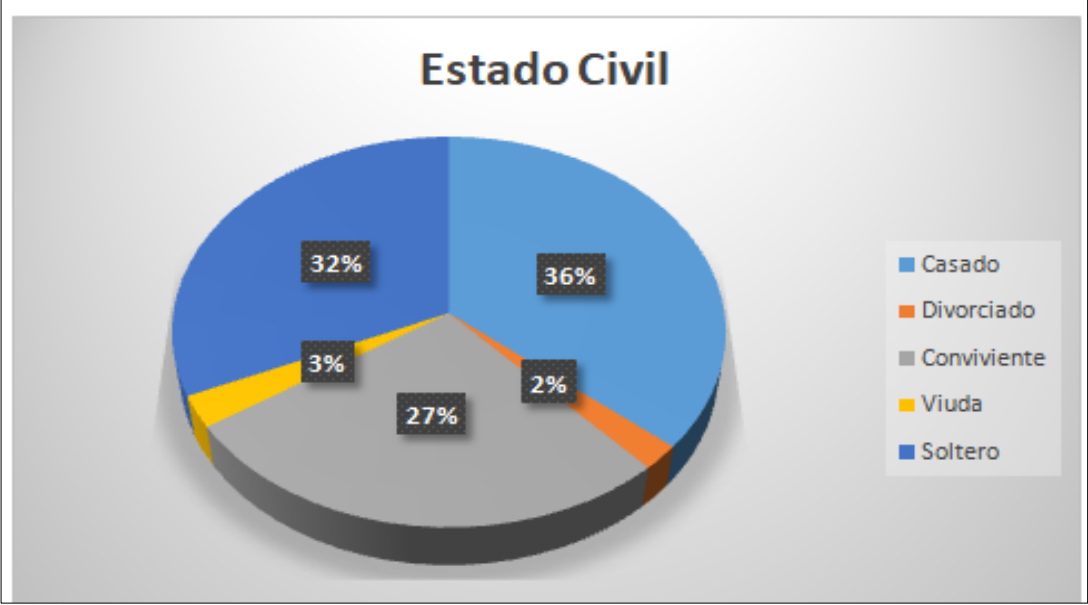

Figura 29. Información obtenida de encuestas de trabajo de campo.

Tres son los grupos que priman, casados (36\%), solteros (32\%) y convivientes $(27 \%)$. 
Pregunta: 4 ¿Grado de instrucción?

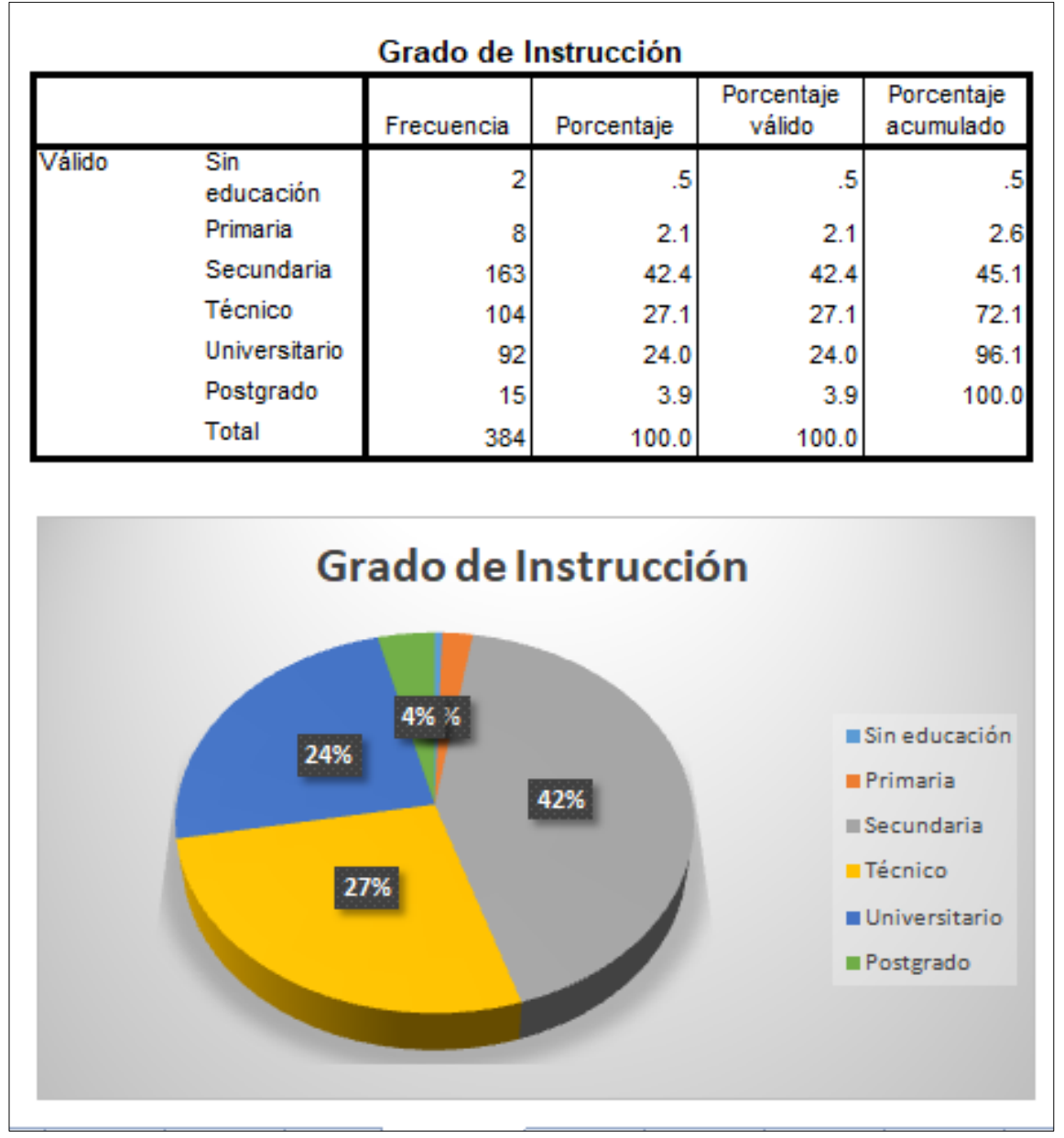

Figura 30. Información obtenida de encuestas de trabajo de campo.

La población según la encuesta está conformada por un $42 \%$ de personas con educación secundaria, $27 \%$ con una carrera técnica y $24 \%$ con carrera universitaria, existe un gran volumen de gente preparada, especialista y con formación profesional. 
Pregunta: 5 ¿Ocupación y estado laboral (dependiente y/o independiente)?

\begin{tabular}{|l|r|r|r|r|}
\hline \multicolumn{5}{|c|}{ ¿Ocupación y estado laboral? } \\
\hline & Frecuencia & Porcentaje & $\begin{array}{c}\text { Porcentaje } \\
\text { válido }\end{array}$ & $\begin{array}{r}\text { Porcentaje } \\
\text { acumulado }\end{array}$ \\
\hline Válido Agricultura & 13 & 3.4 & 3.4 & 3.4 \\
Manufactura & 53 & 13.8 & 13.8 & 17.2 \\
Comercio & 114 & 29.7 & 29.7 & 46.9 \\
Servicio & 65 & 16.9 & 16.9 & 63.8 \\
Gestion, & 31 & 8.1 & 8.1 & 71.9 \\
Administracion & 51 & 13.3 & 13.3 & 85.2 \\
Construcción & 27 & 7.0 & 7.0 & 92.2 \\
Enseñanza & 30 & 7.8 & 7.8 & 100.0 \\
Otros & 384 & 100.0 & 100.0 & \\
Total & & & & \\
\hline
\end{tabular}

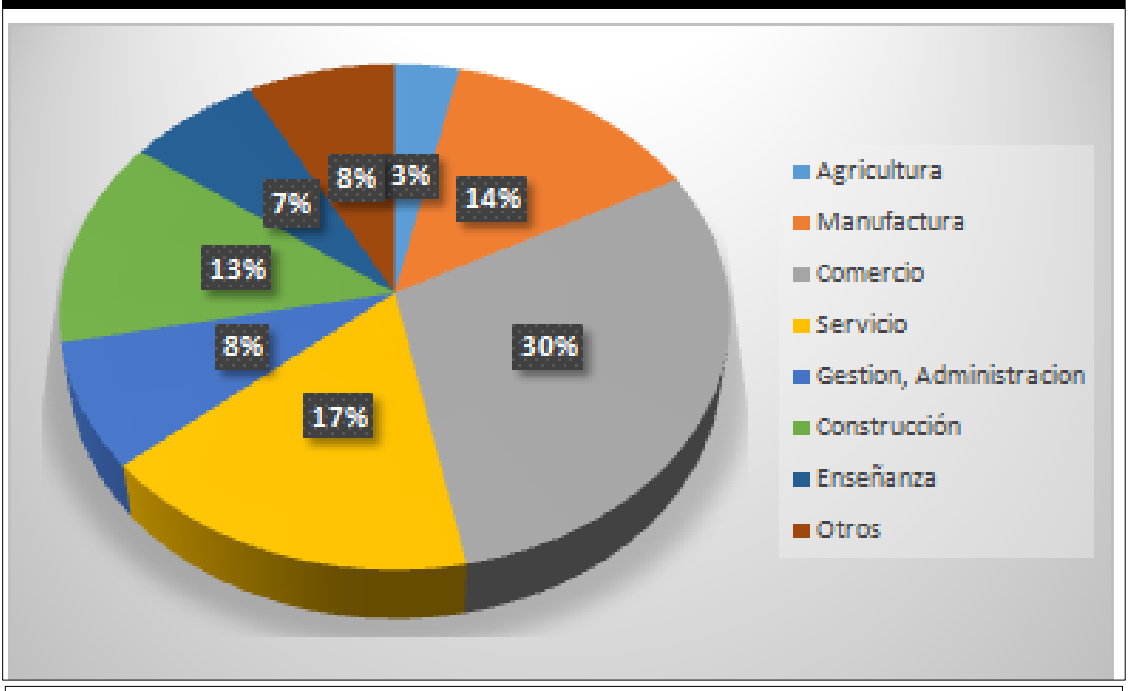

\begin{tabular}{|c|c|c|c|c|c|}
\hline & & Frecuencia & Porcentaje & $\begin{array}{c}\text { Porcentaje } \\
\text { válido }\end{array}$ & $\begin{array}{l}\text { Porcentaje } \\
\text { acumulado }\end{array}$ \\
\hline \multirow[t]{4}{*}{$\overline{\text { Válido }}$} & $\begin{array}{l}\text { Trabajo } \\
\text { independiente }\end{array}$ & 192 & 50.0 & 50.0 & 50.0 \\
\hline & $\begin{array}{l}\text { Trabajo } \\
\text { dependiente }\end{array}$ & 168 & 43.8 & 43.8 & 93.8 \\
\hline & Ambos & 24 & 6.3 & 6.3 & 100.0 \\
\hline & Total & 384 & 100.0 & 100.0 & \\
\hline
\end{tabular}

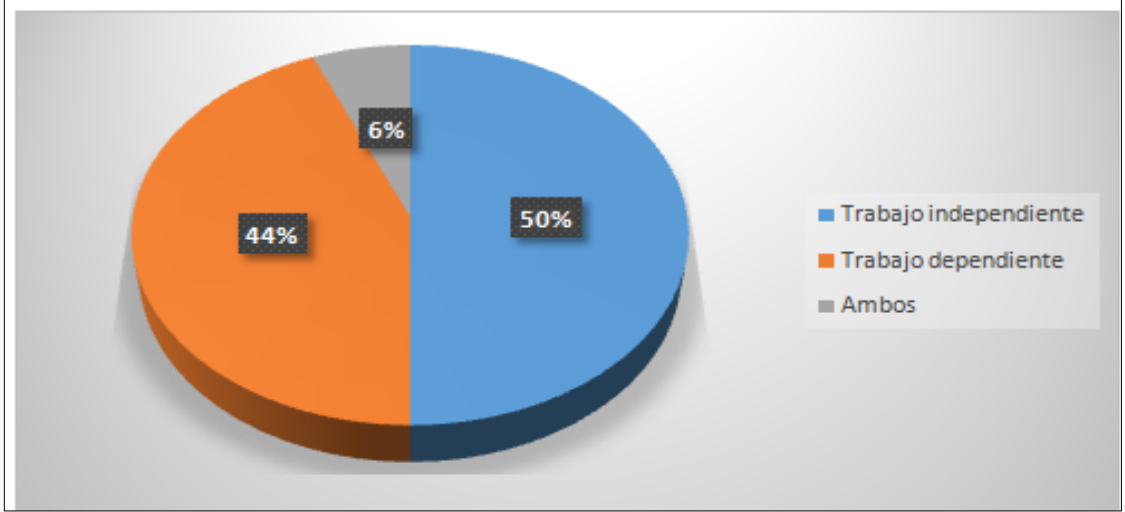

Figura 31. Información obtenida de encuestas de trabajo de campo. 
Dentro de las actividades que más se desarrolla se encuentra en primer lugar el comercio (30\%), seguido por los trabajos referidos a servicios (mantenimiento, asesoría, aseo), manufactura (transformación, incluye artesanía) y construcción.

Pregunta: 6 ¿Realiza o está dispuesto a emprender un negocio o está interesado en financiar alguno?

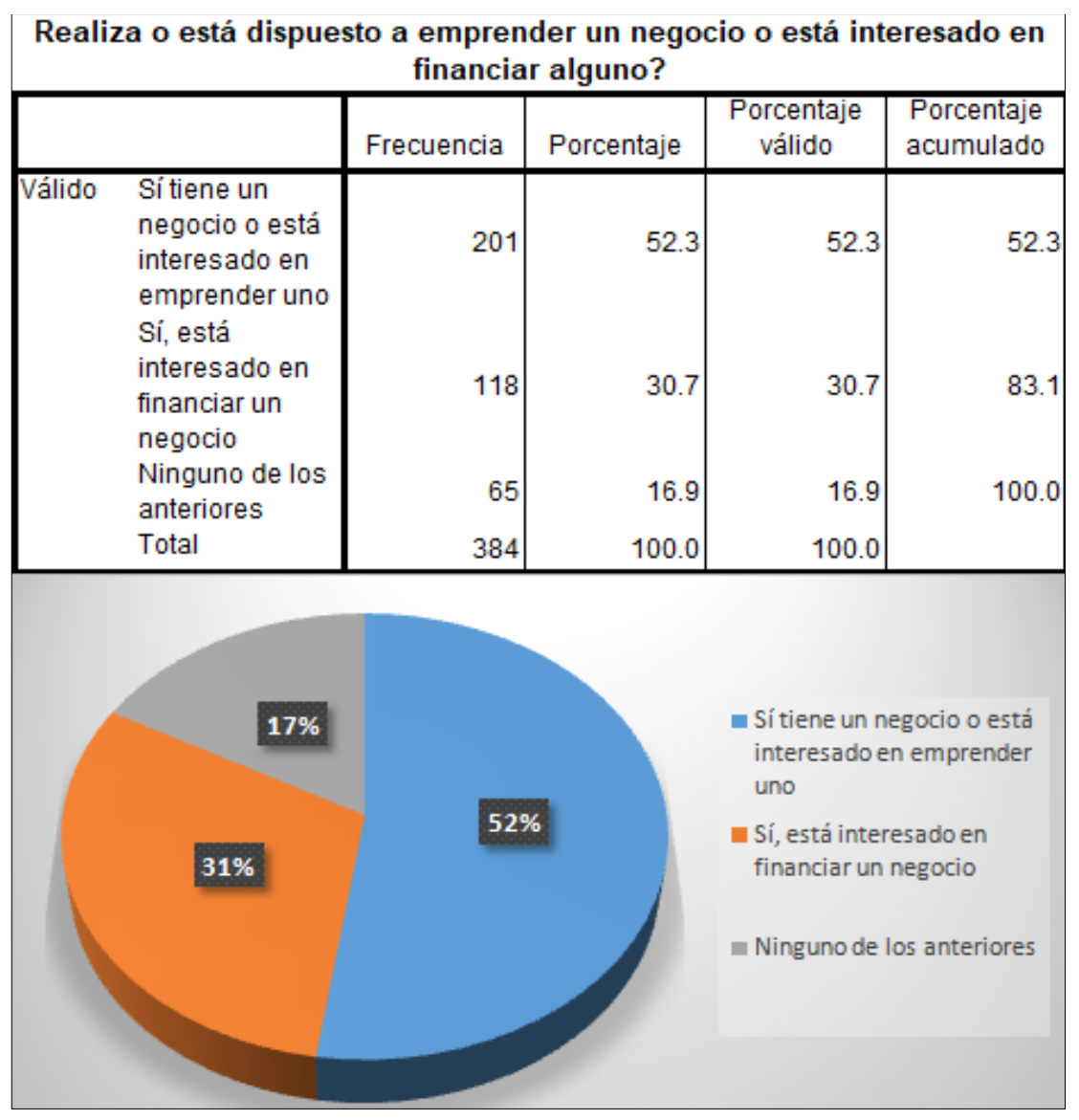

Figura 32. Información obtenida de encuestas de trabajo de campo.

Este resultado muestra y confirma la hipótesis obtenida de la investigación cualitativa que existe un alto interés en los habitantes en emprender (52\%) o invertir en algún negocio (31\%), existiendo un alto porcentaje que puede representar un mercado disponible.

Pregunta: 7 ¿Hace uso de los servicios de una entidad financiera formal o informal para solicitar préstamos o colocar sus ahorros en ella? 
¿Hace uso de los servicios de una entidad financiera formal o informal para solicitar préstamos o colocar sus ahorros en ella?

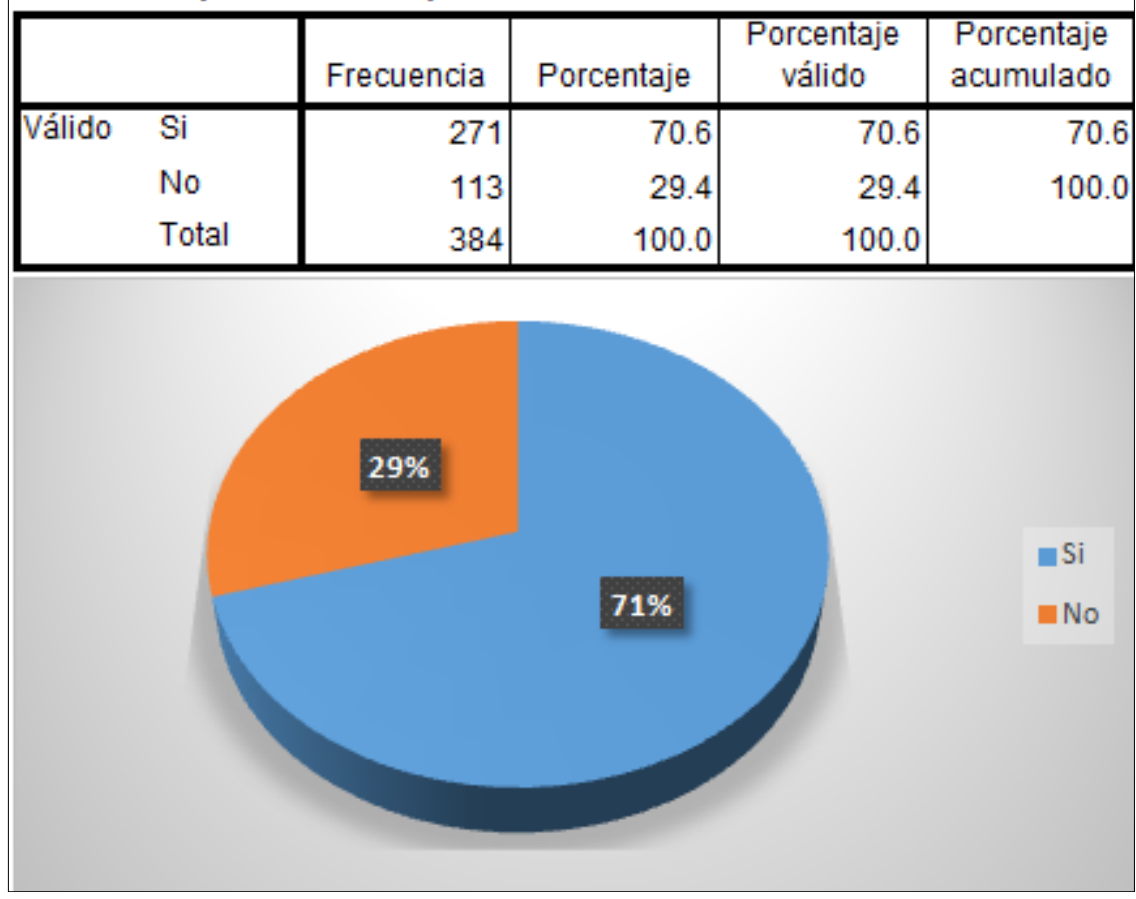

Figura 33. Información obtenida de encuestas de trabajo de campo.

Este resultado demuestra que existe un alto porcentaje de personas en Arequipa que hacen uso de una entidad financiera sea formal o informal, tanto en calidad de préstamo o inversión, en tanto que un $29.4 \%$ indica que no hace uso o no tiene acceso a este tipo de servicio. 
Pregunta: 8 ¿De realizar actividades emprendedoras o de querer invertir en una, cuál sería el rubro de negocio en el que participaría?

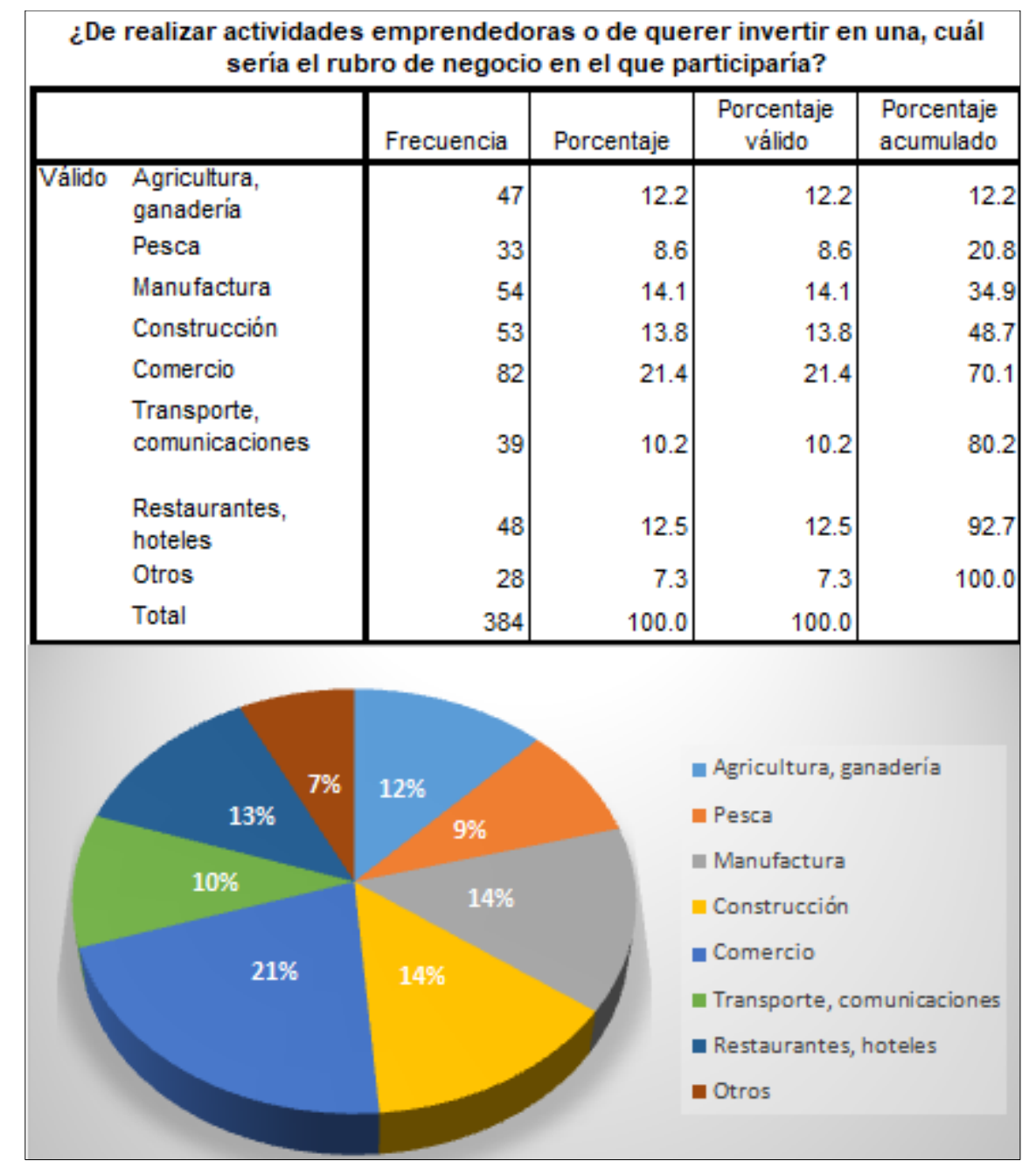

Figura 34. Información obtenida de encuestas de trabajo de campo.

De esta pregunta se puede ver que el rubro de negocio en el que la población arequipeña tiene mayor interés de emprender o de invertir, está en primer lugar el comercio, seguido por la construcción, la manufactura, comida, agricultura; por lo que estos son los sectores de negocio al cual se tiene que enfocar el proyecto aquí propuesto. 
Pregunta: 9 ¿De realizar actividades emprendedoras cual sería el lugar más indicado para desarrollar dicha actividad o negocio?

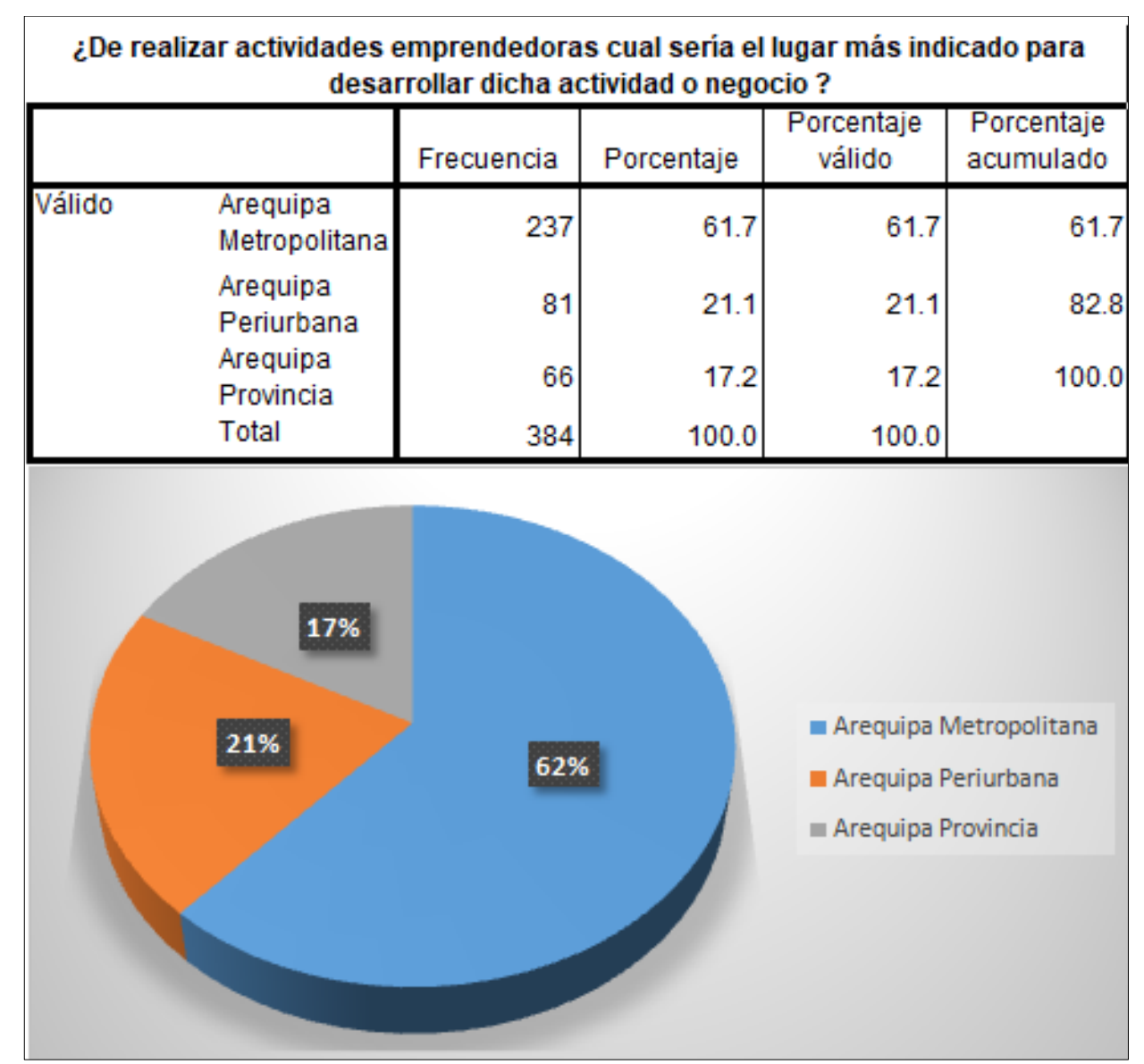

Figura 35. Información obtenida de encuestas de trabajo de campo.

Los clientes tienen mayor preferencia de realizar sus negocios en la ciudad de Arequipa (62\%), que la zona periurbana de la ciudad y la misma provincia de Arequipa, por lo que es necesario concentrar la atención del presente proyecto en una zona céntrica de la ciudad de Arequipa y de fácil acceso.

Pregunta: 10 ¿Le interesaría tener alternativas de inversión más rentables que las dadas en modo tradicional por Bancos, Cajas Municipales, entre otros? De ser "NO”, indique una razón que agrade más 
¿Le interesaría tener alternativas de inversión más rentables que las dadas en modo tradicional por Bancos, Cajas Municipales, entre otros?

\begin{tabular}{|ll|r|r|r|r|}
\hline & Frecuencia & Porcentaje & $\begin{array}{r}\text { Porcentaje } \\
\text { válido }\end{array}$ & $\begin{array}{r}\text { Porcentaje } \\
\text { acumulado }\end{array}$ \\
\hline Válido & Si & 293 & 76.3 & 76.3 & 76.3 \\
& No & 91 & 23.7 & 23.7 & 100.0 \\
& Total & 384 & 100.0 & 100.0 & \\
\hline
\end{tabular}
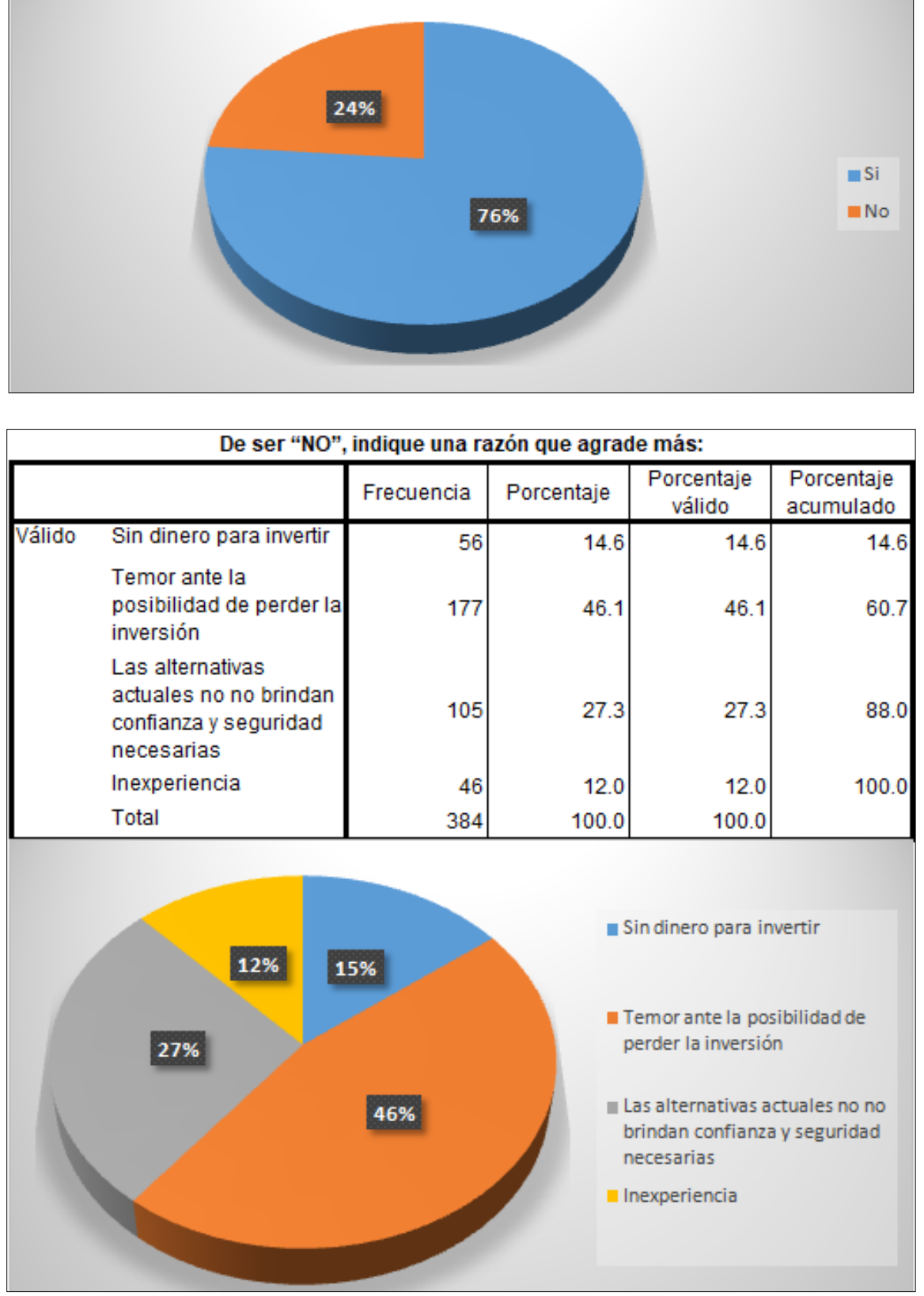

Figura 36. Información obtenida de encuestas de trabajo de campo.

Existe un alto porcentaje de personas que muestran su interés en nuevas alternativas de inversión, indicando con ello su disconformidad con las tradicionales o que estas no satisfacen sus necesidades, confirmando con ello las hipótesis obtenidas de la investigación cualitativa, por otro lado hay que considerar que las personas que respondieron que No, es 
debido al temor y falta de confianza hacia los nuevos modelos de financiación y préstamo, mostrando la necesidad que existe de una educación financiera.

Pregunta: 11 ¿Le ayudaría obtener apalancamiento económico (financiación) a bajo costo o alternativas financieras nuevas e innovadoras en el crecimiento de su negocio? De ser “NO”, indique una razón que agrade más:

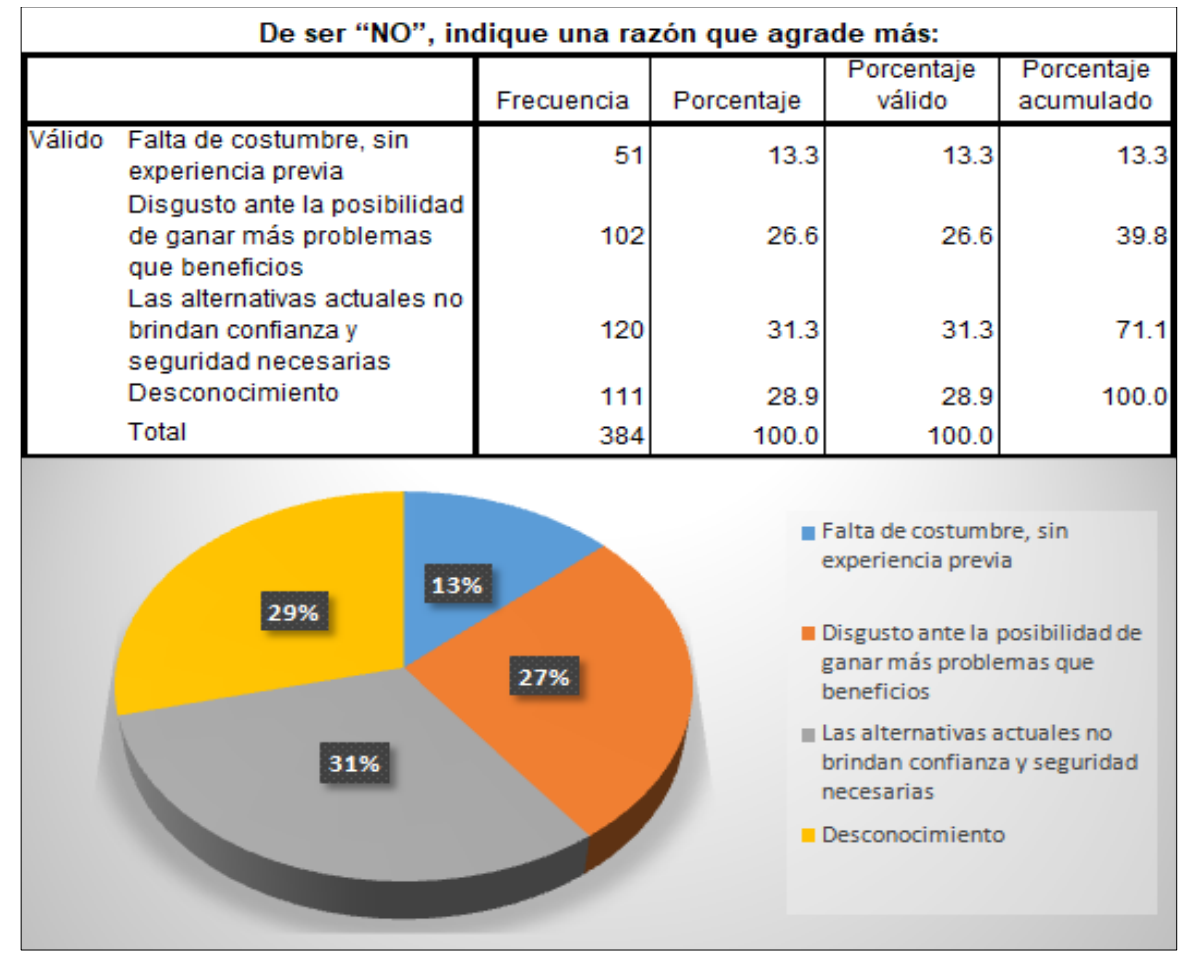

\begin{tabular}{|c|c|c|c|c|}
\hline \multicolumn{5}{|c|}{$\begin{array}{l}\text { ¿Le ayudaría obtener apalancamiento económico (financiación) a bajo costo o } \\
\text { alternativas financieras nuevas e innovadoras en el crecimiento de su negocio? }\end{array}$} \\
\hline & Frecuencia & Porcentaje & $\begin{array}{l}\text { Porcentaje } \\
\text { válido }\end{array}$ & $\begin{array}{l}\text { Porcentaje } \\
\text { acumulado }\end{array}$ \\
\hline Válido Si & 270 & 70.3 & 70.3 & 70.3 \\
\hline No & 114 & 29.7 & 29.7 & 100.0 \\
\hline Total & 384 & 100.0 & 100.0 & \\
\hline
\end{tabular}

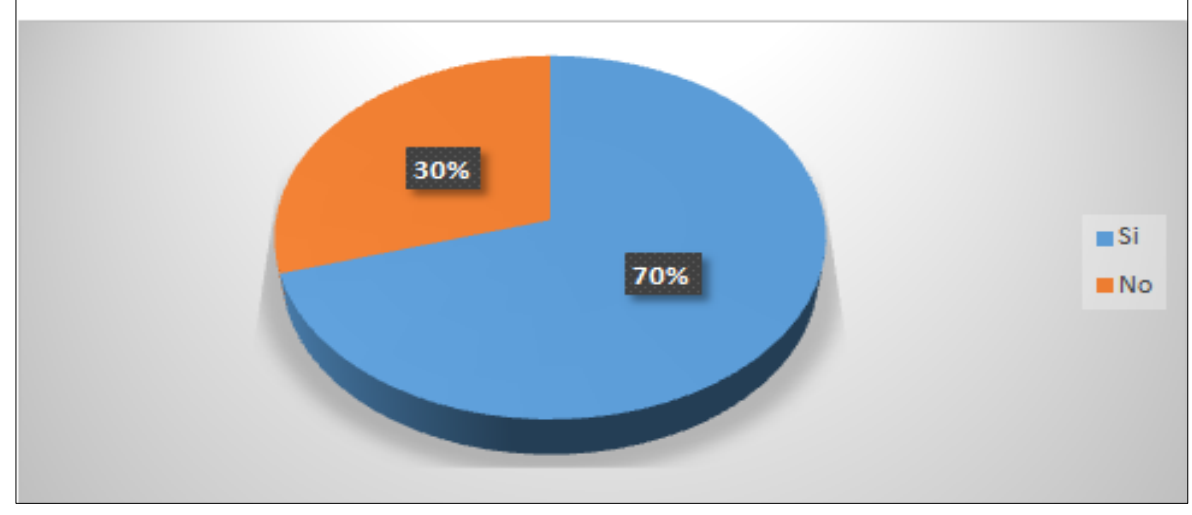

Figura 37. Información obtenida de encuestas de trabajo de campo. 
Un $70 \%$ de las personas que buscan un préstamo ve muy atractivo y una gran oportunidad el poder obtener financiamiento por medio de nuevas alternativas, indicando con ello su disconformidad a lo tradicional, confirmando así las hipótesis obtenidas de la investigación cualitativa, las personas que dieron como respuesta NO (no solicitan crédito) indican que es debido a que no tienen confianza, son engorrosos y ven más dificultades que beneficios.

Pregunta: 12 ¿Cuál de estas opciones le daría más confianza ante una nueva alternativa de financiamiento e inversión diferente a las tradicionales? (orden de prioridad)

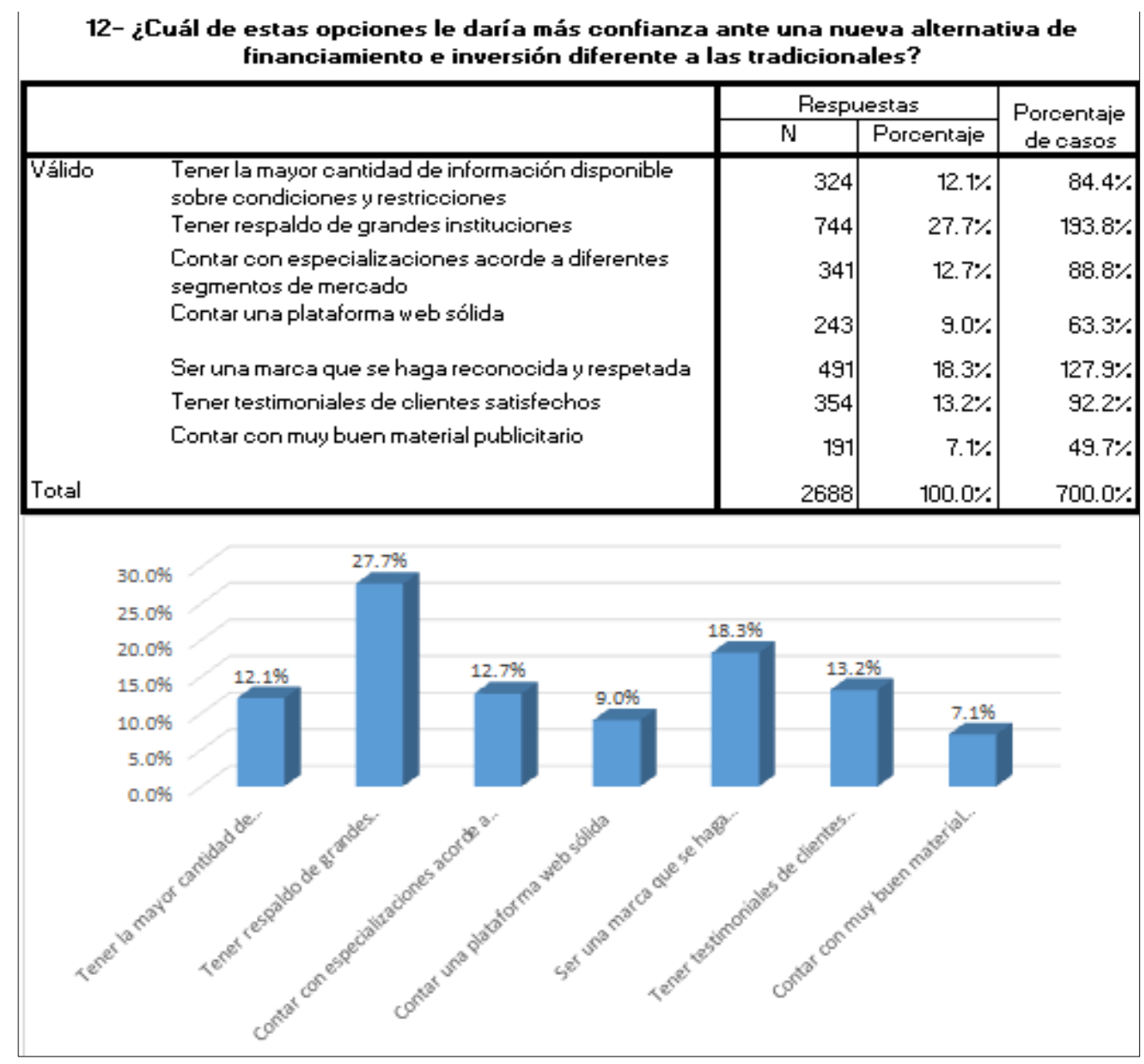

Figura 38. Información obtenida de encuestas de trabajo de campo.

Las personas buscan una entidad que les brinde confianza y seguridad al invertir su dinero, además tener el respaldo de otras instituciones y testimonios de otras personas que lo acrediten. 
Pregunta: 13 ¿Qué ayudaría a mejorar su negocio, emprendimiento o al querer hacer una inversión?

\begin{tabular}{|c|c|c|c|c|}
\hline & & \multicolumn{2}{|c|}{ Respuestas } & \multirow{2}{*}{$\begin{array}{c}\text { Porcentaje de } \\
\text { casos }\end{array}$} \\
\hline & & $\mathrm{N}$ & Porcentaje & \\
\hline \multirow[t]{5}{*}{ Válido } & Dictar talleres educativos & 335 & $17.4 \%$ & $87.2 \%$ \\
\hline & $\begin{array}{l}\text { Desarrollar talleres intensivos e } \\
\text { interdisciplinarios, así como ferias }\end{array}$ & 389 & $20.3 \%$ & $101.3 \%$ \\
\hline & Asesoramiento & 476 & $24.8 \%$ & $124.0 \%$ \\
\hline & $\begin{array}{l}\text { Mejores tasas (ya sea para un } \\
\text { préstamo o para invertir) }\end{array}$ & 521 & $27.1 \%$ & $135.7 \%$ \\
\hline & Mayor publicidad & 199 & $10.4 \%$ & $51.8 \%$ \\
\hline Total & & 1920 & $100.0 \%$ & $500.0 \%$ \\
\hline
\end{tabular}

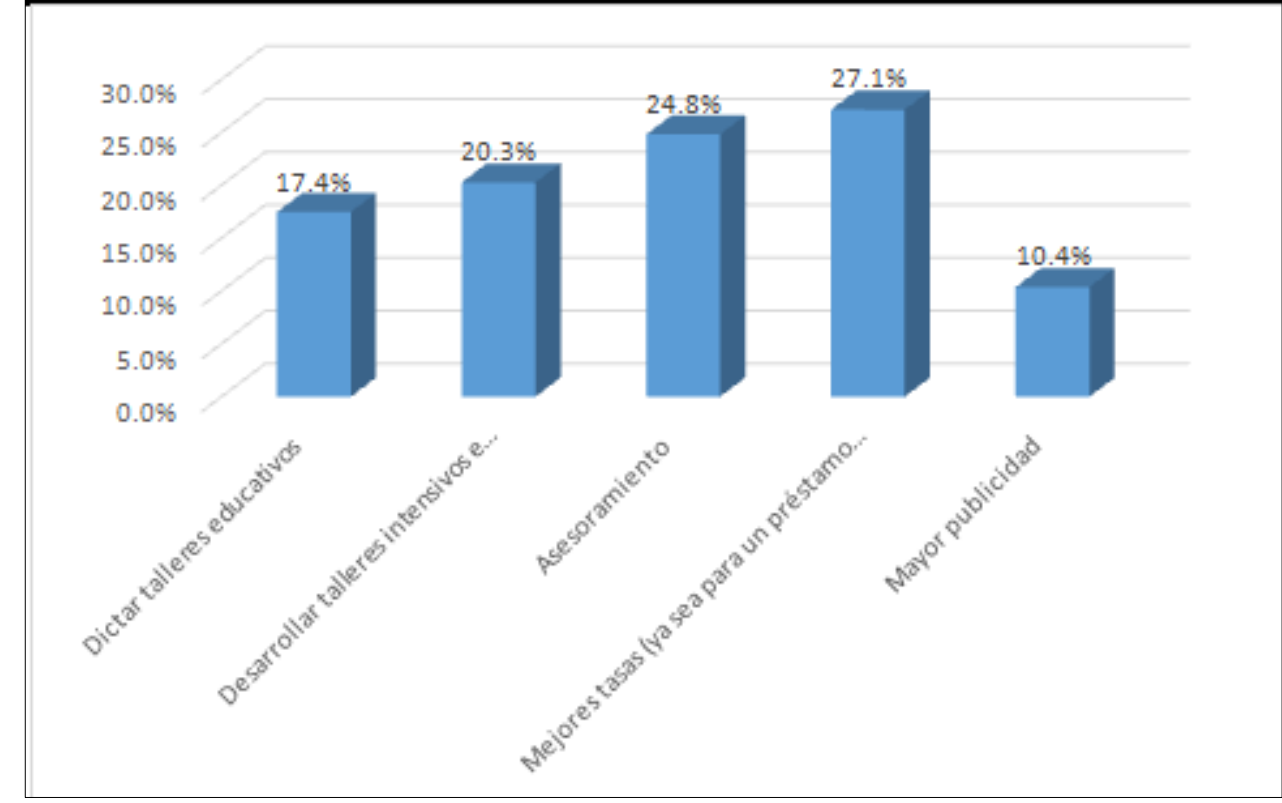

Figura 39. Información obtenida de encuestas de trabajo de campo.

Después de mejores tasas, las personas consideran que tener asesoramiento y talleres ayuda en el desarrollo y crecimiento de su negocio o emprendimiento, al igual que los que desean invertir. 
Pregunta: 14 En orden de prioridad, qué considera más importante, al momento de buscar servicios financieros (préstamos e inversiones)

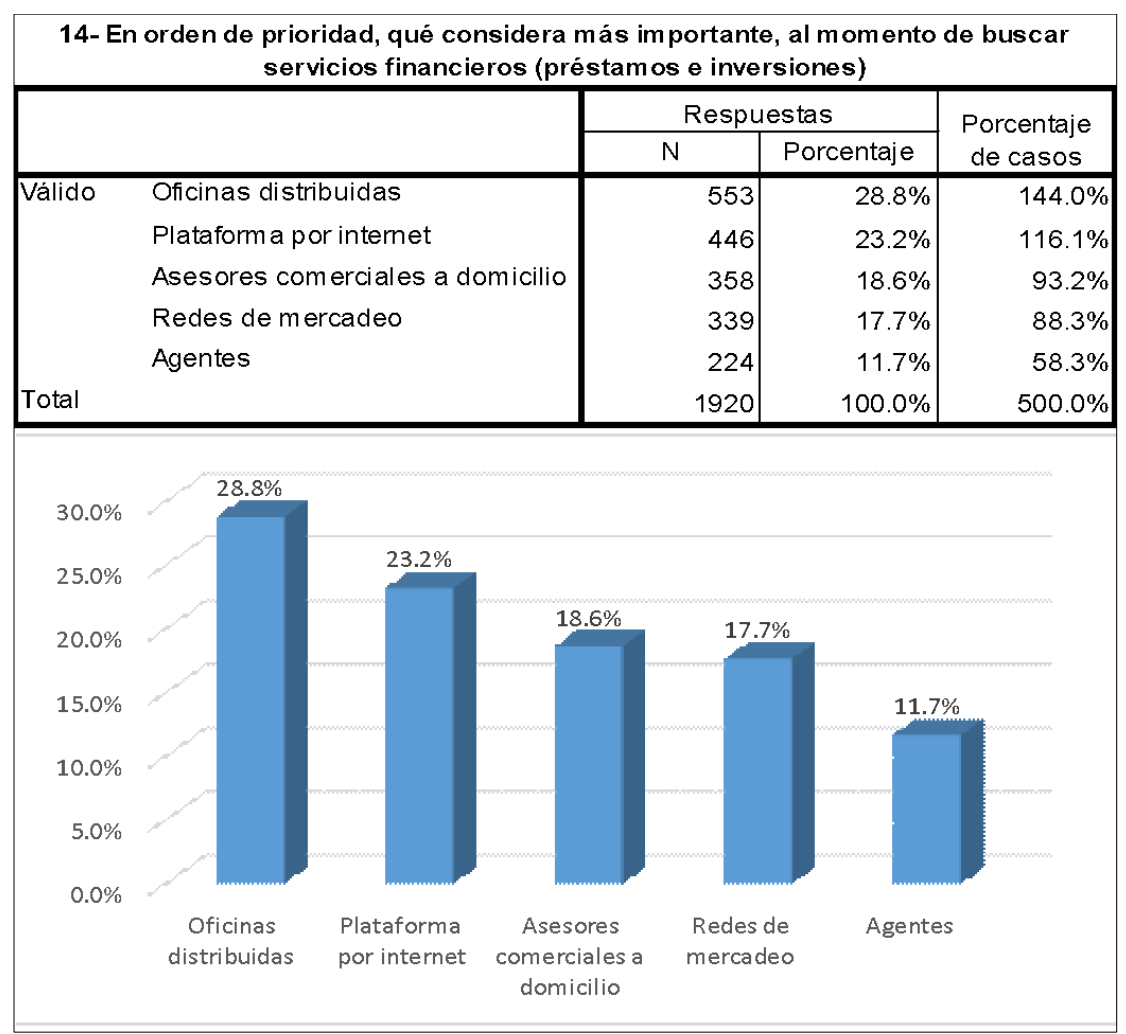

Figura 40. Información obtenida de encuestas de trabajo de campo.

Las personas buscan una entidad financiera que se accesible, con una ubicación estratégica, que cuente con una plataforma web, así también consideran tener un asesoramiento asistido a domicilio o negocio.

\subsection{Conclusiones y recomendaciones del Estudio Cualitativo y Cuantitativo}

Los resultados cualitativos y cuantitativos justifican y muestran el interés del mercado, tanto de las personas que buscan un financiamiento como las que buscan donde invertir, que no sean las tradicionales, se puede percibir la falta de conformidad con las entidades financieras tradicionales, hay un $44 \%$ que está dispuesto a probar nuevas alternativas distintas a las tradicionales. 
Se pudo encontrar que existe un alto porcentaje de personas emprendedoras (36\%) con ideas innovadoras pero que ven frustrados o cortos de alcanzar sus metas por falta de capital y que recurren al financiamiento informal, corriendo el riesgo de pagar altos intereses.

También se debe considerar la falta de una educación financiera, así como asesoramiento, que es la actividad más solicitada (44\%) cuando se trata de hacer crecer o emprender un negocio. El poder brindar un servicio amigable y sencillo, que se acomode a las necesidades del cliente es muy importante.

Los resultados del estudio indican que la mayor concentración de clientes (más del $50 \%$ ) y sus proyecciones se encuentran concentradas en Arequipa urbana.

Ente los negocios más atrayentes o propagados en la ciudad de Arequipa se encuentran los relacionados al rubro del comercio (14\%) y los pequeños negocios (32\%).

De todo ello se determinó que entre las características de los clientes está: que un cliente que busca un préstamo requiere que este se consiga en corto tiempo y con mejores tasas, asimismo los clientes que desean invertir se ven interesados ya que obtienen una mayor ganancia que cuando invierten en la banca tradicional, pero junto a ello requieren mayor información acerca de estas nuevas formas de inversión y /o asesoramiento. Entre los negocios más atrayentes en la ciudad de Arequipa está el comercio de productos o servicios.

\subsection{Perfil del consumidor tipo y sus variantes}

El perfil del consumidor para el proyecto propuesto está dado por personas que geográficamente se ubican en la ciudad de Arequipa (Arequipa urbana), entre los 25 y 55 años, aunque este puede extenderse, ya que existe un porcentaje que representa a los emprendedores menores de 25 años y personas con experiencia en los negocios mayores a los 55 años. Todos ellos pertenecientes a la PEA. Son personas con ideas de negocio o ya tienen uno constituido que pretenden ampliar o mejorar tecnológicamente, y también personas que buscan no sólo ahorrar si no realizar inversiones disminuyendo riesgos. 


\section{Capítulo IV. Proyección del Mercado Objetivo}

\subsection{El ámbito de la proyección}

En este punto se estima el comportamiento futuro de la demanda y oferta de los servicios propuestos por el proyecto. Por lo cual es necesario cuantificar la demanda existente por el servicio que se pretende ofrecer, a fin de determinar cuál será la demanda que satisfaga el proyecto. Preparando de esta manera el planificar una estrategia de comercialización adecuada a la naturaleza del servicio y caracterizada al usuario o consumidor, para finalmente determinar la cantidad de bienes y servicios provenientes de la empresa del proyecto, que los consumidores estarán dispuestos a adquirir.

La empresa propuesta se desarrolla en un ambiente donde el mercado se encuentra entre las personas que están entre los 25 y 55 años de edad, ubicado geográficamente en la ciudad de Arequipa, que pertenece a la población económicamente activa (PEA) y dentro de los niveles socioeconómicos (NSE) A, B, C+.

\subsection{Selección del método de proyección}

El objetivo es elaborar un pronóstico útil aplicando la técnica que resulte apropiada para los diferentes patrones de demanda. Según Sapag (2011) los métodos para hacer proyecciones son complementarios, basados en comportamientos empíricos. Estas técnicas se clasifican en dos categorías: cuantitativas y cualitativas. Si se cuenta con datos históricos suficientes, es viable utilizar métodos cuantitativos de proyección, y si estos no existen o son insuficientes, lo mejor es emplear los métodos cualitativos.

En cuanto a los métodos cualitativos, estas técnicas se basan en el valor que tienen las experiencias pasadas y la capacidad de las personas y así poder conocer previamente los efectos sobre las variables más significativas en la viabilidad de un proyecto, así como el 
obtener información importante de éxitos, fracasos y modelos de desempeño, todos ellos se basan en opiniones de expertos los que se obtienen a partir de las técnicas como: (1) El método Delphi, que es un proceso que está conformado por un grupo heterogéneo de expertos, donde cada uno de ellos proporciona información de manera interactiva, concluyéndose en una convergencia de opiniones que da como resultado una predicción ampliamente consensuada; (2) La investigación de mercados, donde se considera la opinión de los clientes como la más adecuada para poder realizar las predicciones, para ello se recolecta la información, a partir por ejemplo de encuestas a una muestra representativa de la población, que es el modelo más característico de este modelo (Sapag, 2011), este método se desarrolló en el capítulo tres (ver sección 3.2).

En los métodos cuantitativos de predicción se tienen los modelos causales y los modelos de series de tiempo. En los modelos causales se requiere identificar las variables donde exista una relación entre sus valores, la forma más común en la proyección del modelo causal es el ajuste de curvas, por medio del método de regresión, el cual predice el valor de la variable dependiente a partir de una línea que puede ser recta, exponencial u otra formada por los datos de la variable independiente. En los modelos de series de tiempo se puede pronosticar el futuro a partir de la extrapolación de valores históricos, siempre y cuando ésta se encuentre completa y sea confiable, este modelo asume que la variable que explica la demanda futura es el paso del tiempo, una serie de tiempo presenta tres tipos de comportamiento: tendencia, cíclica y estacional.

Para el presente proyecto se aplica el método de regresión lineal con el objeto de determinar la tendencia del crecimiento de las microempresas así como de los habitantes en la ciudad de Arequipa, durante los años y luego poder proyectar el Mercado Objetivo y las Ventas. El método de los mínimos cuadrados o regresión lineal ayudará a determinar la recta 
que mejor represente la tendencia de la relación entre las variables, para usarlas como base de la proyección de la tendencia futura.

Proyección del número de las microempresas: Se formula la ecuación que explique el comportamiento de todos los datos, la cual está dada por: $y=a+b x$, donde los valores de

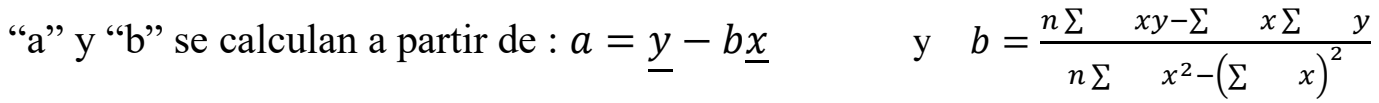

Tabla 5

Datos recolectados del número de Microempresas por año en la Ciudad de Arequipa

\begin{tabular}{ccc}
\hline No. & Año & $\begin{array}{c}\text { Microempresa } \\
\text { s }\end{array}$ \\
\hline 1 & 2016 & 112138 \\
2 & 2015 & 108351 \\
3 & 2014 & 104371 \\
4 & 2013 & 96067 \\
5 & 2012 & 87331 \\
6 & 2010 & 66402 \\
7 & 2009 & 62868 \\
8 & 2008 & 60900 \\
\hline
\end{tabular}

Nota. Adaptado de "Estructura empresarial por segmento a nivel Nacional," por el Instituto Nacional de Estadística e Informática (INEI), 2012-2016; “Estadísticas,” por el Consejo Nacional para el desarrollo de la micro y pequeña empresa (CODEMYPE), 2009-2010; "IV Censo Nacional Económico 2008," por el INEI. Recuperado de http://www.inei.gob.pe/media/MenuRecursivo/publicaciones_digitales/Est/Lib1382/index.ht ml, http://www2.produce.gob.pe/remype/data/mype2010.pdf, http://www2.produce.gob.pe/remype/data/mype2009.pdf, http://censos.inei.gob.pe/cenec2008/tabulados/Docs/FICHATECNICAIVCENEC.pdf, respectivamente. 


\begin{tabular}{lr}
\hline \multicolumn{2}{c}{ Estadísticas de la regresión } \\
\hline Coeficiente de corre & 0.988044612 \\
Coeficiente de deter & 0.976232156 \\
$\mathrm{R}^{\wedge} 2$ ajustado & 0.972270848 \\
Error típico & 3537.458386 \\
Observaciones & 8 \\
\hline
\end{tabular}

ANÁLISIS DEVARIANZA

\begin{tabular}{|c|c|c|c|c|c|c|}
\hline & Grados de libertad & & Suma de cuadrados & Prom de los cuadrados & $F$ & Valor crítico de F \\
\hline Regresión & & 1 & 3083878395 & 3083878395 & 246.4419095 & $4.23378 \mathrm{E}-06$ \\
\hline Residuos & & 6 & 75081670.99 & 12513611.83 & & \\
\hline Total & & 7 & 3158960066 & & & \\
\hline
\end{tabular}

\begin{tabular}{|c|c|c|c|c|c|c|}
\hline & Coeficientes & Errortipico & Estadístico t & Probabilidad & inferior $95 \%$ & Superior $95 \%$ 'nferior $95.0 \%$ uperior $95.0 \%$ \\
\hline Intercepción & -14475269.63 & 927643.768 & -15.60434094 & $4.38603 \mathrm{E}-06$ & -16745132.15 & -12205407.1 $-16745132.2-12205407.1$ \\
\hline Variable X1 & 7237.409766 & 461.0264894 & 15.69846838 & $4.23378 \mathrm{E}-06$ & 6109.318588 & $\begin{array}{lll}3 & 865.50094 & 6109.31859 \quad 8365.50094\end{array}$ \\
\hline
\end{tabular}

Figura 41. Resultados de la Regresión lineal para determinar el número de Microempresas.

De la figura anterior, se tiene que: $a=-14475269.63$ y $b=7237.41$ y el coeficiente $\mathrm{R}^{\wedge} 2$ tiene un valor de $97.23 \%$, lo que indica que las variables $\mathrm{x}$ e y tienen un comportamiento altamente relacionados (Sapag, 2011).

Con los parámetros hallados se procede a estimar el número de Microempresas futuras, reemplazando en la fórmula: $y=a+b x$

Tabla 6

Proyección del número de Microempresas por año en la Ciudad de Arequipa

\begin{tabular}{ccc}
\hline No. & Año & Microempresas \\
\hline 1 & 2019 & 137061 \\
2 & 2020 & 144298 \\
3 & 2021 & 151536 \\
4 & 2022 & 158773 \\
5 & 2023 & 166010
\end{tabular}

$\overline{\text { Nota. } \text { Valores obtenidos de la regresión lineal } a}=-14475269.63$ y $b=7237.41, \mathrm{R}^{\wedge} 2=$ $97.23 \%$. 
Proyección del número de habitantes: de igual forma se procede a estimar los valores de "a" y "b" a partir de los siguientes datos:

Tabla 7

Datos recolectados del número de Habitantes por año en la Ciudad de Arequipa

\begin{tabular}{ccc}
\hline No. & Año & Habitantes \\
\hline 1 & 2008 & 303627 \\
2 & 2009 & 307283 \\
3 & 2010 & 310933 \\
4 & 2011 & 314629 \\
5 & 2012 & 318272 \\
6 & 2013 & 321808 \\
7 & 2014 & 325163 \\
8 & 2015 & 328298
\end{tabular}

Nota. Adaptado de "Población total al 30 de junio, por grupos quinquenales de edad, según departamento, provincia y distrito," por INEI, 2008 - 2015. Recuperado de https://www.inei.gob.pe/media/MenuRecursivo/indices_tematicos/cuadro001_1.xls

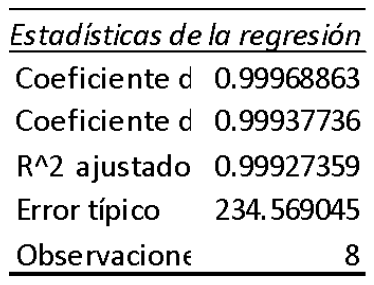

ANÁLISIS DE VARIANZA

\begin{tabular}{|c|c|c|c|c|c|}
\hline & Grados de libert? & a de cuadran & io de los cua & $F$ & alor crítico de $F$ \\
\hline Regresión & 1 & 529890912 & 529890912 & 9630.41653 & 7.545E-11 \\
\hline Residuos & 6 & 330135.821 & 55022.6369 & & \\
\hline Total & 7 & 530221048 & & & \\
\hline
\end{tabular}

Coeficientes Error típico Estadistico t Probabilidad Inferior 95\% Superior 95\%'nferior 95.0\%uperior 95.0\%

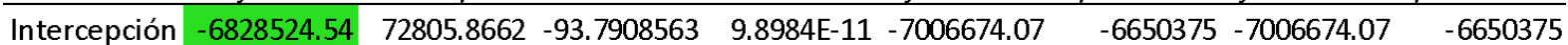
\begin{tabular}{lllllllll} 
Variable X1 & 3551.96429 & 36.1947895 & 98.1346857 & $7.545 \mathrm{E}-11$ & 3463.39883 & 3640.52974 & 3463.39883 & 3640.52974 \\
\hline
\end{tabular}

Figura 42. Resultados de la Regresión lineal para determinar el número de habitantes. 
Con los parámetros obtenidos: $a=-6828524.54$ y $b=3551.96429$ y el coeficiente $\mathrm{R}^{\wedge} 2$ tiene un valor de $99.93 \%$, se procede a estimar la población futura, así se tiene:

Tabla 8

Proyección del número de Habitantes por año en la Ciudad de Arequipa

\begin{tabular}{ccc}
\hline No. & Año & Habitantes \\
\hline 1 & 2019 & 342891 \\
2 & 2020 & 346443 \\
3 & 2021 & 349995 \\
4 & 2022 & 343547 \\
5 & 2023 & 357099
\end{tabular}

Nota. Valores obtenidos de la regresión lineal $a=-6828524.54$ y $b=3551.96429, \mathrm{R}^{\wedge} 2$ $=99.93 \%$.

\subsubsection{Mercado Potencial}

De acuerdo a A. Müller (2016), es el conjunto de consumidores que podrían necesitar el bien o servicio que es materia del proyecto. El mercado potencial se determina después de haberlo segmentado.

Según la publicación realizada por Aurum Consultoría y Mercado (2015), en Arequipa se considera que el $95.4 \%$ de la PEA trabajan en microempresas.

Con este valor y los valores proyectados del número futuro de microempresas por año, se procede a calcular el mercado potencial, utilizando los criterios de nivel socioeconómico y demográfico, agrupándolo en número de microempresas y por habitantes proyectados para cada año. 
Tabla 9

Detalle de la estimación del Mercado Potencial (MP)

\begin{tabular}{llrrc}
\hline No. & \multicolumn{3}{c}{ Microempresa } & Habitante \\
Año & s & S & MP \\
\hline 1 & 2019 & 137,061 & 342,891 & 327,118 \\
2 & 2020 & 144,298 & 346,443 & 330,507 \\
3 & 2021 & 151,536 & 349,995 & 333,896 \\
4 & 2022 & 158,773 & 353,547 & 337,284 \\
5 & 2023 & 166,010 & 357,099 & 340,673 \\
\hline
\end{tabular}

Nota. Valores proyectados para MP

Así de la tabla anterior tiene el mercado potencial futuro que están entre los 25 y 55 años de edad, ubicado geográficamente en la ciudad de Arequipa, que pertenece a la PEA (95.4\%) y dentro de los niveles socioeconómicos (NSE) A, B, C+.

\subsubsection{Mercado Disponible}

Este mercado, deriva del mercado potencial (Müller, 2016), según los resultados de la encuesta los cuales se dieron en el estudio de mercado, este mercado está formado por el conjunto de personas que realizan o desean emprender un negocio o por quienes estén interesados en financiar alguno, aplicando las respuestas de las preguntas filtro:

A las preguntas:

P6: ¿Realiza o está dispuesto a emprender un negocio o está interesado en financiar alguno?

Sí tiene un negocio o está interesado en emprender uno. $\quad 52.3 \%$

Sí, está interesado en financiar un negocio. $\quad 30.7 \%$

$\begin{array}{ll}\text { Ninguno de los anteriores. } & 16.9 \%\end{array}$ 
P7: ¿Hace uso de los servicios de una entidad financiera formal o informal para solicitar préstamos o colocar sus ahorros en ella?

$\begin{array}{ll}\text { Sí } & 70.6 \% \\ \text { No } & 29.4 \%\end{array}$

De la aplicación de las respuestas, de las preguntas filtro se obtiene:

$$
\text { Mercado Disponible }=\mathrm{MP} *(\% \text { preguntas filtro })
$$

Tabla 10

Estimación del Mercado Disponible (MD)

\begin{tabular}{lccccc}
\hline MD & 2019 & 2020 & 2021 & 2022 & 2023 \\
\hline P6 (52.3\%) & 171,083 & 172,855 & 174,627 & 176,400 & 178,172 \\
P6 (30.7\%) & 100,425 & 101,466 & 102,506 & 103,546 & 104,587 \\
Total P6 & 271,508 & 274,321 & 277,133 & 279,946 & 282,758 \\
P7 (70.6\% del 52.3\% de & 120,785 & 122,036 & 123,287 & 124,538 & 125,789 \\
P6) & & & & \\
P7 (70.6\% del 30.7\% de & 70,900 & 71,635 & 72,369 & 73,104 & 73,838 \\
P6) & 191,685 & 193,670 & 195,656 & 197,642 & 199,627 \\
\hline
\end{tabular}

Nota. Valores obtenidos de la aplicación de los filtros al MP a partir de las preguntas filtro seis y siete de la encuesta. (*) Personas que hacen unos de alguna entidad financiera y que cuenta con negocio o están interesados en emprender uno $\left(^{* *}\right)$ personas que hacen uso de alguna entidad financiera que están interesados en financiar algún negocio

\subsubsection{Mercado Efectivo}

Mercado que está formado por el conjunto de consumidores que además de la necesidad, tienen la intención de comprar el bien o servicio que ofrece el proyecto (Müller, 2016). Es entonces la población que deriva del mercado disponible a través de las preferencias relacionadas a la encuesta.

$$
\text { Mercado Efectivo }=\text { MD * (aceptación del producto\% })
$$


A las preguntas:

P10: ¿Le interesaría tener alternativas de inversión más rentables que las dadas en modo tradicional por Bancos, Cajas Municipales, entre otros?

Sí $\quad 76.3 \%$

No $\quad 23.7 \%$

P11: ¿Le ayudaría obtener apalancamiento económico (financiación) a bajo costo o alternativas financieras nuevas e innovadoras en el crecimiento de su negocio?

Sí

$70.3 \%$

No

$29.7 \%$

El porcentaje de aceptación del producto, lo extraemos del análisis de encuestas, los cuales nos reflejan un $76.3 \%$ y 70.3\% de aceptación respectivamente, interés y posibilidad de adquisición por parte de los encuestados analizados en el estudio de mercado.

Tabla 11

Estimación del Mercado Efectivo (ME)

\begin{tabular}{lccccc}
\hline ME & 2019 & 2020 & 2021 & 2022 & 2023 \\
\hline P10 $(76.3 \%)$ & 92,159 & 93,113 & 94,068 & 95,023 & 95,977 \\
P11 $(70.3 \%)$ & 49,843 & 50,359 & 50,876 & 51,392 & 51,908 \\
Total ME & 142,001 & 143,472 & 144,943 & 146,414 & 147,885 \\
\hline
\end{tabular}

Nota. Valores obtenidos de la aplicación de los filtros al MD a partir de las preguntas filtro siete y ocho.

\subsubsection{Mercado Objetivo}

Denominado también mercado meta (Müller, 2016), es el mercado al cual se dirigen la totalidad de los esfuerzos y acciones de marketing, con la finalidad de que todos ellos se 
conviertan en clientes reales del producto. Para lo cual se ha considerado el 5\% del mercado efectivo ya que se trata de una nueva propuesta, que como tal no existe en el mercado arequipeño. Se toma como referencia del promedio de variación del PBI de los últimos 11 años, para considerar el crecimiento de la participación de la empresa en el mercado en el sector de otros servicios, el cual es $5.83 \%$.

\begin{tabular}{|c|c|}
\hline \multicolumn{2}{|c|}{$\begin{array}{c}\text { Producto bruto interno por } \\
\text { sectores productivos } \\
\text { (variaciones porcentuales } \\
\text { reales) - Otros Servicios }\end{array}$} \\
\hline Fecha & \% Var. \\
\hline 2008 & 7.60 \\
\hline 2009 & 4.60 \\
\hline 2010 & 7.70 \\
\hline 2011 & 7.30 \\
\hline 2012 & 7.40 \\
\hline 2013 & 6.50 \\
\hline 2014 & 6.00 \\
\hline 2015 & 5.00 \\
\hline 2016 & 4.30 \\
\hline 2017 & 3.20 \\
\hline 2018 & 4.55 \\
\hline $\begin{array}{l}\text { Variación } \\
\text { Promedio }\end{array}$ & 5.83 \\
\hline
\end{tabular}

Figura 43. Producto bruto interno por sectores productivos (variaciones porcentuales reales) Otros Servicios. Tomado de Gerencia Central de Estudios Económicos por Banco Central de Reserva del Perú, 2017. Recuperado de https://estadisticas.bcrp.gob.pe/estadisticas/series/anuales/resultados/PM04981AA/html

\begin{tabular}{|c|c|c|c|c|c|}
\hline \multirow{2}{*}{$\begin{array}{c}\text { Participación } \\
(\%)\end{array}$} & $\mathbf{2 0 1 9}$ & $\mathbf{2 0 2 0}$ & $\mathbf{2 0 2 1}$ & $\mathbf{2 0 2 2}$ & $\mathbf{2 0 2 3}$ \\
\cline { 2 - 6 } & 5.00 & 5.29 & 5.60 & 5.93 & 6.27 \\
\hline
\end{tabular}

Figura 44. Participación de mercado de IDeltas S.A.C. Elaboración propia.

Tabla 12

Estimación del Mercado Objetivo (MO)

\begin{tabular}{rrrrrr}
\hline & 2019 & 2020 & 2021 & 2022 & 2023 \\
\hline MO & 7,100 & 7,592 & 8,117 & 8,678 & 9,276 \\
\hline
\end{tabular}




\subsection{Pronóstico de Ventas}

Luego de determinar el mercado objetivo, a partir de ello se calcula esta misma variable pero en unidades monetarias para poder calcular el pronóstico de ventas proyectado. Cabe resaltar que en el modelo de negocio propuesto los clientes son inversores así como aspirantes a financiación.

En base al estudio cuantitativo, se calcula los montos promedio de gasto por persona al año en cada uno de los servicios/productos que se ofrecerán a fin de totalizar el monto anual en soles que se espera captar del mercado objetivo (7,100 clientes) para el primer año de evaluación de proyecto

Tabla 13

Pronóstico de Ventas

\begin{tabular}{lccc}
\hline Servicio/ & Precio Promedio & Unidades & Importe \\
Producto & US\$ & Por Año & US\$ \\
\hline Ventas por adelantado & 151.5 & 410 & 62,121 \\
Financiamiento & 151.5 & 260 & 39,394 \\
Servicios Especiales & 30.3 & 80 & 2,424 \\
Asesoría permanente & 66.7 & 100 & 6,667 \\
Asesoría por horas & 21.2 & 120 & 2,545 \\
Capacitación, Cursos & 151.5 & 100 & 15,152 \\
Total en dólares & & & 128,303 \\
Total en soles & & & 423,400 \\
\hline
\end{tabular}

Nota: Estimación de precios, valores dados en dólares. 
Tabla 14

Pronóstico de ventas por año

\begin{tabular}{lccccc}
\hline & \multicolumn{5}{c}{ Año } \\
& 1 & 2 & 3 & 4 & 5 \\
\hline Ingreso por ventas \$ & 128,303 & 138,567 & 148,832 & 159,096 & 169,360 \\
Ingreso por ventas S/. & 423,400 & 457,272 & 491,144 & 525,016 & 558,888 \\
\hline
\end{tabular}

Ventas por adelantado - Refiere al servicio que propone ofrecer una oportunidad de acceder a liquidez a través de ventas por adelantado a clientes (buscador de financiamiento) que deseen ofertar sus productos con un descuento considerable a cambio de recibir el pago por adelantado. La empresa propuesta en este proyecto, se ubica entre el buscador de financiamiento y el financiador como mediador permitiendo viabilizar la operación y cobrando una comisión promedio del $15 \%$ de la utilidad de la operación al financiador y $15 \%$ al buscador de financiamiento; considerando que el interés promedio mensual es de 1.7\% sobre monto solicitado (TEA 20\%). Para poder lograr una meta de \$62,121 de ingresos anuales, se ha estimado un tiempo promedio de operaciones de 3 meses, dado que muchas de las necesidades de financiación son eventuales, así mismo un cliente puede tener más de una inversión y si su evaluación lo permite más de un requerimiento de financiación (liquidez). De este modo se precisaría de 137 clientes en el primer año, con una meta promedio de 11 clientes por mes el primer año de funcionamiento del proyecto.

Financiamiento - Refiere al servicio que propone ofertar una oportunidad de acceder a liquidez a través de un préstamo de este modo un cliente buscador de financiamiento es contactado con un o unos clientes financiador (es) para poder acceder a liquidez a través de un préstamo. El proyecto se ubica entre ambos clientes como mediador permitiendo viabilizar 
la operación y cobrando una comisión promedio del 16\% de la utilidad de la operación al oferente y $16 \%$ al demandante; considerando que el interés promedio mensual es de $1.7 \%$ sobre monto solicitado (TEA 20\%). Para poder lograr una meta de \$39,394 de ingresos anuales se necesitan de 173 clientes en el primer año, con una meta promedio de 14 clientes por mes el primer año de funcionamiento del proyecto.

Servicios Especiales - Refiere al servicio que propone a los clientes la modificación de sus contratos analizando el entorno legal, elaboración de contratos sofisticados o específicos, revisión, traspaso de contratos, etc. Refiere también a la compra y venta de derechos a realizar, ya sea de ventas por adelantado, así como derechos de compra (el cual puede darse después de haberse dado una transacción y aparece un nuevo interesado que quiera participar de alguna manera), financiación directa a bajo costo, inversión directa en necesidades de capitalización inmediata, entre otros. Aquí se considera llegar a una meta de \$2,424 al primer año o lo que es decir 80 clientes al año, para lo cual se precisaría de seis operaciones por mes.

Asesoría permanente - sobre los puntos mencionados en "Elaboración y revisión de contratos", aquí se considera que los clientes que tomen el servicio a modo de membrecía en promedio continuarían en promedio seis meses por cliente, se necesitaría de un ingreso de $\$$ 6,667, equivalente a 17 clientes al año.

Asesoría por horas - sobre los puntos mencionados en "Elaboración y revisión de contratos", aquí se considera que los clientes que tomen el servicio por horas en promedio dos horas por cliente, se estima llegar a la meta de ingreso anual por este servicio de $\$ 2,545$, con un promedio de 60 clientes al año, lo que es equivalente a cinco clientes por mes. 
Capacitación, cursos - sobre los puntos mencionados en "Elaboración y revisión de contratos", metodologías que permitan maximizar ganancias, entre otros. Se estima un ingreso anual de $\$ 15,152$ o lo que es decir de 33 clientes, equivalente a tres clientes por mes.

Tabla 15

Resumen

\section{CUADRO RESUMEN}

\section{Clientes considerados}

Ingresos por ventas estimadas en Soles $\quad 425,604$ soles

Ingresos estimados el primer año
250 clientes al primer año

128,303 dólares

91,190 soles

Nota: Mayor detalle en el capítulo de plan de marketing, ya que esta proyección está alineada al plan de marketing.

\subsection{Aspectos críticos que impactan el pronóstico de ventas}

Los aspectos más considerados en el impacto de ventas es lograr una atención eficiente las 24 horas así como generar un equipo de asesores comerciales altamente capacitados con remuneraciones que puedan ser soportadas por el modelo económico del proyecto.

Este pronóstico también puede ser afectado por fuerza externas que interactúan en el sector financiero y que pueden condicionar el desempeño. Por lo que se debe tomar en consideración las amenazas que resultan del análisis del contexto esperado y actual realizado en el Capítulo II. También puede estará afectado por la variación del Mercado Objetivo, variación en la frecuencia de uso de los servicio y productos, cambios en la tasa de crecimiento anual que se espera para el proyecto. 


\section{Capítulo V. Ingeniería Del Proyecto}

\subsection{Estudio de ingeniería}

Diseño de una organización de servicios es la tarea que se explicara en este punto, se considerará a los servicios y a la calidad de manera similar, de modo que el cliente sea el punto central de toda decisión así como de las acciones de la organización (R. B. Chase, F. Jacobs \& N. J. Aquilano, 2009).

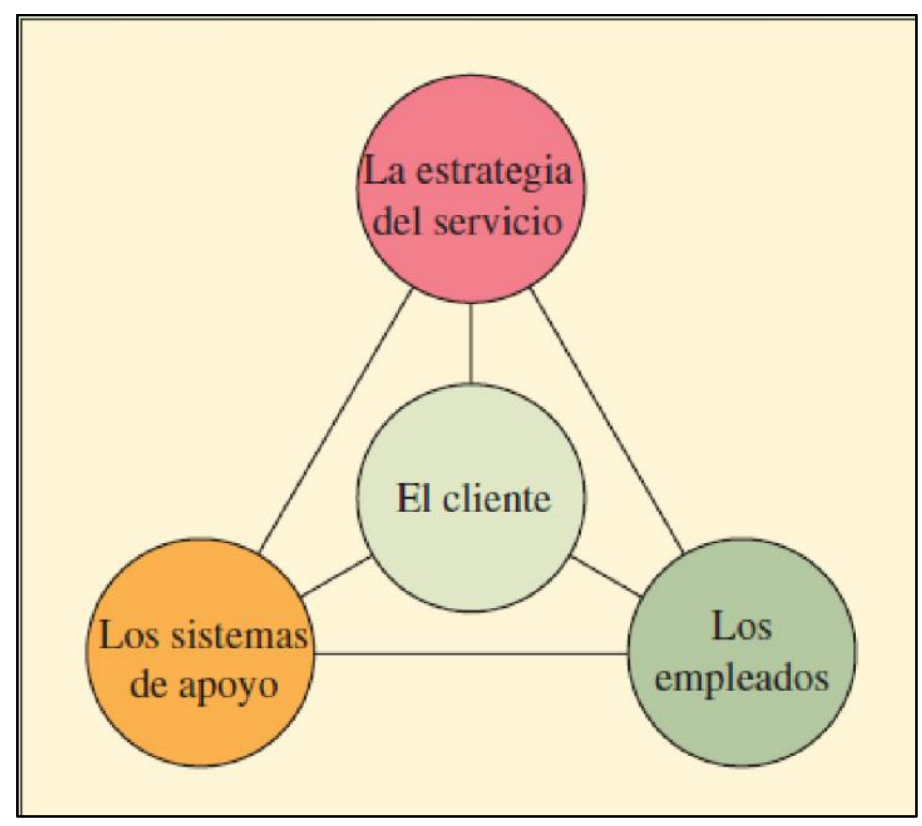

Figura 45. Triángulo de los servicios. Tomado de Administración de Operaciones (p.256), por R.B. Chase, F. R. Jacobs y N.J. Aquilano, 2009, México D.F.:McGrall Hill. Copyright 2009 McGrall Hill Companies Inc.

El modelo de negocio propuesto al cliente, es único en el mercado local, a nivel internacional se da, pero por medios electrónicos, de modo que se tiene una importante referencia sobre experiencias y modelos con resultados exitosos En este punto se analizará el funcionamiento e instalación de las instalaciones (Baca Urbina, 2010). De este modo se analizaran los requerimientos necesarios para poder cumplir con los procesos que precisan las 
operaciones necesarias en proceso del plan de negocios propuesto. Por tal motivo es preciso especificar cuáles son los productos ofrecidos por el proyecto.

\subsubsection{Modelamiento y selección de procesos productivos}

La selección del proceso es una decisión estratégica importante, esto involucra seleccionar qué tipos de procesos de producción debemos considerar, todo esto acorde a las prioridades competitivas como son: Costo, calidad, flexibilidad y tiempo. Para poder modelar los procesos necesarios, nos guiamos de la guía propuesta por (L. Krajewski, L. P. Ritzman \& M. K. Malhotra, ,2008) para “decisiones clave para procesos efectivos”, tal y como nos resume la siguiente figura:

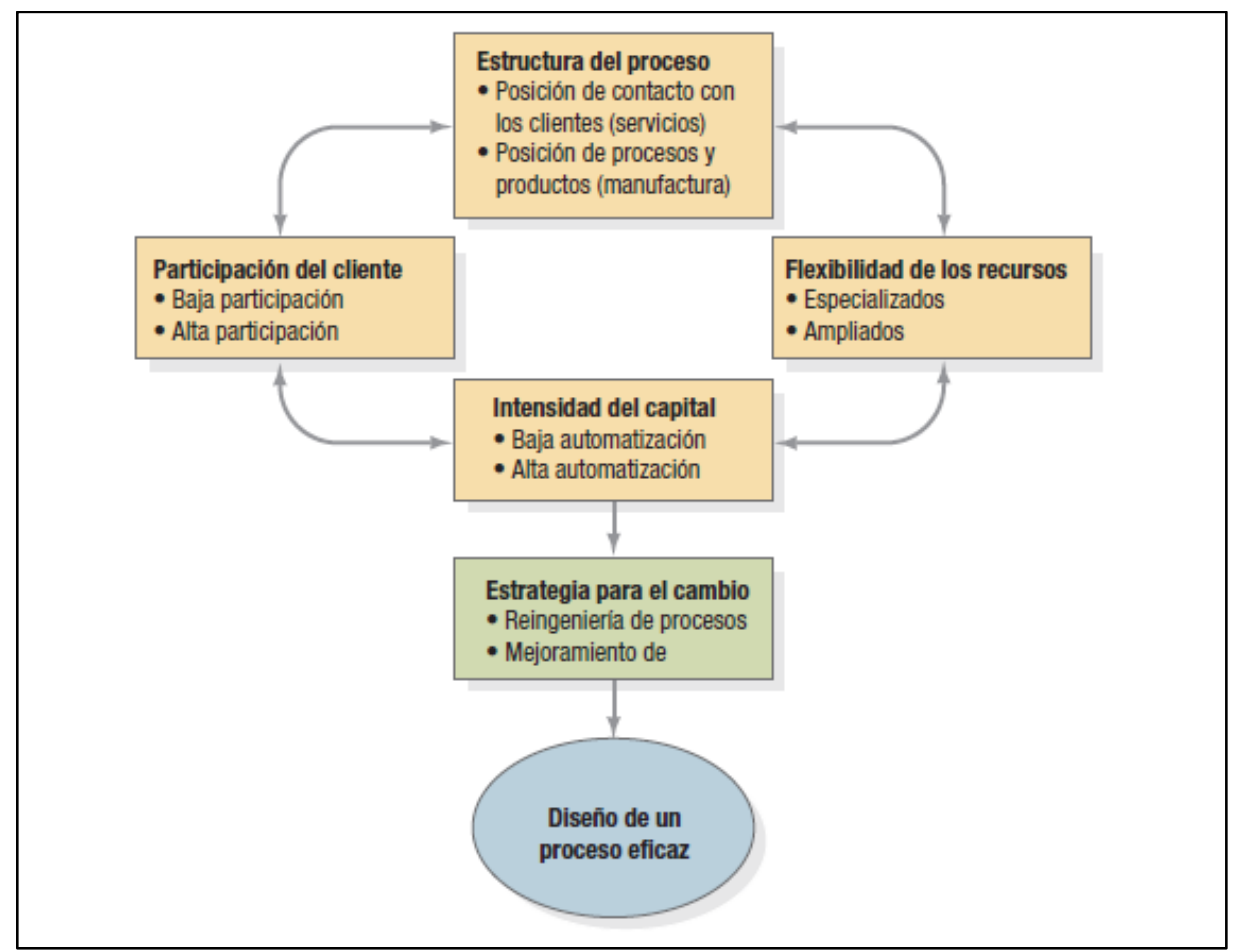

Figura 46. Principales decisiones para procesos eficaces. Tomado de Administración de Operaciones. (p. 122), por L. Krajewski, L. P. Ritzman y M. K. Malhotra (2008), México: Pearson Education. Copyright 2008 


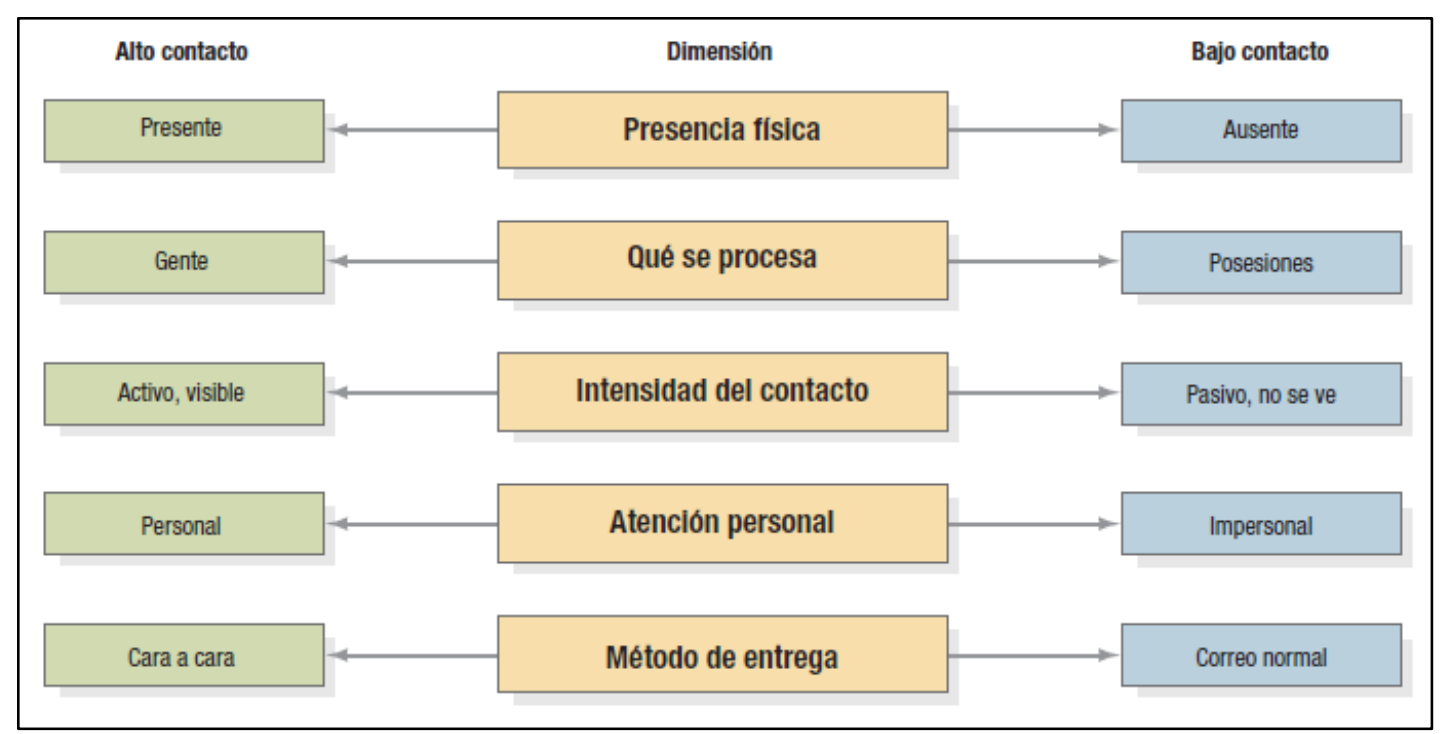

Figura 47. Diferentes dimensiones de contacto con el cliente en los procesos de servicio. Tomado de Administración de Operaciones. (p. 122), por L. Krajewski, L. P. Ritzman y M. K. Malhotra (2008), México: Pearson Education. Copyright 2008

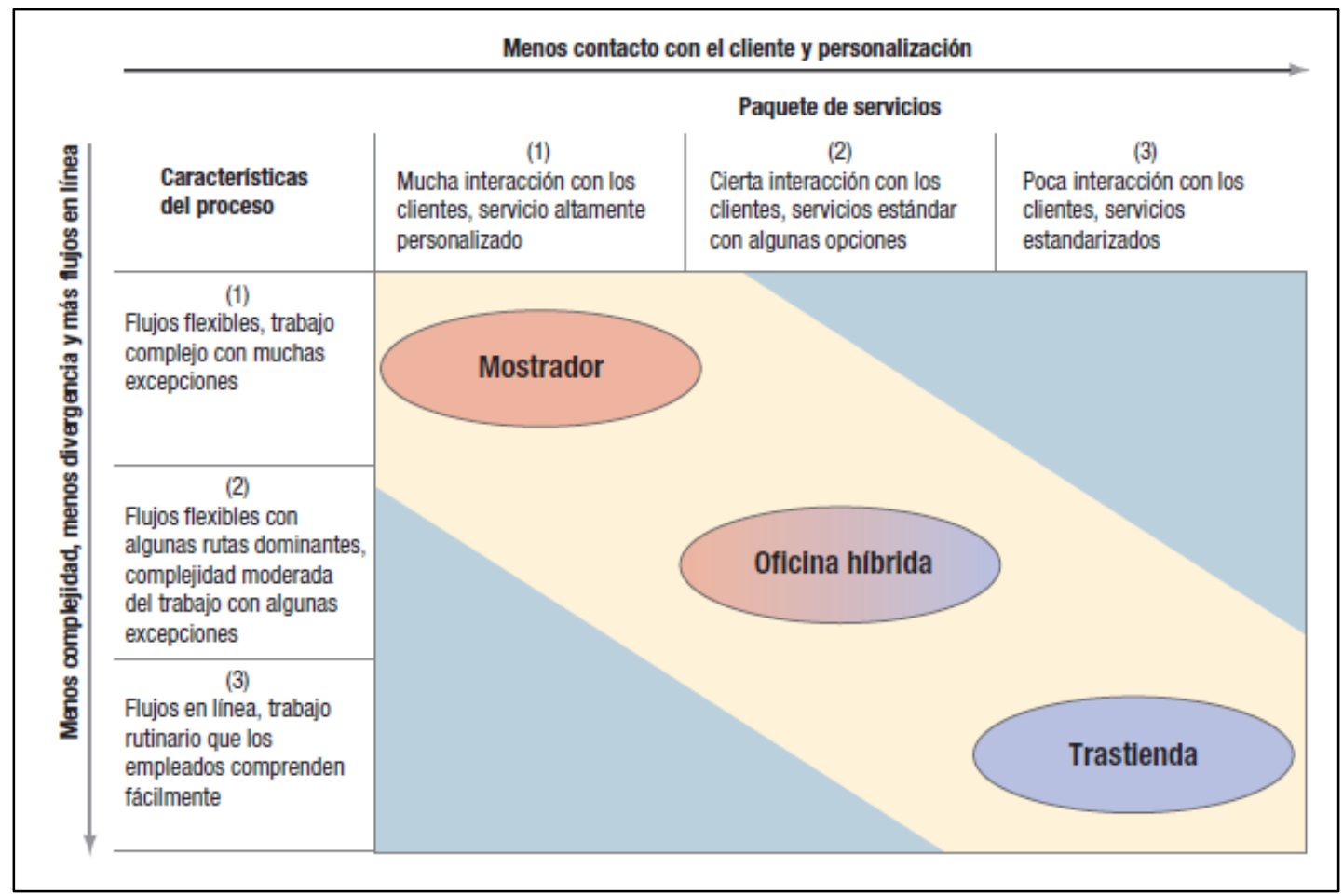

Figura 48. Matriz cliente-contacto para proceso de servicio. Tomado de Administración de Operaciones. (p. 122), por L. Krajewski, L. P. Ritzman y M. K. Malhotra (2008), México: Pearson Education. Copyright 2008 


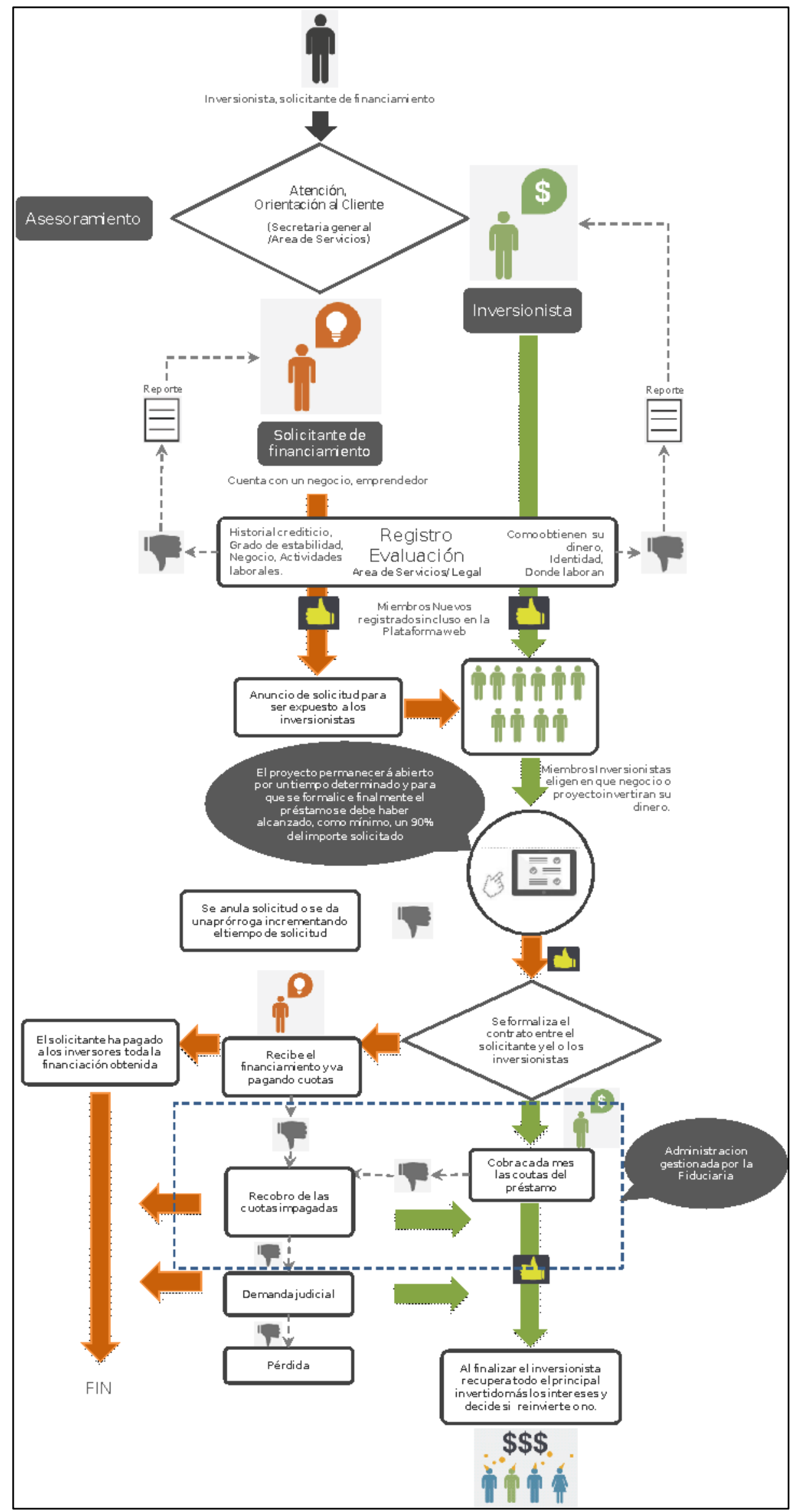

Figura 49. Estructura del proceso realizado por IDeltas 
Según C. Richard, F. Jacobs \& N. J. Aquilano (2009), el uso estratégico de la matriz refiere a:

1- $\quad$ Permitir la integración sistémica de las operaciones y estratégicas de mercado.

2- Definir con exactitud qué combinación de entrega de servicios está proveyendo realmente la empresa.

3- Permitir comparaciones sobre la manera en que otras empresas entregan servicios específicos.

4- Indicar los cambios evolucionarlos o en los ciclos de vida que podrían presentarse a medida que crece la compañía.

El proceso contempla garantías de servicio, siendo incondicional, significativa para el cliente, fácil de entender y comunicar así mismo fácil de invocar

Como se mencionó en el capítulo tres se realizará un proceso de selección y evaluación para validar a los clientes que pueden participar del modelo de negocio propuesto para ello se ejecutarán los siguientes filtros de evaluación:

a. Solicitante de préstamo

- Persona particular

1. Validación de Identidad del solicitante

2. Residente en Arequipa

3. Tipo de actividad con los cuales los genera sus ingresos 


\begin{tabular}{|l|c|c|c|}
\hline Aspectos/Valoracion & 1 & 2 & 3 \\
\hline Edad (años) & $18-24$ & $24-30 ;>55$ & $25-55$ \\
\hline Dependiente (antiguedad laboral) & $<6$ meses & $6-12$ meses & $>12$ meses \\
\hline Dependiente (Ingreso minimo de S/.1500) & $<6$ meses & $6-12$ meses & $>12$ meses \\
\hline Independiente (antiguedad laboral) & $<12$ meses & $1-2$ años & $>2$ años \\
\hline Independiente (Ingreso minimo de S/.1500) & $<12$ meses & $1-2$ años & $>2$ años \\
\hline Experiencia Crediticia & $<6$ meses & $6-18$ meses & $>18$ meses \\
\hline Años de experiencia en negocios & $<6$ meses & $6-18$ meses & $>18$ meses \\
\hline Predisposicion en el pago de deudas, buenos antecedentes & Bajo & Regular & Bueno \\
\hline
\end{tabular}

Figura 50. Filtro aplicado para solicitantes de crédito personas

- Empresa

1. Validación de Identidad del solicitante

2. Residente en Arequipa

3. Tipo de actividad

\begin{tabular}{|l|c|c|c|}
\hline Aspectos/Valoracion & 1 & 2 & 3 \\
\hline Debidamente constituida & Bajo & Regular & Bueno \\
\hline Rentabilidad obtenida en los ultimos años & Bajo & Regular & Bueno \\
\hline Historial Crediticio & Bajo & Regular & Bueno \\
\hline Ratios financieros: \% de endeudamiento & Bajo & Regular & Bueno \\
\hline $\begin{array}{l}\text { Capacidad de la empresa en convertir } \\
\text { sus resultados en efectivos } \\
\text { (Autofinanciacion) }\end{array}$ & Bajo & Regular & Bueno \\
\cline { 2 - 4 } & Bajo & Regular & Bueno \\
\hline
\end{tabular}

Figura 51. Filtro aplicado para solicitantes de crédito, empresas

b. Financiador

- Persona particular

1. Validación de Identidad del solicitante

2. Residente en Arequipa 
3. Edad mayor de 25 años

4. Ingresos superiores a S/. 3,000

5. Tipo de actividad con los cuales los genera sus ingresos

6. Perciben o mantienen cuentas en el sistema financiero tradicional.

- Empresa

1. Validación de Identidad del solicitante

2. Debidamente constituida

3. Rentabilidad obtenida en los últimos años

c. Del proyecto, emprendimiento o idea

Tabla 15

Procedimiento para la publicación del proyecto

Proceso de Gestión para el proyecto, emprendimiento o idea

1. Quien busca acceder de financiamiento (Beneficiario) registra el proyecto en la pagina web o de manera personal en la oficinas de IDeltas.

2. Brindar una descripción con objeticos claros y concretos (con imágenes, información $\mathrm{y}$ de ser posible un video informativo y descriptivo del proyecto).

3. Colocar el monto necesario, cómo se utilizarán los recursos y tiempo de recaudación.

4. Especificar si se brindaran recompensas o beneficios atractivos para quienes apoyen el proyecto.

5. El proyecto será evaluado y pasara por un proceso de asesoramiento, con la finalidad de hacer al proyecto realmente de interés a la colectividad, diferenciado y que ofrezca un valor al cliente.

6. Se debe especificar que tipo de financiamiento se desea: completo o parcial en el caso que no se llegara alcanzar el 100\% del financiamiento requerido, esto esta sujeto para casos en que montos parciales ayuden a completar el proyecto.

7.Las campañas y publicación del proyecto en la pagina web serán hasta por 90 días.

Nota: Este procedimiento se aplica una vez pasado los filtros anteriores 


\subsubsection{Selección del equipamiento}

Tabla 16

Maquinaria y Equipos para servicios de consultoría

\begin{tabular}{|c|c|c|c|c|}
\hline Concepto & Cnt. & $\begin{array}{l}\text { V. Unitario } \\
\text { (US\$) }\end{array}$ & $\begin{array}{l}\text { Valor Total } \\
\text { (US\$) }\end{array}$ & $\begin{array}{c}\text { Valor Total } \\
(\mathrm{S} / .)\end{array}$ \\
\hline $\begin{array}{l}\text { Computador portátil, notebook 14”, } \\
\text { disco duro de } 1 \mathrm{~TB} \text {, procesador } \\
\text { Intel Core i3, 6GB DDR3 }\end{array}$ & 6 & 505.1 & 3,030 & 10,000 \\
\hline $\begin{array}{l}\text { Impresora CANON IB } 4010 \text {, } \\
\text { inyección de tinta, conectividad } \\
\text { USB 2.0, WI-FI }\end{array}$ & 4 & 67.3 & 404 & 1,332 \\
\hline Periféricos, & - & - & 263 & 867 \\
\hline Mouse Logitech, USB, 2 botones & 6 & 5.1 & & \\
\hline $\begin{array}{l}\text { Cable de bloqueo Xtech XTA } 110 \\
\text { tipo "notebook" }\end{array}$ & 6 & 5.7 & & \\
\hline $\begin{array}{l}\text { Print Server, TP-LINK, TL- } \\
\text { WPS510U, wireless }\end{array}$ & 1 & 87.6 & & \\
\hline $\begin{array}{l}\text { Supresor de picos, CDP, SS- } 6,6 \\
\text { tomas de corriente }\end{array}$ & 6 & 3.6 & & \\
\hline $\begin{array}{l}\text { Tinta CANON, PGI- } 2100 \text { cian, } \\
\text { magenta, amarillo, negro }\end{array}$ & 4 & 22.2 & & \\
\hline $\begin{array}{l}\text { Discos Externos, Toshiba Canvio } \\
\text { Connect II, } 1 \text { TB }\end{array}$ & 7 & 64.4 & 451 & 1,488 \\
\hline $\begin{array}{l}\text { Router Inalámbrico, mikrotik, } 5 \\
\text { puertos, 1PoE, Capacidad antena } \\
\text { WI-FI }\end{array}$ & 2 & 74.6 & 149 & 493 \\
\hline $\begin{array}{l}\text { Teléfono analógico, con posibilidad } \\
\text { de recepción de adaptador de } \\
\text { teléfono digital a analógico, } \\
\text { Intelbras Pleno }\end{array}$ & 7 & 18.3 & 128 & 424 \\
\hline $\begin{array}{l}\text { Equipos de Comunicación Móvil, } \\
\text { LG Magna, Android V5.0, 2G } \\
\text { GSM }\end{array}$ & 7 & 127.1 & 890 & 2,937 \\
\hline Memorias USB, Toshiba 16 GB 2.0 & 8 & 6.2 & 50 & 165 \\
\hline Escritorios & - & - & 485 & 1,600 \\
\hline $\begin{array}{l}\text { Escritorio de Trabajo, Cristal } \\
\text { Asenti }\end{array}$ & 3 & 64.3 & & \\
\hline $\begin{array}{l}\text { Escritorio Ejecutivo, Function Café } \\
\text { Tvilum }\end{array}$ & 3 & 97.3 & & \\
\hline
\end{tabular}




\begin{tabular}{lcccc}
\hline Concepto & Cnt. & $\begin{array}{c}\text { V. Unitario } \\
\text { (US\$) }\end{array}$ & $\begin{array}{c}\text { Valor Total } \\
\text { (US\$) }\end{array}$ & $\begin{array}{c}\text { Valor Total } \\
\text { (S/.) }\end{array}$ \\
\hline Mesa de Juntas & 1 & 836.3 & 836 & 2,760 \\
Archivadores y Sillas & - & - & 388 & 1,280 \\
Archivador, 2 cajones Moduart & 3 & 68.8 & & \\
Silla Operativa, Negro Karson & 6 & 30.3 & & 300 \\
Mesa de Centro Para Recepción & 1 & 90.9 & 91 & 2,760 \\
Mesa de Reuniones, Tramontina & 1 & 836.3 & 836 & 2,757 \\
2.16m & - & - & 836 & \\
Silla de Reuniones y Sofás & 22 & 18.2 & & \\
Silla de Reuniones, fijo Iso negro & 3 & 72.7 & & \\
Asenti & 3 & 72.7 & & \\
Sofá Bipersonal, cama Turin & - & - & 309 & 30,343 \\
Sofá Personal, cama Turin & 7 & 6.9 & 49 & \\
Archivadores, papelería & & & 9,195 & \\
Basureros con pedal 3L Ecole & & & & \\
$\quad$ Total & & & & \\
\hline
\end{tabular}

Nota. Valores obtenidos de cotizaciones hechas en la ciudad de Arequipa, en dólares.

Tabla 17

Maquinaria y Equipos para servicios de consultoría (Adecuaciones de oficina)

\begin{tabular}{|c|c|c|c|c|}
\hline Concepto & Cnt. & $\begin{array}{l}\text { V. Unitario } \\
(\$)\end{array}$ & $\begin{array}{c}\text { Valor } \\
\text { Total }(\$)\end{array}$ & $\begin{array}{c}\text { Valor } \\
\text { Total (S/.) }\end{array}$ \\
\hline $\begin{array}{l}\text { Pisos y Alfombras (incluye material, } \\
\text { calibrado, mano de obra, cepillado y } \\
\text { pulido, zócalos y rodos acabado con d.d. } \\
\text { tekno } 4 \text { capas, shihuahuaco) }\end{array}$ & $103 \mathrm{~m} 2$ & 25.2 & 2,600 & 8,580 \\
\hline $\begin{array}{l}\text { Pinturas (incluye mano de obra, pintura } \\
\text { alta calidad y empastado) }\end{array}$ & $382 \mathrm{~m} 2$ & 1.8 & 695 & 2,294 \\
\hline Accesorios & - & - & 212 & 700 \\
\hline Total & & & 3,507 & 11,573 \\
\hline
\end{tabular}

Nota. Valores obtenidos de cotizaciones hechas en la ciudad de Arequipa 
Tabla 18

Maquinaria y Equipos para servicios de consultoría

\begin{tabular}{|c|c|c|}
\hline Detalle & $\mathrm{S} /$. & US\$ \\
\hline Alquiler del local más garantía & 4,000 & 1,212 \\
\hline Apertura de cuenta de Fideicomiso & 1,000 & 303 \\
\hline Licencias de SW (ERP) & 2,400 & 727 \\
\hline Transportes & 460 & 139 \\
\hline Gastos de luz, agua, teléfono, internet & 700 & 212 \\
\hline Materiales y Utiles de Oficina & 350 & 106 \\
\hline Seguros & 300 & 91 \\
\hline Mantenimiento & 150 & 45 \\
\hline Sistema de Vigilancia & 175 & 53 \\
\hline Gastos laborales & 1,000 & 303 \\
\hline Capacitación & 500 & 152 \\
\hline Marketing y publicidad & 3,900 & 1,182 \\
\hline Lanzamiento de proyecto & 3,000 & 909 \\
\hline Limpieza y Ornato & 200 & 61 \\
\hline Mantenimiento portal web & 700 & 212 \\
\hline TOTAL & 18,835 & 5,708 \\
\hline
\end{tabular}

Nota. Valores obtenidos de cotizaciones hechas en la ciudad de Arequipa

\subsubsection{Lay out}

La distribución de planta se va hacer de tal forma que permita realizar operaciones, de manera económica y en condiciones óptimas para brindar los servicios, considerando la distribución actual. 


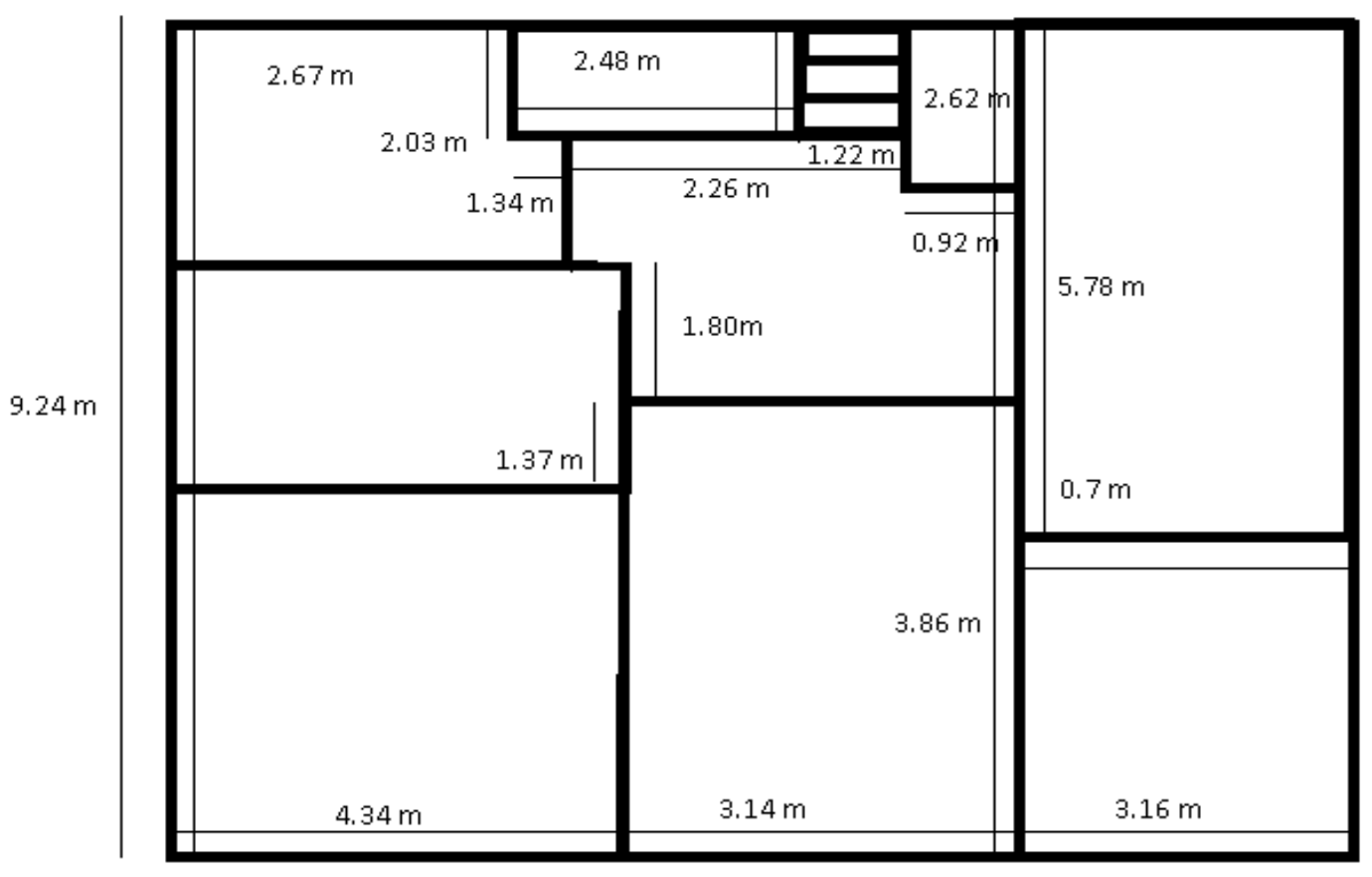

Figura 52. Plano de distribución de la Empresa.

\subsubsection{Distribución de equipos y maquinarias}

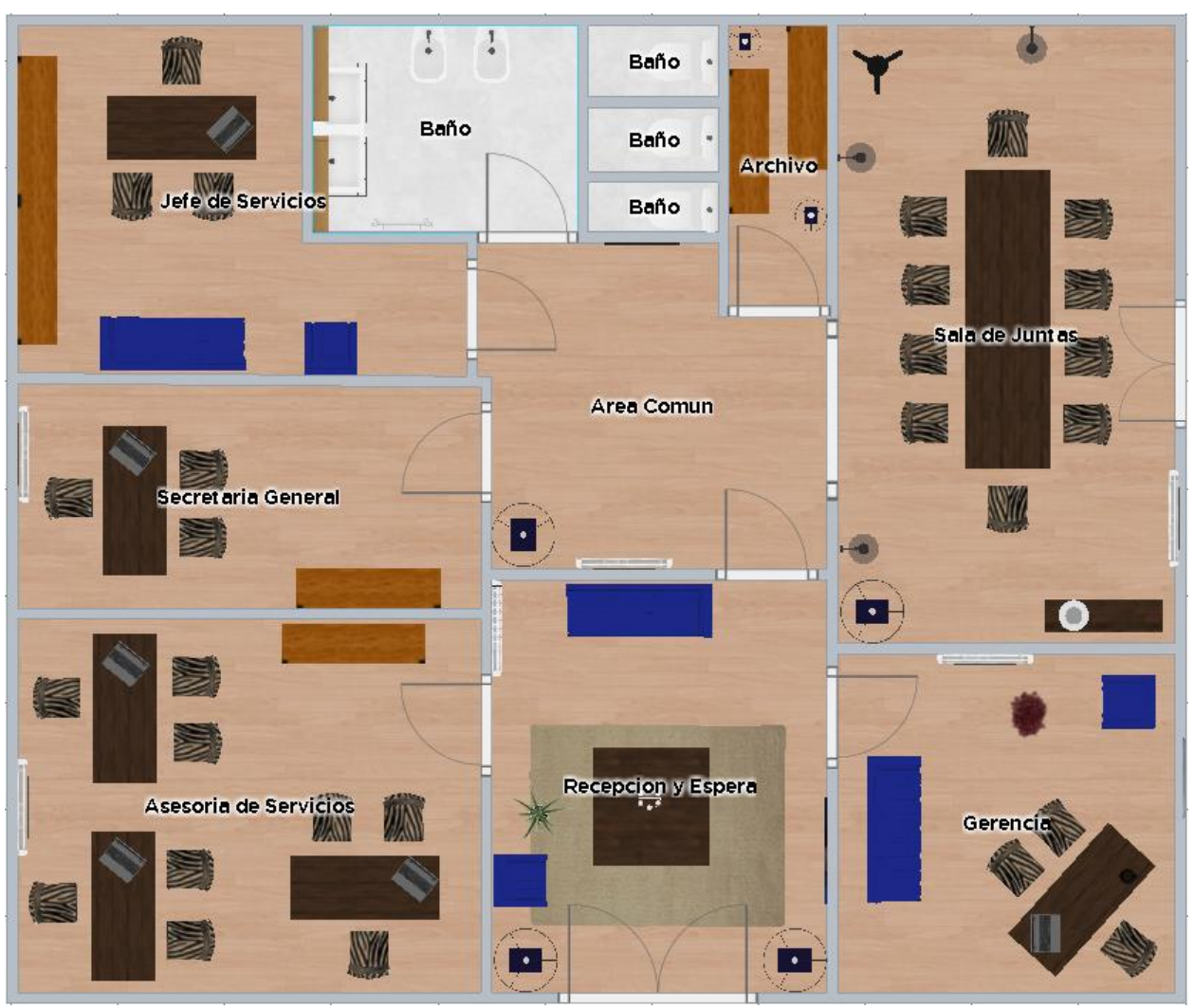

Figura 53. Distribución de las áreas. 


\subsection{Determinación del Tamaño}

Para poder iniciar operaciones, la empresa dispone de un terreno alquilado de 102.01 m2, ubicado en Yanahuara, estratégicamente ubicado entre las avenidas metropolitana y Víctor Andrés Belaunde. El tamaño y capacidad de este proyecto en particular, se debe a dos aspectos principales: en primer punto, la porción de demanda insatisfecha que se pretende cubrir con el proyecto, y a la dimensión del área total con la que se cuenta como terreno disponible para la instalación de la empresa, el cual tendrá una capacidad promedio para 36 personas, hay que según la norma de capacidad máxima de las instalaciones INDECI, se considera un espacio de $2.8 \mathrm{~m} 2$ por persona, para este giro de negocio.

Por otro lado, es necesario señalar que el local en cuestión se encuentra en buen estado, sin embargo, si la empresa desea realizar algunas modificaciones, correrá por cuenta de ellas, salvo que se pongan de acuerdo con el propietario del terreno previamente.

\section{Tabla 19}

Distribución Empresa

\begin{tabular}{lc}
\hline Área Administrativa & Área \\
\hline Gerencia & $9.98 \mathrm{~m} 2$ \\
Jefatura de Servicios y legal & $10.56 \mathrm{~m} 2$ \\
Secretaria General & $9.11 \mathrm{~m} 2$ \\
Atención al Público y Recepción & $12.12 \mathrm{~m} 2$ \\
& \\
Total & $41.77 \mathrm{~m} 2$ \\
\hline
\end{tabular}


Tabla 20

Distribución Empresa

\begin{tabular}{lc}
\hline Área Operativa & Área \\
\hline Asesoría de Servicios & $15.15 \mathrm{~m} 2$ \\
Sala de Juntas & $18.26 \mathrm{~m} 2$ \\
Área Común & $9.05 \mathrm{~m} 2$ \\
Archivo & $2.41 \mathrm{~m} 2$ \\
SS HH & $15.37 \mathrm{~m} 2$ \\
$\quad$ TOTAL DEL ÁREA & $102.01 \mathrm{~m} 2$ \\
\hline
\end{tabular}

\subsubsection{Proyección de crecimiento}

El proyecto tiene como mercado objetivo a 7100 clientes, de los cuales se considera captar como clientes propiamente dichos a 250 personas el primer año (ver sección 4.3). La proyección de crecimiento se está considerando según la variación del PBI de los últimos 11 años que en promedio es 5.83 (ver figura 43) y el crecimiento del mercado objetivo.

Tabla 21

Crecimiento según el Mercado Objetivo

\begin{tabular}{rrrrr}
\hline & 2020 & 2021 & 2022 & 2023 \\
\hline $\begin{array}{r}\text { \% de crecimiento según el } \\
\text { mercado objetivo }\end{array}$ & 6.93 & 6.92 & 6.91 & 6.90 \\
\hline
\end{tabular}

La meta propuesta de atención por asesor de servicios es de 5 clientes diarios.

Finalmente, el área adquirida en alquiler, cuenta con dos plantas superiores con características similares a las de la primera planta, esto podría permitir una mayor ampliación de operaciones.

Se considera que la ubicación de las instalaciones adquiridas es estratégica así como en capacidad de expansión. 


\subsubsection{Recursos}

Según Sapag (2011), se requiere considerar un balance de equipos, como primera inversión el calcular los activos físicos necesarios a fin de asegurar el correcto funcionamiento del proyecto, esto está detallado en el punto 5.1.2 bajo el título maquinaria y equipos para servicios de consultoría, incluyendo las adecuaciones. En cuanto al balance de obras físicas, se puede ver el detalle propuesto en el punto 5.2, en cuanto al balance de personal se puede apreciar un detalle en el capítulo cuatro, finalmente, el balance de insumos corresponde a la capacidad de generar nuevos intangibles en base al conocimiento y experiencia en modelos legales que puedan sustentar y dinamizar una economía de intercambio entre prestamistas y prestatarios, sin la intervención de intermediarios muy grandes.

Los recursos mencionados, cubren actividades primarias que se dividen en: logística interna, operaciones (producción), logística externa, ventas y marketing, servicios posventa (mantenimiento). Para que estas actividades puedan ser apoyadas por: dirección de administración y recursos humanos (secretaria general), atención al cliente especializada y abastecimientos (jefatura de servicios).

\subsubsection{Tecnología}

La tecnología a utilizar se encuentra tercerizada por un modelo de SaaS (Software como servicio), el cual corresponde a un completo sistema informático ERP (Microsoft Dynamics NAV 2016), el cual trabaja en la nube, brindando de este modo operatividad a las operaciones internas del presente proyecto. Para el tema de publicidad se hará uso de un portal web y un sistema de emailing, el cual se detallará en el plan de marketing.

\subsubsection{Flexibilidad}

El modelo de negocio, junto con la capacidad instalada considerada, brinda la posibilidad de ajustarse a un crecimiento moderado. Del mismo modo se tiene considerada la 
tercerización de las necesidades informáticas de la empresa, los recursos humanos, toda oficina contable así como el departamento legal.

\subsubsection{Selección del tamaño ideal}

El tamaño actual acorde al estudio de mercado, es óptimo, dado que se tiene una capacidad instalada capaz de afrontar la demanda planteada y tiene posibilidad de expandir sus operaciones considerando la misma capacidad instalada y por la ubicación estratégica del local adquirido, se tiene la posibilidad de utilizar el segundo y tercer piso de la propiedad, siendo este el tamaño ideal considerado.

\subsection{Estudio de localización}

Según Sapag (2011) la ubicación más adecuada será la que posibilite maximizar el logro del objetivo definido para el proyecto, mayor cantidad posible de población o logro de alta rentabilidad. (Baca Urbina 2010) Nos habla sobre lograr la mayor tasa de rentabilidad (criterio privado) o sobre obtener el costo unitario mínimo (criterio social).

Se verá entonces la ubicación adecuada del proyecto, considerando obtener una máxima producción, maximización de beneficios y reducción de costos. Se tomará el criterio de (Sapag 2011) en tal sentido, se considera dos factores a considerar.

- Macro localización - El autor sugiere elegir la región o zona. Por tal razón se consideró la provincia de Arequipa, ciudad de Arequipa, dado que cuenta con medios de transporte adecuados, disponibilidad de mano de obra técnica, del mismo modo se encuentra cerca al mercado meta, dado que el proyecto se basa en brindar servicios que brindan oportunidades y/o alternativas de inversión y del mismo modo oportunidades y/o alternativas de financiación de emprendimientos. Acorde al estudio de mercado y a datos secundarios como los reportados por la "inclusión financiera" entre otros, demuestran que existe una gran demanda insatisfecha, entre prestamistas e inversores. 


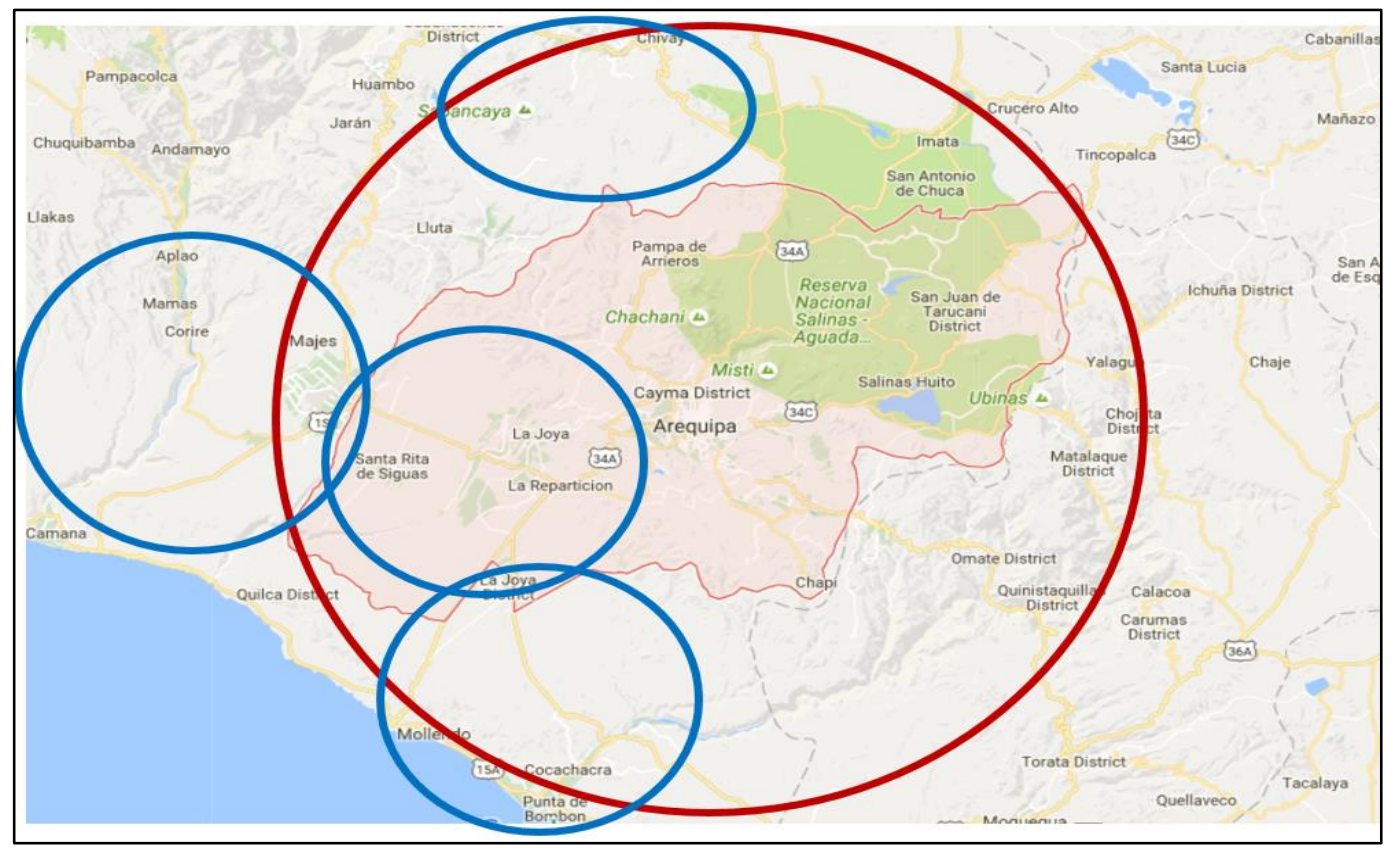

Figura 54. Propuesta a nivel Arequipa Región. Adaptado de Google Maps, 2016. Recuperado de https://www.google.com.pe/maps

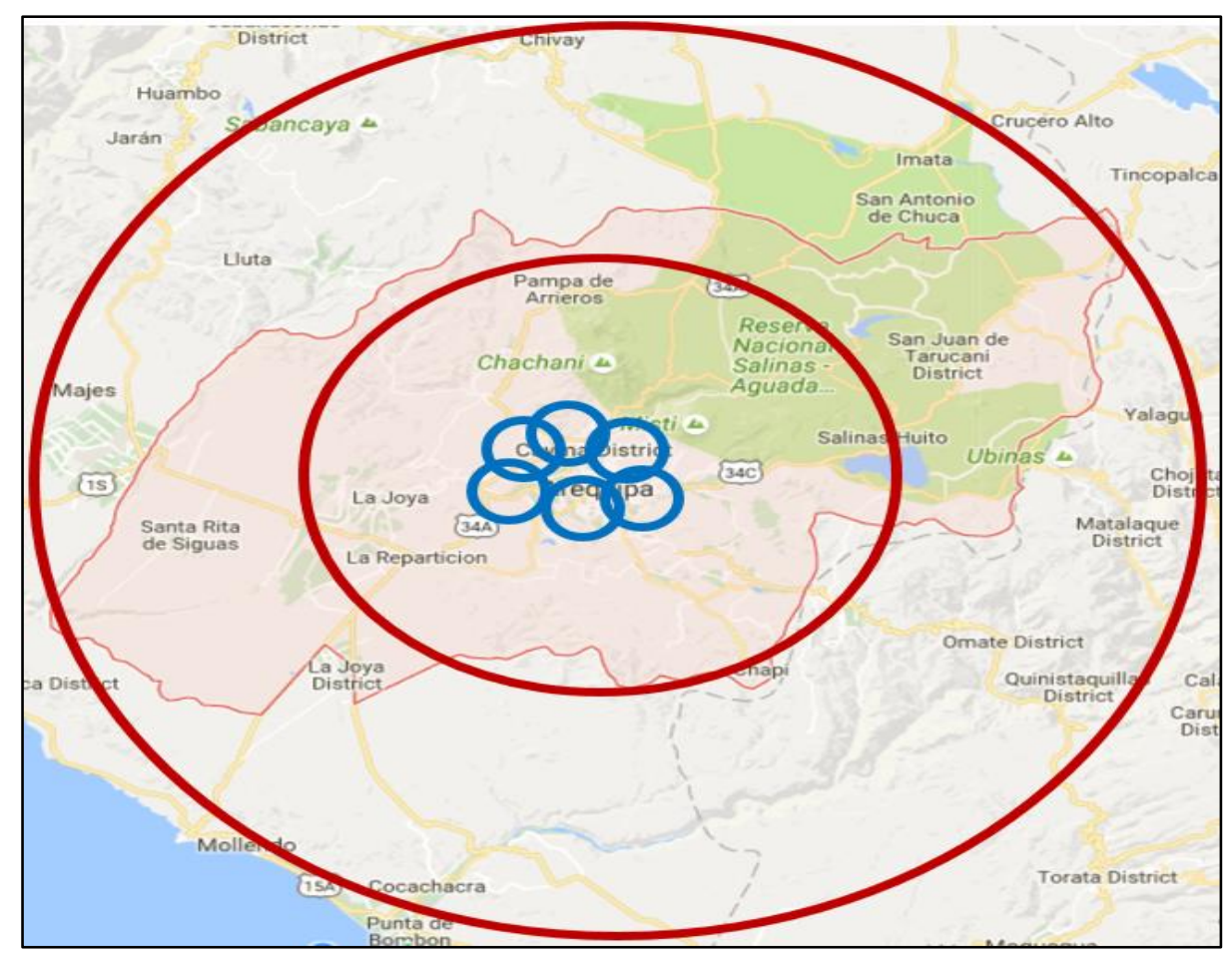

Figura 55. Propuesta a nivel Arequipa Provincia. Adaptado de Google Maps, 2016. Recuperado de https://www.google.com.pe/maps 


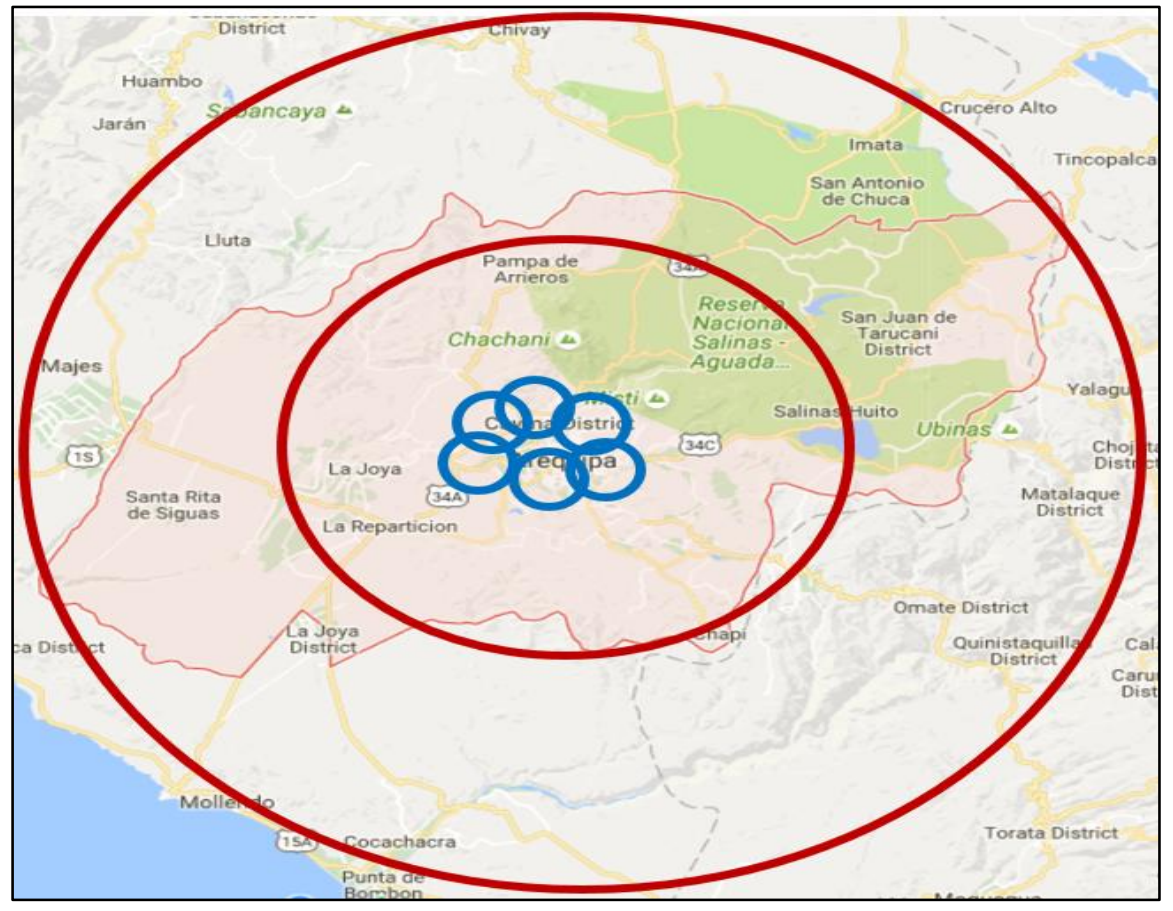

Figura 56. Propuesta a nivel Arequipa Ciudad. Adaptado de Google Maps, 2016. Recuperado de https://www.google.com.pe/maps

- Micro localización - La oficina central del proyecto deberá estar ubicada en una zona que se encuentre cerca a los potenciales consumidores de los servicios que se brinda, la ubicación considerada se encuentra equidistante a las áreas de influencia de seleccionadas (Selva Alegre, Cayma, Cerro Colorado, Jacobo Hunter, Mariano Melgar, Miraflores, Sachaca, Yanahuara, José Luis Bustamante y Rivero). 


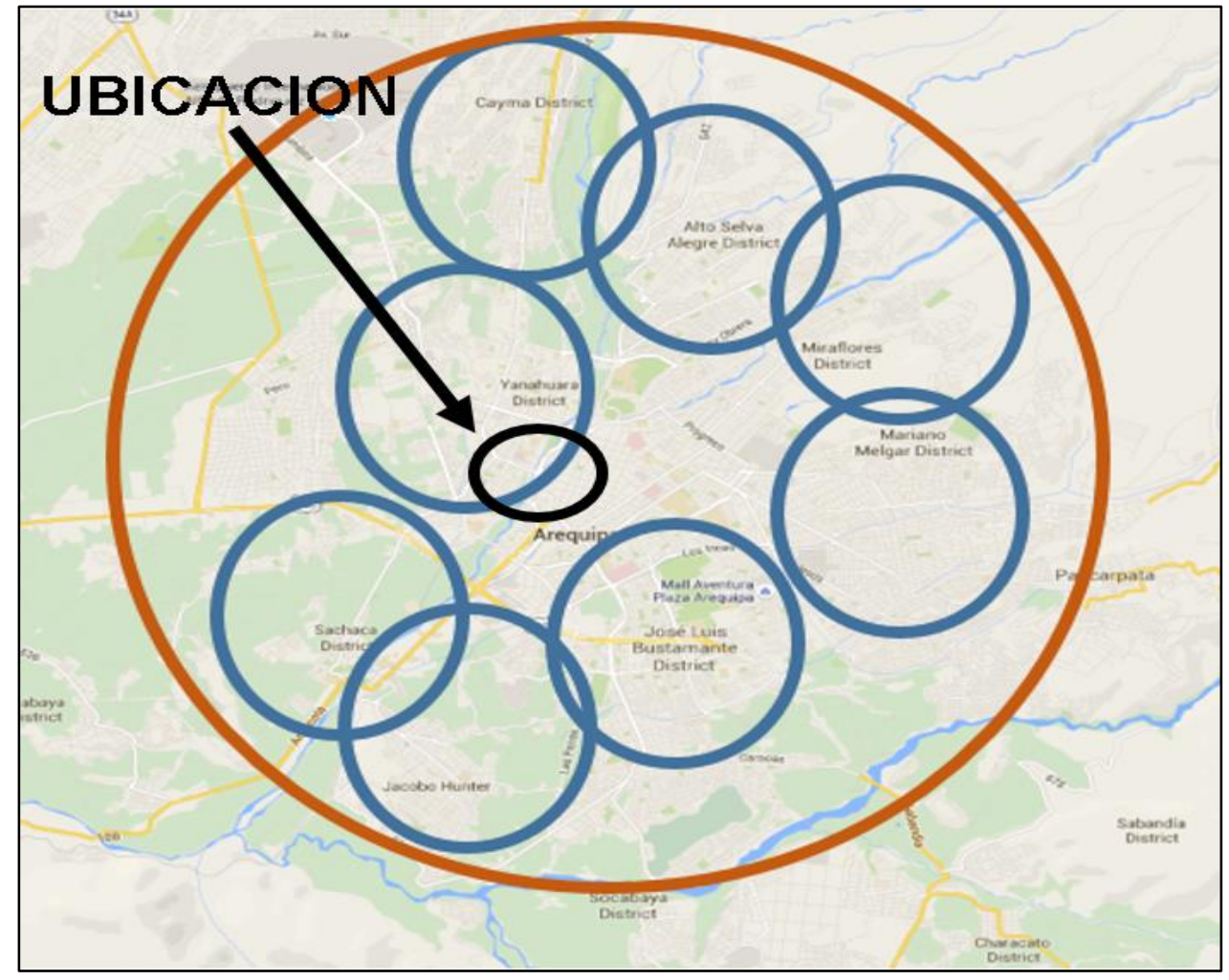

Figura 57. Microlocalización. Adaptado de Google Maps, 2016. Recuperado de https://www.google.com.pe/maps

\subsubsection{Definición de factores localizaciones}

Ahora se toma el método cualitativo por puntos, resaltando ventajas y desventajas (Baca Urbina 2010), el método consiste en asignar una serie de factores que se consideran relevantes para la localización. Este método permite ponderar factores de preferencia para el investigador al tomar la decisión. 


\begin{tabular}{|l|l|l|l|l|l|}
\hline & \multirow{2}{*}{$\begin{array}{l}\text { Factor } \\
\text { Relevante }\end{array}$} & Peso & \multicolumn{2}{l|}{ Yanahuara } \\
\cline { 3 - 6 } & Asignado & $\begin{array}{l}\text { Calificac } \\
\text { ión }\end{array}$ & $\begin{array}{l}\text { Calificación } \\
\text { Ponderada }\end{array}$ & Calificación & $\begin{array}{l}\text { Calificación } \\
\text { Ponderada }\end{array}$ \\
\hline $\begin{array}{l}\text { M.P. } \\
\text { Disponible }\end{array}$ & 0.33 & 8 & 2.64 & 7 & 2.31 \\
\hline $\begin{array}{l}\text { M.O } \\
\text { Disponible }\end{array}$ & 0.25 & 7 & 1.75 & 6 & 1.5 \\
\hline $\begin{array}{l}\text { Costo de los } \\
\text { Insumos }\end{array}$ & 0.20 & 5 & 1 & 7 & 1.4 \\
\hline $\begin{array}{l}\text { Infraestructu } \\
\text { ra }\end{array}$ & 0.07 & 8 & 0.56 & 6 & 0.42 \\
\hline $\begin{array}{l}\text { Cercanía al } \\
\text { Mercado }\end{array}$ & 0.15 & 9 & 1.35 & 7 & 1.05 \\
\hline TOTAL & 1.00 & & 7.3 & & 6.68 \\
\hline
\end{tabular}

Figura 58. Evaluación de factores para la localización

Como resultado del método aplicado, se pudo obtener 7.3 para la ubicación de las oficinas centrales en el distrito de Yanahuara y 6.68 para la ubicación de las oficinas en Cono Norte (perteneciente a la jurisdicción de Cerro Colorado). En este punto se considera óptimo ubicar las oficinas centrales en el distrito de Yanahuara, esto porque se encuentra rodeada por la avenida Víctor Andrés Belaunde así como la avenida Metropolitana y la troncal Misti (vía de alta afluencia hacia el parque industrial de Río Seco) ; importante también es la capacidad de estacionamiento de automóviles en este punto y finalmente otro importante beneficio representa el fácil acceso y buenas vías de acceso con las que cuenta las oficinas en el distrito de Yanahuara, ubicándose de manera equidistante a las nueve áreas de influencia propuestas.

\subsubsection{Consideraciones legales}

a) Búsqueda y reserva del nombre de la empresa en Registros Públicos - Es necesario acudirá la Superintendencia Nacional de los Registros Públicos 
(SUNARP), y verificar que no exista en el mercado un nombre o razón social igual al que deseamos para la empresa, la búsqueda, por no tener un código registral tiene un costo de S/. 4.00 nuevos soles. Se debe asegurar también, de que no haya alguno que se parezca o suene igual al que queremos utilizar, así, cada hoja de información con el nombre de las empresas tiene un costo de S/. 6.00 nuevos soles. Una vez realizada la búsqueda y está confirmado que no existen nombres iguales o similares, pasamos a reservar el nombre, para que otra empresa no pueda inscribirse con el mismo, siendo efectiva la reserva por un plazo de 30 días.

b) Elaboración de la minuta - La minuta es un documento en el cual los miembros de la sociedad manifiestan su voluntad de constituir la empresa, y en donde se señalan todos los acuerdos respectivos. La minuta consta del pacto social y los estatutos, además de los insertos que se puedan adjuntar a ésta, el costo de realizar una minuta junto con el registro de Mype tiene un costo de S/. 500.00 nuevos soles. Los elementos fundamentales de una minuta son: a) Los generales de ley de cada socio (Datos personales, documentos de identidad); b) El giro de la sociedad; c) El tipo de empresa o sociedad (SAC); d) El tiempo de duración de la sociedad (Plazo fijo o indeterminado); e) La fecha en la que se va a dar inicio a las actividades comerciales; f) El lugar en donde va a funcionar la sociedad (Domicilio comercial); g) La denominación o razón social de la sociedad; h) El lugar en donde van a funcionar las agencias o sucursales; i) La persona que va a administrar o representar la sociedad; j) Los aportes de cada socio: Dinero y sus medios sustitutos; k) Otros acuerdos que establezcan los socios. 
c) Elevar minuta a escritura pública (Sólo Persona Jurídica) - Una vez redactada la minuta, se lleva a una notaría para que un notario público la revise y la eleve a escritura pública. Por lo general, los documentos a llevar junto con la minuta son: a) La constancia o el comprobante de depósito del capital aportado en una cuenta bancaria a nombre de la empresa; b) Un inventario detallado y valorizado de los bienes no dinerarios; c) Una vez elevada la minuta, ésta no se puede cambiar. Al final, se genera la Escritura Pública, Testimonio de Sociedad o Constitución Social, que es el documento que da fe de que la minuta es legal, la cual debe estar firmada y sellada por el notario.

d) Inscribir Escritura Pública en Registros Públicos - Una vez que se ha obtenido la Escritura Pública, se lleva a la Oficina de Registros Públicos, en donde se realizarán los trámites necesarios para inscribir la empresa. La Persona Jurídica existe a partir de su inscripción en los Registros Públicos.

e) Obtención del número de RUC - El Registro Único de Contribuyentes (RUC), es lo que identifica a una persona o empresa ante la Superintendencia Nacional de Administración Tributaria (SUNAT) para el pago de los impuestos. Toda Persona Natural o Jurídica está obligada a inscribirse en el RUC, de lo contrario será sancionada de acuerdo con el Código Tributario, igual que los inscritos en el RUC que no presenten la declaración. Para obtenerlo, se debe acudir a la SUNAT, llenar un formulario de justificación y esperar notificación.

f) Elegir régimen tributario - En SUNAT, también se debe determinar a qué régimen tributario acogerse para el pago de los impuestos, ya sea al Régimen Único Simplificado (RUS), al Régimen Especial de Impuesto a la Renta (RER), o al Régimen General. Una vez que se cuenta con número de RUC y se ha elegido un 
régimen tributario, se puede imprimir los comprobantes de pago (boleta y/o factura) a utilizar.

g) Comprar y legalizar libros contables - En este paso se compra los libros contables necesarios, dependiendo del régimen tributario acogido y, posteriormente, son llevamos a una notaría para que sean legalizados por un notario público.

h) Licencia Municipal de Funcionamiento - Es la autorización que otorga la municipalidad para el desarrollo de actividades económicas, ya sea como persona natural o jurídica. Esta licencia es importante, porque permitirá la realización de actividades legalmente permitidas, conforme a la planificación urbana, bajo condiciones de seguridad y evitará multas o el cierre del establecimiento. Permite también acreditar la formalidad del negocio ante entidades públicas y/o privadas, y garantiza el libre desarrollo de la actividad económica autorizada por la Municipalidad. Por lo general, los documentos que se deben presentar son: a) Una fotocopia del RUC; b) Certificado de Zonificación (Zona industrial, comercial o residencial); c) Un croquis de la ubicación de la empresa; d) Una copia del contrato de alquiler o del título de propiedad del local; e) Una copia de la Escritura Pública; f) El recibo de pago por derecho de licencia; g) El formulario de solicitud.

i) Certificado de Defensa Civil - En el caso de que el área del establecimiento sea menor a 500 metros cuadrados (como en el presente caso), se solicita el documento en la oficina de Defensa Civil de la Municipalidad de Chiclayo. Una vez solicitado, hay 4 días hábiles para que la Municipalidad designe a las personas que harán la inspección del local, quienes tienen 7 días para hacer la evaluación. Los inspectores señalarán qué cosas se deben mejorar o cambiar en el local, y si 
este es apto para funcionar como negocio y recibir al público. Para recibir este certificado es necesario: a) Tener los planos del local, hechos por un arquitecto; b) Se tendrá que capacitar a todo el personal en primeros auxilios y en acciones para los casos de incendios; c) Se debe establecer y señalizar las salidas de emergencia en caso de un siniestro dentro del local.

j) Permisos y Limitaciones - Adquirir el Libro de Actas y elaborar el acta de Constitución, la minuta y el estatuto. Luego se hace la búsqueda negativa de nombre en la SUNARP (Registros Públicos), se hace la reserva del mismo; con esto se dirige al notario y se realiza la escritura pública. Con una copia literal de esta escritura, en la SUNAT se saca el RUC (Registro Único de Contribuyente), luego ir al SATCH, para tramitar la licencia de funcionamiento, conjuntamente con el certificado de Defensa Civil y queda constituida la empresa.

k) Patentar la marca en INDECOPI - La marca es la única manera que tiene el empresario de crear una imagen, y un estilo para sus productos o servicios, lo cual es fundamental para conseguir una posición en el mercado. La marca es importante, porque brinda la facilidad de publicitar un producto o servicio y hacer que los consumidores los conozcan. Es así que el registro es la única manera de proteger la marca creada, frente a las posibles copias de los demás empresarios que quieran aprovechar su prestigio. Así, el registro convierte al titular en el dueño de la marca, siendo el único autorizado para utilizarla por los siguientes diez años, por lo que el registro de una marca, es la única forma de cuidar sus derechos sobre ellas. La búsqueda de antecedentes en el sistema tiene un costo de S/. 30.00 Nuevos Soles, este sistema mostrará al usuario hasta 200 marcas como máximo por consulta, siendo las visualizadas aquellas que guarden mayor similitud fonética con la que es objeto de búsqueda. Si se comprueba que no existe algún 
nombre similar al que se desea patentar, se realiza un pago de S/. 550.00 Nuevos Soles para hacer los trámites y sea posible publicarlo en el Diario El Peruano.

\subsubsection{Identificación del marco legal}

El presente proyecto se encuentra localizado en el entorno servicios, específicamente “Actividades de Asesoramiento Empresarial" con CIIU: 74145 y tiene por finalidad brindar servicios de asesoría empresarial en materia de financiamiento e inversión, ambos con contratos amparados el código civil peruano. Este tipo de negociación respaldada en un contrato podría tener garantías mobiliarias así como inmobiliarias, amparado por la ley de garantía mobiliaria Nro.28677, esto puede darse con o sin desposesión del bien mueble, siendo sobre uno o varios bienes muebles específicos, sean presentes o futuros (Ley de Garantías Mobiliarias). Existe un paquete de disposiciones generales en el código civil que va desde el artículo Nro. 1351 (Noción de contrato) hasta el artículo Nro. 1528 (Nulidad del pacto de liberación o limitación del saneamiento), donde se encuentra el respaldo legal de los contratos a realizarse, el detalle se encuetra en el "Libro VII - Fuentes De Las Obligaciones Sección Primera - Contratos en general", donde encontramos:

TÍTULO I - Disposiciones generales,

TÍTULO II - El consentimiento,

TÍTULO III - Objeto del contrato,

TÍTULO IV - Forma del contrato,

TÍTULO V - Contratos preparatorios,

TÍTULO VI - Contrato con prestaciones recíprocas,

TÍTULO VII - Cesión de posición contractual,

TÍTULO VIII - Excesiva onerosidad de la prestación,

TÍTULO IX - Lesión,

TÍTULO X - Contrato en favor de tercero, 
TÍTULO XI - Promesa de la obligación o del hecho de un tercero,

TÍTULO XII - Contrato por persona a nombrar,

TÍTULO XIII - Arras confirmatorias,

TÍTULO XIV - Arras de retractación,

TÍTULO XV - Obligaciones de saneamiento

\subsubsection{Ordenamiento de la localización óptima}

La localización óptima (ver gráfico del punto 5.3 de esta misma sección) está acorde a una ubicación geográfica estratégica, pues se encuentra rodeada de las áreas de influencia principal planteadas como meta.

\subsection{Determinación de la localización}

La decisión final la encontramos entre Arequipa Urbana y Arequipa Periurbana

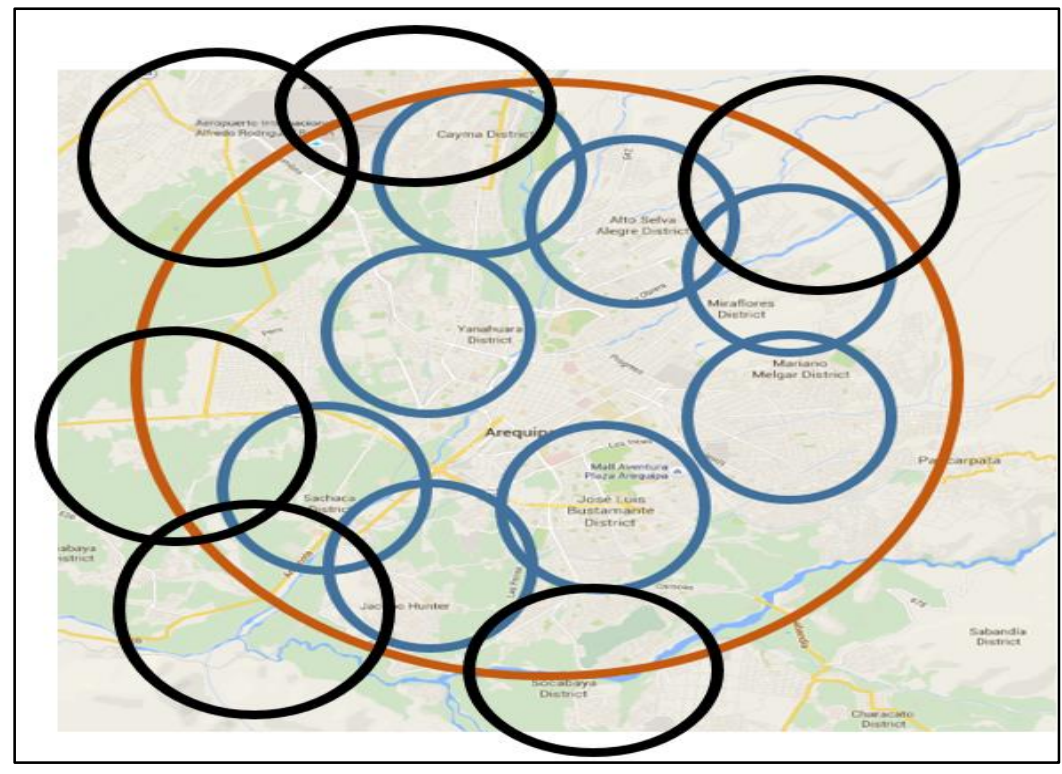

Figura 59 Arequipa Urbana y Periurbana. Adaptado de Google Maps, 2016. Recuperado de https://www.google.com.pe/maps

A nivel de objetivos por densidad demográfica se concluyó que existe mayor potencial de mercado en la zona periurbana que en la zona designada "Arequipa ciudad”. Sin 
embargo es importante considerar en este análisis, que no se identificó una zona de densidad significativa, eso quiere decir que el mercado objetivo estaría muy disperso, lo cual significa mayor inversión, por consiguiente mayor riesgo. Estos resultados se mostrarán con más detalle en el capítulo VII que es el plan de Marketing donde se detallará qué decisión se asume, acorde a las oportunidades y limitaciones con las cuales contamos, del mismo modo el riesgo que se está considerando asumir.

Como se puede apreciar, gracias a los datos arrojados por el estudio de mercado, se pudo validar una densidad de mercado en "Arequipa ciudad", considerando de este modo a los distritos de Alto Selva Alegre, Cayma, Cerro Colorado, Jacobo Hunter, Mariano Melgar, Miraflores, Sachaca, Yanahuara, José Luis Bustamante y Rivero, Cercado.

Propuesta del plan de negocios, propone que la ubicación del proyecto será en:

$\begin{array}{ll}\text {. } & \text { Departament } \\ \text {. } & \text { Provincia } \\ \text {. } & \text { Diudad } \\ & \text { Distrito }\end{array}$

Departamento

\author{
: Arequipa \\ : Arequipa \\ : Arequipa \\ : Yanahuara (en el límite con cercado)
}




\section{Capítulo VI. Aspectos Organizacionales}

\subsection{Caracterización de la cultura organizacional deseada}

La cultura organizacional es el conjunto de hábitos y creencias no escritas que se van estableciendo por medio de normas informales, valores, actitudes y expectativas que comparten y orientan el comportamiento de los miembros de la organización (Chiavenato, 2011).

\subsubsection{Visión}

La visión organizacional, se refiere a cómo desea ser en el futuro la organización. La visión debe ser inspiradora y explicar por qué es que las personas dedican la mayor parte de su tiempo al éxito de su organización. Mientras más enlazada esté la visión del negocio con los intereses de sus socios, tanto más podrá la organización cumplir con sus propósitos.

Visión es ser el recurso informático preferido por los emprendedores e inversionistas, que brinde soluciones innovadoras tanto de inversión como de financiación.

\subsubsection{Misión}

Misión organizacional es la expresión del propósito y el alcance de la empresa en términos del producto y del mercado, es en donde se define la razón de ser de la organización dentro de la sociedad en la que se desarrolla. La misión de la organización está definida en términos de la satisfacción de alguna necesidad del ambiente externo y no de ofrecer un simple producto o servicio.

Misión es ayudar a financiar de manera innovadora a las empresas para que puedan crecer de forma sostenible y a la vez ofrecer a los inversores oportunidades de inversión donde puedan obtener una rentabilidad deseada. 


\subsubsection{Principios}

Son los valores de una compañía, son las creencias, características y normas conductuales que se esperan de su personal cuando realiza negocios de la compañía y persigue su visión estratégica y su misión. Los valores están relacionados con un trato justo, íntegro, conducta ética, sentido innovador, trabajo en equipo, calidad suprema, servicio superior al cliente, responsabilidad social y ciudadanía comunitaria, entre otros aspectos, los cuales deben estar claramente definidos y ser promovidos internamente (Thompson, 2012)

Entre los principios que se promoverán para la presente organización están:

- Liderazgo: que posean una visión de futuro y dinamismo que les permite adelantarse a la competencia y aprovechar las oportunidades que emergente; con espíritu de trabajo, constancia y perseverancia que transmite a sus colaboradores.

- Fomentar un espíritu emprendedor: es un elemento fundamental ya que invita a la participación y toma de decisiones en todos los niveles de la organización, mejorando los productos y servicios.

- Integridad: Honestidad, seriedad, cordialidad y fe en el negocio

- Confianza: Brindar transparencia, seguridad y calidad en los productos y servicios tanto a los clientes como al equipo de trabajo.

- Sensibilidad Social: Estar comprometidos con el desarrollo e inclusión financiera de nuestros clientes y no a la discriminación. 


\subsection{Formulación de Estrategias de Negocio}

Según David (2013), señala las diferentes técnicas para la formulación de estrategias las cuales pueden integrarse en un modelo de toma de decisiones de tres etapas, que pueden ayudar a identificar, evaluar y elegir estrategias. Estas etapas son:

- Etapa 1: Etapa de los insumos: integrado por las matrices de evaluación de los factores externos (EFE), de evaluación de factores internos (EFI) y la matriz de Perfil Competitivo (MPC).

- Etapa 2: Etapa de adecuación: conformada por la matriz de fortalezas, oportunidades, debilidades y amenazas (FODA).

- Fase 3: Etapa de decisión, que comprende la matriz cuantitativa de la planificación estratégica (MCPE).

Para el presente estudio se desarrolló en la etapa I la Matriz de evaluación de los factores externos (EFE) la cual se elaboró a partir del análisis del contexto actual esperado (ver sección 2.5), permitiéndonos conocer el impacto que tendría este en la empresa en base a las oportunidades y amenazas y nos ayudará a evaluar las efectividad de las estrategias, donde los valores de ponderación, oscilan entre 0.0 (no importante) y 1.0 (muy importante) y el valor de calificación de 1 a 4 (4 = la respuesta es superior, 3 = la respuesta es superior al promedio, 2 = respuesta promedio y $1=$ respuesta deficiente). Luego, la puntuación ponderada total promedio es de 2.5 (David, 2013). 


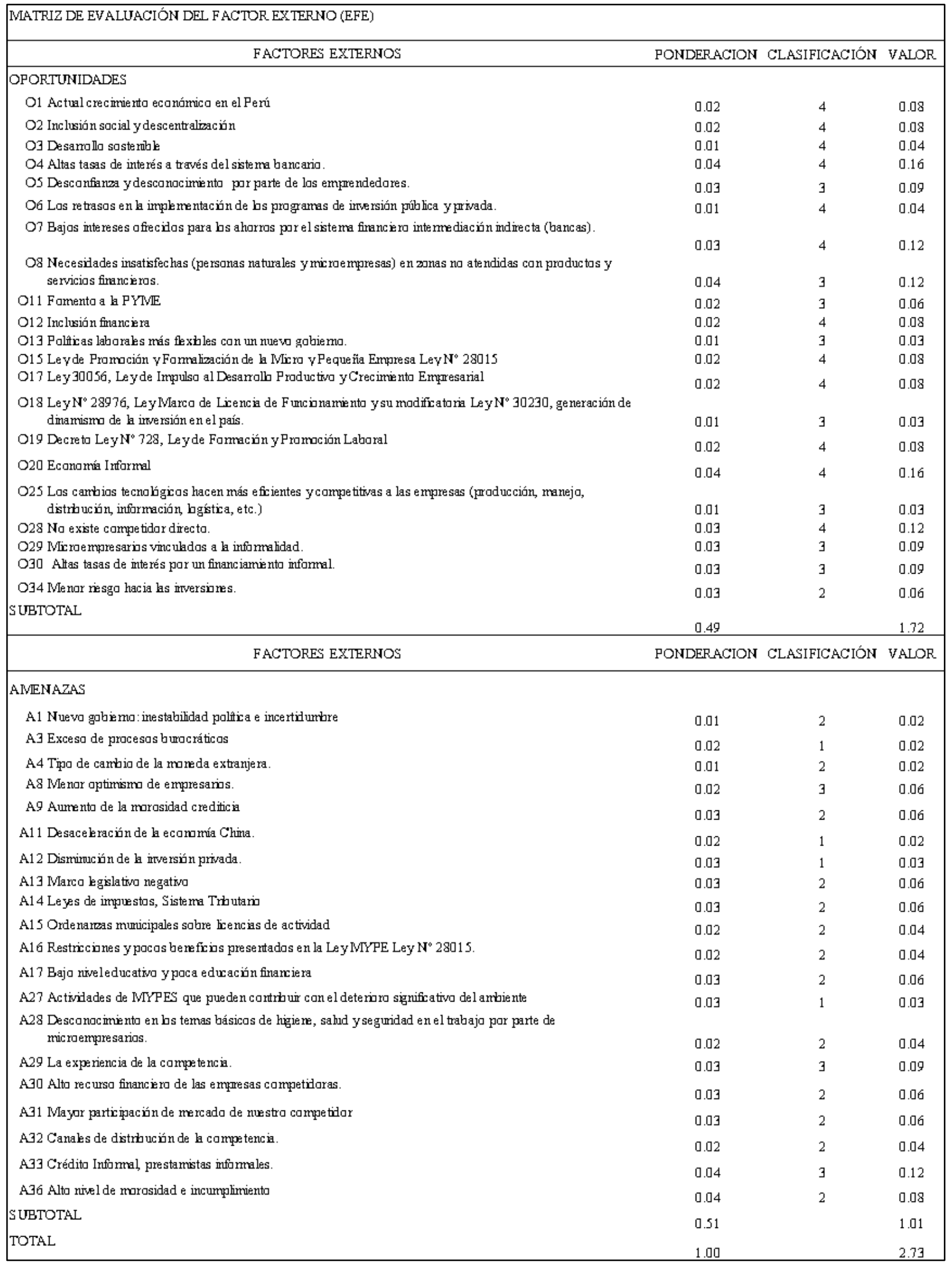

Figura 60. Matriz de Evaluación de Factores Externos (EFE) 
De la evaluación se obtuvo una puntuación ponderada total de 2.73 , siendo un valor óptimo por encontrarse por encima del valor promedio de 2.5 , asimismo el subtotal ponderado de las Oportunidades es de 1.72 y el de las Amenazas de 1.01, lo cual indica que el medio externo es favorable para la futura empresa.

Luego en la sección 2.4.3 se desarrolló la matriz MPC donde se evaluó la relación que hay entre la empresa propuesta y sus competidores más cercanos (Entidad informal y Caja Arequipa), de dicha matriz se puede ver que la entidad financiera Caja Arequipa tiene una mejor participación en el mercado y lealtad de sus clientes, una entidad informal cuenta con buena posición financiera y la empresa propuesta ofrece una mejor calidad de productos y competitividad de precios. De lo que la entidad informal resulta ser la más débil y la entidad financiera la más fuerte. La empresa propuesta puede competir frente a sus rivales en cuanto a la competitividad de precios así como la calidad del producto lo cual puede generar en el tiempo un crecimiento tanto en la participación del mercado como influir en la lealtad del cliente.

Finalmente de la Etapa I, tenemos la matriz de evaluación de los factores internos (EFI), donde se evalúa las fortalezas y debilidades más importantes.

\begin{tabular}{|llcl|}
\hline \multicolumn{1}{|c}{ FACTORES INTERNOS CLAVE } & PONDERACION & CLASIFICACIÓN & VALOR \\
\hline FORTALEZAS & & & \\
F1 Atención personalizada al cliente & 0.07 & 3 & 0.21 \\
F2 Ventajas en costos & 0.12 & 4 & 0.48 \\
F3 Habilidad para la innovacion de productos & 0.09 & 4 & 0.36 \\
F4 Uso eficiente de la tecnología, para la mejor & & 3 & 0.21 \\
$\quad$ atención a clientes & 0.07 & 4 & 0.32 \\
F5 Calidad en el servicio & 0.08 & 4 & 0.40 \\
F6 Personal calificado & 0.10 & & \\
DEBILDADES & & 2 & 0.16 \\
D1 Pocos canales de atención & 0.08 & 1 & 0.11 \\
D2 Baja experiencia frente a la competencia & 0.11 & 1 & 0.10 \\
D3 Bajo posicionamiento en el mercado & 0.10 & 2 & 0.14 \\
D4 Sensibilidad al comportamiento de la economía & 0.07 & 1 & 0.11 \\
D5 Desconfianza por parte del usuario & 0.11 & & 2.60 \\
\hline TOTAL & 1.00 & & \\
\hline
\end{tabular}

Figura 61. Matriz de Evaluación de Factores Internos (EFI) 
La matriz EFI contiene 11 factores claves del éxito, lo que dio una puntuación ponderada de 2.6, valor que se encuentra por encima del promedio, lo que indica que sus factores internos se encuentran en buena posición, donde hay posibilidades de mejorar y otras donde explotar.

Para la Etapa II tenemos la matriz FODA, donde se desarrolló cuatro tipo de estrategias FO (fortalezas-oportunidades), estrategias DO (debilidades-oportunidades), estrategias FA (fortalezas-amenazas) y estrategias DA (debilidades-amenazas). Las estrategias FO se obtienen de las fortalezas internas de la empresa y poder aprovechar las oportunidades externas. Las estrategias DO buscan enfrentar las debilidades internas haciendo uso de las oportunidades externas. Las estrategias FA utilizan las fortalezas de la empresa para evitar o reducir el golpe que pueden producir las amenazas externas. Las estrategias DA son técnicas defensivas que ayudan a minimizar las debilidades internas y evitar las amenazas externas. 


\begin{tabular}{|c|c|c|}
\hline & Fortaleza & Debilidades \\
\hline & $\begin{array}{l}1 \text { Atencín persanalizada al cliente } \\
2 \text { Ventajas encostas } \\
3 \text { Habilidad para la inmocion de productos } \\
4 \text { Uso eficiente de h tecrobgía, para la mejar } \\
\text { atención a cliertes } \\
5 \text { Calidad en el servicio } \\
6 \text { Persanal calificada }\end{array}$ & 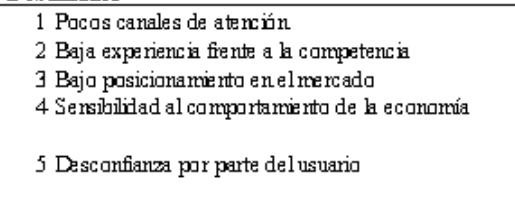 \\
\hline Qportunidades & Estrateqias FO & Estrategias DO \\
\hline 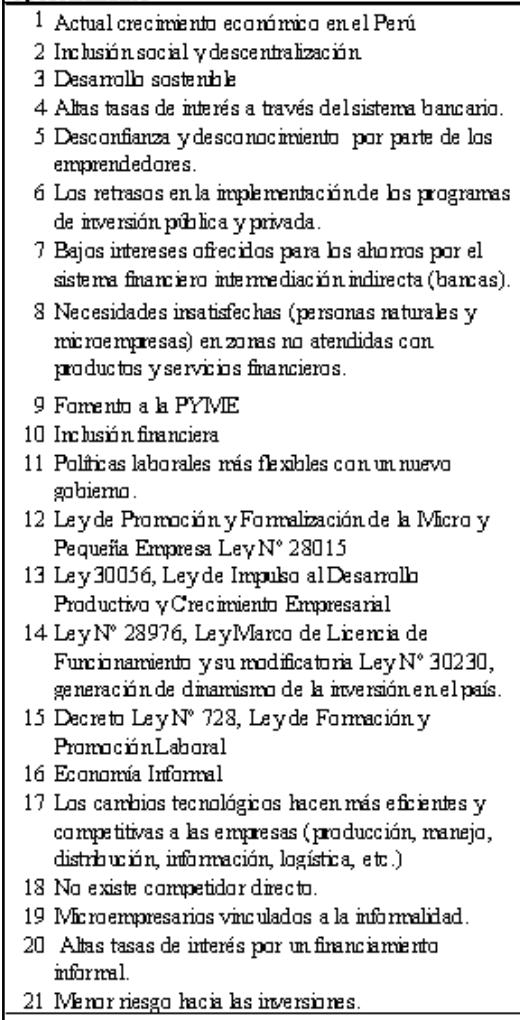 & $\begin{array}{l}\text { Difusion ycapactacinn de nuevas altemativas de } \\
\text { finariamiento (F3, F6, F1, O7, O6, O10, O13, } \\
\text { O18). } \\
\text { Desarrolhr productos de ac uerdo al enfoque del } \\
\text { cliente (F1, F5, O8, O9 O12, O14, O16). }\end{array}$ & 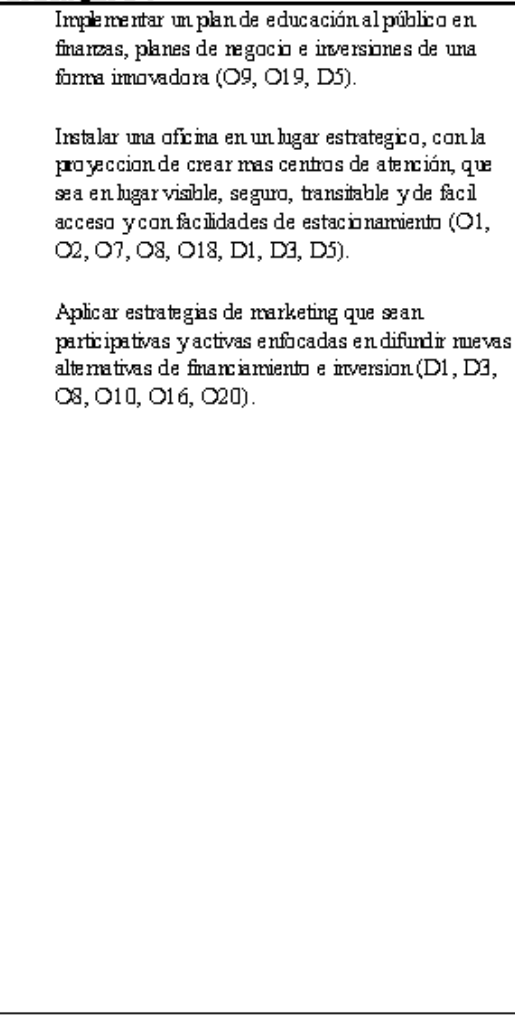 \\
\hline \multicolumn{3}{|l|}{ Amemas } \\
\hline 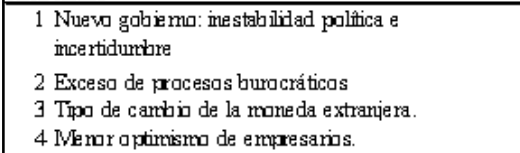 & $\begin{array}{l}\text { Contar con informacion a tiermo y actualizada de b } \\
\text { economia y mercado actual (F3, } \mathrm{F} 6, \mathrm{~A} 2, \mathrm{~A} 4, \mathrm{~A} 5 \text {, } \\
\mathrm{A} 6, \mathrm{~A}, \mathrm{~A} 9, \mathrm{~A} 10, \mathrm{~A} 11)\end{array}$ & $\begin{array}{l}\text { Cantar con ura oficira con una buera ubicacion de } \\
\text { facil accesa a bs clientes, con mobiliari adeacuado, } \\
\text { sala de entrenamiento (D1, DS, A1 1, A12, A1 ?, } \\
\text { A1 8). }\end{array}$ \\
\hline 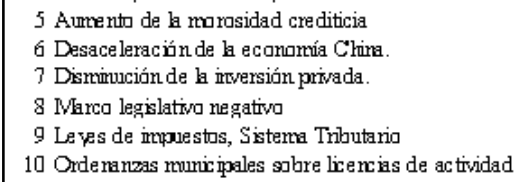 & $\begin{array}{l}\text { Contar con personal especializado, que recha } \\
\text { entre namiento constante (F3, F6, A2, A4, A5, A6, } \\
\mathrm{A} 8, \mathrm{~A} 9, \mathrm{~A} 10, \mathrm{~A} 15 \text { ). }\end{array}$ & $\begin{array}{l}\text { Contar can ura phataforma virtual amigable, donde } \\
\text { tambien se pueda recibir cansultas e interactur can } \\
\text { bs clientes (D1, D3, D5, A4, A1 5, A1?, A18). }\end{array}$ \\
\hline 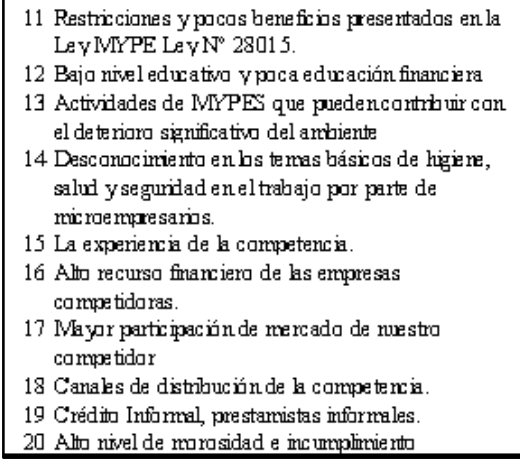 & $\begin{array}{l}\text { Realizar visitas a las empresas de los clientes y } \\
\text { poder realizar el ase saramiento ydiagnostica in situ } \\
\text { (F1, F3, F5, F6, A4, A12, A13, A14, A15, A18). }\end{array}$ & \\
\hline
\end{tabular}

Figura 62. Matriz FODA. Adaptado de “Conceptos de Administración Estratégica," por F. David, (2013). 
Tabla 22

Matriz de estrategias de negocio

\begin{tabular}{|c|c|c|}
\hline Objetivos & Estrategias & Resultados \\
\hline \multicolumn{3}{|c|}{ Crecimiento } \\
\hline $\begin{array}{l}\text { Posicionar a IDeltas y la } \\
\text { nueva alternativa de } \\
\text { financiamiento e } \\
\text { inversión, como una } \\
\text { opción más eficiente y con } \\
\text { un alto grado de calidad } \\
\text { frente a la intermediación } \\
\text { bancaria. }\end{array}$ & $\begin{array}{l}\text { - Estudio de Investigación de } \\
\text { mercados. } \\
\text { - Elaboración e implementación } \\
\text { del Plan de Marketing. }\end{array}$ & $\begin{array}{l}\text { - Obtener } \\
\text { posicionamiento en el } \\
\text { mercado potencial de la } \\
\text { ciudad de Arequipa. } \\
\text { - Lograr el interés de } \\
\text { nuevos clientes tanto } \\
\text { inversores como } \\
\text { solicitantes de } \\
\text { financiamiento. }\end{array}$ \\
\hline $\begin{array}{l}\text { Crecimiento en el } \\
\text { mercado con una nueva } \\
\text { alternativa económica: } \\
\text { confiable, eficiente, } \\
\text { innovadora y adecuados a } \\
\text { las necesidades de los } \\
\text { clientes. }\end{array}$ & $\begin{array}{l}\text { - Conseguir base de inversores, } \\
\text { que financien los proyectos o } \\
\text { negocios. } \\
\text { - Captación de clientes a través } \\
\text { de asesoramiento personalizado. } \\
\text { - Instalar una oficina en un lugar } \\
\text { estratégico, con la proyección de } \\
\text { crear más centros de atención, } \\
\text { un lugar visible, seguro, } \\
\text { transitable y de fácil acceso. } \\
\text { - Contar con una plataforma } \\
\text { virtual amigable, donde también } \\
\text { se pueda recibir consultas e } \\
\text { interactuar con los clientes. } \\
\text { - Realizar visitas a las empresas } \\
\text { de los clientes y poder realizar } \\
\text { el asesoramiento y diagnóstico } \\
\text { en sus mismos negocios o } \\
\text { empresas. } \\
\text { - Realizar alianzas estratégicas } \\
\text { con instituciones (universidades, } \\
\text { institutos, cámaras de comercio, } \\
\text { organizaciones, etc.) }\end{array}$ & $\begin{array}{l}\text { - Lograr contactar con } \\
\text { inversores con gran } \\
\text { capacidad de ahorro que } \\
\text { deseen invertir en } \\
\text { el mercado. } \\
\text { - Clientes inversionistas } \\
\text { satisfechos que } \\
\text { reinviertan en nuevos } \\
\text { proyectos o negocios. } \\
\text { - Clientes que buscan un } \\
\text { financiamiento y están } \\
\text { satisfechos y que } \\
\text { regresen a solicitar } \\
\text { nuevos créditos. }\end{array}$ \\
\hline
\end{tabular}




\section{Rentabilidad}

Buscar un crecimiento

rentable, con una

estructura de costes

variable que permita ir

adaptándose

progresivamente a las

necesidades de los

clientes.
- Realizar una estrategia de precios, que lidere los del mercado.
- Precios rentables, que de una estabilidad a la empresa y que maximice las utilidades al transcurrir el tiempo y que vayan de acuerdo al mercado

\begin{tabular}{|c|c|c|}
\hline Objetivos & Estrategias & Resultados \\
\hline \multicolumn{3}{|c|}{ Seguridad } \\
\hline $\begin{array}{l}\text { - Control de los riesgos a } \\
\text { los cuales están expuestos } \\
\text { los clientes y los propios } \\
\text { de la empresa. } \\
\text { - Permanecer siempre por } \\
\text { debajo de un } 1 \% \text { de tasa } \\
\text { de morosidad. }\end{array}$ & $\begin{array}{l}\text { - Análisis y evaluación } \\
\text { exhaustiva de los clientes por } \\
\text { parte de nuestro equipo. } \\
\text { - Implementar un procedimiento } \\
\text { y/o política de protección de } \\
\text { información personal del cliente. }\end{array}$ & $\begin{array}{l}\text { - Incrementar la } \\
\text { confianza de los clientes } \\
\text { hacia la empresa y los } \\
\text { procesos. } \\
\text { - Clientes satisfechos } \\
\text { que recomiendan } \\
\text { IDeltas a otros. }\end{array}$ \\
\hline \multicolumn{3}{|c|}{ Tecnología } \\
\hline $\begin{array}{l}\text { Adquirir un software } \\
\text { adecuado que permita } \\
\text { tener un buen control de } \\
\text { las Actividades de la } \\
\text { empresa. }\end{array}$ & $\begin{array}{l}\text { - Desarrollo continuo de la } \\
\text { plataforma, para actualizar y } \\
\text { subsanar problemas durante el } \\
\text { proceso de financiación e } \\
\text { inversión, así como la } \\
\text { comunicación continúa con el } \\
\text { cliente (mensajería, chat). }\end{array}$ & $\begin{array}{l}\text { - Software } \\
\text { implementado en la } \\
\text { empresa y en la } \\
\text { plataforma. } \\
\text { - Posicionamiento de la } \\
\text { empresa. }\end{array}$ \\
\hline
\end{tabular}

Nota: Elaboración Propia

\subsection{Determinación de las ventajas competitivas críticas}

Según Kotler (2012), la ventaja competitiva es una ventaja sobre los competidores que se obtiene entregando un gran valor al cliente, ya sea ofreciendo precios bajos o precios altos que estén justificados con obtener más beneficios. Por lo que es necesario buscar puntos de diferenciación en cada espacio de contacto con el cliente. Estos puntos pueden ser: productos, servicios, canales, personal o imagen. 
- Diferenciación de productos, donde la marca se puede distinguir a partir de sus características, desempeño, estilo y diseño. Es así que la empresa propuesta presenta un producto innovador y de calidad que garantice tanto a los emprendedores como inversionistas y poder conseguir un financiamiento e incrementar sus ingresos.

- Diferenciación de servicios, atención personalizada los siete días de la semana, con el objetivo de satisfacer las necesidades de negocio del cliente.

- Diferenciación de canal, que se da a partir de la forma en cómo se diseña la cobertura, experiencia y desempeño. Por lo que los canales a emplear serán por vía web, de forma física a través de una oficina de atención, telefónica, difusiones, charlas, presentaciones, visita a los clientes, entre otros.

- Diferenciación del personal, se contará con personal competente, quienes recibirán capacitaciones.

- Diferenciación de imagen, con el que se busca transmitir los beneficios distintivos y el posicionar al producto, que sustente por todo lo que la empresa dice y ofrece. Los cuales se deben transmitir a través de una publicidad que hable de la personalidad de la empresa.

\subsection{Diseño de la estructura organizacional deseada}

El diseño de la estructura de la empresa se plantea de tal forma que facilite las intenciones estratégicas de la empresa en proyecto.

La empresa por encontrarse en sus inicios y por ser de menos costo se organizara bajo una estructura funcional, agrupada en tareas y actividades según las funciones que se realicen (David, 2013). 


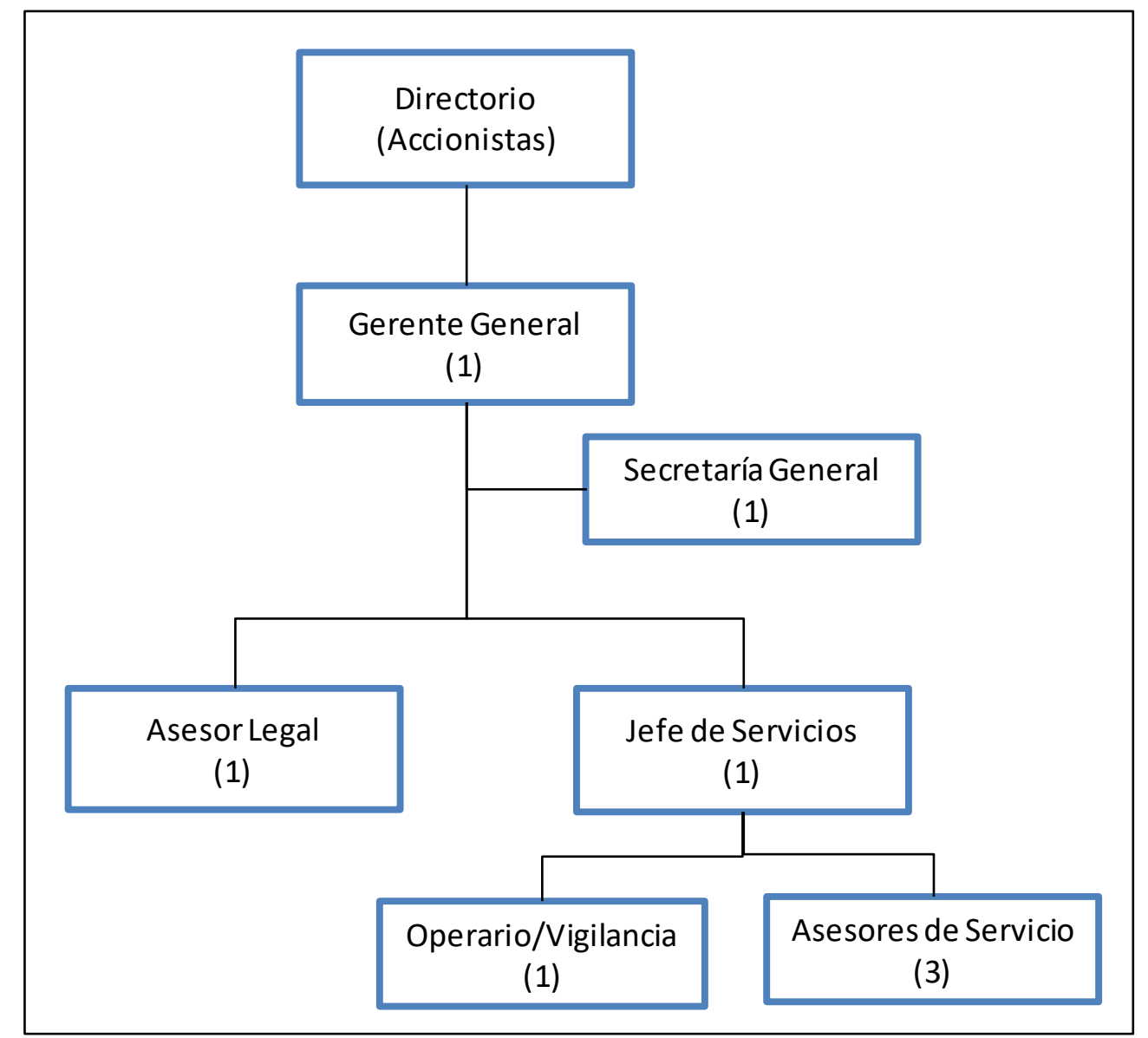

Figura 63. Estructura organizacional de la empresa propuesta

\subsection{Diseño de los perfiles de puesto clave}

El diseño del perfil de puesto clave se tomará a partir de un modelo de gestión por competencias el cual debe ser conciso, fiable y efectivo para predecir el éxito de una persona en su puesto; por ello será una herramienta válida contar con un perfil por competencias. En este punto es necesario considerar los objetivos propuestos por Recursos Humanos requerido tanto para la selección de personal, de este modo se propone una colaboración eficaz, considerando:

- Captar a personas que tengan los mismos valores que los asociados de la empresa, en este sentido colaboración, solidaridad, pasión por el servicio; siendo necesaria la 
proactividad y respeto por las personas independiente de su origen o condición y del mismo modo normas establecidas.

- Promover la capacitación continua así como el desarrollo integral del personal.

- Promover la equidad e integración entre los miembros de la empresa, promoviendo solo aquellos actos que añadan valor a la empresa.

El enfoque de la empresa, presenta un diseño organizacional que representa los resultados de un proceso de toma de decisiones que incluye (a) fuerzas ambientales, (b) factores tecnológicos y (c) elecciones estratégicas (Hellriegel \& Slocum, 2004). Específicamente se propone:

- Facilitar el flujo de información y de este modo lograr acelerar la toma de decisiones para satisfacer las demandas de los clientes/consumidores e instituciones vinculadas, del mismo modo brindar información oportuna en la mejor manera posible.

- Definir con claridad la autoridad y responsabilidad de trabajos, equipos y áreas de la empresa.

- Crear los niveles de integración (coordinación) deseados, construyendo procedimientos para una rápida respuesta a cambios en el ambiente.

El tipo de organización que regirá es la denominado organización mecánica, diseñada para que los integrantes de la empresa y funciones se conduzcan en formas predecibles. Se caracteriza por (a) fundarse en reglas y disposiciones formales; (b) centralizar la toma de decisiones; (c) responsabilidades estrictamente definidas y (d) una rígida jerarquía de autoridad (Hellriegel \& Slocum, 2004).

Los requisitos, funciones y responsabilidades específicas para cada puesto, serán las siguientes: 
Tabla 23

Perfil del Director General

\begin{tabular}{lll}
\hline \multicolumn{1}{c}{ Requisitos } & \multicolumn{1}{c}{ Funciones } & \multicolumn{1}{c}{ Competencias } \\
\hline $\begin{array}{l}\text { Representado por } \\
\text { cualquiera de sus } \\
\text { accionistas }\end{array}$ & $\begin{array}{l}\text { Cumplirá las funciones de guía de la } \\
\text { empresa como son: } \\
\text { (a) Diseñar e implementar el plan } \\
\text { estratégico a desarrollarse en la empresa }\end{array}$ & $\begin{array}{l}\text { (a) Capacidad } \\
\text { organizativa y de } \\
\text { planificación. } \\
\text { (b) Capacidad de análisis } \\
\text { y resolución. }\end{array}$ \\
$\begin{array}{l}\text { Educacionales: } \\
\text { Conocimientos en } \\
\text { Administración de } \\
\text { empresas, Contabilidad }\end{array}$ & $\begin{array}{l}\text { permitirán el inicio, promoción y } \\
\text { crecimiento de la empresa }\end{array}$ & (c) Espíritu emprendedor \\
$\begin{array}{l}\text { Años de experiencia: } \\
\text { cinco años }\end{array}$ & $\begin{array}{l}\text { (c) Seleccionar el personal que integrará } \\
\text { la empresa }\end{array}$ & \\
& $\begin{array}{l}\text { (d) Redactar la normas y principios } \\
\text { éticos que regirán en la empresa }\end{array}$ \\
& $\begin{array}{l}\text { (e) Redactar el manual de funciones de } \\
\text { cada uno de los colaboradores de la } \\
\text { empresa, y }\end{array}$ \\
& $\begin{array}{l}\text { (f) Supervisar y controlar las actividades } \\
\text { y resultados del Gerente General. }\end{array}$ \\
&
\end{tabular}

Nota: Elaboración Propia 
Tabla 24

Perfil del Gerente General

Requisitos

Designado por el

Directorio

Educacionales:

Conocimientos en

Administración de empresas, Contabilidad

Años de experiencia:

cinco años
Funciones

Será el responsable de la empresa, emitirá los reportes periódicos al

Directorio

(a) Supervisar y controlar las actividades y resultados del Jefe de Servicios y del Jefe de Seguridad

(b) Hacer auditorias mensuales sobre el manejo de la contabilidad y nivel de producción de la empresa, y

(c) Promover relaciones perdurables en el tiempo, con los clientes corporativos e individuales.
Competencias

(a) Liderazgo de personas

(b) Capacidad organizativa y de planificación.

(c) Capacidad de análisis y resolución.

(d) Espíritu emprendedor

(e) Capacidad de comunicación

Nota: Elaboración Propia

Tabla 25

Perfil del Secretaria General

Requisitos

Educacionales:

Estudios de

Contabilidad finalizados

Estudios de

especialización en

Finanzas

Dominio Microsoft

Office, programas de contabilidad

Años de experiencia: dos años
Funciones

Competencias

(a) Aptitudes para la

(a) Capacitar a los colaboradores que formen parte del área de asesoría en temas contables administrativos correspondientes;

(b) Cumplir y hacer cumplir los requisitos contables, las normas y principios éticos que regirán en la empresa;

Atención y Orientación al Cliente

(b) Capacidad de Negociación

(c) Sociabilidad. Dinámico

(d) Dominio de la comunicación oral

(e) Buena presencia.

(c) Brindar soporte corporativo al Jefe de Servicios y Gerencia General. (f) Espíritu emprendedor

(g) Capacidad de comunicación 
Tabla 26

Perfil del Jefe de Servicios

Requisitos

Funciones

Competencias

Educacionales:

Estudios de

Administración o

Ingeniería Comercial a

nivel universitario

\section{Estudios de}

especialización en

Finanzas

Estudios de

especialización en

Marketing (deseable)

Licencia de conducir

A-1

Años de experiencia: dos años (a) Contratar el personal que integrará la empresa,

(b) Cumplir y hacer cumplir el manual de funciones de cada uno de los colaboradores del área administrativa, así como las normas y principios éticos que regirán en la empresa,

(c) Encargarse de la apertura de cuenta corriente, en el Banco seleccionado por el Directorio, para el depósito y pago de dinero;

(d) Desarrollar nuevas campañas de publicidad y promoción de la empresa, página web

(e) Promover la venta a través del sistema de visitas especializadas a clientes;

(f) Crear y mantener relaciones perdurables en el tiempo, con los clientes corporativos e individuales;

(g) Hacer llegar los servicios a los clientes a través de los asesores de servicios;

(h) Manejar las cuentas más grandes de la compañía, y

(i) Ser responsable de la logística de entrega de los productos a los clientes. (a) Liderazgo de personas

(b) Capacidad organizativa y de planificación.

(c) Capacidad de análisis y resolución

(d) Espíritu emprendedor

(e) Aptitudes para la

Atención y Orientación al

Cliente

(f) Capacidad de Negociación

(g) Sociabilidad. Dinámico

(h) Dominio de la comunicación oral

(i) Buena presencia

(j) Capacidad negociadora.

(k) Visión de negocio.

Nota: Elaboración Propia 
Tabla 27

Perfil del Asesores de Servicios

Requisitos

Educacionales:

Estudios en

Administración,

Finanzas,

Contabilidad, a nivel

universitario;

Licencia de conducir

A-1

Años de experiencia: dos años
Funciones

Competencias (a) Realizar las actividades de asesoría a clientes, requiriendo financiamiento $\mathrm{y} / \mathrm{o}$ alternativas de inversión. acuerdo con las normas establecidas por la organización; (b) Elaborar, presentar e informar paquetes pre diseñados para clientes de nichos específicos;

(c) Realizar el mantenimiento y seguimiento de las cuentas cerradas, activas y potenciales, desarrollándose en modo óptimo en el ejercicio de sus funciones, (d) Realizar el correcto funcionamiento de las transacciones, asegurándose de la satisfacción final del cliente,

(e) Participar activamente en ferias de emprendimientos, y actividades que influyan en la adquisición de una mayor cartera de clientes. (a) Aptitudes para la

Atención y

Orientación al

Cliente

(b) Capacidad de

Negociación

(c) Sociabilidad

Dinámico

(d) Dominio de la comunicación oral

(e) Buena presencia

(f) Espíritu emprendedor

(g) Capacidad de comunicación

Nota: Elaboración Propia

Tabla 28

Perfil del Asesor Legal

\section{Requisitos}

Educacionales:

Profesional en derecho.

Colegiatura que lo habilite para el ejercicio

profesional.

Conocimientos en derecho Administrativo, comercial y laboral.

Conocimiento en herramientas informáticas Años de experiencia: tres años
Funciones

(a) Brindar asesoría legal en materia de contratos.

(b) Elaborar las bases para las contrataciones.

(c) Brindar asesoría legal a las áreas que lo requieran, previniendo potenciales riesgos.

(d) Redactar y revisar contratos, actas, cartas y otros documentos legales.

(e) Realizar la actualización de las normas legales en la página web.

(f) Garantizar la viabilidad legal de las alternativas propuestas.
Competencias

(a) Capacidad para poner en operación conocimientos, habilidades, valores y resolución de problemas en las diversas situaciones de orden laboral.

(b)Manejo de conflictos y situaciones críticas

(c) Buena capacidad de negociación

(d) Espíritu emprendedor

(e) Habilidad para la organización del trabajo 
Tabla 29

Perfil del Operario/vigilancia

\begin{tabular}{|c|c|c|}
\hline Requisitos & Funciones & Competencias \\
\hline $\begin{array}{l}\text { Educacionales: } \\
\text { Estudios Secundarios. } \\
\text { Con conocimientos técnicos } \\
\text { relacionados con almacenes } \\
\text { y vigilancia } \\
\text { Licencia de conducir A-2B }\end{array}$ & $\begin{array}{l}\text { (a) Realizar labores de control de } \\
\text { ingreso y salida de equipos, } \\
\text { materiales, etc. } \\
\text { (b) De requerirse realizar el } \\
\text { transporte de equipos o materiales; }\end{array}$ & $\begin{array}{l}\text { (a) Aptitudes para la } \\
\text { Atención } \\
\text { (b) Dinámico } \\
\text { (c) Responsable } \\
\text { (d) Con Capacidad de } \\
\text { trabajo }\end{array}$ \\
\hline Años de experiencia: un año & & \\
\hline
\end{tabular}

Nota: Elaboración Propia

Finalmente en cumplimiento de las resoluciones de las sentencias emitidas por el Tribunal Constitucional peruano, en materia de discriminación laboral; en la solicitud de los puestos no se incluirán rasgos determinados de (a) raza, (b) sexo, y (c) edad o algún otro elemento que pudiera indicar algún tipo de discriminación. Sin embargo el Directorio procurará cubrir las plazas propuestas, seleccionando a los aspirantes mediante una evaluación integral.

\subsection{Remuneraciones, compensaciones e incentivos}

La empresa contará con una planilla conformada por 13 colaboradores, los cuales gozarán de los beneficios laborales establecidos por ley, es decir que además de su remuneración mensual percibirán una Compensación por Tiempo de Servicios (C.T.S.); vacaciones pagadas de 30 días, así como, el derecho de participar en el Régimen Contributivo de Seguridad Social en Salud (RCSSS). Costos que serán asumidos por la empresa, tal como lo señala la siguiente tabla. 
Tabla 30

Sistema de remuneraciones y compensaciones del Plan de Negocios

\begin{tabular}{lcccccc}
\hline Cargo & Cantidad & $\begin{array}{c}\text { Monto/mes } \\
(\mathrm{S} / .)\end{array}$ & $\begin{array}{c}\text { Vacacione } \\
\mathrm{s}\end{array}$ & $\begin{array}{c}\text { ESSALU } \\
(\mathrm{S} / .)\end{array}$ & $\begin{array}{c}\text { Total/mes } \\
(\mathrm{S} / .)\end{array}$ & $\begin{array}{c}\text { Total/mes } \\
(\mathrm{S} / .)\end{array}$ \\
\hline Vigilante & 1 & 930 & 465 & 84 & 1,479 & 448 \\
Asesor de Servicios & 3 & 4,500 & 2,250 & 405 & 7,155 & 2,168 \\
Asesor Legal & 1 & 2,700 & 1,350 & 243 & 4,293 & 1,301 \\
Secretaria General & 1 & 2,000 & 1,000 & 180 & 3,180 & 964 \\
Jefe de Servicios & 1 & 2,700 & 1,350 & 243 & 4,293 & 1,301 \\
Gerente General & 1 & 3,700 & 1,850 & 333 & 5,883 & 1,783 \\
TOTAL & 8 & 16,530 & 8,265 & 1,488 & 26,283 & 7,964 \\
\hline
\end{tabular}

Nota: Tipo de cambio 3.3

\subsection{Política de recursos humanos}

Las políticas de recursos humanos estarán orientadas al establecimiento del clima laboral, decálogo del desarrollo empresarial y a la selección del personal. Los Directivos de la empresa tendrán a su cargo esta responsabilidad, la cual deberá estar plasmada en un manual de procedimientos que promueva y valore el trabajo de cada uno de los integrantes de la empresa.

Respecto al comportamiento esperado, éste se regirá por lo valores de:

- Pasión por el trabajo.

- Liderazgo, promoviendo cualquier acción de mejora continua.

- Honradez y responsabilidad en el ejercicio de sus actividades.

- Igualdad y justicia.

- Cordialidad en el trato, como piedra angular de la organización, esto tanto en las relaciones internas como en las relaciones con los clientes. 
Respecto a los métodos para mantener la cultura organizacional, se promoverá:

- Reacciones rápidas y asertivas frente a las situaciones de crisis, al fomentar la coerción mutua.

- Enseñanza y asesoría permanente de las funciones a desempeñar.

- Reclutamiento, selección, ascensos y despidos, cuando estos sean necesarios. 


\section{Capítulo VII. Plan de Marketing}

\subsection{Estrategias de Marketing}

Según Kotler y Armstrong (2012), para el diseño de las estrategias de marketing se debe entender por completo a los consumidores y al mercado y tener respuesta a dos preguntas importantes: ¿A qué clientes debemos servir?, es decir ¿cuál es nuestro mercado meta?, y de ¿qué manera serviremos mejor a esos clientes? o ¿cuál es nuestra propuesta de valor?

En el capítulo tres se efectuó el desarrollo del mercado meta al cual deseamos llegar, así como la descripción del servicio y productos a ofrecer.

Como estrategia de marketing se diseñará una mezcla de marketing integrado, conformada por los factores: producto, precio, plaza (distribución) y promoción (las cuatro P). La mezcla de marketing es el conjunto de herramientas tácticas que la empresa combina para obtener la respuesta que desea en el mercado meta. La mezcla de marketing consiste en todo lo que la empresa es capaz de hacer para influir en la demanda de su producto (Kotler, 2012).

-Objetivo general: Realizar un plan de marketing, identificando los canales o medios óptimos de contacto con los clientes, basados en la identificación de las necesidades y tendencias de los clientes.

\subsubsection{Estrategias de Producto}

La estrategia de productos también requiere construir una línea de productos. Una línea de productos es un grupo de productos que están estrechamente relacionados porque funcionan de manera similar, se venden a los mismos grupos de clientes (Kotler, 2012). El producto encierra los bienes y servicios que ofrece una empresa y es el medio a través del 
cual se satisfacen las necesidades de los clientes. Entre los aspectos importantes del producto se encuentra la marca, imagen o los servicios post venta.

Entre los productos y servicios que se ofrecen se tiene:

- Servicios de inversión y financiamiento: Licitación de préstamo, para obtención de acceder a liquidez a cambio de un interés.

- Ventas: Se ofrecen los servicios de ventas por adelantado;

- Servicios especiales: Venta de derechos o participaciones, elaboración de contratos, asesoría empresarial, entre otros.

- Asesoría y Capacitación.

En cuanto a la marca IDeltas SAC; tanto el nombre, siglas, símbolo, diseño de la empresa servirán para identificar los productos o servicios y diferenciar a la empresa de la competencia.

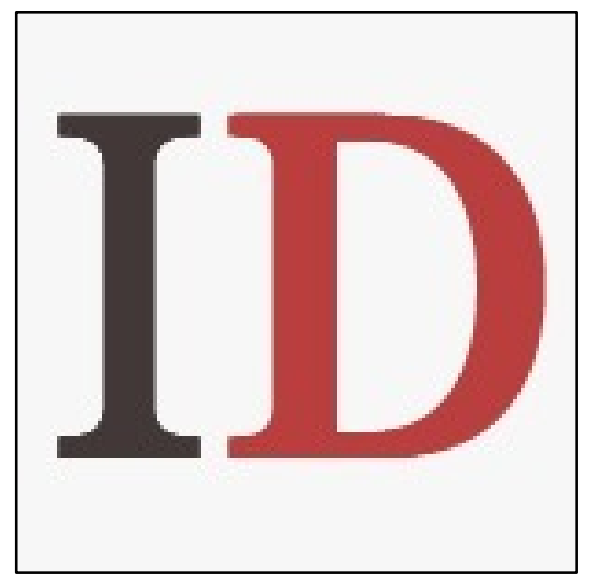

Figura 64. Logotipo de la empresa IDeltas SAC

Se desea posicionar a IDeltas como la mejor empresa de intermediación y asesoramiento, especializada en inversión y financiación de negocios y emprendimientos en 
la ciudad de Arequipa. Es decir, posicionar a la empresa en la mente de inversores como una alternativa más eficiente y con un alto grado de calidad frente a la intermediación bancaria.

\subsubsection{Estrategias de precio}

Existen dos estrategias generales para la fijación de precios para el lanzamiento de nuevos productos: la de fijar el precio para capturar el nivel más alto del mercado existente y la de fijar el precio para penetrar en el mercado (Kotler \& Amstrong, 2012).

Ya que los productos que se ofrecen en la empresa propuesta se tratan de nuevas alternativas de financiamiento es que para penetrar en el mercado y fijar los precios, se plantea ofrecer inicialmente precios bajos para estos nuevos productos, con el objetivo de atraer el mayor número de clientes (inversionistas y quienes buscan financiamiento) y poder conseguir una importante participación en el mercado, en el menor tiempo posible.

Para la fijación de los precios de los servicios va en función a la estructura de los costos, para evitar el riesgo de que no vayan con la realidad del mercado y que permita alcanzar una tasa de rendimiento sobre la inversión, maximizar las utilidades al transcurrir el tiempo y que se establezca la empresa. Nuestra estrategia de precios frente a los que buscan un financiamiento, será el de cobrar comisiones por debajo de las comisiones bancarias para que vean en la financiación alternativa una gran oportunidad de financiar su negocio.

Tabla 31

Estimación de precios

\begin{tabular}{ccccccc}
\hline $\begin{array}{c}\text { Servicio/ } \\
\text { Producto }\end{array}$ & $\begin{array}{c}\text { Ventas por } \\
\text { adelantado }\end{array}$ & $\begin{array}{c}\text { Financia } \\
\text { miento }\end{array}$ & $\begin{array}{c}\text { Servicios } \\
\text { Especiales }\end{array}$ & $\begin{array}{c}\text { Asesoría } \\
\text { permane } \\
\text { nte }\end{array}$ & $\begin{array}{c}\text { Asesoría } \\
\text { por horas }\end{array}$ & $\begin{array}{c}\text { Capacita } \\
\text { ción }\end{array}$ \\
\hline $\begin{array}{c}\text { Precio } \\
\text { Promedi } \\
\text { o (S/.) }\end{array}$ & 500 & 500 & 100 & 221.1 & 70 & 500 \\
$\begin{array}{c}\text { Precio } \\
\text { Promedi } \\
\text { o }\end{array}$ & 151.5 & 151.5 & 30.3 & 67 & 21.2 & 151.5 \\
$(\mathrm{US} \$)$ & & & & & & \\
\hline
\end{tabular}




\subsubsection{Estrategias de distribución}

Consisten en acciones comerciales cuyo objetivo es captar un mayor número de clientes, incentivar las ventas, lograr mayor cobertura o exposición de los productos o servicios, etc. Una buena estrategia de distribución permitirá a la empresa lograr aquellos objetivos de ventas que se hayan establecido.

Incluye las actividades de la compañía que hacen que el producto esté a la disposición de los consumidores meta (Kotler \& Amstrong, 2012).

El principal canal de la empresa será el que se brinda en el mismo establecimiento de forma directa, ya que los contratos requieren el contacto directo entre representantes de IDeltas, inversionista y quien solicita financiamiento. También se plantea realizar visitas empresariales (negocios, casas) hacia los clientes o futuros clientes, para tener un mayor contacto con el servicio ofrecido.

Otros canales de distribución están: a través de una plataforma online, vía telefónica (telemercadotecnia) y correo electrónico. También algunos medios escritos como tarjetas de presentación, distribución de portafolios con contenido promocional y presentación de servicios, toda la papelería que salga de la empresa debe estar identificada con la imagen corporativa de la organización.

\subsubsection{Estrategias de promoción y publicidad}

La promoción involucra un conjunto de actividades que anuncian las ventajas del producto y inducen a los clientes meta de que lo compren (Kotler \& Amstrong, 2012).

Para estar al día con nuestra competencia y lograr el éxito en las ventas, hoy en día se busca más que un excelente producto y/o servicio, es por esa razón que las personas requieren incentivos para adquirirlos y tal motivo la promoción se ha vuelto necesaria para los productos o marcas. El objetivo de la promoción y publicidad de un producto es el de 
maximizar las ventas, atraer a nuevos clientes, extender el conocimiento del producto y posicionar la marca. Las estrategias de promoción de un producto benefician a las empresas con el aumento de demanda y a la vez beneficia a los consumidores brindándoles la información necesaria sobre la disposición del producto, sus usos y beneficios. Usualmente son para funcionar a corto plazo, animando a los consumidores a comprar el producto antes de que expire dicha promoción.

Para lograr posicionarse y mantenerse en el mercado la empresa IDeltas SAC tiene los objetivos publicitarios y promocionales:

- Diseñar material publicitario y de comunicación.

- Evaluar y desarrollar los procesos de mercadeo y publicidad.

- Recopilar información sobre las áreas de mercadeo

- Participar y realizar una fuerte presencia en eventos empresariales.

- Material publicitario a través de la plataforma online.

Entre las estrategias publicitarias y promocionales para hacer conocer los servicios, se propone:

- Día de lanzamiento: Se ofrecerá un cóctel de bienvenida a todos los representantes de las pequeñas y microempresas invitadas ubicados en la ciudad de Arequipa, el cual durará tres horas, y se realizará en las instalaciones de la empresa, se calcula un total de cien participantes, el evento estará a cargo de la Dirección y gerencia general. El lanzamiento tendrá como eslogan: "Descubre un mundo de oportunidades, se parte de tus soluciones"

- Mercadeo: Se hará la distribución de un portafolio que contenga la presentación de la empresa y los servicios que brinda, así como contenido promocional, cada documento estará debidamente identificado con la imagen de la empresa. Todas 
las personas que laboran para la empresa, estarán debidamente identificadas con un fotochek dado por la empresa.

- Se empleara la telemercadotecnia como una forma de acceder a una importante cantidad de consumidores potenciales. La creación de una plataforma web oferte todos los servicios y mantenga actualizado e informado al usuario. También hacer uso intensivo de redes sociales, blogs en internet y medios publicitarios. Se creará un perfil en Twitter, Facebook, Linkedin, canal de Youtube con la finalidad de dar a conocer a la empresa e informar sobre los eventos y descuentos promocionales. El generar un vínculo digital con el cliente sumado a la presencia por las oficinas así como por los asesores de servicios, nos permitirá tener una amplia red de contactos los cuales puedan ser convertidos en clientes, gracias a los buenos resultados por el marketing de contenidos.

Por otro lado, se maneja la estrategia digital que es el de alianzas estratégicas con influencers (bloggers, youtubers, influencers en facebook, influencers en instagram, influencers en Twitter), la consecuencia esperada es lograr influencia focalizada (por rango de edad como geográfica y nivel socioeconómico). 


\begin{tabular}{|c|c|c|c|}
\hline & Atraer Clientes & Convertir Clientes & Fidelizar Clientes \\
\hline Líneas & $\begin{array}{l}\text { Marketing en buscadores (SEM } \\
\text { y SEO) }\end{array}$ & $\begin{array}{l}\text { Web Marketing } \\
\text { (usabilidad, } \\
\text { navegabilidad, diseño, } \\
\text { arquitectura) }\end{array}$ & Email Marketing \\
\hline $\begin{array}{l}\text { Estratégicas } \\
\text { De } \\
\text { Marketing }\end{array}$ & $\begin{array}{l}\text { Publicidad online (Google } \\
\text { Adwords, Facebook Ads, ...) }\end{array}$ & $\begin{array}{l}\text { Publicidad Online (Google } \\
\text { Adwords, Facebook Ads) }\end{array}$ & $\begin{array}{l}\text { Marketing Relacional } \\
\text { (CRM) }\end{array}$ \\
\hline \multirow[t]{8}{*}{ Online } & Inboud Marketing & & \\
\hline & Social Media Marketing & & \\
\hline & Email Marketing & & \\
\hline & Relaciones Públicas Online & & \\
\hline & Información Estratégica & $\begin{array}{l}\text { Tradicional/BTL } \\
\text { - Redes Sociales . } \\
\text { - Fidelización } \\
\text { - Posicionamiento } \\
\end{array}$ & $\begin{array}{c}\text { Sistema Integrado, } \\
\text { Velocidad de } \\
\text { Atención }\end{array}$ \\
\hline & $\begin{array}{l}\text { Orientación } \\
\text { Empresarial }\end{array}$ & $\begin{array}{l}\text { Personalizacion } \\
\text { Rn -siclientes }\end{array}$ & $\begin{array}{l}\text { Maximizar Recursos } \\
\text { Infraestructura }\end{array}$ \\
\hline & & Rerendas) & Innovación \\
\hline & $\begin{array}{l}\text { Posicionamiento } \\
\text { Mundial "Sistemas } \\
\text { Integral Gratuito" }\end{array}$ & $\begin{array}{c}\text { Sorpresas } \\
\text { (Campañas pre } \\
\text { estructuradas) } \\
\end{array}$ & $\begin{array}{l}\text { Proyección } \\
\text { de } \\
\text { Servicios }\end{array}$ \\
\hline
\end{tabular}

Figura 65. Estrategia de Marketing publicitario a través de la página web

- Relaciones publicitarias: Realizar la presentación de los productos y servicios a las empresas, por lo que se requiere hacer contacto con sus representantes, también el de realizar visitas y ofrecer un servicio personalizado para determinar el grado de satisfacción del cliente.

- Eventos: Participar en eventos empresariales, mediante la presentación de un stand o realizados en las instalaciones de la empresa con el fin de hacer conocer a la empresa. Cada evento contará con un mensaje que incentive a reconocer la oportunidad de apoyar en el desarrollo de la pequeña y microempresa, como por ejemplo: "Supera tus expectativas, apoya tus soluciones" 
- Reforzamiento de la marca: esta estrategia lo que se busca es crear lealtad de nuestros clientes a la marca, para ello se hará el uso de membresías con las que los clientes pueden adquirir una serie de descuentos y promociones.

- Crear demanda: ofrecer una promoción por tiempo limitado (asesoramiento gratuitos, o envío de información importante para el desarrollo su empresa), un descuento porcentual o demostrar a los consumidores que nuestro producto es mejor que el de la competencia.

- En la plataforma, como actividad promocional, se presentará un video informativo acerca de lo que propone y realiza IDeltas. El objetivo de este video es generar confianza en nuestros clientes, y que puedan entender el proceso completo tanto de inversión para los clientes inversores como de financiación para los clientes emprendedores o que tienen un negocio.
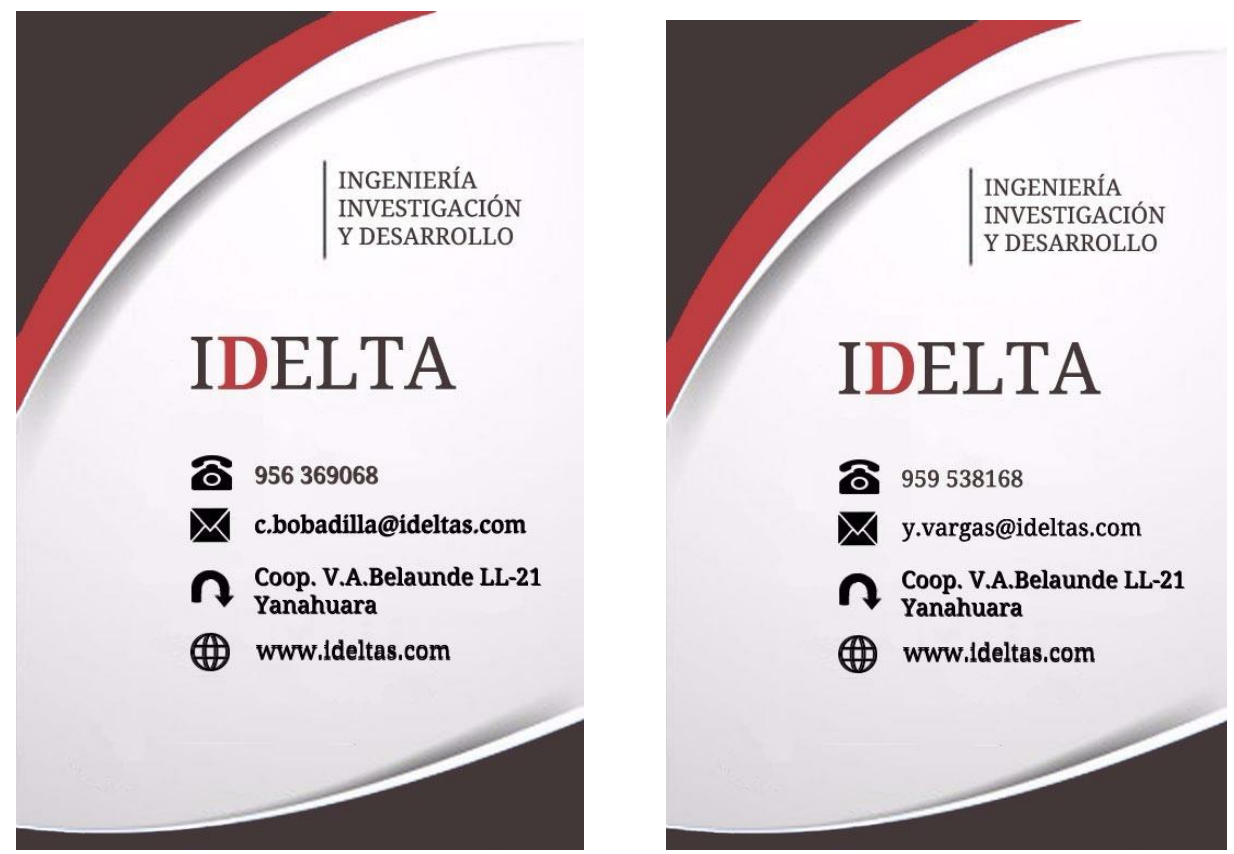

Figura 66. Estrategia de Marketing publicitario a través de la presentación 


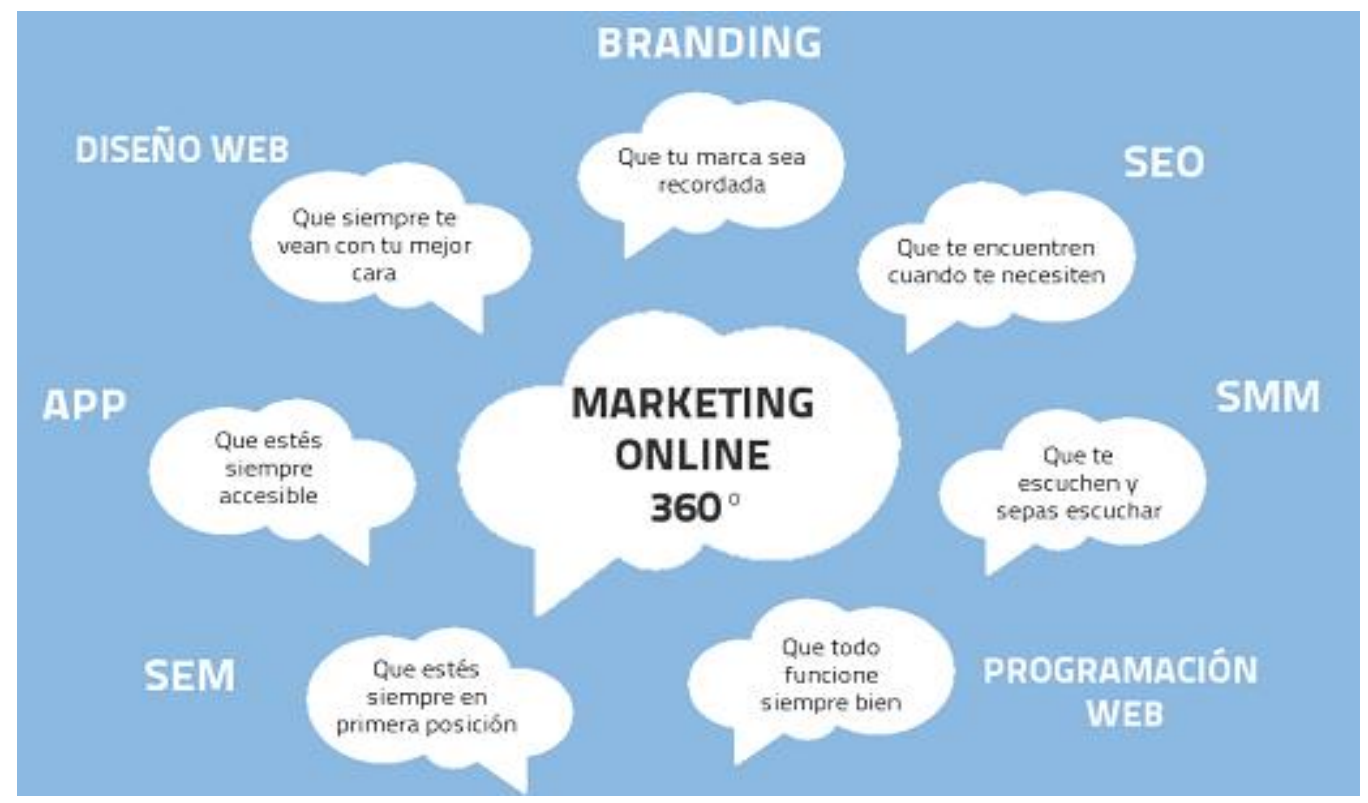

Figura 67. Estrategia de Marketing publicitario online

Tabla 32

Presupuesto de publicidad

\begin{tabular}{lccr}
\hline Publicidad y Promoción & Cantidad & $\begin{array}{c}\text { Valor } \\
\text { Unitario }\end{array}$ & Total \\
\hline Lanzamiento & & & \\
\hline Cóctel & 100 & 17.0 & 1700 \\
Cartas de invitación & 100 & 3.0 & 300 \\
Portafolios & 50 & 10.0 & 500 \\
Total Lanzamiento & & & 3000 \\
\hline Publicidad y Promoción & & & \\
mensual & 200 & 6.0 & 1200 \\
\hline Visitas empresariales & 300 & 0.5 & 150 \\
Tarjetas de presentación & 100 & 10.0 & 1000 \\
Portafolios & 1 & 650.0 & 650 \\
Página web & & & 3000 \\
\hline Total gasto mensual & & & \\
\hline
\end{tabular}

Nota. Valores tomado de cotizaciones en soles.

\subsection{Estrategias de ventas}

En este punto se tratarán las ventas personales y la promoción de ventas. Las ventas personales son la interacción interpersonal con los clientes actuales y potenciales para generar relaciones y generar ventas. Por otro lado la promoción de ventas consiste en incentivos a 
corto plazo con la finalidad de fomentar la compra de un producto o servicio (Kotler \& Armstrong, 2012).

El equipo de ventas está conformado por el área de servicios, quienes serán los responsables de realizar las ventas en las instalaciones de la empresa, a través de la plataforma online, vía telefónica, por internet, visita a clientes potenciales que precisen de información del servicio.

Dentro de las estrategias de ventas se tiene:

1. Se deberán de difundir como mínimo a cinco clientes al día con finalidad de aumentar la base de datos de clientes potenciales de la empresa.

2. La difusión será también a través de la plataforma online donde habrá un chat en tiempo real donde se informe y se aclaren las dudas. Así mismo el seguimiento diario de las redes sociales y medios publicitarios con el objetivo de visualizar cuántos clientes potenciales están interesados en los servicios y productos.

\subsubsection{Plan de ventas}

El proyecto considera llegar a un objetivo mínimo de 500 clientes en el primer año. El objetivo propuesto para el primer año es de 1.38 clientes por día.

Dentro del plan de ventas se tendrán las siguientes actividades:

- Desarrollar un presupuesto mensual de ventas en base a la demanda.

- Establecer un objetivo mensual de ventas a través de las ventas de telemercadotecnia y ventas directas.

- Capacitación constante al equipo referente a ventas de los servicios y productos que ofrece la empresa.

- Entrega de incentivos al mejor vendedor. 
- Informes financieros quincenales elaborados por el Gerente General para tener un seguimiento detallado de la empresa y controlar si los objetivos mensuales se están logrando.

\subsubsection{Políticas de servicios y garantías.}

La calidad del servicio que se puede brindar es muy importante para el desarrollo y gestión de la empresa por lo que los esfuerzos se enfocarán en conseguir brindar el mejor servicio a los clientes. Se espera lograr esto por medio de la estandarización de los procesos de la organización y así garantizar un servicio eficiente en el trato con los clientes y en la calidad de los servicios y productos que se ofrecen. Por otro lado es muy importante para la empresa el conocer la opinión de los clientes por lo que se acondicionara un buzón de sugerencias dentro del local, además de la elaboración de una encuesta corta sobre la opinión de la atención recibida el cual será analizado mensualmente.

Dentro de la política de ventas se tiene:

- $\quad$ La atención en las oficinas será de 8:30 a.m. a 17:00 p.m.

- $\quad$ Los cobros se realizan en moneda nacional.

- $\quad$ La empresa no otorgará crédito alguno.

- $\quad$ Los asesores no podrán realizar descuento alguno sobre los productos y servicios a menos que la Gerencia General lo autorice.

- $\quad$ Los casos en los que clientes presenten quejas tanto sobre el servicio o por los productos estos serán atendidos directamente por el jefe de asesoramiento o por el jefe legal. 
- $\quad$ Una vez concretada la venta, se realizará un contrato de entre IDeltas, inversionista y solicitante de financiamiento, según sea el caso.

- $\quad$ En cuanto a la prenda o garantía (de existir), esta deberá estar fijada según el precio del financiamiento, esta figurará en el contrato de mutuo, y será liberada íntegramente una vez se dé por exitosa la transacción entre el comprador y el vendedor (ver sección 3.1).

- $\quad$ Las demoras que pudieran producirse, tanto en el pago del principal, como en el de los intereses, tarifas, devengarán diariamente, hasta su completo pago, a favor del inversionista.

- $\quad$ Los datos de carácter personal del prestatario y el/los prestamistas, serán tratados de conformidad con la Ley de Protección de Datos Personales - Ley $\mathrm{N}^{\mathrm{o}}$ 29733 y su Reglamento, con la mayor confidencialidad.

- $\quad$ El inversionista y el solicitante de financiamiento consienten que IDeltas, recabe, comunique, intercambie o solicite información a otras entidades públicas y privadas, con la finalidad de verificar y evaluar la información facilitada y determinar que el cliente cumple con las condiciones del perfil. 


\section{Capítulo VIII: Planificación financiera}

\subsection{La inversión}

La inversión es el uso de recursos con el objetivo de generar beneficios o ganancias en el futuro.

Se considera un Plan Financiero lo más conservador posible por tratarse de una empresa de nueva creación, de acuerdo a los lineamientos propuestos por los socios de la empresa, de manera que se logren determinar las inversiones necesarias, sus fuentes de financiación, costos del servicio, administración y venta de los servicios de asesorías.

\subsubsection{Inversión pre-operativa}

Estos son los costos que se requieren para la compra de todos los activos necesarios desde la formulación de la idea del negocio hasta antes de iniciar operaciones. La inversión pre-operativa incluye costos como inversión en maquinaria, licencias, mobiliario, etc. Todo ello formará parte del activo de la empresa.

A continuación, se detalla la relación de activos que forman parte de la inversión preoperativa de la consultora dividiéndolos en activos fijos tangibles y activos intangibles. Los activos fijos son aquellos bienes físicos cuyo uso proporciona beneficios para la empresa como son los edificios y equipos. La depreciación es el gasto relacionado a estos activos a medida que se desgastan a lo largo de su vida útil.

Por otro lado, los activos intangibles son aquellos cuyo valor no proviene de propiedades físicas, como la obtención de licencias. Así como los activos fijos se deprecian, los activos intangibles reducen su valor en el tiempo a través de amortización (Horngren, Aarrison, \& Oliver, 2010). 


\begin{tabular}{|c|c|}
\hline \multicolumn{2}{|c|}{ INVERSION PRE-OPERATIVA: ACTIVOS FIJOS } \\
\hline CONCEPTO & Monto (U.S. Dólares) \\
\hline TERRENO & 0 \\
\hline EQUIPO Y MAQUINARIA & 0 \\
\hline \multicolumn{2}{|l|}{ EQUIPO DE OFICINA } \\
\hline \multicolumn{2}{|l|}{ Equipos de Computo } \\
\hline Laptop & 3,030 \\
\hline Impresora & 404 \\
\hline Perifericos & 263 \\
\hline Discos Externos & 451 \\
\hline Router Inalambrico & 149 \\
\hline Telefono Fijo & 128 \\
\hline Telefono Celular & 890 \\
\hline Memorias USB & 50 \\
\hline \multicolumn{2}{|l|}{ Muebles y Enseres } \\
\hline Escritorios & 485 \\
\hline Mesa de Juntas & 836 \\
\hline Archivadores y Sillas & 388 \\
\hline Mesa de Centro Para Recepción & 91 \\
\hline Mesa de Reuniones & 836 \\
\hline Sillas de reuniones y Sofas & 836 \\
\hline \multicolumn{2}{|l|}{ OBRAS CIVILES } \\
\hline Pisos y alfombras & 2,600 \\
\hline Pintura y accesorios & 907 \\
\hline TOTAL & 12,344 \\
\hline IMPREVISTOS (5\%) & 617 \\
\hline TOTAL ACTIVOS FIJOS & 12,961 \\
\hline
\end{tabular}

Figura 68. Inversión Pre-operativa: Activos fijos

\begin{tabular}{|c|c|}
\hline \multicolumn{2}{|c|}{ INVERSIÓN PRE-OPERATIVA: ACTIVOS INTANGIBLES } \\
\hline CONCEPTO & Monto (U.S. Dólares) \\
\hline \multicolumn{2}{|l|}{ ESTUDIO DE PRE-INVERSIÓN } \\
\hline Estudio de Marketing & 1,000 \\
\hline Estudio de Recursos Humanos & 750 \\
\hline Estudio Legal & 1,500 \\
\hline \multicolumn{2}{|l|}{ GASTOS DE GESTIÓN } \\
\hline Gastos de Selección y Contratación & 750 \\
\hline Elaboración y contrato fiducidiario & 4,500 \\
\hline Estudio de Mercado & 1,250 \\
\hline Hosting y Dominio y Desarrollo portal web & 1,000 \\
\hline Adquisición de Software & 500 \\
\hline Desarrollo de Software & 500 \\
\hline Asistencia Técnica & 1,200 \\
\hline \multicolumn{2}{|c|}{ GASTOS DE ORGANIZACIÓN Y CONSTIUUCIÓN DE LA EMPRESA } \\
\hline Licencias, certificados, registro de marca, otros. & 800 \\
\hline TOTAL & 13,750 \\
\hline IMPREVISTOS (5\%) & 688 \\
\hline TOTAL ACTIVOS INTANG IBLES & 14,438 \\
\hline
\end{tabular}

Figura 69. Inversión Pre-operativa: Activos Intangibles 


\subsubsection{Inversión de capital de trabajo}

Se ha calculado el requerimiento de capital de trabajo considerando el monto total de gastos operativos del primer mes del año uno.

\begin{tabular}{|c|c|c|c|c|c|c|}
\hline \multicolumn{7}{|c|}{ INVERSIÓN EN CAPITAL DE TRABANO } \\
\hline \multicolumn{7}{|l|}{ SUELDOSY SALARIOS } \\
\hline Cargo & Cantidad & $\begin{array}{c}\text { Monto/mes } \\
(\mathrm{S} / .)\end{array}$ & $\begin{array}{c}\text { Vacaciones } \\
(\mathrm{S} / .)\end{array}$ & $\begin{array}{c}\text { ESSALUD } \\
(\mathrm{S} / .)\end{array}$ & $\begin{array}{c}\text { Total/mes } \\
(\mathrm{S} / .)\end{array}$ & $\begin{array}{c}\text { Total/mes } \\
\text { (U.S.\$) }\end{array}$ \\
\hline Vigilante & 1 & 930 & 465 & 84 & 1,479 & 448 \\
\hline Asesor de Servicios & 3 & 4500 & 2250 & 405 & 7,155 & 2,168 \\
\hline Asesor Legal & 1 & 2700 & 1350 & 243 & 4,293 & 1,301 \\
\hline Secretaria General & 1 & 2000 & 1000 & 180 & 3,180 & 964 \\
\hline Jefe de Servicios & 1 & 2700 & 1350 & 243 & 4,293 & 1,301 \\
\hline Gerente General & 1 & 3700 & 1850 & 333 & 5,883 & 1,783 \\
\hline TOTAL & 8 & 16530 & 8265 & 1488 & 26,283 & 7,964 \\
\hline
\end{tabular}

Figura 70. Inversión Capital de Trabajo: Sueldos y Salarios.

\begin{tabular}{|l|r|r|}
\hline \multicolumn{2}{|c|}{ DESEMBOLSOS DIVERSOS } \\
\hline Detalle & S/. & US\$ \\
\hline Alquiler del local más garantía & 3,200 & 970 \\
\hline Matenimiento Fiduciario & 2,640 & 800 \\
\hline Licencias de SW (ERP) & 2,400 & 727 \\
\hline Transportes & 320 & 97 \\
\hline Gastos de luz, agua, teléfono, internet & 700 & 212 \\
\hline Materiales y Utiles de Oficina & 350 & 106 \\
\hline Seguros & 300 & 91 \\
\hline Mantenimiento & 150 & 45 \\
\hline Sistema de Vigilancia & 175 & 53 \\
\hline Gastos laborales & 1,000 & 303 \\
\hline Capacitación & 500 & 152 \\
\hline Marketing y publicidad & 3,200 & 970 \\
\hline Lanzamiento de proyecto & 3,000 & 909 \\
\hline Limpieza y Ornato & 200 & 61 \\
\hline Mantenimiento portal web & 700 & 212 \\
\hline TOTAL & 18,835 & $\mathbf{5 , 7 0 8}$ \\
\hline IMPREVISTOS (5\%) & & $\mathbf{1 4 , 3 5 6}$ \\
\hline TOTAL CAPITAL DE TRABAJO & & 684 \\
\hline
\end{tabular}

Figura 71. Inversión Capital de Trabajo: Desembolsos diversos 


\subsubsection{Costo del proyecto}

\begin{tabular}{|l|r|}
\hline \multicolumn{2}{|c|}{ COSTO DEL PROYECTO } \\
\hline CONCEPTO \\
\hline ACTVOS FIJOS \\
\hline EQUIPO DE OFICINA & 8,837 \\
\hline OBRAS CIVILES & 3,507 \\
\hline IMPREVISTOS (5\%) & 617 \\
\hline ACTTVOS INTANGIBLES & 3,250 \\
\hline ESTUDIO DE PRE-INVERSIÓN & 9,700 \\
\hline GASTOS DE GESTIÓN & 800 \\
\hline GASTOS DE ORGANIZACIÓN Y CONSTITUCIÓN DE LA EMPRESA & 688 \\
\hline IMPREVISTOS (5\%) & 7,964 \\
\hline INVERSIÓN EN CAPITAL DE TRABAJO & 5,708 \\
\hline SUELDOS Y SALARIOS & 684 \\
\hline DESEMBOLSOS DIVERSOS & \\
\hline IMPREVISTOS (5\%) & 12,961 \\
\hline INVERSION TOTAL & 14,438 \\
\hline ACTIVOS FIJOS & 14,356 \\
\hline ACTIVOS INTANGIBLES & 41,754 \\
\hline INVERSIÓN EN CAPITAL DE TRABAJO & \\
\hline TOTAL &
\end{tabular}

Figura 72. Inversión Total para el proyecto

\subsubsection{Inversiones futuras}

Dentro de este rubro se está considerando la reposición de activos tangibles (fijos) que por su vida útil deben ser cambiados dentro del periodo de evaluación del proyecto.

Cabe señalar que solo se está considerando la reposición de equipos de cómputo, los mismos que tienen una vida útil estimada de 5 años, que coincide con su periodo de depreciación contable tributaria. Se adjunta el cuadro detallado de equipos a reponer y el monto de inversión a realizar en el quinto año de evaluación del proyecto. 


\begin{tabular}{|l|r|}
\hline \multicolumn{2}{|c|}{ INVERSION FUTURA } \\
\hline CONCEPTO & Monto (U.S. \$) \\
\hline Laptop & 3,030 \\
\hline Impresora & 404 \\
\hline Perifericos & 263 \\
\hline Discos Externos & 451 \\
\hline Router Inalambrico & 149 \\
\hline Telefono Fijo & 128 \\
\hline Telefono Celular & 890 \\
\hline Memorias USB & 50 \\
\hline Escritorios & 485 \\
\hline Mesa de Juntas & 836 \\
\hline Archivadores y Sillas & 388 \\
\hline Mesa de Centro Para Recepciór & 91 \\
\hline Mesa de Reuniones & 836 \\
\hline Sillas de reuniones y Sofas & 836 \\
\hline TOTAL & $\mathbf{8 , 8 3 7}$ \\
\hline
\end{tabular}

Figura 73. Inversión Futura

\subsection{Financiamiento}

\subsubsection{Endeudamiento y condiciones}

Para la implementación del proyecto se requiere un capital de US\$ 41,754, el cual será aportado en su totalidad por dos inversionistas.

Antes de tomar la decisión de optar por un préstamo, se realizó un análisis de los costos de financiamiento que ofrece la banca peruana, encontrando que en algunos casos los bancos no financian proyectos, por lo que se ha considerado por conveniente que los accionistas inviertan con capital propio.

\subsubsection{Capital y costo de oportunidad}

La estructura de financiamiento del proyecto está constituida por el 100\% de aportes al capital por parte de los accionistas.

Respecto al cálculo del costo de oportunidad de los inversionistas (Ke o COK), no se cuenta con información disponible y precisa, en especial para la construcción del indicador beta des-apalancado de la industria de servicios y asesoría en temas de financiamiento e inversión en el Perú. 
Por esta situación, se decidió calcular el Ke (COK) del inversionista tomando como guía los indicadores en el mercado norteamericano. Para hallar el Ke se aplicará el modelo CAPM, para lo cual se necesitaran los siguientes valores: beta des-apalancado, rendimiento de los bonos de gobierno de los EEUU (tasa de riesgo libre (Rf)), prima de riesgo (Rf-RM) y riesgo país Perú.

\begin{tabular}{|c|c|c|c|c|c|c|c|c|}
\hline Date updated: & \multicolumn{6}{|l|}{ 5-Jan-18 } & & \multirow{3}{*}{$\begin{array}{l}\text { if you are loo } \\
\text { unlevered bet }\end{array}$} \\
\hline Created by: & \multicolumn{6}{|c|}{ Aswath Damodaran, adamodar@stern.nyu.edu } & & \\
\hline What is this data? & \multicolumn{6}{|c|}{ Beta, Unlevered beta and other risk measures } & & \\
\hline Home Page: & \multicolumn{6}{|c|}{ http://www.damodaran.com } & & \multirow{4}{*}{$\begin{array}{l}\text { betas can mo } \\
\text { sector beta ad } \\
\text { reasons, is le }\end{array}$} \\
\hline Data website: & \multicolumn{6}{|c|}{ http://www.stern.nyu.edu/ adamodar/New Home Page/data.html } & & \\
\hline Companies in each industry: & \multicolumn{6}{|c|}{ http://www.stern.nyu.edu/ adamodar/pc/datasets/indname.xls } & & \\
\hline Variable definitions: & \multicolumn{6}{|c|}{ http://www.stern.nyu.edu/ adamodar/New Home Page/datafile/variable.htm } & & \\
\hline \multirow{2}{*}{\multicolumn{5}{|c|}{$\begin{array}{l}\text { Do you want to use marginal or effective tax rates in unlevering betas? } \\
\text { If marginal tax rate, enter the marginal tax rate to use }\end{array}$}} & Marginal & & & \\
\hline & & & & & $24.00 \%$ & & & \\
\hline Industry Name & Number of firm: $=$ & Beta & D/E Ratio - & $\begin{array}{l}\text { Effective } \\
\text { Tax rate }\end{array}$ & Unlevered bet: & Cash/Firm value & Unlevered beta corrected for cas $\sqrt{-}$ & HiLo Rish = \\
\hline Hospitals/Healthcare Facilities & 35 & 1.18 & $176.51 \%$ & $10.57 \%$ & 0.50 & $1.75 \%$ & 0.51 & 0.4592 \\
\hline Hotel/Gaming & 70 & 0.94 & $39.91 \%$ & $14.01 \%$ & 0.72 & $3.22 \%$ & 0.74 & 0.4199 \\
\hline Household Products & 131 & 1.00 & $21.03 \%$ & $7.35 \%$ & 0.86 & $2.31 \%$ & 0.88 & 0.6009 \\
\hline Information Services & 61 & 0.88 & $15.71 \%$ & $15.90 \%$ & 0.79 & $4.07 \%$ & 0.82 & 0.3503 \\
\hline Insurance (General) & 21 & 0.78 & $38.50 \%$ & $14.71 \%$ & 0.61 & $3.99 \%$ & 0.63 & 0.2871 \\
\hline Insurance (Life) & 25 & 1.01 & $57.06 \%$ & $15.32 \%$ & 0.70 & $12.71 \%$ & 0.81 & 0.2369 \\
\hline Insurance (Prop/Cas.) & 50 & 0.84 & $26.43 \%$ & $18.50 \%$ & 0.70 & $4.06 \%$ & 0.73 & 0.2254 \\
\hline Investments \& Asset Management & 165 & 0.99 & $42.08 \%$ & $8.30 \%$ & 0.75 & $13.70 \%$ & 0.87 & 0.3629 \\
\hline
\end{tabular}

Figura 74. Beta desapalancada. Tomado de Implied Equity Risk Premiums - United States. Recuperado de http://people.stern.nyu.edu/adamodar/New_Home_Page/datacurrent.html

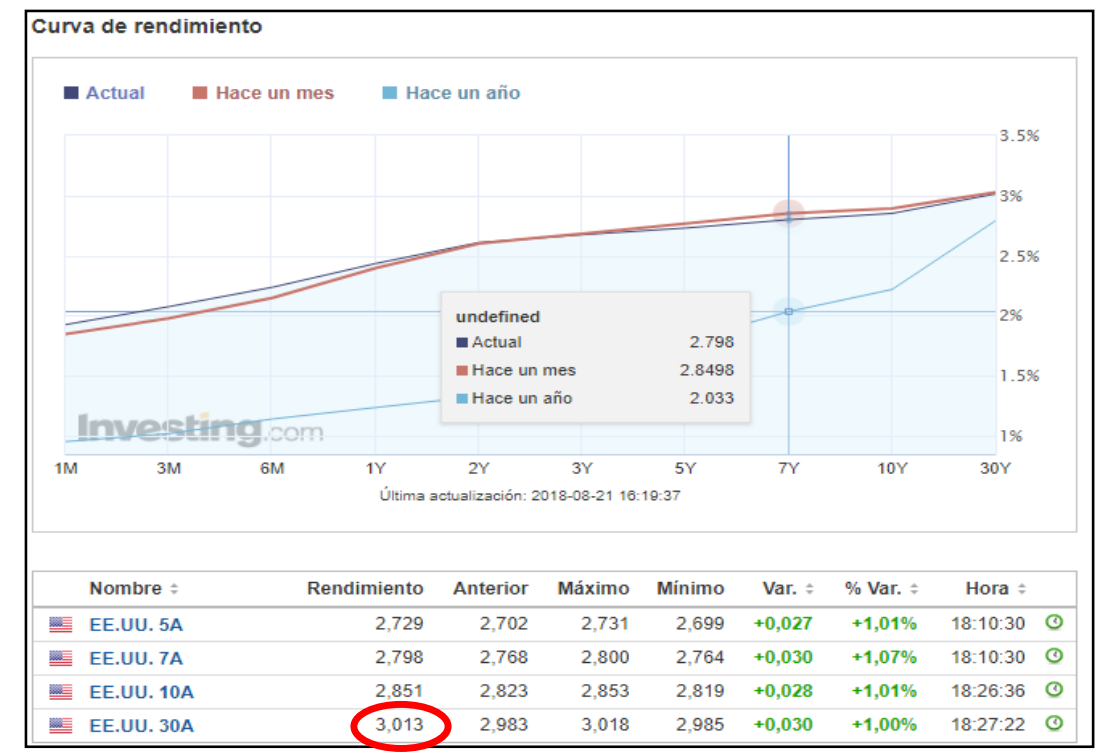

Figura 75. Tasa de riesgo libre (Rf). Tomado de Rendimiento de los bonos de gobierno de los EEUU. Recuperado de https://es.investing.com/rates-bonds/usa-governmentbonds?maturity_from $=130 \&$ maturity_to $=290$ 


\begin{tabular}{|c|c|c|c|c|c|c|c|}
\hline \multirow{2}{*}{\multicolumn{4}{|c|}{ Arithmetic Average }} & \multicolumn{2}{|c|}{ Risk Premium } & \multicolumn{2}{|c|}{ Standard Error } \\
\hline & & & & \multirow{2}{*}{\begin{tabular}{|r|} 
Stocks - T.B \\
$8.09 \%$ \\
\end{tabular}} & \multirow{2}{*}{\begin{tabular}{|r|} 
Stocks - T.Bo \\
$6.38 \%$ \\
\end{tabular}} & \multirow{2}{*}{$\begin{array}{r}\text { Stocks - T.Z } \\
2.10 \% \\
\end{array}$} & \multirow{2}{*}{$\begin{array}{c}\text { Stocks - T.Bond } \\
2.24 \% \\
\end{array}$} \\
\hline $1928-2017$ & $11.53 \%$ & $3.44 \%$ & $5.15 \%$ & & & & \\
\hline $1968-2017$ & $11.41 \%$ & $4.82 \%$ & $7.17 \%$ & $6.58 \%$ & $4.24 \%$ & $2.39 \%$ & $2.70 \%$ \\
\hline 2008-2017 & $10.27 \%$ & $0.42 \%$ & $4.29 \%$ & $9.85 \%$ & $5.98 \%$ & $6.12 \%$ & $8.70 \%$ \\
\hline \multirow{2}{*}{\multicolumn{4}{|c|}{ Geometric Average }} & \multicolumn{2}{|c|}{ Risk Premium } & & \\
\hline & & & & Stocks - T.B & Stocks - T.Bo & nds & \\
\hline $1928-2017$ & $9.65 \%$ & $3.39 \%$ & $4.88 \%$ & $6.26 \%$ & $4.77 \%$ & & \\
\hline $1968-2017$ & $10.05 \%$ & $4.77 \%$ & $6.76 \%$ & $5.28 \%$ & $3.29 \%$ & & \\
\hline $2008-2017$ & $8.42 \%$ & $0.41 \%$ & $3.86 \%$ & $8.01 \%$ & $4.56 \%$ & & \\
\hline
\end{tabular}

Figura 76. Prima de riesgo (Rf-RM). Recuperado de http://pages.stern.nyu.edu/ adamodar/New_Home_Page/datafile/Betas.html

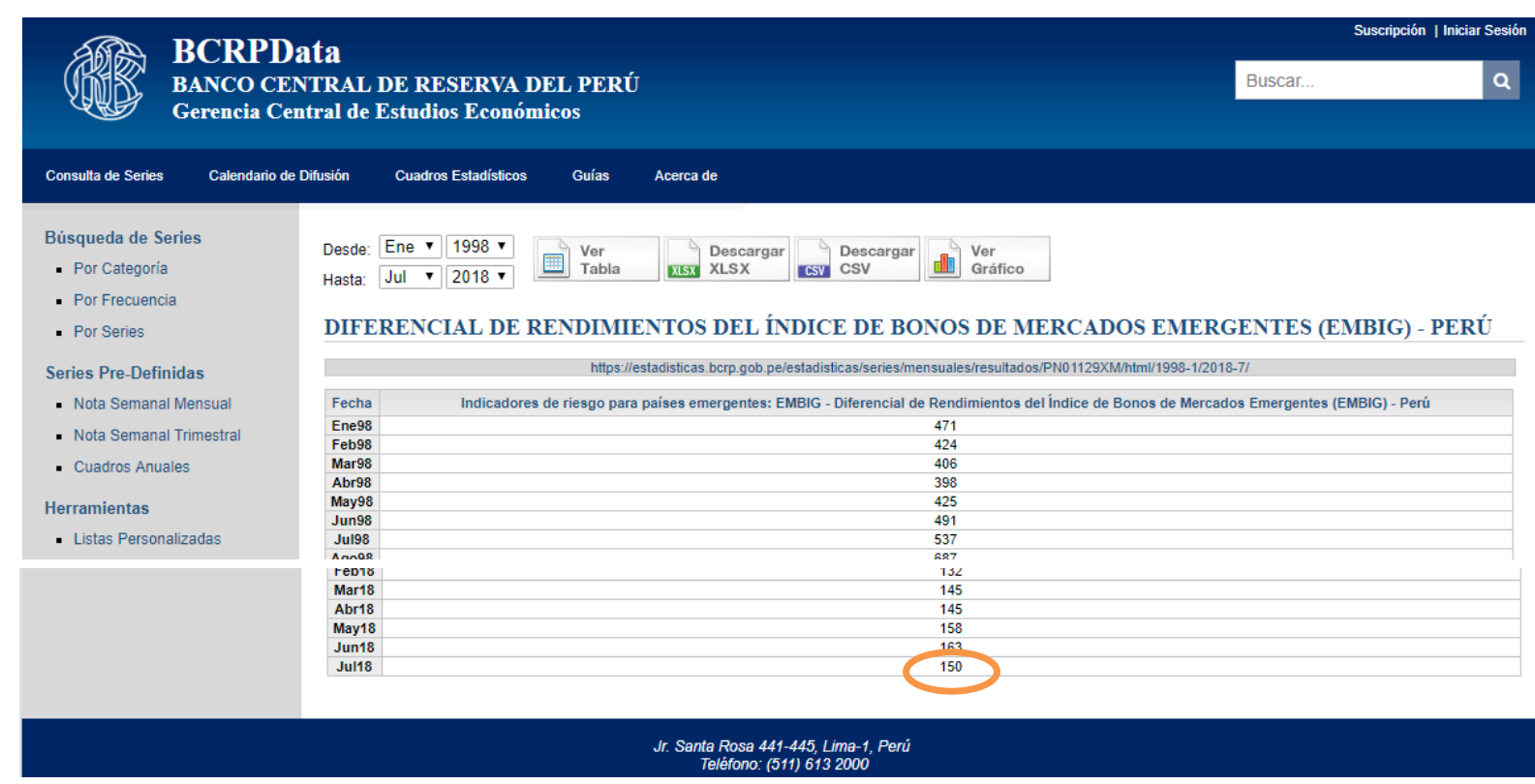

Figura 77. Riesgo país Perú. Banco Central de Reserva del Perú, Gerencia Central de Estudios Económicos. Recuperado de https://estadisticas.bcrp.gob.pe/estadisticas/series/mensuales/resultados/PN01129XM/html

\begin{tabular}{|l|c|r|}
\hline Inversión del proyecto & US\$ & 41,754 \\
Tasa de Riesgo libre EEUU & $\mathrm{Rf}$ & $3.01 \%$ \\
Prima de Riesgo & $\mathrm{Rm}-\mathrm{Rf}$ & $6.38 \%$ \\
Beta desapalancada & $\beta$ & 0.82 \\
Riesgo país: EMBIG Perú & $\mathrm{pbs}$ & 150 \\
\hline
\end{tabular}

Figura 78. Datos empleados para los cálculos de capital y costo de oportunidad.

Hallar Ke:

$$
\begin{gathered}
K e=R f+(R m-R f) \beta \\
K e=8.24 \%
\end{gathered}
$$


Este valor de Ke es lo que pedirían los accionistas de ejecutarse el proyecto en EE.UU. Se ajusta el costo de oportunidad de los inversionistas por el riesgo país. Se utiliza la aproximación simple, esto es sumar al Ke, el riesgo país, lo que equivale a $1.5 \%$.

Ajustamos Ke:

$$
\text { Ke }+ \text { Riesgo país }=9.74 \%
$$

Lo cual indica que los accionistas que quieran invertir en este proyecto en el Perú, esperan ganar no menos de $9.74 \%$ en dólares.

\subsubsection{Costo de capital promedio ponderado}

Luego de haber calculado el Ke (COK) del inversionista, se procede a calcular el costo promedio de capital (CPPC) o WACC (Weighted Average Cost of Capital).

Considerando que el proyecto no cuenta con apalancamiento financiero, el costo promedio ponderado será el mismo que el Ke (Perú) calculado.

\subsection{Presupuesto Base}

Se efectuará la estimación de los diferentes presupuestos que aplica a la empresa de servicios. En la figura 79 se muestra los valores de los desembolsos mensuales, los cuales serán clasificados en los diferentes presupuestos de cada área de la empresa.

\begin{tabular}{|l|r|}
\hline \multicolumn{1}{|c|}{ DESEMBOLSOS MENSUALES } & $\begin{array}{c}\text { Monto/mes } \\
\text { (U.S.\$) }\end{array}$ \\
\hline Materiales y Utiles de Oficina & 106 \\
\hline Sueldos y salarios & 7,964 \\
\hline Alquiler & 606 \\
\hline Gastos de luz, agua, teléfono, internet & 212 \\
\hline Mantto. Fiduciario & 364 \\
\hline Mantto. Portal web & 212 \\
\hline Mantto. Y limpieza & 106 \\
\hline Seguros, sistema de vigilancia & 144 \\
\hline Marketing y publicidad & 970 \\
\hline Capacitación & 152 \\
\hline
\end{tabular}

Figura 79. Costos de Desembolsos mensuales. Montos en dólares. 


\subsubsection{Presupuesto de ventas}

La presente proyección por ventas parte de la demanda presentada en el Capítulo IV pronóstico de ventas, proyección del mercado objetivo.

Tabla 33

Ingreso de ventas por año

\begin{tabular}{cccccc}
\hline & \multicolumn{5}{c}{ Año } \\
& 1 & 2 & 3 & 4 & 5 \\
\hline Ingresos Ventas US\$. & 128,303 & 138,567 & 148,832 & 159,096 & 169,360 \\
Ingresos Ventas S/. & 423,400 & 457,272 & 491,144 & 525,016 & 558,888 \\
\hline
\end{tabular}

\subsubsection{Presupuesto de costo de producción}

\begin{tabular}{|l|r|r|r|r|r|}
\hline Concepto Costo de Producción & $\mathbf{2 0 1 9}$ & $\mathbf{2 0 2 0}$ & $\mathbf{2 0 2 1}$ & $\mathbf{2 0 2 2}$ & $\mathbf{2 0 2 3}$ \\
\hline Materiales y Utiles de Oficina & 1,273 & 1,361 & 1,455 & 1,556 & 1,663 \\
\hline Sueldos y salarios & 95,573 & 95,573 & 95,573 & 95,573 & 95,573 \\
\hline Alquiler & 7,273 & 7,273 & 7,273 & 7,273 & 7,273 \\
\hline Gastos de luz, agua, teléfono, internet & 1,527 & 1,527 & 1,527 & 1,527 & 1,527 \\
\hline Mantto. Fiduciario y Mantto. Portal web & 6,909 & 6,909 & 6,909 & 6,909 & 6,909 \\
\hline Depreciacion & 2,039 & 2,039 & 2,039 & 2,039 & 2,039 \\
\hline Total & 114,594 & 114,683 & 114,777 & 114,877 & 114,985 \\
\hline
\end{tabular}

Figura 80. Costos de Producción. Montos en dólares.

\subsubsection{Presupuesto de compras}

No se considera en este punto pues no hay consumo de material primas e insumos, ya que no se elaboran productos sino se brindan servicios.

\subsubsection{Presupuesto de costo de ventas}

Costo de Ventas es igual al Costo de Producción, todo lo que se produce se vende, ya que se trata de servicios. 


\subsubsection{Presupuesto de gastos administrativos}

\begin{tabular}{|l|r|r|r|r|r|}
\hline Concepto de Gastos Administrativos & $\mathbf{2 0 1 9}$ & $\mathbf{2 0 2 0}$ & $\mathbf{2 0 2 1}$ & $\mathbf{2 0 2 2}$ & $\mathbf{2 0 2 3}$ \\
\hline Mantto. Y limpieza & 1,273 & 1,273 & 1,273 & 1,273 & 1,273 \\
\hline Gastos de luz, agua, teléfono, internet & 1,018 & 1,018 & 1,018 & 1,018 & 1,018 \\
\hline Seguros, sistema de vigilancia & 1,727 & 1,727 & 1,727 & 1,727 & 1,727 \\
\hline Amortizacion & 400 & 400 & 400 & 400 & 400 \\
\hline Total & 4,418 & 4,418 & 4,418 & 4,418 & 4,418 \\
\hline
\end{tabular}

Figura 81. Gastos administrativos, montos dados en dólares.

\subsubsection{Presupuesto de marketing y ventas}

\begin{tabular}{|l|r|r|r|r|r|}
\hline Concepto Gastos Marketing y Ventas & $\mathbf{2 0 1 9}$ & $\mathbf{2 0 2 0}$ & $\mathbf{2 0 2 1}$ & $\mathbf{2 0 2 2}$ & $\mathbf{2 0 2 3}$ \\
\hline Marketing y publicidad & 1,182 & 1,249 & 1,321 & 1,397 & 1,479 \\
\hline Capacitación & 152 & 152 & 152 & 152 & 152 \\
\hline Total & 1,333 & 1,401 & 1,472 & 1,549 & 1,631 \\
\hline
\end{tabular}

Figura 82. Presupuesto para marketing y ventas, montos dados en dólares.

\subsubsection{Presupuesto de gastos financieros}

Este punto no aplica, el gasto por concepto de mantenimiento de la cuenta fiduciaria se encuentra en desembolsos diversos (ver figura 71).

\subsection{Presupuesto de Resultados}

\subsubsection{Estado de Resultados}

\begin{tabular}{|l|r|r|r|r|r|}
\cline { 2 - 5 } \multicolumn{1}{c|}{ Montos en (U.S. \$) } & $\mathbf{2 0 1 9}$ & $\mathbf{2 0 2 0}$ & $\mathbf{2 0 2 1}$ & $\mathbf{2 0 2 2}$ & $\mathbf{2 0 2 3}$ \\
\hline Ingresos de Ventas & 128,303 & 138,567 & 148,832 & 159,096 & 169,360 \\
\hline Costos & 114,594 & 114,683 & 114,777 & 114,877 & 114,985 \\
\hline Utilidad Bruta & 13,709 & 23,885 & 34,055 & 44,219 & 54,375 \\
\hline Gastos de Administración & 4,418 & 4,418 & 4,418 & 4,418 & 4,418 \\
\hline Gastos de Marketing y Ventas & 1,333 & 1,401 & 1,472 & 1,549 & 1,631 \\
\hline Utilidad Operativa & 7,957 & 18,066 & 28,164 & 38,252 & 48,327 \\
\hline Gastos Financieros & - & - & - & - & - \\
\hline Utilidas antes de Inpuestos & 7,957 & 18,066 & 28,164 & 38,252 & 48,327 \\
\hline Impuestos a la Renta 10\% & 796 & 1,807 & 2,816 & 3,825 & 4,833 \\
\hline Utilidas antes de Dividendos & 7,161 & 16,259 & 25,348 & 34,426 & 43,494 \\
\hline Dividendos 25\% & - & - & 6,337 & 8,607 & 10,874 \\
\hline Utilidad/Pérdida & 7,161 & 16,259 & 19,011 & 25,820 & 32,621 \\
\hline
\end{tabular}

Figura 83. Ganancias y pérdidas proyectadas. 
- Los Gastos de administración y ventas incluyen la depreciación de los activos correspondientes.

- $\quad$ El Impuesto a la Renta utilizado es 10\%.

- Todas las cifras se encuentran expresadas en dólares americanos. El tipo de cambio es de S/. 3.3 por dólar.

- El horizonte de evaluación es de 5 años.

\subsubsection{Balance proyectado}

\begin{tabular}{|c|c|c|c|c|c|c|}
\hline Montos en (U.S.\$) & Año 0 & Año 1 & Año 2 & Año 3 & Año 4 & Año 5 \\
\hline Activos & & 2019 & 2020 & 2021 & 2022 & 2023 \\
\hline \multicolumn{7}{|l|}{ Activos Corrientes } \\
\hline Cajas & 15,660 & 26,057 & 45,766 & 74,563 & 106,100 & 144,434 \\
\hline Cuentas por cobrar & 0 & 0 & 0 & 0 & 0 & 0 \\
\hline Total Activos Corrientes & 15,660 & 26,057 & 45,766 & 74,563 & 106,100 & 144,434 \\
\hline \multicolumn{7}{|l|}{ Activ os No Corrientes } \\
\hline Otros activos financieros & 0 & 0 & 0 & 0 & 0 & 0 \\
\hline Inmueble, maquinaria y equipo neto & 12,344 & 12,344 & 12,344 & 12,344 & 12,344 & 12,344 \\
\hline Depreciación & & $(2,039)$ & $(4,078)$ & $(6,118)$ & $(8,157)$ & $(10,196)$ \\
\hline Activos intangibles Neto & 13,750 & 13,750 & 13,750 & 13,750 & 13,750 & 13,750 \\
\hline Amortización & & $(400)$ & $(800)$ & $(1,200)$ & $(1,600)$ & $(2,000)$ \\
\hline Otros activos & 0 & 0 & 0 & 0 & 0 & 0 \\
\hline Total Activos No Corrientes & 26,094 & 23,655 & 21,215 & 18,776 & 16,337 & 13,898 \\
\hline TOTALACTIVOS & 41,754 & 49,711 & 66,981 & 93,339 & 122,437 & 158,332 \\
\hline \multicolumn{7}{|l|}{ PASIVOS } \\
\hline \multicolumn{7}{|l|}{ Pasivos Corrientes } \\
\hline Préstamos bancarios & - & - & - & - & - & - \\
\hline Tributos por pagar & - & 796 & 1,807 & 2,816 & 3,825 & 4,833 \\
\hline Dividendos & - & - & - & 6,337 & 8,607 & 10,874 \\
\hline Total Pasivos Corrientes & - & 796 & 1,807 & 9,153 & 12,432 & 15,706 \\
\hline \multicolumn{7}{|l|}{ Pasivos No Corrientes } \\
\hline Obligaciones financie ras a largo plazo & - & - & - & - & - & - \\
\hline Total Pasivos No Corrientes & - & - & - & - & - & - \\
\hline TOTAL PASIVOS & - & 796 & 1,807 & 9,153 & 12,432 & 15,706 \\
\hline \multicolumn{7}{|l|}{ PATRIMONIO } \\
\hline Capital Social & 41,754 & 41,754 & 41,754 & 41,754 & 41,754 & 41,754 \\
\hline Utilidad del ejercicio & 0 & 7,161 & 16,259 & 19,011 & 25,820 & 32,621 \\
\hline Utilidad acumulada & 0 & - & 7,161 & 23,421 & 42,432 & 68,251 \\
\hline Total Patrimonio & 41,754 & 48,916 & 65,175 & 84,186 & 110,006 & 142,626 \\
\hline TOTAL PASIVOS Y PATRIMONIO & 41,754 & 49,711 & 66,981 & 93,339 & 122,437 & 158,332 \\
\hline
\end{tabular}

Figura 84. Balance Proyectado. 


\subsubsection{Flujo de caja proyectado}

\begin{tabular}{|c|c|c|c|c|c|c|}
\hline Montos en (U.S.\$) & Año 0 & Año 1 & Año 2 & Año 3 & Año 4 & Año 5 \\
\hline & & 2019 & 2020 & 2021 & 2022 & 2023 \\
\hline \multicolumn{7}{|l|}{ Ingresos } \\
\hline Ventas & & 151,398 & 163,509 & 175,621 & 187,733 & 199,845 \\
\hline Total de Ingresos & & 151,398 & 163,509 & 175,621 & 187,733 & 199,845 \\
\hline \multicolumn{7}{|l|}{ Egresos } \\
\hline Materiales y Utiles de Oficina & & 1,273 & 1,361 & 1,455 & 1,556 & 1,663 \\
\hline Sueldos y salarios & & 95,573 & 97,963 & 100,352 & 102,741 & 105,131 \\
\hline Alquiler & & 11,636 & 11,636 & 11,636 & 11,636 & 11,636 \\
\hline Gastos de luz, agua, teléfono, internet & & 1,527 & 1,527 & 1,527 & 1,527 & 1,527 \\
\hline Mantto. Fiduciario & & 2,545 & 2,545 & 2,545 & 2,545 & 2,545 \\
\hline Sub-total de Costos de Produccion & & 112,555 & 115,033 & 117,516 & 120,006 & 122,503 \\
\hline Gastos de Administración & & 4,018 & 4,018 & 4,018 & 4,018 & 4,018 \\
\hline Gastos de Marketing y Ventas & & 1,333 & 1,401 & 1,472 & 1,549 & 1,631 \\
\hline Depreciación & & 2,039 & 2,039 & 2,039 & 2,039 & 2,039 \\
\hline Amortización & & 400 & 400 & 400 & 400 & 400 \\
\hline Total de Egresos & & 120,346 & 122,891 & 125,446 & 128,012 & 130,591 \\
\hline Utilidad antes de impuestos & & 31,052 & 40,619 & 50,175 & 59,721 & 69,254 \\
\hline Impuesto a la renta & & $3,105.16$ & $4,061.87$ & $5,017.53$ & $5,972.08$ & $6,925.43$ \\
\hline Dividendos & & - & - & 6,337 & 8,607 & 10,874 \\
\hline Flujo de caja proyectado sin IGV & $(41,754)$ & 27,946 & 36,557 & 38,821 & 45,142 & 51,455 \\
\hline
\end{tabular}

Figura 85. Flujo de caja proyectado

\begin{tabular}{l|l|c|c|c|c|c|c|}
\cline { 2 - 7 } \multirow{2}{*}{$\begin{array}{l}\text { Montos en (U.S. \$) } \\
\text { IGV }\end{array}$} & Año 0 & Año 1 & Año 2 & Año 3 & Año 4 & Año 5 \\
\cline { 2 - 7 } & & $\mathbf{2 0 1 9}$ & $\mathbf{2 0 2 0}$ & $\mathbf{2 0 2 1}$ & $\mathbf{2 0 2 2}$ & $\mathbf{2 0 2 3}$ \\
\hline IGV Recibido & & $23,094.55$ & $24,942.11$ & $26,789.67$ & $28,637.24$ & $30,484.80$ \\
\hline IGV Pagado & $(5,959.10)$ & $(4,459.05)$ & $(4,487.02)$ & $(4,516.87)$ & $(4,548.74)$ & $(4,582.75)$ \\
\hline IGV a Pagar & & $(18,635.49)$ & $(20,455.09)$ & $(22,272.80)$ & $(24,088.50)$ & $(25,902.05)$ \\
\hline Crédito Fiscal & $5,959.10$ & - & - & - & - & - \\
\hline IGV Neto & - & $(12,676.39)$ & $(20,455.09)$ & $(22,272.80)$ & $(24,088.50)$ & $(25,902.05)$ \\
\hline
\end{tabular}

Figura 86. IGV en el flujo de caja.

\begin{tabular}{|c|c|c|c|c|c|c|}
\hline \multirow[b]{2}{*}{ Montos en (U.S. \$) } & Año 0 & Año 1 & Año 2 & Año 3 & Año 4 & Año 5 \\
\hline & & 2019 & 2020 & 2021 & 2022 & 2023 \\
\hline Flujo de caja proyectado & $(41,754)$ & 27,946 & 36,557 & 38,821 & 45,142 & 51,455 \\
\hline IGV Neto & - & $(12,676)$ & $(20,455)$ & $(22,273)$ & $(24,088)$ & $(25,902)$ \\
\hline Flujo Neto Incluido IGV & $(41,754)$ & 15,270 & 16,102 & 16,548 & 21,054 & 25,553 \\
\hline VAN & 26,074 & & & & & \\
\hline TIR & $31 \%$ & & & & & \\
\hline
\end{tabular}

Figura 87. Flujo de caja proyectado incluido IGV. 


\section{- Periodo de recuperación de la inversión DESCONTADO}

Tasa de Descuento utilizada para valorar la inversión es del 10\%

Desembolso inicial es de 41754.18

Flujo de neto incluido IGV

$$
\begin{aligned}
& 15270.05 \times(1+10 \%)^{\wedge}(-1)=13881.86 \\
& 16101.75 \times(1+10 \%)^{\wedge}(-2)=13307.23 \\
& 16548.02 \times(1+10 \%)^{\wedge}(-3)=12432.77 \\
& 21053.59 \times(1+10 \%)^{\wedge}(-4)=14379.88
\end{aligned}
$$

Primer año se recupera 13881.86 dólares

Segundo año se recupera 13307.23 dólares

Tercer año se recupera 12432.77 dólares

El cuarto año 14379.88 (1198.32 por mes)

Por lo que

$$
\begin{gathered}
41754.18-39621.86=2132.32 \\
2132.32 / 1198.77=1.77
\end{gathered}
$$

Finalmente, el desembolso inicial de 41754.18 se recuperará en cuatro años con 1.77 meses. Como la inversión tiene una duración superior (5 años), se logra recuperar la cantidad desembolsada inicialmente por lo que se trata de una inversión efectuable según el plazo de recuperación descontado. 


\section{Capítulo IX. Evaluación Económica Financiera}

\subsection{Evaluación Financiera}

\subsubsection{TIR}

Este punto refiere a la tasa interna de retorno o tasa interna de rentabilidad de una inversión. Gitman dice, “TIR es la tasa de rendimiento que ganara la empresa si invierte en el proyecto y recibe las entradas de efectivo esperadas".

Luego de haber calculado el costo de oportunidad de los inversionistas (Ke o COK) en el punto 8.2.2. del presente documento, se utilizará para comparar la inversión del dinero con respecto a otra oportunidad con rentabilidad alternativa; del mismo modo para calcular el TIR.

$\mathrm{Ke}$ o $\mathrm{COK}$

TIR ECONÓMICO (TIRE)
$9.74 \%$

$31 \%$

A nivel de flujos económicos, el TIR económico del proyecto se encuentra por encima del $\mathrm{Ke}(\mathrm{COK})$, dando un indicador parcial de viabilidad del proyecto.

\subsubsection{VAN}

Este punto refiere al valor presente neto, es el método usado por la mayoría de las grandes empresas para evaluar proyectos de inversión. Para calcular este indicador, es necesario considerar el costo de las fuentes de financiamiento.

\section{VAN ECOMICO (VANE) US $\quad$ U26,074}

Según el resultado del presente indicador, se puede aprobar la inversión debido que el VAN es mayor de cero, indicando que el proyecto es rentable o recomendable, además que retornaría 26.074 dólares como monto adicional a la recuperación del dinero de la inversión. 


\subsubsection{ROE}

Este punto refiere a la capacidad que tiene el proyecto para remunerar a sus inversionistas. Se obtiene calculando el cociente entre el beneficio neto después de impuestos y los fondos propios.

Tabla 34

$R O E$

\begin{tabular}{llccccc}
\hline Indicador & Fórmula & Año 1 & Año 2 & Año 3 & Año 4 & Año 5 \\
\hline ROE & $\begin{array}{l}\text { Utilidad Neta/Capital } \\
\text { Social }\end{array}$ & 0.17 & 0.39 & 0.46 & 0.62 & 0.78 \\
\hline
\end{tabular}

Se puede apreciar que el indicador muestra una rentabilidad positiva, el primer año empieza a recibir 17 dólares por cada 100 dólares invertidos; manteniendo una tendencia estable.

\subsubsection{Ratios}

-Margen de Beneficio Neto (Rentabilidad de los Ingresos)

Este indicador lo obtenemos dividiendo las utilidades antes de intereses y/o impuestos entre las ventas, indicando el beneficio obtenido por cada dólar de venta.

Tabla 35

Margen Beneficio Neto

\begin{tabular}{llccccc}
\hline Indicador & Fórmula & Año 1 & Año 2 & Año 3 & Año 4 & Año 5 \\
\hline $\begin{array}{l}\text { Beneficio } \\
\text { Neto }\end{array}$ & $\begin{array}{l}\text { Utilidad antes de } \\
\text { intereses o } \\
\text { Impuestos / ventas }\end{array}$ & 0.06 & 0.13 & 0.19 & 0.24 & 0.29 \\
& & & & & \\
\hline
\end{tabular}

Este indicador muestra una utilidad de 6 centavos de dólar, por cada dólar que se invierte, sin embargo, empezando con un margen bajo, pero con una tendencia de crecimiento positiva en los siguientes años.

-Rendimiento sobre la inversión (Índice rentabilidad económica) 
Este indicador lo obtenemos dividiendo las utilidades antes de intereses y/o impuestos entre el activo total, indicando el beneficio obtenido por cada dólar invertido en el activo total.

Tabla 36

Rendimiento sobre la inversión

\begin{tabular}{llccccc}
\hline Indicador & Fórmula & Año 1 & Año 2 & Año 3 & Año 4 & Año 5 \\
\hline $\begin{array}{l}\text { Rendimiento } \\
\text { sobre }\end{array}$ & $\begin{array}{l}\text { Utilidad antes de } \\
\text { intereses y/o }\end{array}$ & 0.16 & 0.27 & 0.30 & 0.31 & 0.31 \\
la inversión & \begin{tabular}{l} 
Impuestos / Activo \\
\hline
\end{tabular}
\end{tabular}

Este indicador muestra una ganancia de 16 centavos de dólar, por cada dólar que se invierte en el total de activos; sin embargo el indicador se mantiene en promedio. De este punto se concluye que se tiene una alta responsabilidad en la eficacia de gestión, pues es preciso tener alta razón de rotación y buen margen de utilidad sobre las ventas, cabe analizar también la posibilidad de invertir en el activo como en equipos e implementación en inmuebles a fin de mejorar las ventas.

\section{-Liquidez corriente}

Este indicador lo obtenemos dividiendo el activo circulante (compuesto por el efectivo, caja y bancos) y el pasivo circulante (obligaciones a corto plazo de la empresa).

Tabla 37

\section{Liquidez Corriente}

\begin{tabular}{|c|c|c|c|c|c|c|}
\hline Indicador & Fórmula & Año 1 & Año 2 & Año 3 & Año 4 & Año 5 \\
\hline \multirow[t]{2}{*}{$\begin{array}{l}\text { Liquidez } \\
\text { corriente }\end{array}$} & Activos Corrientes & \multirow[t]{2}{*}{1.10} & \multirow[t]{2}{*}{2.16} & \multirow[t]{2}{*}{3.97} & \multirow[t]{2}{*}{6.49} & \multirow[t]{2}{*}{10.39} \\
\hline & Pasivos Corrientes & & & & & \\
\hline
\end{tabular}


Este indicador nos muestra que para el año 2019 (primer año) por cada dólar de deuda a corto plazo se cuenta con 1.10 dólares para pagar, es decir existe suficiente caja para hacer frente a mis obligaciones financieras.

-Índice de endeudamiento

Este indicador lo obtenemos dividiendo el total de pasivos entre el total de activos.

Tabla 38

Índice de Endeudamiento

\begin{tabular}{lcccccc}
\hline Indicador & Fórmula & Año 1 & Año 2 & Año 3 & Año 4 & Año 5 \\
\cline { 1 - 2 } $\begin{array}{l}\text { Índice de } \\
\text { Endeudamiento }\end{array}$ & Total pasivo & 0.02 & 0.03 & 0.10 & 0.10 & 0.10 \\
\cline { 2 - 3 } & Total activo & & & & & \\
\hline
\end{tabular}

Este indicador da una visión de la magnitud de la deuda de la empresa, en el proyecto, este indicador muestra un bajo grado de apalancamiento de $2 \%$, sin embargo esto se sustenta en el riesgo asumido por los accionistas/inversores, esto permitiría también al proyecto enfrentar responsabilidades financieras en los próximos años.

-Margen utilidad operativa

Este indicador lo obtenemos dividiendo la utilidad operativa con respecto a las ventas.

Tabla 39

Margen utilidad operativa

\begin{tabular}{lcccccc}
\hline Indicador & Fórmula & Año 1 & Año 2 & Año 3 & Año 4 & Año 5 \\
\hline $\begin{array}{l}\text { Margen de } \\
\text { utilidad } \\
\text { operativa }\end{array}$ & Utilidad operativa & 0.06 & 0.13 & 0.19 & 0.24 & 0.29 \\
\cline { 2 - 2 } & Ventas & & & & & \\
\hline
\end{tabular}


Este indicador dice cuál ha sido la eficiencia de la empresa de generar ingresos durante un periodo determinado, este indicador muestra que el proyecto empieza una tendencia creciente y sostenida, a partir del segundo año. En el caso del proyecto, los resultados del indicador muestra la relación directa entre los costos de venta y los gastos operacionales del proyecto, mostrando una utilidad mínima que permite cubrir actividades a partir del segundo año, pero con una tendencia al alta, sólida y creciente. Esto se sustenta en que se cuenta con más costos fijos que variables, generando al proyecto mayor riesgo, pero mayor rentabilidad.

-Margen de utilidad neta

Este indicador se obtiene dividiendo la utilidad neta con respecto a las ventas.

Tabla 41

Margen de utilidad neta

\begin{tabular}{lcccccc}
\hline Indicador & Fórmula & Año 1 & Año 2 & Año 3 & Año 4 & Año 5 \\
\hline $\begin{array}{l}\text { Margen de } \\
\text { utilidad }\end{array}$ & Utilidad neta & 0.06 & 0.12 & 0.13 & 0.16 & 0.19 \\
\cline { 2 - 3 } $\begin{array}{l}\text { Neta } \\
\text { Ventas }\end{array}$ & & & & & \\
\hline
\end{tabular}

Este indicador demuestra la tasa de utilidad obtenida de las ventas y otros ingresos por cada dólar de venta, este indicador muestra que el proyecto presenta una tendencia creciente.

\subsection{Análisis de Riesgo}

Los criterios de evaluación mencionados hasta ahora para calcular la rentabilidad del proyecto no son exactos ya que solamente están indicando uno de los posibles escenarios del proyecto.

Hay que tener en cuenta que los cambios del entorno y de las variables estimadas son imposibles de predecir con exactitud. Por ejemplo, puede ocurrir que los precios a cobrar una 
vez que se inaugure el proyecto sean menores que los estimados, o que la demanda sea mayor, o que los salarios a pagar sean mayores, etc.

Por tal razón, la decisión de invertir o no en este proyecto no debería basarse solamente en el cálculo del VAN realizado previamente, sino en la comprensión del origen de la rentabilidad del proyecto y del posible cambio en las variables estimadas. La finalidad del análisis de sensibilidad consiste en mejorar la calidad de la información para que el inversor tenga una herramienta adicional para decidir si invierte o no en el proyecto.

\subsubsection{Análisis de punto de equilibrio}

\begin{tabular}{|lr|}
\hline PUNTO DE EQUILIBRIO & \\
\hline COSTOS FIJOS & 88950.70 \\
COSTOS VARIABLES & 31395.27 \\
INGRESOS ANO 1 & 151397.58 \\
BENEFICIO ANUAL & 15270.05 \\
Relacion Ingresos/Egresos & 0.79 \\
\hline PUNTO DE EQUILIBRIO EN VOLUMEN & \\
\hline Margen de Contribucion = Total de Ventas - Total de Costos Variables \\
$\%$ de Margen bruto = (Precio de venta - costo variable) / precio de venta \\
P.E. : Costos Fijos / Margen de Contribución \\
P.E. : 88950.7/(0.79) \\
P.E. : U.S.\$112595.8
\end{tabular}

Figura 88. Punto de equilibrio

Se debe vender en volumen US\$112 595.8 dólares para no ganar o perder, los ingresos proyectados el primer año superan por $34 \%$ el punto de equilibrio, el cual se debe estar alcanzando en el mes 9.

\subsubsection{Análisis de sensibilidad}

Aquí se evaluará hasta qué punto pueden cambiar las variables del proyecto para que el VAN sea cero. Es un análisis unidimensional, o sea que se estudia una variable por vez, manteniendo todas las demás constantes.

- Los precios estimados disminuyen en $4.9 \%$ (Precios/ Ventas)

- $\quad$ Si los costos fijos se incrementan en más de $8.74 \%$ (CF) 
- Si los costos variables se incrementan en más de 24.1\% (CV Servicios)

- Si las inversiones se incrementan en $300 \%$

Como se puede observar, el proyecto es sensible ante la variación de precios y/o descuentos, no pudiendo ser mayor al $4.9 \%$, en segundo término al incremento de un $8.74 \%$ por parte de los costos fijos, esto es comprensible dado que se tiene alto riesgo por inversión en costos fijos en comparación de costos variables. Es también sensible al incremento de más de $24.1 \%$ en los costos variables y finalmente al incremento del $300 \%$ por parte de las inversiones. En tal sentido se podría considerar a los precios y costos fijos como variables críticas a considerar.

Como se pudo apreciar, tanto en el análisis de ratios así como en el análisis de sensibilidad, el riesgo más alto del proyecto se encuentra ubicado en la cantidad de ventas o en la baja de precios en las en las ventas; sin embargo, es importante considerar que el los productos ofrecidos, en la forma que se han modelado, presentan una alternativa bastante amplia en posibilidades a un segmento de mercado que no encontraría opciones similares en el medio. El presente proyecto se presenta como una alternativa bastante atractiva para viabilizar movimientos económicos tanto a nivel de préstamo como inversión, con los suficientes medios legales que reduzcan riesgos en comparación de operaciones informales y/o ilegales. Bajo la presente consideración, se podría sustentar que el número de ventas propuestas se encuentra en un escenario bastante conservador acercándose a un escenario pesimista, por lo que se estimaría tener más ventas que las propuestas.

Es importante considerar también que se cuenta con capacidad operativa a medio nivel, por lo que se podría ser más agresivo en la captación y retención de clientes, del mismo modo se contaría con la capacidad de generar subproductos especializados por sector 
productivo y generar mayor diversificación de productos o subproductos más especializados en áreas que sean las más redituables.

Finalmente es importante considerar que por la capacidad operativa disponible, ante un escenario de pocas ventas, se podría maximizar recursos disponibles, orientándolos a búsqueda, seguimiento y optimización en la captación de clientes, con por ejemplo workshops, cursos básicos promocionales gratuitos, visitas a centros de emprendimientos en universidades institutos entre otros, realizando alianzas estratégicas con incubadoras de negocios, empresas que trabajen patrocinando o buscando o formando start ups, municipios, grupos religiosos, entre otros. 


\section{Conclusiones y Recomendaciones}

\section{Conclusiones}

\section{Análisis del micro y macro entorno de la industria}

Se considera necesario encontrar nuevas vías y sistemas de financiación para poder ofrecer a la población nuevas alternativas de financiamiento e inversión, llegando a la conclusión de que realmente hay un nicho insatisfecho de clientes que, dado el desarrollo de las nuevas tecnologías, demandan de un servicio más acorde a sus necesidades. Por lo que el presente plan de negocio considera que el establecer una empresa que ayude a financiar a ideas de negocio y emprendimientos es factible tanto en términos de mercado, técnicos, económicos y financieros, toda vez que esta representa una alternativa frente al financiamiento tradicional el cual podría llegar hacer inviable un emprendimiento inicial colaborando con su posible mortandad. Se concluye que existe un sustento claro a la falta de inclusión financiera, tanto por cultura financiera de la población, productos financieros alternativos y más rentables para los usuarios finales, asesores independientes o empresas con mecanismos que incluyan los mecanismos que en este proyecto proponemos.

\section{Estudio de mercado para el proyecto justificando la cantidad de servicios u ofertas}

\section{financieras a brindar y la mejor forma para comercializar}

Se evidencia un nicho de mercado el cual no es satisfecho por el sistema financiero tradicional. El público objetivo son hombres y mujeres de 25 a 55 años de edad, pertenecientes al PEA y a los NSE A, B, C, D y E, que radican en la ciudad de Arequipa. El local de atención se encontrará ubicado en el distrito de Yanahuara. Los resultados cualitativos y cuantitativos justifican y demuestran el interés del mercado, tanto de las personas que buscan un financiamiento como las que buscan donde invertir, que no sean las tradicionales, se puede percibir la falta de conformidad con las entidades financieras tradicionales, hay un $44 \%$ que está dispuesto a probar nuevas alternativas distintas a las 
tradicionales. Se pudo encontrar que existe un alto porcentaje de personas emprendedoras (36\%) con ideas innovadoras pero no se concretan por falta de capital y que recurren al financiamiento informal, corriendo el riesgo de pagar altos intereses.

También se debe considerar la falta de una educación financiera, así como asesoramiento, que es la actividad más solicitada (44\%) cuando se trata de hacer crecer o emprender un negocio.

3 Ingeniería del proyecto, determinando la estrategia para brindar calidad superior a los rivales, costos más bajos, alternativas más atractivas y obtener una satisfacción más elevada

Se concluyen como productos aceptables para ejecutar el proyecto, los productos expuestos en el presente proyecto:

- Servicios de inversión y financiamiento: Licitación de préstamo, para obtención de acceder a liquidez a cambio de un interés.

- Ventas: Se ofrecen los servicios de ventas por adelantado;

- Servicios especiales: Venta de derechos o participaciones, elaboración de contratos, asesoría empresarial, entre otros.

- Asesoría y Capacitación.

La empresa contará con una oficina donde se realizarán todas las actividades del servicio, así como también se contará con una plataforma online en donde se podrá encontrar toda la información de los servicios y de cómo funciona el sistema, también la publicación de solicitudes de financiamiento, servicio de chat en línea y de mensajería.

IDelta se encargará de recopilar información tanto de los inversionistas como de los que buscan financiamiento y armar un perfil de cada cliente, ellos podrían destinar entre S/ 
5,000 soles y S/ 10,000 soles como inversión para diferenciar su riesgo a cambio de mejores tasas de rentabilidad, que oscilan entre 10-17\% anual. En el caso de los que buscan financiamiento se evalúa su historial crediticio, su grado de estabilidad y la del negocio y las actividades laborales o comerciales que realiza. Como valor del producto demandan la seguridad de la inversión, un valor que genera confianza en el servicio.

\section{Plan de marketing, identificando los canales o medios óptimos de contacto con los clientes, basados en la identificación de las necesidades y tendencias de los clientes}

Se concluye que la empresa contará con una oficina donde se realizarán todas las actividades del servicio, así como también se contará con una plataforma online en donde se podrá encontrar toda la información de los servicios y de cómo funciona el sistema, también la publicación de solicitudes de financiamiento, servicio de chat en línea y de mensajería. IDeltas se encargará de recopilar información tanto de los inversionistas como de los que buscan financiamiento y armar un perfil de cada cliente. En el caso de los que buscan financiamiento se evalúa su historial crediticio, su grado de estabilidad y la del negocio y las actividades laborales o comerciales que realiza. Como valor del producto demandan la seguridad de la inversión, un valor que genera confianza en el servicio. Soportando así el plan de marketing el cual se data en marketing tradicional y marketing digital.

- Nuestra estrategia de precios frente a los que buscan un financiamiento, será el de cobrar comisiones por debajo de las comisiones bancarias.

- El principal canal de la empresa será el que se brinda en el mismo establecimiento de forma directa. Otros canales de distribución están: a través de una plataforma online, vía telefónica (telemercadotecnia) y correo electrónico. También algunos medios escritos como tarjetas de presentación, distribución de portafolios con contenido promocional y presentación de servicios, toda la papelería que salga de la empresa debe estar identificada con la imagen corporativa de la organización. 
- Para lograr posicionarse y mantenerse en el mercado la empresa IDeltas SAC tiene los objetivos publicitarios y promocionales: Diseñar material publicitario y de comunicación. Recopilar información sobre las áreas de mercadeo. Participar y realizar una fuerte presencia en eventos empresariales. Material publicitario a través de la plataforma online. Así también se considera realizar eventos como el Día de Lanzamiento. Mercadeo y relaciones publicitarias.

\section{Análisis de la rentabilidad o viabilidad financiera del proyecto}

Se concluye que la inversión inicial requerida es de US\$41,754. Luego de proyectar los ingresos y egresos asociados al proyecto se observa que es rentable generando un valor actual neto económico igual a US\$26,07

El análisis financiero nos brinda indicadores positivos, sin embargo es sensible a una baja variación en ventas así como en los costos fijos; la razón que justifica esto es que el proyecto tiene como prioridad generar confianza entre los usuarios con costos y utilidades atractivas a nuestros clientes, siendo una apuesta rentable y socialmente positiva al entorno.

\section{Recomendaciones}

1. En un proyecto como el que se sustenta, se recomienda a futuros estudiantes ampliar esta línea de investigación dado que por interés económico personal y de apoyo a una problemática nacional (inclusión financiera), queda mucho por innovar y mejorar, el análisis del micro y macro entorno evidencia la oportunidad existente. Los nuevos modelos de financiación se presentan como una oportunidad para sectores olvidados por la banca tradicional, o que no pueden acceder a ella por el alto costo de financiamiento.

2. Ante lo evidenciado por el análisis del entorno, llega el sustento del estudio de mercado el cual nos llevaría a recomendar principalmente el ampliar el área de 
influencia, después de Arequipa ciudad se podría continuar con la Región Arequipa y hacia todo el país. Es necesario que el Estado mejore sus estrategias para impulsar inclusión financiera y aprovechar nuevas oportunidades, por ejemplo, en las zonas rurales, quienes son afectados por no contar con medios que vayan de acuerdo a sus necesidades.

3. Los mecanismos propuestos por el proyecto, permitirían aprovechar nuevas oportunidades, por lo que se recomendaría ampliar la zona de influencia a través de la ingeniería del proyecto propuesta, por ejemplo, en las zonas rurales, quienes son afectados por no contar con medios que vayan de acuerdo a sus necesidades. Los nuevos modelos de financiación se presentan como una oportunidad para sectores olvidados por la banca tradicional, o que no pueden acceder a ella por el alto costo de financiamiento.

4. Se recomienda ampliar la potencialidad del marketing digital propuesto por el proyecto a fin de ampliar el mercado objetivo en cuanto a edad, crear alianzas estratégicas con entidades educativas (universidades, institutos superiores), gobierno regional y municipal. Mejorando la capacitación en educación financiera, así como al emprendimiento con la finalidad de mejorar los negocios, el estilo de vida nuestro entorno económico, social y cultural.

5. Se recomienda finalmente mejorar la rentabilidad del proyecto a través de mejoras donde se pueda contar con un marco legal que regule los nuevos modelos de financiamiento, tomando en consideración todo lo que nos permiten las leyes actuales, que puedan así aproximarse a formas que han tenido y tienen éxito en el extranjero, como es el crowdfunding y sus derivados. 


\section{ANEXOS:}

ANEXO 1: Guías de entrevistas

\section{Guía de entrevista para inversionista}

\begin{tabular}{|c|c|c|}
\hline Día: & Hora: & \\
\hline Lugar: & Entrevistado: & \\
\hline Tema: & \multicolumn{2}{|c|}{ Oportunidades y/o Alternativas de inversión y financiación de emprendimientos } \\
\hline Pregunta 1: & \multicolumn{2}{|c|}{$\begin{array}{l}\text { ¿Qué factores considera importantes para poder determinar dónde colocar sus } \\
\text { inversiones? }\end{array}$} \\
\hline Pregunta 2: & \multicolumn{2}{|c|}{$\begin{array}{l}\text { ¿Qué sistema o alternativa de inversión uso últimamente (por ejemplo en una } \\
\text { entidad financiera o como capitalista en un negocio, etc)? }\end{array}$} \\
\hline Pregunta 3: & \multicolumn{2}{|c|}{$\begin{array}{l}\text { ¿Qué tan satisfecho o insatisfecho se sintió con esta última actividad } \\
\text { inversora? }\end{array}$} \\
\hline Pregunta 4: & \multicolumn{2}{|c|}{$\begin{array}{l}\text { ¿De invertir en algún emprendimiento o negocio, cuál cree que sería el rubro } \\
\text { de negocio con mayor expectativa? }\end{array}$} \\
\hline Pregunta 5: & \multicolumn{2}{|c|}{$\begin{array}{l}\text { ¿Le interesaría tener alternativas de inversión más rentables que las dadas en } \\
\text { modo tradicional por Bancos, Cajas Municipales, entre otros? }\end{array}$} \\
\hline Pregunta 6: & \multicolumn{2}{|c|}{$\begin{array}{l}\text { ¿Qué políticas, metodologías, condiciones y/o acciones le daría más confianza } \\
\text { ante una entidad que le ofrezca alternativas de financiación? ¿Qué } \\
\text { recomendaciones daría? }\end{array}$} \\
\hline Pregunta 7: & \multicolumn{2}{|c|}{$\begin{array}{l}\text { ¿Qué recomendaciones sobre nuevos productos/servicios (productos/servicios } \\
\text { financieros innovadores, económicos, viables) daría? (Por ejemplo generar } \\
\text { talleres, presentaciones de inversionistas e inversores) }\end{array}$} \\
\hline
\end{tabular}




\section{Guía de entrevista para emprendedor/prestatario}

\begin{tabular}{|c|c|c|}
\hline Día: & Hora: & \\
\hline Lugar: & Entrevistado: & \\
\hline Tema: & \multicolumn{2}{|c|}{ Oportunidades y/o Alternativas de inversión y financiación de emprendimientos } \\
\hline Pregunta 1: & \multicolumn{2}{|c|}{$\begin{array}{l}\text { ¿Qué factores considera importantes para poder determinar de dónde obtener } \\
\text { financiamiento para su negocio o emprender uno? }\end{array}$} \\
\hline Pregunta 2: & \multicolumn{2}{|c|}{$\begin{array}{l}\text { ¿Qué sistema o alternativa de financiamiento uso últimamente (sea de una } \\
\text { entidad formal o informal)? }\end{array}$} \\
\hline Pregunta 3: & \multicolumn{2}{|c|}{$\begin{array}{l}\text { ¿Qué tan satisfecho o insatisfecho se sintió con esta última actividad de } \\
\text { financiación? }\end{array}$} \\
\hline Pregunta 4: & \multicolumn{2}{|c|}{$\begin{array}{l}\text { ¿De emprender en algún negocio, cuál es el rubro de este negocio que cree que } \\
\text { tiene mayor expectativa? ¿Por qué? }\end{array}$} \\
\hline Pregunta 5: & \multicolumn{2}{|c|}{$\begin{array}{l}\text { ¿Le interesaría tener alternativas de financiación más rentables y más bajo } \\
\text { costo que las dadas en modo tradicional por Bancos, Cajas Municipales, entre } \\
\text { otros? }\end{array}$} \\
\hline Pregunta 6: & \multicolumn{2}{|c|}{$\begin{array}{l}\text { ¿Qué políticas, metodologías, condiciones y/o acciones le daría más confianza } \\
\text { ante una entidad que le brinde nuevas alternativas de financiación? ¿Qué } \\
\text { recomendaciones daría? }\end{array}$} \\
\hline Pregunta 7: & \multicolumn{2}{|c|}{$\begin{array}{l}\text { ¿Qué productos o servicios financieros ayudaría a que su negocio o } \\
\text { emprendimiento sea mejor? (Por ejemplo generar talleres, asesoramiento, etc.) }\end{array}$} \\
\hline
\end{tabular}


ANEXO 2: Ejecución de entrevistas

FICHA TÉCNICA DEL ENTREVISTADO

\begin{tabular}{|c|c|}
\hline Nombre: & Gaby Palma \\
\hline Edad: & 55 \\
\hline Nacionalidad: & peruana \\
\hline Ocupación: & Gerente de Empresa \\
\hline Profesión: & Administrador de negocios \\
\hline Distrito de Residencia: & Cayma \\
\hline Breve reseña: & $\begin{array}{l}\text { Inversionista. Se desempeña como distribuidor a nivel del sur del Perú } \\
\text { de productos de abarrotes, con más de } 10 \text { años de experiencia en el } \\
\text { rubro y con proyecciones a invertir en el mercado inmobiliario. }\end{array}$ \\
\hline Nombre: & Henry Jáuregui \\
\hline Edad: & 36 \\
\hline Nacionalidad: & peruana \\
\hline Ocupación: & Laboratorista \\
\hline Profesión: & Técnico Metalurgista \\
\hline Distrito de Residencia: & José Luis Bustamente y Rivero \\
\hline Breve reseña: & $\begin{array}{l}\text { Emprendedor. Trabajador dependiente en el rubro de la minería, a la } \\
\text { vez cuenta con una microempresa de juegos de entretenimiento para } \\
\text { niños. También se encuentra interesado en invertir en otros negocios en } \\
\text { el área de servicios. }\end{array}$ \\
\hline Nombre: & José Velásquez \\
\hline Edad: & 37 \\
\hline Nacionalidad: & peruana \\
\hline Ocupación: & Analista de Laboratorio \\
\hline Profesión: & Ingeniero \\
\hline Distrito de Residencia: & Hunter \\
\hline Breve reseña: & $\begin{array}{l}\text { Inversionista y emprendedor. Se desempeña como trabajador } \\
\text { dependiente en el rubro de la minería, a la vez cuenta con dos negocios } \\
\text { en el rubro de la ganadería y el catering. Cuenta con } 4 \text { años de } \\
\text { experiencia en el negocio. }\end{array}$ \\
\hline
\end{tabular}




\section{ENTREVISTA A INVERSIONISTA}

\begin{tabular}{|c|c|c|c|}
\hline Día: & 07/11/2016 & Hora: & $19: 30$ \\
\hline Lugar: & $\begin{array}{l}\text { Entrevista hecha en su } \\
\text { domicilio }\end{array}$ & Entrevistado: & Gaby Palma \\
\hline Tema: & \multicolumn{3}{|c|}{ Oportunidades y/o Alternativas de inversión y financiación de emprendimientos } \\
\hline Pregunta 1: & \multicolumn{3}{|c|}{$\begin{array}{l}\text { ¿Qué factores considera importantes para poder determinar dónde colocar sus } \\
\text { inversiones? } \\
\text { Evalúa el negocio como se mueve en el mercado, su tamaño y como va } \\
\text { creciendo, si va a invertir en otra empresa analiza al gerente y al grupo de } \\
\text { trabajo, el segmento de clientes y los canales de distribución, sobre todo } \\
\text { conocer y empaparse del negocio, el costo que implica y las ganancias que } \\
\text { genera. }\end{array}$} \\
\hline Pregunta 2: & \multicolumn{3}{|c|}{$\begin{array}{l}\text { ¿Qué sistema o alternativa de inversión uso últimamente (por ejemplo en una } \\
\text { entidad financiera o como capitalista en un negocio, etc)? } \\
\text { Opera con entidades financieras }\end{array}$} \\
\hline Pregunta 3: & \multicolumn{3}{|c|}{$\begin{array}{l}\text { ¿Qué tan satisfecho o insatisfecho se sintió con esta última actividad } \\
\text { inversora? } \\
\text { Satisfecho, aun no ha llegado a sus metas, aun es nuevo el negocio }\end{array}$} \\
\hline Pregunta 4: & \multicolumn{3}{|c|}{$\begin{array}{l}\text { ¿De invertir en algún emprendimiento o negocio, cuál cree que sería el rubro } \\
\text { de negocio con mayor expectativa? } \\
\text { Bienes y raíces }\end{array}$} \\
\hline Pregunta 5: & \multicolumn{3}{|c|}{$\begin{array}{l}\text { ¿Le interesaría tener alternativas de inversión más rentables que las dadas en } \\
\text { modo tradicional por Bancos, Cajas Municipales, entre otros? } \\
\text { Se ve interesante, necesitaría mayor información. }\end{array}$} \\
\hline Pregunta 6: & \multicolumn{3}{|c|}{$\begin{array}{l}\text { ¿Qué políticas, metodologías, condiciones y/o acciones le daría más confianza } \\
\text { ante una entidad que le ofrezca alternativas de financiación? ¿Qué } \\
\text { recomendaciones daría? } \\
\text { Que se a una entidad que demuestre confianza, que sea estable y este } \\
\text { regulada, de una garantía a los depósitos. }\end{array}$} \\
\hline Pregunta 7: & \multicolumn{3}{|c|}{$\begin{array}{l}\text { ¿Qué recomendaciones sobre nuevos productos/servicios (productos/servicios } \\
\text { financieros innovadores, económicos, viables) daría? (Por ejemplo generar } \\
\text { talleres, presentaciones de inversionistas e inversores). } \\
\text { Aprender acerca de finanzas, mayor cultura financiera, asesoramiento. } \\
\text { Nuevas formas o metodologías para mejorar marketing, incluir la } \\
\text { tecnología ya sea en infraestructura, informática. }\end{array}$} \\
\hline
\end{tabular}


ENTREVISTA A EMPRENDEDOR/PRESTATARIO

\begin{tabular}{|c|c|c|c|}
\hline Día: & $03 / 11 / 2016$ & Hora: & $17: 30$ \\
\hline Lugar: & Centro de Trabajo & Entrevistado: & Henry Jaúregui \\
\hline Tema: & \multicolumn{3}{|c|}{ Oportunidades y/o Alternativas de inversión y financiación de emprendimientos } \\
\hline Pregunta 1: & \multicolumn{3}{|c|}{$\begin{array}{l}\text { ¿Qué factores considera importantes para poder determinar de dónde obtener } \\
\text { financiamiento para su negocio o emprender uno? } \\
\text { Tasas de interés, que requisitos solicitan. }\end{array}$} \\
\hline Pregunta 2: & \multicolumn{3}{|c|}{$\begin{array}{l}\text { ¿Qué sistema o alternativa de financiamiento uso últimamente (sea de una } \\
\text { entidad formal o informal)? } \\
\text { Préstamo personal de un banco. }\end{array}$} \\
\hline Pregunta 3: & \multicolumn{3}{|c|}{$\begin{array}{l}\text { ¿Qué tan satisfecho o insatisfecho se sintió con esta última actividad de } \\
\text { financiación? Regularmente satisfecho debido a que las tasas son elevadas, las } \\
\text { ganancias no son muy visibles. }\end{array}$} \\
\hline Pregunta 4: & \multicolumn{3}{|c|}{$\begin{array}{l}\text { ¿De emprender en algún negocio, cuál es el rubro de este negocio que cree que } \\
\text { tiene mayor expectativa? ¿Por qué? Centro de entretenimiento para niños, no } \\
\text { hay mucha competencia en el mercado arequipeño, está creciendo. }\end{array}$} \\
\hline Pregunta 5: & \multicolumn{3}{|c|}{$\begin{array}{l}\text { ¿Le interesaría tener alternativas de financiación más rentables y más bajo } \\
\text { costo que las dadas en modo tradicional por Bancos, Cajas Municipales, entre } \\
\text { otros? } \\
\text { Por supuesto, ya que no he tenido buena experiencia con los bancos, } \\
\text { especialmente por sus altas tasas. }\end{array}$} \\
\hline Pregunta 6: & \multicolumn{3}{|c|}{$\begin{array}{l}\text { ¿Qué políticas, metodologías, condiciones y/o acciones le daría más confianza } \\
\text { ante una entidad que le brinde nuevas alternativas de financiación? ¿Qué } \\
\text { recomendaciones daría? Que sea un empresa que brinde confianza, quizá tener } \\
\text { testimonios de otras personas, mejores tasas de interés. }\end{array}$} \\
\hline Pregunta 7: & \multicolumn{3}{|c|}{$\begin{array}{l}\text { ¿Qué productos o servicios financieros ayudaría a que su negocio o } \\
\text { emprendimiento sea mejor? (Por ejemplo generar talleres, asesoramiento, etc.) } \\
\text { Asesoramiento, cursos o talleres de finanzas e información de otros métodos } \\
\text { de obtener financiamiento. }\end{array}$} \\
\hline
\end{tabular}


ENTREVISTA A INVERSIONISTA

\begin{tabular}{|c|c|c|c|}
\hline Día: & $04 / 11 / 2016$ & Hora: & $18: 30$ \\
\hline Lugar: & Centro de Trabajo & Entrevistado: & José Velásquezz \\
\hline Tema: & \multicolumn{3}{|c|}{ Oportunidades y/o Alternativas de inversión y financiación de emprendimientos } \\
\hline Pregunta 1: & \multicolumn{3}{|c|}{$\begin{array}{l}\text { ¿Qué factores considera importantes para poder determinar dónde colocar sus } \\
\text { inversiones? La rentabilidad que voy a obtener, si se trata de un negocio, } \\
\text { evaluó el mercado, si hay oportunidad de crecimiento y si hay acogida por el } \\
\text { público. }\end{array}$} \\
\hline Pregunta 2: & \multicolumn{3}{|c|}{$\begin{array}{l}\text { ¿Qué sistema o alternativa de inversión uso últimamente (por ejemplo en una } \\
\text { entidad financiera o como capitalista en un negocio, etc)? Préstamo } \\
\text { hipotecario.de una entidad financiera }\end{array}$} \\
\hline Pregunta 3: & \multicolumn{3}{|c|}{$\begin{array}{l}\text { ¿Qué tan satisfecho o insatisfecho se sintió con esta última actividad } \\
\text { inversora? Bien ayudo a crecer mi negocio. }\end{array}$} \\
\hline Pregunta 4: & \multicolumn{3}{|c|}{$\begin{array}{l}\text { ¿De invertir en algún emprendimiento o negocio, cuál cree que sería el rubro } \\
\text { de negocio con mayor expectativa? Catering y organización de eventos. }\end{array}$} \\
\hline Pregunta 5: & \multicolumn{3}{|c|}{$\begin{array}{l}\text { ¿Le interesaría tener alternativas de inversión más rentables que las dadas en } \\
\text { modo tradicional por Bancos, Cajas Municipales, entre otros? Sí, porque } \\
\text { parece ser buena alternativa, ya que el sistema financiero que tenemos no se } \\
\text { acoge bien a las necesidades de los clientes, y creo que pueden mejorar } \\
\text { nuestros ingresos otras alternativas. }\end{array}$} \\
\hline Pregunta 6: & \multicolumn{3}{|c|}{$\begin{array}{l}\text { ¿Qué políticas, metodologías, condiciones y/o acciones le daría más confianza } \\
\text { ante una entidad que le ofrezca alternativas de financiación? ¿Qué } \\
\text { recomendaciones daría? Una que ofrezca garantía a nuestro dinero y que sea } \\
\text { regulado. }\end{array}$} \\
\hline Pregunta 7: & \multicolumn{3}{|c|}{$\begin{array}{l}\text { ¿Qué recomendaciones sobre nuevos productos/servicios (productos/servicios } \\
\text { financieros innovadores, económicos, viables) daría? (Por ejemplo generar } \\
\text { talleres, presentaciones de inversionistas e inversores) } \\
\text { Es importa tener más conocimiento en finanzas, costos, marketing, porque } \\
\text { afuera (otros países) se encuentran mucho más avanzados que el nuestro y aquí } \\
\text { hay mucho por crecer }\end{array}$} \\
\hline
\end{tabular}


ANEXO 3: Entrevistas en grupos de enfoque sobre oportunidades y/o alternativas de inversión y financiación de emprendimientos

\section{A. Objetivos de Investigación:}

- Conocer las características que los clientes (inversionistas y emprendedor/prestatario) consideran para la adquisición de financiamiento o el invertir a partir de métodos alternativos.

- Obtener características de demandantes por estratos, ubicación, rubro de interés para el negocio.

- Determinar los canales de distribución, la mejor forma llegar a los clientes.

\section{B. Perfil del participante:}

Se consideran a personas que además de estar en la segmentación geográfica (ciudad de Arequipa), sociográfica (25 a 55 años), así como psicográfica (pertenecientes a la PEA), que sean personas con ideas de negocio o que hayan emprendido uno, o inversionistas que cuenten con trayectoria en los negocios y finanzas

\section{Guía del moderador para la sesión de entrevistas en grupos de enfoque}

\section{Introducción}

Buenos damos la bienvenida a cada uno de los participantes, así como las gracias por haber aceptado nuestra invitación a este grupo de enfoque, mi nombre es Los aquí presentes somos estudiantes de postgrado y estamos realizando una investigación de mercado cualitativa en la que trataremos el tema de generar una empresa que brinde oportunidades y/o alternativas de inversión así como de financiamiento de emprendimientos. 
La reunión tendrá un tiempo de duración de aproximadamente 60 minutos y será grabada con fines de recopilación de información, por lo dicho, no deben preocuparse ya que la grabación sólo será empleado con fines de investigación y utilizado solo por el equipo, mas no será difundido a terceros. Cada una de sus opiniones y respuestas son muy importantes, así lo considere sencilla, pueden intervenir en cualquier momento. No hay respuestas buenas ni malas, solo respuestas reales y siéntase con la libertad de discutir y defender sus ideas. Se tendrá una conversación informal, no se trata de ventas, nos los llamaremos después para tratar de ofrecerles nada. Siéntanse cómodos y relajados solo expresen sus opiniones y sentimientos.

Se les hará llegar unas fichas las cuales nos permitirá conocer un poco de los participantes. ¿Si tuvieran preguntas? (se responden las preguntas de los participantes). Iniciemos.

\section{Calentamiento}

La sesión iniciara con una dinámica en donde cada participante dirá su nombre y algo acerca de si mismo (se pregunta a cada participante, promoviendo la dinámica del grupo así como un lugar cómodo entre los miembros).

\section{Presentación del primer tema}

Desde su punto de vista, ¿Cuántas veces ha participado o invertido su dinero en entidades financieras formales o informales?

¿Cuánto veces a adquirido o solicitado algún préstamo que le ha servido para crear o impulsar su negocio? 
Sondear:

a. Tipo de empresas o personas a quienes hayan recurrido y a los que recurrirían en un futuro.

b. Programas o recursos que los convencieron para elegir dicha entidad.

\section{Segundo tema importante}

Ahora piensen en cómo las personas toman sus decisiones y ¿Qué aspectos considera importantes al buscar una entidad, sea empresa o persona, para obtener financiamiento o para colocar sus inversiones o ahorros?

Sondear:

a. Detalles y características que buscan.

b. Actividad, rubro y ubicación geográfica donde le gustaría invertir o emprender un negocio.

\section{Elementos concretos de diseño}

Ahora piensen en que: Si le interesaría tener alternativas de inversión y de financiación más rentables que las dadas en modo tradicional por bancos, cajas municipales, entre otros.

Sondear:

a. Elementos específicos que le impulsarían a tomar dicha decisión.

b. Que esperaría recibir de dicha alternativa, que le resulte satisfecho.

\section{Cierre de la sesión con sugerencias e ideas finales}

Teniendo en cuenta nuestra conversación, ¿Qué acciones sugerirían o recomendarían al equipo de diseño para que la idea de oportunidades y/o alternativas de inversión y financiación de emprendimientos sea la mejor posible? 
Sondear:

a. Diseño estructural

b. Calidad

V. Fin de la sesión de enfoque
A. Agradecimiento a los participantes por su cooperación y aportaciones
B. Entrega de presentes a los participantes.
C. Los deseos para cada uno de sus objetivos.

IV. Sugerencias e ideas finales

V. Fin de sesión de enfoque 
Ficha Técnica de Entrevista de Grupo de Enfoque

\begin{tabular}{|l|l|}
\hline Persona Número: & 1 \\
\hline Nombre: & Gaby Palma \\
\hline Edad: & 55 \\
\hline Nacionalidad: & peruana \\
\hline Ocupación: & Gerente \\
\hline Profesión: & Administración \\
\hline Distrito de Residencia: & Cayma \\
\hline Breve reseña: & $\begin{array}{l}\text { Inversionista. Se desempeña como distribuidor a nivel del sur del } \\
\text { Perú de productos de abarrotes, con más de } 10 \text { años de experiencia en } \\
\text { el rubro y con proyecciones a invertir en el mercado inmobiliario. }\end{array}$ \\
\hline
\end{tabular}

\begin{tabular}{|l|l|}
\hline Persona Número: & 2 \\
\hline Nombre: & Velda Salazar \\
\hline Edad: & 52 \\
\hline Nacionalidad: & peruana \\
\hline Ocupación: & Gerente \\
\hline Profesión: & Diseñadora de modas \\
\hline Distrito de Residencia: & Cayma \\
\hline Breve reseña: & $\begin{array}{l}\text { Se desempeña como gerente en una empresa de modas, diseñando } \\
\text { ropa exclusiva y cuenta con una tienda de ventas, así como de } \\
\text { asesoramiento en moda. }\end{array}$ \\
\hline
\end{tabular}

\begin{tabular}{|l|l|}
\hline Persona Número: & 3 \\
\hline Nombre: & Sandra San Martin \\
\hline Edad: & 49 \\
\hline Nacionalidad: & peruana \\
\hline Ocupación: & Asesora Comercial \\
\hline Profesión: & Economista \\
\hline Distrito de Residencia: & Yanahuara \\
\hline Breve reseña: & Se desempeña como asesora de banca empresarial. \\
\hline
\end{tabular}




\begin{tabular}{|l|l|}
\hline Persona Número: & 4 \\
\hline Nombre: & Jorge Montenegro \\
\hline Edad: & 55 \\
\hline Nacionalidad: & peruana \\
\hline Ocupación: & Ventas, comercio \\
\hline Profesión: & Técnico \\
\hline Distrito de Residencia: & Cercado \\
\hline Breve reseña: & $\begin{array}{l}\text { Tiene su propia empresa en ventas y distribución de papelería y } \\
\text { tarjetería. }\end{array}$ \\
\hline
\end{tabular}

\begin{tabular}{|l|l|}
\hline Persona Número: & 5 \\
\hline Nombre: & Luciano Vargas \\
\hline Edad: & 52 \\
\hline Nacionalidad: & peruana \\
\hline Ocupación: & Manteniento \\
\hline Profesión: & Técnico Mecánico \\
\hline Distrito de Residencia: & Cayma \\
\hline Breve reseña: & $\begin{array}{l}\text { Se desempeña como técnico mecánico de mantenimiento, tiene un } \\
\text { trabajo dependiente, en una empresa de proyectos. }\end{array}$ \\
\hline
\end{tabular}

\begin{tabular}{|l|l|}
\hline Persona Número: & 6 \\
\hline Nombre: & Dennis \\
\hline Edad: & 46 \\
\hline Nacionalidad: & peruana \\
\hline Ocupación: & Ventas, comercio, \\
\hline Profesión: & Técnico \\
\hline Distrito de Residencia: & Miraflores \\
\hline Breve reseña: & $\begin{array}{l}\text { Tiene su propia empresa en la fabricación y venta de muebles en } \\
\text { madera. }\end{array}$ \\
\hline
\end{tabular}




\section{ANEXO 4: Encuesta: Oportunidades y/o alternativas de inversión y de financiación de emprendimientos.}

Introducción:

Buenos días (tardes, noches)

Estamos trabajando en un estudio que servirá para elaborar una tesis profesional de maestría sobre un plan de negocios que desarrolla la posibilidad de generar una empresa que brinde oportunidades y/o alternativas de inversión y de financiación de emprendimientos.

Quisiéramos pedir su ayuda para que conteste algunas preguntas que no llevaran mucho tiempo (aproximadamente 15 minutos). Sus respuestas serán confidenciales y anónimas. No habrá preguntas sensibles y/o delicadas.

Las personas que fueron seleccionadas para el estudio tienen al menos un emprendimiento en el cual están trabajando y/o tienen interés en conocer oportunidades y/o alternativas de inversión seguras y más rentables que las tradicionales.

Las opiniones de todos los encuestados, serán sumados e incluidos en la tesis profesional, en ningún caso se comunicarán datos individuales.

Necesitamos su apoyo a fin de poder conocer más acerca de la realidad que vive el emprendedor y/o inversor, por tal razón te pedimos que contestes el cuestionario con la mayor sinceridad posible. No existen respuestas correctas e incorrectas.

Por favor lea las instrucciones cuidadosamente, ya que existen preguntas en las que solo se puede responder una opción; otras son de varias opciones. No dude en comunicarnos cualquier duda e inquietud a través del medio que recibe la presenta encuesta (Teléfono, Internet o Entrevista personal). 
Instrucciones Iniciales:

Emplee un lápiz o bolígrafo de tinta negra para llenar el cuestionario (si está en formato físico). Estas respuestas reflejaran su opinión personal.

Marque con claridad con cruz "+" o equis "x". Si no puede contestar una pregunta o si la pregunta no tiene sentido para usted, por favor, pregúntele a la persona que le entregó este cuestionario y le explicó la importancia de su participación.

Confidencialidad: Todas sus respuestas serán anónimas y absolutamente confidenciales. Los cuestionarios serán presentados por personas externas. Además, como usted puede ver, en ningún momento se le pide su nombre.

De antemano: ¡MUCHAS GRACIAS POR SU COLABORACION!

1- ¿Podría indicarme su edad?

Años

2- ¿Género?

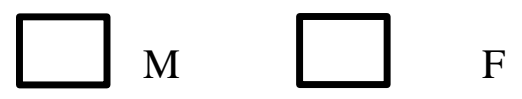

3- ¿Estado Civil?

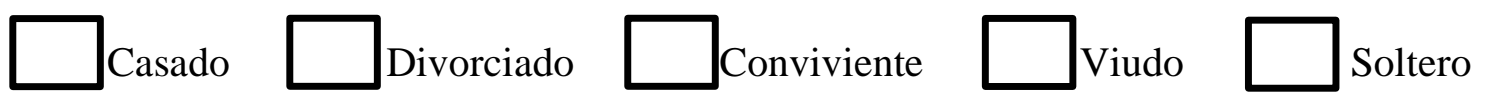

4- ¿Grado de instrucción?

Sin educación.

Primaria 
Secundaria

Técnico

Universitario

Postgrado

5- ¿ ¿Ocupación y estado laboral (dependiente y/o independiente)?

Agricultura (trabajo en campo, cría de animales de corral, pastoreo, etc.)

Artesanía y manufactura (confección de adornos, accesorios, etc.)

Comercio (ventas, distribuidor, etc.)

Enseñanza (inglés, matemática, física, química, computación, etc.)

Labores de oficina (secretariado, empleo administrativo, etc.)

Obrero(a) (alimentos procesados, textiles, metal mecánica, construcción civil, etc.)

Servicios de acondicionamiento (aseo, oficinas, mantenimiento, etc.)

Otros (ama de casa, etc.)

Trabajo independiente

Trabajo dependiente

Ambos

6- ¿Realiza o está dispuesto a emprender un negocio o está interesado en financiar alguno?

Sí tiene un negocio o está interesado en emprender uno.

Sí, está interesado en financiar un negocio.

Ninguno de los anteriores. 
7- ¿Hace uso de los servicios de una entidad financiera formal o informal para solicitar préstamos o colocar sus ahorros en ella?
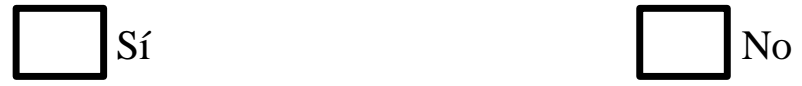

8- ¿De realizar actividades emprendedoras o de querer invertir en una, cuál sería el rubro de negocio en el que participaría?

Agricultura, ganadería.

Pesca

Manufactura

Construcción

Comercio

Transporte, comunicaciones

Restaurantes, hoteles

Otros.

9- ¿ ¿De realizar actividades emprendedoras cual sería el lugar más indicado para desarrollar dicha actividad o negocio?

Alto Selva Alegre, Cayma, Cerro Colorado, Jacobo Hunter, Mariano Melgar, Miraflores, Sachaca, Yanahuara, José Luis Bustamante y Rivero, Cercado.

Arequipa Periurbana: Characato, Chiguata, Mollebaya, Pocsi, Polobaya, Quequeña, Socabaya, Tiabaya, Uchumayo, Yarabamba, Yura.

Arequipa Provincia: San Juan de Siguas, Tarucani, Santa Isabel de Siguas, Santa Rita de Siguas, La Joya, Vítor.

10- ¿Le interesaría tener alternativas de inversión más rentables que las dadas en modo tradicional por Bancos, Cajas Municipales, entre otros?
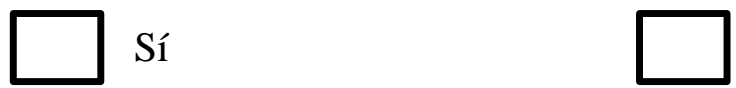

No 
De ser "NO", indique la razón:

Sin dinero para invertir.

Temor ante la posibilidad de perder la inversión.

Las alternativas actuales no brindan confianza y seguridad necesarias

Inexperiencia.

11- ¿Le ayudaría obtener apalancamiento económico (financiación) a bajo costo o alternativas financieras nuevas e innovadoras en el crecimiento de su negocio?

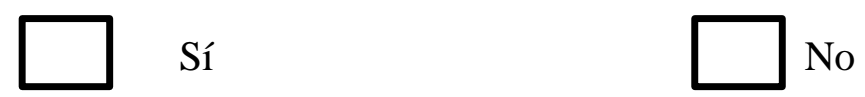

De ser "NO", indique una razón que agrade más:

Falta de costumbre, sin experiencia previa.

Disgusto ante la posibilidad de ganar más problemas que beneficios.

Las alternativas actuales no brindan confianza y seguridad necesarias.

Desconocimiento.

12- ¿Cuál de estas opciones le daría más confianza ante una nueva alternativa de financiamiento e inversión diferente a las tradicionales? (orden de prioridad)

a.___ Tener la mayor cantidad de información disponible sobre condiciones y restricciones.

b.__ Tener respaldo de grandes instituciones.

c.___ Tener testimoniales de clientes satisfechos (reputación online, boca a boca, etc.)

d.___ Ser una marca que se haga reconocida y respetada.

e.___ Contar una plataforma web sólida, consistente, con módulos de simulación, con soporte las 24 horas, amigable, eficiente y accesible.

f.___ Contar con muy buen material publicitario (Tarjetas de presentación, folletos informativos, videos, volantes, email corporativo, marketing email, casos de éxito). g.___ Contar con especializaciones acorde a diferentes segmentos de mercado. 
13- ¿ Qué ayudaría a mejorar su negocio, emprendimiento o al momento de invertir?

a.___ Dictar talleres educativos (cursos especializados y generales)

b.___ Desarrollar talleres intensivos e interdisciplinarios, así como ferias.

c.___ Asesoramiento

d.___ Mejores tasas (ya sea para un préstamo o para invertir)

e.___ Mayor publicidad

14- En orden de prioridad, qué considera más importante, al momento de buscar servicios financieros (préstamos e inversiones)

a.___ Oficinas distribuidas (ubicaciones estratégicas a ubicación geográfica)

b.___ Plataforma por internet

c.___ Asesores comerciales a domicilio

d.___ Redes de mercadeo

e.___ Agentes (como agente de tienda BCP) 


\section{ANEXO 5: Análisis Complementario al Análisis Cuantitativo}

- Análisis cruzado de las preguntas seis y siete de la encuesta

\begin{tabular}{|c|c|c|c|c|}
\hline & \multicolumn{2}{|c|}{$\begin{array}{c}\text { ¿Hace uso de los servicios } \\
\text { de una entidad financiera } \\
\text { formal o informal para } \\
\text { solicitar préstamos o } \\
\text { colocar sus ahorros en } \\
\text { ella? }\end{array}$} & \multirow[b]{2}{*}{ Total } \\
\hline & & Si & No & \\
\hline $\begin{array}{l}\text { Realiza o } \\
\text { está } \\
\text { dispuesto a } \\
\text { emprender } \\
\text { un negocio o } \\
\text { está } \\
\text { interesado } \\
\text { en financiar } \\
\text { alguno? }\end{array}$ & $\begin{array}{l}\text { Sí tiene un } \\
\text { negocio o } \\
\text { está } \\
\text { interesado } \\
\text { en } \\
\text { emprender } \\
\text { uno } \\
\mathrm{SI}_{\text {, está }} \\
\text { interesado } \\
\text { en financiar } \\
\text { un negocio } \\
\text { Ninguno de } \\
\text { los } \\
\text { anteriores }\end{array}$ & $\begin{array}{l}78 \\
41\end{array}$ & 24 & $\begin{array}{r}118 \\
65\end{array}$ \\
\hline Total & & 271 & 113 & 384 \\
\hline
\end{tabular}

- Análisis cruzado de las preguntas 10 y 11 de la encuesta

Tabla cruzada ¿Le interesaría tener alternativas de inversión más rentables que las dadas en modo tradicional por Bancos, Cajas Municipales, entre otros?* ¿Le ayudaría obtener apalancamiento económico (financiación) a bajo costo o alternativas financieras nuevas e innovadoras en el crecimiento de su negocio?

Recuento

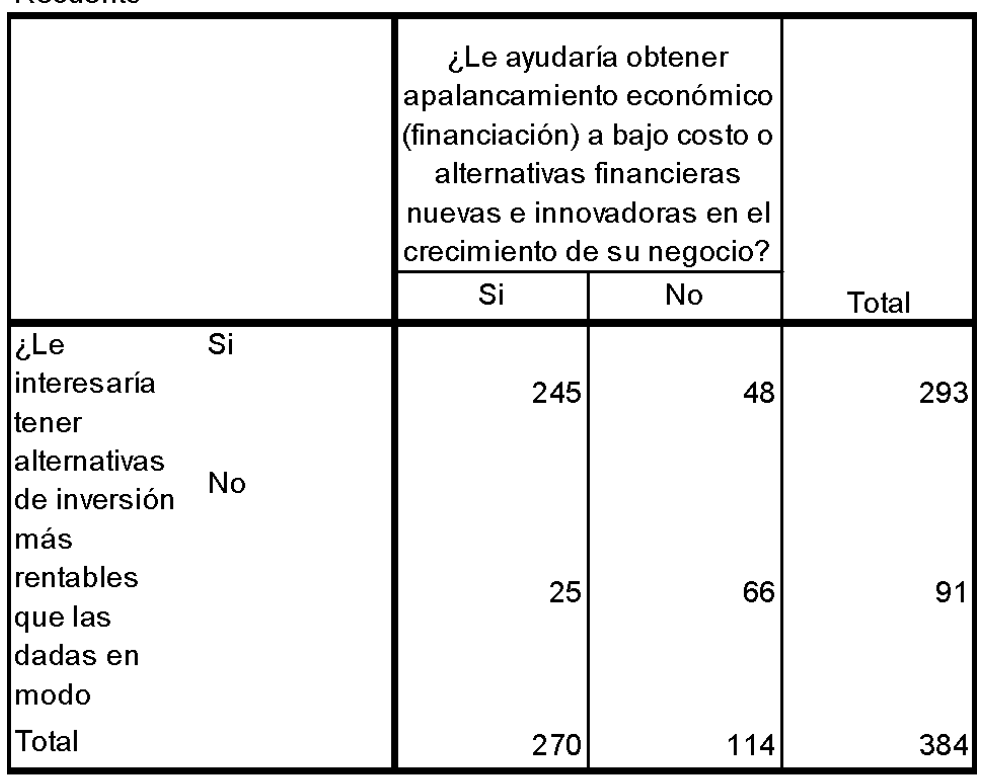


- Análisis cruzado de las preguntas cuatro y diez de la encuesta

\section{Tabla cruzada Grado de Instrucción* ¿Le interesaría tener alternativas de inversión más rentables que las dadas en modo tradicional por Bancos, Cajas Municipales, entre otros?}

\begin{tabular}{|c|c|c|c|c|}
\hline & & $\begin{array}{r}\text { alternativas } \\
\text { más rentab } \\
\text { dadas en mo } \\
\text { por Bancc } \\
\text { Municipales, }\end{array}$ & $\begin{array}{l}\text { versión } \\
\text { ue las } \\
\text { dicional } \\
\text { ajas } \\
\text { otros? }\end{array}$ & \multirow[b]{2}{*}{ Total } \\
\hline & & Si & No & \\
\hline \multirow[t]{6}{*}{$\begin{array}{l}\text { Grado de } \\
\text { Instrucción }\end{array}$} & $\begin{array}{l}\text { Sin } \\
\text { educación }\end{array}$ & 1 & 1 & 2 \\
\hline & Primaria & 8 & 0 & 8 \\
\hline & Secundaria & 125 & 38 & 163 \\
\hline & Técnico & 85 & 19 & 104 \\
\hline & Universitario & 62 & 30 & 92 \\
\hline & Postgrado & 12 & 3 & 15 \\
\hline Total & & 293 & 91 & 384 \\
\hline
\end{tabular}

Análisis de Fiabilidad según Alfa Cronbach

Estadísticas de fiabilidad

\begin{tabular}{|r|r|}
\hline $\begin{array}{c}\text { Alfa de } \\
\text { Cronbach }\end{array}$ & $\begin{array}{c}\text { N de } \\
\text { elementos }\end{array}$ \\
\hline .614 & 28 \\
\hline
\end{tabular}

El método de consistencia interna basado en el alfa de Cronbach permite estimar la fiabilidad de un instrumento de medida a través de un conjunto de ítems que se espera que midan el mismo constructo o dimensión teórica.

Bajo este concepto y después del análisis hecho, se obtiene un valor de alfa de Cronbach de 0.614, indicando una fiabilidad cercanamente aceptable. 


\section{ANEXO 6: Rivalidad entre competidores. Factoring y Confirming}

Las actividades que el presente proyecto propone, no compite con las actividades de

Factoring y Confirming. Más bien propone buscar llenar los vacíos financieros que permitan mayor inclusión financiera. A continuación presentamos una aclaración detallada, donde exponemos el proceso de factoring y confirming, enfrentándolo a los productos que el proyecto propone:

- Diferencias a nivel conceptual:

\begin{tabular}{|c|c|c|}
\hline & $\begin{array}{l}\text { Ventas Adelantadas y } \\
\text { Préstamos proyecto IDeltas }\end{array}$ & $\begin{array}{l}\text { Factoring, Confirming y Préstamo con garantía } \\
\text { en facturas cuentas por cobrar }\end{array}$ \\
\hline $\begin{array}{l}\text { Defin } \\
\text { icion } \\
\text { es }\end{array}$ & $\begin{array}{l}\text { Ventas adelantadas - Se efectúa } \\
\text { siguiendo el concepto de una } \\
\text { preventa donde el incentivo viene } \\
\text { por el descuento en comparación } \\
\text { al precio final así como la } \\
\text { motivación de apoyar un } \\
\text { emprendimiento por las } \\
\text { características que lo configuran } \\
\text { (interés en el tema, apoyo social, } \\
\text { fomento empresarial, etc.). } \\
\text { Técnicamente es efectuar una } \\
\text { venta por anticipado enlazando a } \\
\text { un productor o un emprendedor } \\
\text { con otra persona o grupo de } \\
\text { personas, que estén dispuestos a } \\
\text { pagar para ver el proyecto } \\
\text { realizado. A cambio las personas } \\
\text { que invierten el dinero obtienen } \\
\text { como beneficio un descuento de } \\
\text { dicho proyecto o producto. } \\
\text { Financiamiento - Sigue el } \\
\text { concepto de préstamo tradicional, } \\
\text { siendo en este caso una figura } \\
\text { directa entre el poseedor del } \\
\text { dinero (prestamista) y el cliente } \\
\text { final (prestatario), sólo que a } \\
\text { manera de subasta o licitación, }\end{array}$ & $\begin{array}{l}\text { Factoring - Es una estrategia financiera mediante } \\
\text { la cual un agente intermediario financia las } \\
\text { cuentas por cobrar. El factoring es esencialmente } \\
\text { una fuente de financiamiento que acuerda pagar a } \\
\text { la compañía el valor de una factura menos un } \\
\text { descuento en comisiones y tarifas. El factor } \\
\text { adelanta la mayor parte del monto facturado a la } \\
\text { compañía inmediatamente y el saldo al recibir los } \\
\text { fondos de la parte facturada. } \\
\text { Confirming - Es un servicio financiero que } \\
\text { permite el pago a proveedores de manera } \\
\text { anticipada, siendo este servicio ofrecido por } \\
\text { algunas entidades financieras en el entorno, Este } \\
\text { mecanismo es inverso al factoring, dado que en } \\
\text { este caso es la empresa que busca tener convenio } \\
\text { con la entidad financiera a fin de poder gestionar } \\
\text { pagos a los proveedores. } \\
\text { Financiamiento de cuentas por cobrar: } \\
\text { Es un tipo de acuerdo de financiamiento de } \\
\text { activos en el cual una compañía utiliza sus cuentas } \\
\text { por cobrar (facturas pendientes o dinero adeudado } \\
\text { por los clientes) para recibir financiamiento. La } \\
\text { compañía recibe una cantidad que es igual a un } \\
\text { valor reducido de las cuentas por cobrar } \\
\text { prometidas. } \\
\text { La antigüedad de las cuentas por cobrar afecta en }\end{array}$ \\
\hline
\end{tabular}




\begin{tabular}{|l|l|l|}
\hline $\begin{array}{l}\text { donde el prestamista(s) que } \\
\text { oferte(n) una menor tasa de interés } \\
\text { serán quienes participen de dicho } \\
\text { préstamo. }\end{array}$ & $\begin{array}{l}\text { gran medida la cantidad de financiamiento que } \\
\text { recibe la compañía. }\end{array}$ \\
& $\begin{array}{l}\text { Préstamo ordinario - Operación financiera en la } \\
\text { que la entidad financiera (prestamista), entrega } \\
\text { una cantidad de dinero a un prestamista, } \\
\text { comprometiéndose a devolver en plazos y } \\
\text { condiciones pactadas de antemano (garantías, } \\
\text { intereses, entre otros) }\end{array}$ \\
\hline
\end{tabular}

Como se puede apreciar en este cuadro conceptual, el factoring, confirming, financiamiento por cuentas por cobrar, así como un préstamo ordinario, tienen un esquema regulado por la SBS, existiendo también entidades informales que brindan servicios similares, sin embargo no las mencionamos dado que el proyecto no trabaja con mecanismos informales en ningún punto.

El proyecto propone un mecanismo de ventas adelantadas, así como licitación de financiamiento amparándose en el marco regulatorio que podemos apreciar en impuesto a la Renta de personas, Rentas de Segunda Categoría - Dividendos, Acciones y Ganancias de Capital, del tipo Otras Rentas de Segunda Categoría:

"Existen otras rentas de segunda categoría distintas a la venta de inmuebles y de acciones o valores mobiliarios...” (SUNAT, 2018)

"Entre los cuales podemos mencionar a aquellas operaciones referidas al pago de intereses (Ej.: intereses ganados por préstamos), regalías (Ej.: regalías derechos de autor), cesión definitiva o temporal de derechos de llave, marca, patentes o similares ..." (SUNAT, 2018) 
- Diferencias a nivel de características del producto:

\begin{tabular}{|l|l|l|}
\hline $\begin{array}{l}\text { Ventas Adelantadas y Préstamos proyecto } \\
\text { IDeltas }\end{array}$ & $\begin{array}{l}\text { Factoring, Confirming y Préstamo } \\
\text { con garantía en facturas cuentas } \\
\text { por cobrar }\end{array}$ \\
\hline $\begin{array}{l}\text { Carac } \\
\text { terísti } \\
\text { cas }\end{array}$ & $\begin{array}{l}\text { *Ventas por adelantado recibe primero el } \\
\text { pago y después se entrega en bien. } \\
\text { *Licitación de financiamiento, en este caso } \\
\text { sigue el modelo de un préstamo tradicional } \\
\text { con la diferencia que IDeltas no desembolsa } \\
\text { ni recibe el dinero de los prestamistas, esto se } \\
\text { realiza entre ambos clientes a través de la } \\
\text { cuenta fiduciaria y cuentas personales de los } \\
\text { clientes. } \\
\text { *En ambos casos el prestatario y prestamista } \\
\text { podría generar vínculos que les permita } \\
\text { formar una alianza estratégica o sociedad. }\end{array}$ & $\begin{array}{l}\text { Modelos en donde se utiliza } \\
\text { factoring, se da porque se entrega } \\
\text { primero el bien/servicio y después se } \\
\text { recibe el dinero, razón por la que se } \\
\text { acude a empresas financieras } \\
\text { autorizadas a que trabajen con } \\
\text { factoring a fin de tener el pago } \\
\text { anticipado con un costo por el } \\
\text { servicio. }\end{array}$ \\
\hline
\end{tabular}

Como se puede apreciar en este cuadro referido a las características de los productos, el caso de confirming, factoring, cuentas por cobrar se dan con instituciones reguladas por el estado y en se da con el cobro de una comisión de la cuenta por cobrar, de manera inequívoca. En el caso de Ventas por adelantado podría verse influenciado en el cliente final razones de apoyo al emprendimiento, giro del negocio y su influencia social, entre otros. Del mismo modo la licitación de préstamos podría obtenerse con un interés bastante bajo, dado que la razón del préstamo se encuentra argumentado y sustentado, la consecuencia de esto es que el prestamista puede buscar apoyar a través de una oferta que sea de mayor conveniencia al prestatario del mismo modo podría a través del proyecto reunirse con el prestatario a fin de trabajar en modelo de participación empresarial u otro que sea de influencia estratégica para el prestamista y prestatario. 
- Diferencias a nivel de costo de capital:

\begin{tabular}{|c|c|c|}
\hline & $\begin{array}{l}\text { entas Adelantadas y Préstamos } \\
\text { oyecto IDeltas }\end{array}$ & $\begin{array}{l}\text { Factoring, Confirming y Préstamo con } \\
\text { garantía en facturas cuentas por cobrar }\end{array}$ \\
\hline $\begin{array}{l}\text { Costo } \\
\text { de } \\
\text { capital }\end{array}$ & $\begin{array}{l}\text { El costo por el acceso al capital es } \\
\text { menor o nulo en comparación al } \\
\text { factoring o figura de financiamiento } \\
\text { por cuentas por cobrar } \\
\text { * Origen del capital } \\
\text { En el caso de ventas adelantadas } \\
\text { Provienen de clientes finales y/o } \\
\text { empresas que les interesa el } \\
\text { descuento por modelo preventa o por } \\
\text { razones de exclusividad. } \\
\text { En el caso de modelos de pronto } \\
\text { pago, no hay obligación de uso de } \\
\text { factoring dado que la empresa o } \\
\text { persona otorgante da beneficio a } \\
\text { cuenta propia (por políticas } \\
\text { empresariales propias) y el cómo } \\
\text { consiga el dinero el cliente } \\
\text { beneficiario no es de obligación a } \\
\text { través de factoring o mecanismo de } \\
\text { confirming, sino de capital propio. } \\
\text { (Es más existe en la página de la } \\
\text { SUNAT la descripción de rentas de } \\
\text { segunda categoría distintas a la venta } \\
\text { de inmuebles y de acciones o valores } \\
\text { mobiliarios. Refiriendo a operaciones } \\
\text { referidas al pago de intereses, } \\
\text { regalías, sesión definitiva o temporal } \\
\text { de derechos de llave, marca, patentes } \\
\text { o similares. En tal caso es } \\
\text { completamente legal y posible que } \\
\text { una persona natural o jurídica, } \\
\text { invierta en este tipo de } \\
\text { oportunidades. }\end{array}$ & $\begin{array}{l}\text { Costo por acceso al capital a corto plazo, de } \\
\text { manera estricta. } \\
\text { *Origen del capital } \\
\text { Solo se podría dar entre empresas; } \\
\text { Del mismo modo, } \\
\text { - Para el caso de Factoring: En el } \\
\text { entorno nacional, se da de dos } \\
\text { maneras, a) primero cuando la } \\
\text { entidad financiera autorizada no tiene } \\
\text { convenio con la empresa que está } \\
\text { pagando de manera diferida, no es } \\
\text { necesario negociar con la empresa o } \\
\text { reportarle el proceso de factoring, } \\
\text { dado que la legislación peruana } \\
\text { permite la negociación de la factura } \\
\text { con empresas habilitadas a } \\
\text { desarrollar sistemas de factoring } \\
\text { acorde a sus condiciones y de las } \\
\text { regulaciones del estado. b) segundo, } \\
\text { cuando la empresa que está pagando } \\
\text { en diferido, tiene convenio con } \\
\text { alguna entidad financiera autorizada } \\
\text { a realizar factoring, el proceso de } \\
\text { pago a cuentas diferidas es mucho } \\
\text { más acelerado y se tiene una tasa más } \\
\text { baja. } \\
\text { Para el caso de confirming, se precisa } \\
\text { un convenio de la empresa que } \\
\text { pagará a proveedores con la entidad } \\
\text { financiera. } \\
\text { Crédito con garantía de cuentas por } \\
\text { cobrar, es una forma de préstamo } \\
\text { donde se pone en garantía las } \\
\text { facturas a cobrar más adelante. } \\
\text { Existen productos de beneficio de } \\
\text { pronto pago donde la entidad } \\
\text { financiera realiza el pago de un } \\
\text { producto de pronto pago y en el caso } \\
\text { de haber un adicional por el } \\
\text { beneficio de pronto pago otorgado } \\
\text { por la empresa, hay utilidad }\end{array}$ \\
\hline
\end{tabular}


En este punto se puede concluir y sustentar que no se está compitiendo con las figuras de factoring confirming o cuentas por cobrar, lo que se está proponiendo son complementos que permitan mayor inclusión financiera así como rentabilidad para la empresa y sus usuarios.

\section{Rivalidad entre competidores: Incubadora de negocios}

.Una incubadora es más una organización (empresa) patrocinadas y/o operadas por compañías privadas, entidades gubernamentales o universidades. Siendo su principal objetivo ayudar a crear y crecer empresas jóvenes brindándoles el apoyo necesario técnicamente y financieramente. Normalmente proporcionan acceso a dinero en una etapa inicial, pero principalmente proporciona infraestructura, asesoramiento, personas, etc. para la puesta en marcha, para que no tengan que preocuparse por eso. En una incubadora, una serie de nuevas empresas normalmente compartirán edificios de oficinas, infraestructura de redes y teléfonos, personal de recursos humanos y finanzas, recepcionistas, etc. a un precio inferior al del mercado. Las incubadoras pueden tener fondos disponibles, pero normalmente se administran por separado.

El modelo de negocio propuesto en la presente tesis tiene como propósito primordial el poder ayudar a contribuir en disminuir el problema de acceso al financiamiento de emprendimientos a partir del uso de los mecanismos del Crowdfunding. Dentro de los servicios ofrecidos también se contempla el asesoramiento y capacitación en cuanto a las nuevas técnicas de adquirir apalancamiento financiero, que a nivel mundial a dado resultados muy positivos. Sin embargo, como parte del crecimiento del negocio propuesto y la mejora continua al servicio al cliente, este sería el siguiente paso a dar: brindar viabilidad técnica, financiera y de mercado, desarrollar los planes de mercadotecnia y ventas, rentar un espacio físico, equipo, logística, coaching y networking. 
Este seria y siguiente paso para el proyecto, haciendo en el siguiente cuadro una comparación con los principales puntos de diferencia entre una incubadora de negocios y el proyecto propuesto en la presente tesis:

\begin{tabular}{|c|c|}
\hline $\begin{array}{l}\text { Ventas Adelantadas, Donaciones y } \\
\text { Préstamos proyecto IDeltas }\end{array}$ & Incubadora de Negocios \\
\hline $\begin{array}{l}\text { * Trabaja sobre ideas de negocio que ya se } \\
\text { están ejecutando y precisan de un } \\
\text { apalancamiento o apoyo. Del mismo modo el } \\
\text { mecanismo propuesto se lleva utilizando por } \\
\text { muchas empresas para el análisis de } \\
\text { lanzamiento de nuevos productos, dado que } \\
\text { antes de hacer un lanzamiento masivo } \\
\text { analizan la respuesta de los consumidores } \\
\text { utilizándolo como parte del estudio de } \\
\text { mercado (Kotler \& Anmstrong, 2012). }\end{array}$ & $\begin{array}{l}\text { * Provee el acceso a un ambiente donde } \\
\text { desarrollar el Minimum Viable Product } \\
\text { (MVP). Sin ofrecer fondos o expectativas de } \\
\text { retorno de inversión, precisando personal } \\
\text { interdisciplinario de alta capacitación y } \\
\text { experiencia a fin de asesorar correctamente. }\end{array}$ \\
\hline $\begin{array}{l}\text { * El modelo del proyecto busca que las ideas } \\
\text { de negocio cuenten con posibles } \\
\text { inversionistas o socios comerciales, brindando } \\
\text { el respaldo y asesoría necesarios } \\
\text { documentación, contactos. Publicidad entre } \\
\text { otros. }\end{array}$ & $\begin{array}{l}\text { * Puede tener relaciones como inversionistas } \\
\text { o no. }\end{array}$ \\
\hline $\begin{array}{l}\text { * Herramienta Estratégica: intermediario entre } \\
\text { incubadora y el financiamiento de mercado. }\end{array}$ & * Herramienta de Formación \\
\hline
\end{tabular}

El proyecto no representa colisión de operaciones con instituciones financieras, en el levantamiento de observaciones del presente documento, en la observación número uno, se detallan las diferencias a nivel conceptual, características del producto así como costo de capital, agregamos finalmente una aclaración sobre este punto. 


\begin{tabular}{|c|c|c|}
\hline & Proyecto IDeltas S.A.C. & $\begin{array}{l}\text { Entidades } \\
\text { Financieras }\end{array}$ \\
\hline $\begin{array}{l}\text { Caso } \\
\text { Factoring }\end{array}$ & $\begin{array}{l}\text { El proyecto no realiza factoring dado que el factoring es } \\
\text { la compra de la deuda por cobrar, y tiene un marco legal } \\
\text { regulado por el estado. } \\
\text { El proyecto en su forma de: } \\
\text { - Venta por adelantado es una forma de financiamiento } \\
\text { que primero cobran y después se entrega el producto o } \\
\text { servicio prometido. } \\
\text { - Licitación de financiamiento es una forma de préstamo } \\
\text { que tiene opciones de encontrar socio comercial, alianza } \\
\text { estratégica o sencillamente financiamiento económico } \\
\text { junto a un beneficio acordado. En este punto el prestamista } \\
\text { puede considerar como indicador o incluso garantia } \\
\text { (factura negociable) una cuenta por cobrar, sin incidir en } \\
\text { figura de factoring. } \\
\text { Cabe resaltar que IDeltas no efectuará intermediación } \\
\text { financiera y que tampoco tiene decisión sobre el destino } \\
\text { del dinero del inversionista ni lo hace suyo, sólo se } \\
\text { encarga de canalizarlo de los inversores hacia los que } \\
\text { buscan un financiamiento. A cambio IDeltas realiza el } \\
\text { cobro de comisiones por el servicio y gestión ofrecido, } \\
\text { siempre y cuando se ejecute. }\end{array}$ & $\begin{array}{l}\text { No todas las } \\
\text { entidades financieras } \\
\text { tienen el producto de } \\
\text { factoring y/o } \\
\text { confirming. } \\
\text { Existen algunas }\end{array}$ \\
\hline
\end{tabular}


ANEXO 7: Términos y Condiciones IDelta S.A.C.

\section{Acerca del Servicio}

IDelta S.A.C. es un agente gestor de un mecanismo con soporte virtual (denominado "Propuesta IDelta"), a través de la cual se presentan alternativas de financiación; financiación por parte de los Usuarios Acreedores en favor de Usuarios Solicitantes, en las modalidades préstamos así como venta/compras por adelantado. La actividad que desarrolla la empresa IDelta S.A.C. se rige principalmente por las normas que se encuentran contenidas en el Código Civil Peruano, Código de Protección y Defensa del Consumidor, el cual está aprobado por la Ley $\mathrm{N}^{\circ} 29571$ y sus respectivas normas complementarias.

IDelta S.A.C. no realiza intermediación financiera

IDelta S.A.C. brinda un servicio de administración de préstamos entre personas naturales o jurídicas (empresas), del mismo modo, brinda un servicio de ventas/compras por adelantado entre personas naturales o jurídicas, todo esto en un entorno llamado finanzas colaborativas. Por lo expuesto, no es, ni implica, intermediación bancaria o financiera.

IDelta S.A.C. gestiona un mecanismo que permite brindar información suficiente para que los acreedores identifiquen diferentes opciones de participación en préstamos o compras por adelantado, conociendo de este modo sus riesgos asociados y pudiendo decidir en qué préstamo(s), venta o compra por adelantado participar, evaluando el riesgo de sus decisiones. IDelta S.A.C. participa administrando el mecanismo, brindando información necesaria, canalizando los flujos de dinero provenientes de los acreedores; y, posteriormente, canalizando los flujos de dinero provenientes de los préstamos para que estén a disposición de los acreedores. IDelta S.A.C. brinda servicios como agente gestor del mecanismo, cobrando comisiones. 
IDelta S.A.C. cuenta con una plataforma abierta, donde las personas interesadas podrán acceder a diferentes servicios, registrándose previamente como usuarios. Los usuarios quienes que tengan interés en obtener la concesión de préstamos por parte de inversores pueden registrarse como miembros (a) en busca de préstamo, y los usuarios que tengan interés en participar otorgando préstamos como (b) financiadores; luego de cumplir con los procesos de validación.

Correspondiente al plan de marketing, se realizarán mecanismos de publicidad tradicional, se realizarán visitas a negocios, participación en ferias, entre otros, se brindará asesoría en oficinas cursos y demás actividades, sin embargo en el punto de publicidad digital, se manejarán dos enfoques, el primero de publicidad digital pagada (adsense de google, facebook ads, optimización por búsquedas orgánicas, así como una canal de youtube donde se impartirán contenidos de alta relevancia para los clientes ), el detalle lo encontramos en las estrategias de promoción y publicidad punto 7.1.4 del plan de marketing.

\begin{tabular}{|c|c|c|c|}
\hline & Atraer Clientes & $\begin{array}{l}\text { Convertir } \\
\text { Clientes }\end{array}$ & $\begin{array}{r}\text { Fidelizar } \\
\text { Clientes }\end{array}$ \\
\hline Líneas & $\begin{array}{l}\text { Marketing en } \\
\text { buscadores (SEM y } \\
\text { SEO) }\end{array}$ & $\begin{array}{l}\text { Web Marketing } \\
\text { (usabilidad, } \\
\text { navegabilidad, } \\
\text { diseño, } \\
\text { arquitectura) }\end{array}$ & $\begin{array}{l}\text { Email } \\
\text { Marketing }\end{array}$ \\
\hline $\begin{array}{l}\text { Estratégic } \\
\text { as } \\
\text { De } \\
\text { Marketin } \\
\mathrm{g}\end{array}$ & $\begin{array}{l}\text { Publicidad online } \\
\text { (Google Adwords, } \\
\text { Facebook Ads, ...) }\end{array}$ & $\begin{array}{l}\text { Publicidad } \\
\text { Online (Google } \\
\text { Adwords, } \\
\text { Facebook Ads) }\end{array}$ & $\begin{array}{l}\text { Marketing } \\
\text { Relacional } \\
(\mathrm{CRM})\end{array}$ \\
\hline \multirow[t]{4}{*}{ Online } & Inbound Marketing & & \\
\hline & $\begin{array}{l}\text { Social Media } \\
\text { Marketing }\end{array}$ & & \\
\hline & Email Marketing & & \\
\hline & $\begin{array}{l}\text { Relaciones Públicas } \\
\text { Online }\end{array}$ & & \\
\hline
\end{tabular}


El generar un vínculo digital con el cliente sumado a la presencia por las oficinas así como por los asesores de servicios, nos permitirá tener una amplia red de contactos los cuales puedan ser convertidos en clientes, gracias a los buenos resultados por el marketing de contenidos.

Por otro lado, se maneja la estrategia digital que es el de alianzas estratégicas con influencers (bloggers, youtubers, influencers en facebook, influencers en instagram, influencers en Twitter), la consecuencia esperada es lograr influencia focalizada (por rango de edad como geográfica y nivel socioeconómico). Desarrollado en el punto 7.1.4 Estrategia de promoción y publicidad, en donde se habla de mercadotecnia

- Personas - Se cuenta con presupuesto para capacitaciones regulares al personal, impartiendo la cultura organizacional entre el personal de manera regular y esta llegue a nuestros clientes finales.

- Procesos - Se cuenta con evaluación de métodos para mejorar el servicio al cliente.

- Presencia Física - Se proporcionará una oficina física que puede ser visitada regularmente, se cuenta con visitas de los asesores de servicios, se tendrá testimonios reales y estadísticas de casos exitosos, buscando transmitir confianza entre los futuros clientes.

\section{Como participar en IDeltas SAC}

a) Para el usuario en busca de préstamo sea persona individual o empresa

- Las personas deberán ser mayores de 18 años de edad y en el caso de empresas con más de 1 año de actividad. 
- Ser una persona residente en el departamento de Arequipa o una persona jurídica o empresa debidamente constituida de acuerdo con la legislación peruana.

- Deberá registrarse como usuario en la web y proporcionar la información y documentación necesaria solicitada (nombre, edad, DNI, RUC, domicilio, actividad, lugar donde labora) para llenar un registro del cliente.

- Debe tener una cuenta bancaria abierta en alguna entidad de crédito de Perú en la que se abonará el monto del préstamo y también donde se cargarán las cuotas correspondientes al pago del préstamo.

b) Para el usuario financiador

- Las personas deberán ser mayores de 25 años de edad y en el caso de empresas con más de 1 año de actividad.

- Ser una persona residente en el departamento de Arequipa o una persona jurídica o empresa debidamente constituida de acuerdo con la legislación peruana.

- Deberá registrarse como usuario en la web y proporcionar la información y documentación necesaria solicitada (nombre, edad, DNI, RUC, domicilio, actividad, lugar donde labora, monto de ingreso bruto o rentabilidad) para llenar y contar con un registro del cliente.

- Debe tener una cuenta bancaria abierta en alguna entidad de crédito de Perú desde la que podrá hacer transferencias a su cuenta de IDelta S.A.C. para participar en los préstamos y a la que se transferirán las cuotas de los pagos.

El usuario garantiza que toda la información proporcionada es verídica, IDelta S.A.C. se reserva el derecho de llevar a cabo las investigaciones necesarias y validar la información 
sobre el usuario como persona o empresa. De igual manera IDelta S.A.C. toma la decisión de no aceptar a un usuario a su discreción.

\section{Procedimiento de solicitud de Préstamo}

Una vez aceptado el proceso de registro junto con la validación se procede a evaluar su historial crediticio y si cuenta deudas, para ello IDelta S.A.C. se Valera de diferentes entidades que brinde información comercial (Infocorp, Equifax). En caso de existir información que muestre incumplimientos de obligaciones o endeudamiento mayor al de sus ingresos, el cliente puede no ser aceptado a la solicitud de préstamos a través del sistema.

Cuando el usuario haya sido aceptado puede acceder a su solicitud de préstamo, el cual lo puede hacerse a través de la plataforma directamente en la oficina IDelta S.A.C., para ello debe describir su proyecto de financiación, indicando el monto necesario, como se utilizaran los recursos y el tiempo de recaudación.

Con la información recaudada del proyecto se procede a su publicación en el sitio web, para la presentación a los financiadores y un eventual otorgamiento de préstamo. El importe máximo de captación de fondos por proyecto de financiación participativa no podrá ser superior a los diez mil soles.

\section{Del préstamo hecho por los financiadores}

En el caso de una persona natural este debe ser como mínimo dos mil soles, y en el caso de empresas estas deben sustentar su rentabilidad obtenida en los últimos años.

\section{Otorgamiento de Préstamo}

Una vez finalizado el proceso de financiación (durante el cual los usuarios que deseen prestar deben emitir sus solicitudes de participación) o cumplido el tiempo de publicación (lo 
primero que ocurra), IDelta S.A.C. se comunicar con el solicitante del préstamo donde debe confirmar su voluntad de realizar el contrato de préstamo.

También podrá otorgarse el contrato de préstamo por un importe menor al solicitado inicialmente, siempre y cuando el solicitante lo acepte y le sea de interés, esto en el caso de que el proceso de financiación concluya y las solicitudes de participación en el préstamo, emitidas por los financiadores no hayan completado la totalidad del préstamo solicitado.

\section{Contrato de Préstamo y garantías}

El otorgamiento del contrato de préstamo se realizará ante Notario Público. Los costes notariales serán por cuenta del solicitante del crédito. Una vez hecho el contrato de préstamo, el importe del préstamo se transferirá por IDeltas S.A.C. a la cuenta bancaria facilitada por el solicitante del crédito.

IDeltas S.A.C. podrá pedir al solicitante del préstamo las correspondientes garantías en función del perfil de riesgo.

IDeltas S.A.C. no asume el riesgo de reposición de los fondos aportados en caso de incumplimiento en los repagos por parte del solicitante del préstamo, dado que el riesgo de incobrabilidad de los préstamos así como compras por adelantado es asumido por los usuarios financiadores de manera directa.

\section{De los aspectos tributarios de los prestamistas y de los prestatarios.}

La tributación necesaria por parte de los prestatarios es de tener ruc con rentas de segunda categoría distintas a la venta de inmuebles y de acciones o valores mobiliarios. Refiriendo a operaciones referidas al pago de intereses, regalías, cesión definitiva o temporal de derechos de llave, marca, patentes o similares. En tal caso es completamente legal y 
posible que una persona natural o jurídica, invierta en este tipo de oportunidades (SUNAT, 2018).

\section{Situación del dinero de los financiadores hasta antes de la ejecución del Contrato de Préstamo.}

Toda la suma de dinero de los financiadores es depositada en una cuenta bancaria, la que se denominará Cuenta de Fideicomiso IDelta, cuyos fondos serán administrados por una Fiduciaria, en donde se transferirá en dominio fiduciario los desembolsos que se reciben de los financiadores y los buscadores de préstamo y garantizar la oportuna canalización.

\section{Comisiones}

IDelta S.A.C. tendrá derecho al cobro de comisiones por la administración y gestión de los servicios. Dentro de las comisiones a cobrar se encuentra: comisión por emisión, por mantenimiento de cuentas, y la comisión de renta de segunda categoría, a todos ellos más el IGV.

\section{Política de Privacidad}

IDelta S.A.C. respeta lo exigido por la Ley 29733 de Protección de Datos Personales. 


\section{ANEXO 8: Detalle productos of recidos}

a) Ventas por adelantado

Precio establecido se encuentra basado en comisión total de ocho por ciento sobre la

utilidad estimada, de modo tal que se cobra cuatro por ciento benefactor y cuatro por ciento al beneficiario, quedando un modelo de cobro que se respalda en resultados los cuales mientras mejores sean para el benefactor así como el beneficiario, mejor es la rentabilidad para la empresa.

Caso empresario que abastece de productos para agricultura, oferta a precio regular geomembrana de 500 micras a un precio de S/. 13, el producto viene en rollos de 50 metros de largo por cuatro de ancho.

Ahora, por el lado de un cliente interesado, un agricultor precisa geomembrana para revestir un reservorio, por el tamaño y requerimientos del personal asignado en la construcción, el agricultor precisa de cinco rollos, lo cual en precio ordinario representaría un precio de S/. 12 en promedio (considerando descuento de un sol por metro cuadrado).

El proyecto buscaría entonces conseguir otros interesados en comprar el mismo material a fin de conseguir menores precios, coordinando con las empresas oferentes a fin de buscar quien es la que brinda el mejor descuento. En este ejemplo propuesto la empresa que abastece productos de agricultura, propone dejar en S/. 10 el metro cuadrado con un volumen mínimo de 30 rollos y pago adelantado de tres meses.

El proyecto encuentra entonces seis agricultores que van a comprar cinco rollos cada uno (en promedio) con las mismas características, el proyecto les muestra entonces

Costo estimado en el mercado S/. 12 x M2, en 30 rollos, seria S/. 72000 Costo estimado con el proyecto, pago por adelantado tres meses S/. 60000 
La utilidad estimada entonces sería de S/. 12000 en favor de los clientes, el proyecto les cobraría el ocho porciento de comisión, es decir S/. 960 (S/. 96 correspondiente al 10\% de la comisión total a la empresa que abastece de productos para agricultura y S/. 864 correspondiente al $90 \%$ a los clientes compradores).

Los costos expuestos en el presente ejemplo podrían variar dependiendo el nivel de seguridad adicional que desee el cliente, S/. 100 por servicios adicionales definidas como personalización de algún contrato, asesoría de finanzas en algún punto específico, planes de negocio entre otros; del mismo modo podría ser asesoría por horas o asesoría por horas en temas libres relacionados.

Con este producto se puede:

- Obtener mejores beneficios que mecanismos tradicionales, en especial cuando existen problemas de financiamiento o capital.

- Publicidad y marketing de productos, en especial cuando se está introduciendo nuevos productos.

- Ideal para investigación de mercados, siendo en muchos casos más rentable.

- Gestión de riesgos y seguridad

- Acceso a mejores precios del medio por parte de los clientes. 


\section{IDELTA}

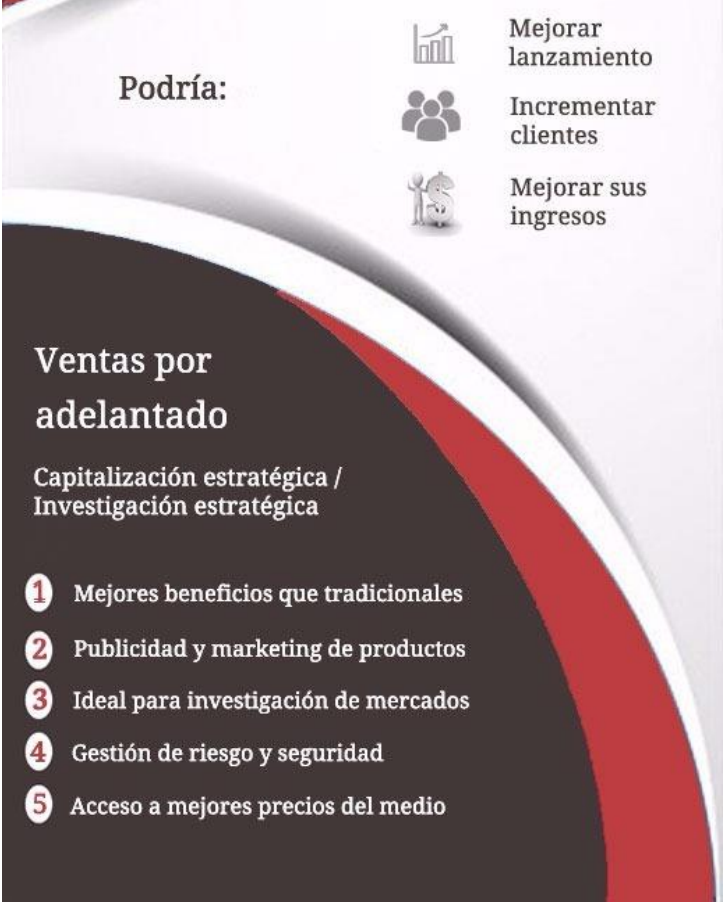

\section{b) Financiamiento}

Precio establecido se encuentra basado en comisión total de ocho porciento sobre la utilidad estimada, de modo tal que se cobra cuatro porciento benefactor y cuatro porciento al beneficiario, quedando un modelo de cobro que se respalda en resultados los cuales mientras mejores sean para el benefactor así como el beneficiario, mejor es la rentabilidad para la empresa.

Caso empresario que abastece de servicios para minería, requiere S/. 60 000, en un plazo de 8 meses, en un banco convencional podría en promedio tener una T.E.A. en soles de $50 \%$ (TCEA $59.10 \%$ ), la cual incluida el seguro de desgravamen $(2.45 \%)$ y $\operatorname{ITF}(0.005 \%)$, totaliza un monto a pagar de S/. 73 775.4.

Costo calculado de S/. 60 000, seria S/.13 775.4. 
Ahora por el lado del inversionista o inversionistas interesados, si desean invertir S/. 60000 con bajo riesgo a 12 meses y acuden a una banca convencional en promedio podrían tener $3.35 \%$ de T.E.A., totalizando un monto a recibir de S/. 62583.60.

Utilidad calculada al inversionista de S/. 60 000, seria S/. 2 583.6.

El proyecto buscaría entonces conseguir los S/. 60000 a un costo promedio de S/. 7 525.4, siendo S/. 6250 más económico al prestamista y siendo S/. 3666.4 soles más rentable al inversionista.

La utilidad total sería S/. 9916.4 de S/. 6250 del prestamista y S/. 3666.4 del inversionista. El proyecto cobraría 8\% de la utilidad total S/. 9916.4 siendo S/. 793.312 a cobrar, cobrándose S/. 500 (63\%) al prestamista y S/. 293,312 (40\% ).

Los costos expuestos en el presente ejemplo podrían variar dependiendo el nivel de seguridad adicional que desee el cliente, S/. 100 por servicios adicionales definidas como personalización de algún contrato, asesoría de finanzas en algún punto específico, planes de negocio entre otros; del mismo modo podría ser asesoría por horas o asesoría por horas en temas libres relacionados.

A fin de sintetizar las metas de venta, se considera como ingreso promedio de la siguiente manera:

Precio promedio $\$ 151.5$ o S/. 500 soles, y el pago viene de la utilidad cobrada al beneficiario y benefactor.

Con este producto se puede:

- Elegir tasas más competitivas que las opciones tradicionales del medio.

- Obtener tasas más competitivas que las opciones tradicionales del medio. 
- Ideal para generar opciones de apalancamiento alternativo.

- Elección del riesgo/beneficio y control directo por parte del inversionista.

- Se pueden presentar diferentes opciones de negociación.

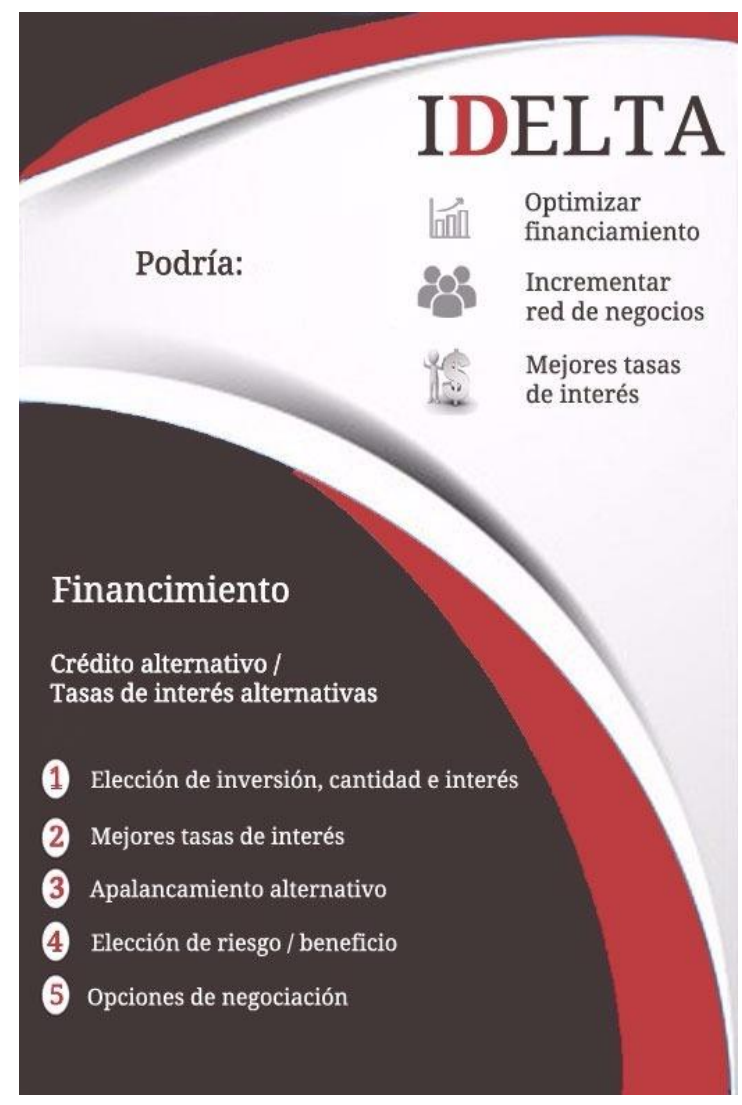

c) Servicios Especiales

Este servicio tiene un costo de S/. 100 soles ( \$ 30.3 ) y le permite al usuario solicitar acorde disponibilidad, y complejidad, algún documento con personalización de algún contrato, asesoría de finanzas en algún punto específico, planes de negocio, trámites con entidades del estado, constitución de sociedades fusiones y adquisiciones, transformaciones societarias, acompañamiento jurídico en juntas de socios o asambleas de accionistas, asesoría en materia de derecho de la competencia atinente a reclamaciones o defensa por competencia desleal, prácticas, restrictivas de la competencia y protección del consumidor, arbitraje y mediación, asesoría financiera, entre otros 
Con este producto se puede:

- Vender derechos de participación.

- Personalizar apalancamiento financiero entre interesados.

- Personalizar inversiones y configurar modelos alternativos o condiciones extraordinarias.

- Renegociación de riesgo / beneficio.

- Personalizar opciones de negociación.

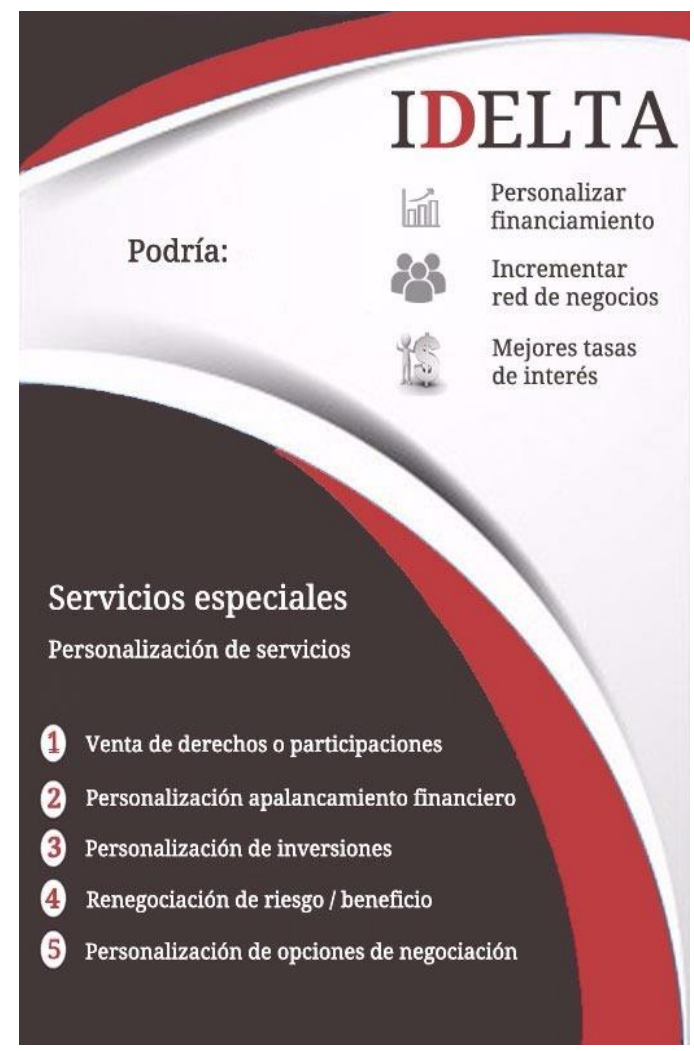

d) Asesoría permanente

Este servicio tiene un costo de S/. 220 soles ( \$ 66.7 ) y le permite al usuario solicitar hasta cinco horas de asesoría por mes en detalles pertinentes a los detallados en el producto de Servicios Especiales. 
Con este producto se puede:

- Asesoría por horas, tareas.

- Personalizar planes corporativos.

- Personalizar asesoría y/o capacitación.

- Cursos regulares, horas o en empresas.

- Atención remota por vía telefónica o video llamada por internet.

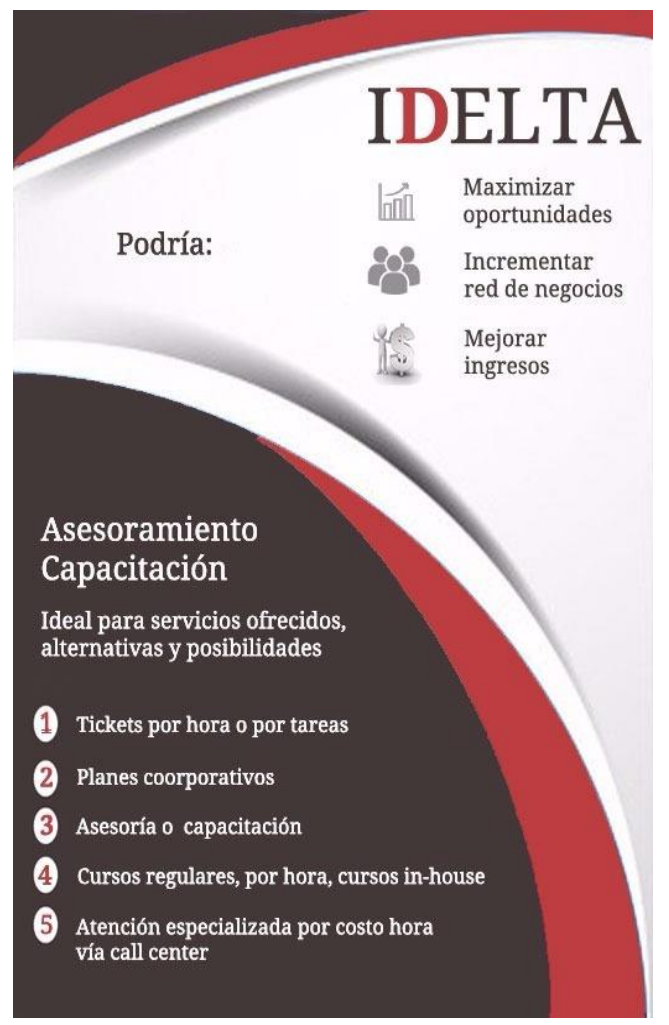

e) Asesoría por horas

Este servicio tiene un costo de S/. 75 soles (\$21.2) y le permite al usuario solicitar una hora de asesoría en detalles pertinentes a los detallados en el producto de Servicios especiales. 


\section{ANEXO 9: Especificaciones Fideicomiso}

El fideicomiso es una relación jurídica en la cual el fiduciante (que refiere a la persona que aporta), que en caso del proyecto puede ser el prestamista o prestatario y este, transfiere bienes en fideicomiso, a un tercero, que se denomina fiduciario ( Banco de Crédito del Perú dado que es un fideicomiso de tipo financiero y el Banco de Crédito es una entidad financiera sujeta a ley con expresa autorización a realizar tal fin ), para la constitución de un patrimonio autónomo, sujeto al dominio fiduciario de este último y afecto al cumplimiento de un fin específico a favor de un tercero denominado beneficiario (que es el usuario en cuyo favor se ejerce la administración de los bienes fideicometidos).

Fideicomiso (del latín fideicommissum, es decir de fe, y de commissus, comisión), consiste en un acto jurídico, de confianza, en el que una persona entrega a otra la titularidad de unos activos para que ésta los administre en beneficio de un tercero constituyendo un patrimonio autónomo e independiente de todas las partes involucradas. Con la finalidad de garantizar la adecuada administración de los fondos que se operan a través de la Empresa IDeltas, todas las sumas de dinero son depositadas en una cuenta bancaria (la Cuenta IDeltas) abierta a nombre del patrimonio fideicometido a crearse y administrarse por el Banco de Crédito del Perú (el Fiduciario) en virtud del contrato de fideicomiso en administración de fecha 22 de junio de 2019 (el Contrato de Fideicomiso), en los términos y condiciones establecidos en el Contrato de Fideicomiso. Las consideraciones aquí mencionadas guardan una estrecha relación en base al contrato efectuado entre la empresa Afluenta y el Banco de Crédito, así mismo tenemos sustento de personal del Banco de Crédito quienes confirmaron el contrato y la posibilidad de celebrar un contrato con las mismas características y los siguientes costos, US\$ 3500 para la elaboración del contrato, US\$ 1000 para contratacion de 
asesoria especializada y finalmente US\$800 de mantenimiento del fideicomiso, habiendo incluido dichos costos en la corrida económica presentada en el proyecto, específicamente en:

\begin{tabular}{|c|c|}
\hline \multicolumn{2}{|c|}{ INVERSIÓN PRE-OPERATIVA: ACTIVOS INTANG IBLES } \\
\hline CONCEPTO & Monto (U.S. Dólares) \\
\hline \multicolumn{2}{|l|}{ ESTUDIO DE PRE-INVERSIÓN } \\
\hline Estudio de Marke ting & 1,000 \\
\hline Estudio de Recursos Humanos & 750 \\
\hline Estudio Legal & 1,500 \\
\hline \multicolumn{2}{|l|}{ GASTOS DE GESTIÓN } \\
\hline Gastos de Se lección y Contratación & 750 \\
\hline Elaboración y con trato fid ucidiario & 4,500 \\
\hline Estudio de Mercado & 1,250 \\
\hline Hostingy Dominio y Desarrollo portal web & 1,000 \\
\hline Adquisición de Software & 500 \\
\hline Desarrollo de Software & 500 \\
\hline Asistencia Técnica & 1,200 \\
\hline \multicolumn{2}{|c|}{ GASTOS DE ORGANIZACIÓNY Y CONSTITUCIÓN DE LA EMPRESA } \\
\hline Lice ncias, certificados, registro de marca, otros. & 800 \\
\hline TOTAL & 13,750 \\
\hline IMPREVISTOS (5\%) & 688 \\
\hline TOTAL ACTIVOSINTANGIBLES & 14,438 \\
\hline
\end{tabular}

\begin{tabular}{|l|r|r|}
\hline \multicolumn{2}{|c|}{ DESEMBOLSOS DIVERSOS } \\
\hline Detalle & \multicolumn{1}{|c|}{ S/. } & \multicolumn{1}{r|}{ US\$ } \\
\hline Matenimiento Fiduciario & 3,200 & 970 \\
\hline Licencias de SW (ERP) & 2,640 & 727 \\
\hline Transportes & 2,400 & 97 \\
\hline Gastos de luz, agua, teléfono, internet & 320 & 212 \\
\hline Materiales y Utiles de Oficina & 700 & 106 \\
\hline Seguros & 350 & 91 \\
\hline Mantenimiento & 300 & 45 \\
\hline Sistema de Vigilancia & 150 & 53 \\
\hline Gastos laborales & 175 & 303 \\
\hline Capacitación & 1,000 & 152 \\
\hline Marketing y publicidad & 500 & 970 \\
\hline Lanzamiento de proyecto & 3,200 & 909 \\
\hline Limpieza y Ornato & 3,000 & 61 \\
\hline Mantenimiento portal web & 200 & 212 \\
\hline TOTAL & 700 & 5,708 \\
\hline
\end{tabular}


Referencia contrato fiducidiario, vigente y confirmado por personal del Banco de Crédito (Testimonio Notarial de Fideicomiso de Administración Afluenta Perú 1, 2019)

Referencias de respaldo Empresa Afluenta, respaldando la legalidad de sus operaciones y de su vigente contrato fiducidiario (Gestión, 2017)

Referencia de la SBS usa fideicomiso para regular fintech mientras sopesa una ley para el sector. Afluenta es la primera fintech que forma fideicomiso para hacer más transparentes sus operaciones (El Comercio, 2017)

\section{Base Legal Normativa Peruana}

1-BASE LEGAL LEY GENERAL DEL SISTEMA FINANCIERO

LEY N 26702: Ley General del Sistema Financiero y del Sistema de Seguros y Orgánica de la Superintendencia de Banca, Seguros y AFP (SBS).

\section{2-REGLAMENTO DEL FIDEICOMISO Y DE LAS EMPRESAS DE SERVICIOS}

FIDUCIARIOS

RESOLUCIÓN SBS No 1010-99: Reglamento Base (1999)

RESOLUCIÓN SBS N 12880-2009: Modificación del Reglamento Base (2009)

\section{3-NORMAS QUE REGULAN LA INSCRIPCIÓN DE FIDEICOMISOS (DIRECTIVA}

SUNARP)

RESOLUCIÓN SUNARP N 316-2008-SUNARP-SN: Normas que regulan la inscripción de fideicomisos.

4-CÓDIGO DE ÉTICA DE LAS EMPRESAS DEL SISTEMA FINANCIERO (ASBANC)

Código de Ética presentado por la Asociación de Bancos del Perú (ASBANC) en el 2002 
5-NORMAS PARA LA PREVENCIÓN DE LAVADO DE ACTIVOS

RESOLUCIÓN SBS N² 2660-2015: "Reglamento de Gestión de Riesgos de Lavado de Activos y del Financiamiento del Terrorismo"

\section{6-LEY DE GARANTÍA MOBILIARIA}

LEY Nº 28677: Ley de la Garantía Mobiliaria.

\section{7-REGLAMENTO DE TRANSPARENCIA}

Resolución SBS N 8181-2012: Reglamento de Transparencia de Información y Contratación con Usuarios del Sistema Financiero (Este es aplicable a La Fiduciaria en lo referido a temas de Atención al Usuario).

\section{8-CIRCULAR SOBRE SERVICIOS DE ATENCIÓN AL USUARIO}

Circular $\mathrm{N}^{\circ} \mathrm{G}$ - 184 - 2015: Circular cuya finalidad es promover una adecuada atención a los usuarios de las empresas reguladas por la SBS.

9-Reglamento de Libro de Reclamaciones

Decreto Supremo Nro 011-2011-PCM

10-Reglamento de Gestión de Conducta de Mercado del Sistema Financiero

Resolución S.B.S. Nro 2018 La Superintendencia de Banca, Seguros y Administradoras Privadas de Fondos de Pensiones 


\section{ANEXO 10: Seguros Adicionales}

Lo correspondiente a seguro multirriesgo, en el proyecto es considerado como un factor de menor riesgo para quienes solicitan financiamiento (prestatarios), o solicitantes de ventas por adelantado.

Las posibilidades de acceso a este seguro multirriesgo, depende de la entidad financiera con la que trabaje la empresa o persona:

Independiente:

Rimac Seguros, Primas accesibles desde \$122 al año (RIMAC, 2015); Seguro Multirriesgo Negocio Primas mensuales desde S/. 79, S/. 142, S/. 197 , S/. 230 (BBVA Banco Continental, 2019); Seguro Multiriesgo (Caja Paita, 2019). 
ANEXO 11: Matriz de riesgos y medidas de manejo

A fin de obtener la mayor cantidad de posibles riesgos, se considerará una RBS (Risk Breakdown Structure - Estructura de desglose del riesgo).

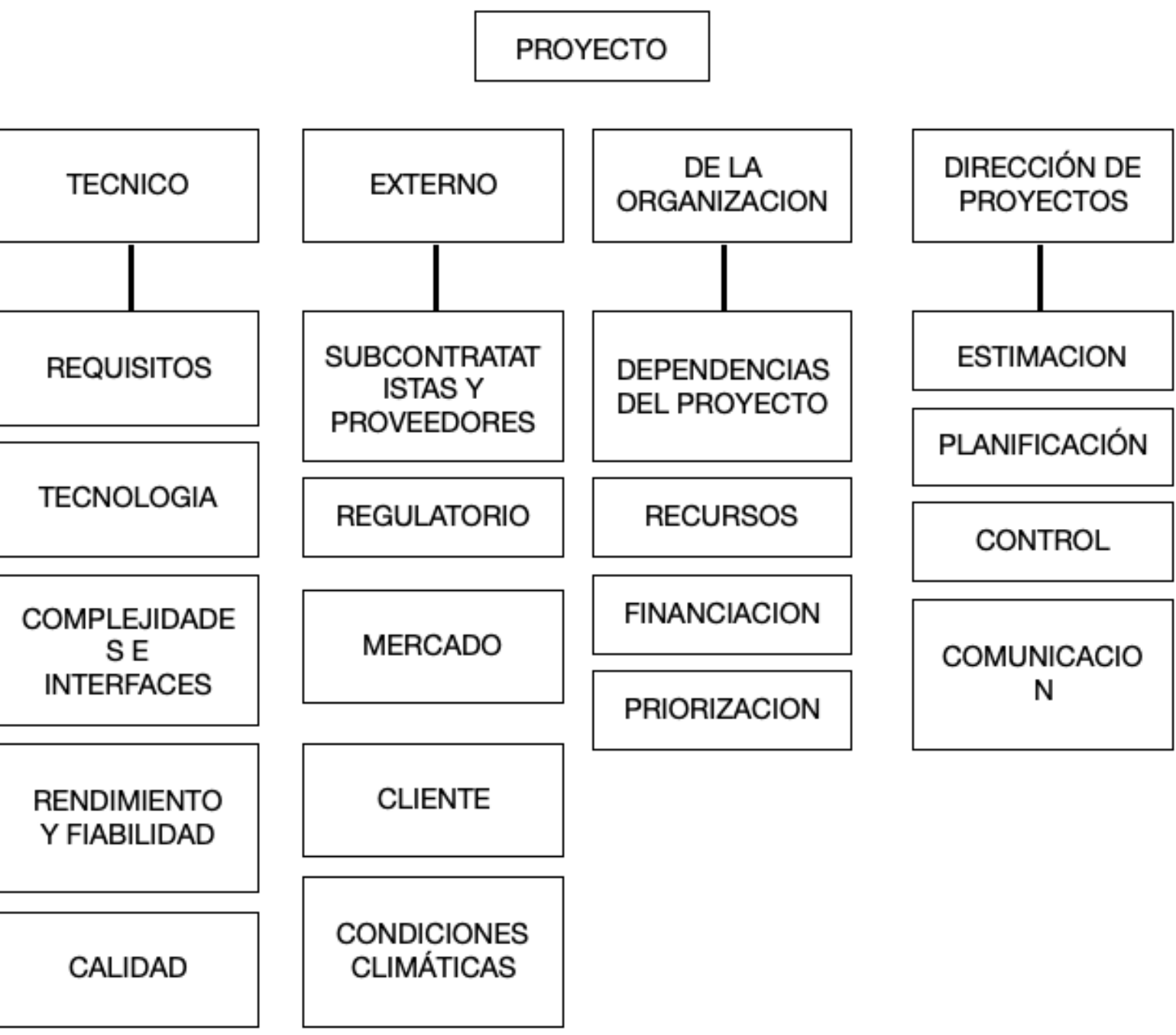

RBS (Risk Breakdown Structure - Estructura de desglose del riesgo), es una estructura de desglose del riesgo que garantiza un proceso completo de identificación sistemática de los riesgos con un nivel de detalle uniforme, contribuyendo de este modo a una enumeración y categorización de riesgos. 
Se procede entonces a realizar la categorización correspondiente:

\begin{tabular}{|c|c|c|c|c|}
\hline $\begin{array}{l}\text { CATEG } \\
\text { ORIA }\end{array}$ & $\begin{array}{l}\text { SUBCATEG } \\
\text { ORIA }\end{array}$ & $\begin{array}{l}\text { CARACTERISTICA } \\
\mathrm{S}\end{array}$ & $\begin{array}{l}\text { COD } \\
\text { IGO }\end{array}$ & RIESGO \\
\hline \multirow{5}{*}{$\begin{array}{l}\text { 1. } \mathrm{T} \\
\mathrm{E} \\
\mathrm{C} \\
\mathrm{N} \\
\mathrm{I} \\
\mathrm{C} \\
\mathrm{O}\end{array}$} & 1.1 Requisitos & $\begin{array}{l}\text { Riesgos asociados a los } \\
\text { requisitos necesarios } \\
\text { (condicionantes) al } \\
\text { desarrollo del } \\
\text { proyecto. }\end{array}$ & $\begin{array}{l}1.1 .1 \\
1.1 .2\end{array}$ & $\begin{array}{l}\text { Demora en la autorización y } \\
\text { expedición de los permisos } \\
\text { necesarios. } \\
\text { Problemas en contrato } \\
\text { fiduciario, se presentan } \\
\text { observaciones o incongruencias } \\
\text { en la elaboración del contrato. }\end{array}$ \\
\hline & 1.2 Tecnología & $\begin{array}{l}\text { Riesgos en } \\
\text { requerimiento de } \\
\text { tecnología. }\end{array}$ & $\begin{array}{l}1.2 .1 \\
1.2 .2\end{array}$ & $\begin{array}{l}\text { Riesgos en manejo de medios } \\
\text { informáticos (tecnología) por } \\
\text { parte de personal de la } \\
\text { empresa. } \\
\text { Riesgos en manejo de medios } \\
\text { informáticos (tecnología) por } \\
\text { parte de personal de los } \\
\text { usuarios (clientes). }\end{array}$ \\
\hline & $\begin{array}{l}1.3 \\
\text { Complejidad e } \\
\text { Interfaces }\end{array}$ & $\begin{array}{l}\text { Riesgos asociados a la } \\
\text { complejidad de } \\
\text { actividades necesarias } \\
\text { en las operaciones } \\
\text { diarias. }\end{array}$ & $\begin{array}{l}1.3 .1 \\
1.3 .2\end{array}$ & $\begin{array}{l}\text { Defectos en elaboración de } \\
\text { contratos } \\
\text { Problemas en publicación de } \\
\text { actualización en la web }\end{array}$ \\
\hline & $\begin{array}{l}1.4 \\
\text { Rendimiento y } \\
\text { Fiabilidad }\end{array}$ & $\begin{array}{l}\text { Riesgos asociados con } \\
\text { la cantidad de } \\
\text { actividades realizadas } \\
\text { en un periodo de } \\
\text { tiempo y su } \\
\text { rendimiento. }\end{array}$ & 1.4 .1 & $\begin{array}{l}\text { Dificultad por parte de los } \\
\text { usuarios (clientes) en el } \\
\text { aprovechamiento de } \\
\text { posibilidades ofrecidas por } \\
\text { parte del proyecto. }\end{array}$ \\
\hline & 1.5 Calidad & $\begin{array}{l}\text { Riesgos asociados con } \\
\text { la calidad de } \\
\text { actividades realizadas. }\end{array}$ & 1.5 .1 & $\begin{array}{l}\text { Descontento por parte de } \\
\text { usuarios (clientes). }\end{array}$ \\
\hline & $\begin{array}{l}2.1 \\
\text { Subcontratista } \\
\text { s y } \\
\text { proveedores }\end{array}$ & $\begin{array}{l}\text { Riesgos asociados al } \\
\text { incumplimiento, } \\
\text { malfuncionamiento o } \\
\text { retraso de funciones, o } \\
\text { tareas. }\end{array}$ & $\begin{array}{l}2.1 .1 \\
2.1 .2 \\
2.1 .3\end{array}$ & $\begin{array}{l}\text { Problemas con el local } \\
\text { alquilado. } \\
\text { Problemas con el software } \\
\text { web. } \\
\text { Problemas en el fideicomiso. }\end{array}$ \\
\hline & $\begin{array}{l}2.2 \\
\text { Regulatorio }\end{array}$ & $\begin{array}{l}\text { Riesgos asociados a los } \\
\text { controles regulatorios } \\
\text { regulares realizados }\end{array}$ & 2.2 .1 & $\begin{array}{l}\text { Cambios en la normativa local } \\
\text { en los reglamentos regulatorios } \\
\text { del medio. }\end{array}$ \\
\hline
\end{tabular}




\begin{tabular}{|c|c|c|c|c|}
\hline \multirow[t]{4}{*}{$\begin{array}{l}2 . \\
\text { EXTERN } \\
\text { O }\end{array}$} & & $\begin{array}{l}\text { por entidades del } \\
\text { medio. }\end{array}$ & $\begin{array}{l}2.2 .2 \\
2.2 .3\end{array}$ & $\begin{array}{l}\text { Uso de reglamentaciones o } \\
\text { documentación obsoleta, no } \\
\text { actualizadas. } \\
\text { Penalidades contractuales (por } \\
\text { daño, robos, desvío de } \\
\text { recursos, etc.). }\end{array}$ \\
\hline & 2.3 Mercado & $\begin{array}{l}\text { Riesgos asociados con } \\
\text { disponibilidad de } \\
\text { recursos necesarios en } \\
\text { el mercado (insumos } \\
\text { en caso de productos) }\end{array}$ & 2.3 .1 & $\begin{array}{l}\text { Disponibilidad y accesibilidad } \\
\text { a recursos necesarios. }\end{array}$ \\
\hline & 2.4 Cliente & $\begin{array}{l}\text { Riesgos asociados con } \\
\text { los cambios en las } \\
\text { especificaciones de } \\
\text { cada cliente. }\end{array}$ & 2.4.1 & $\begin{array}{l}\text { Exceso de costos debido a las } \\
\text { especificaciones propuestas } \\
\text { (requeridas). }\end{array}$ \\
\hline & $\begin{array}{l}2.5 \\
\text { Condiciones } \\
\text { Climáticas }\end{array}$ & $\begin{array}{l}\text { Riesgos asociados a las } \\
\text { condiciones climáticas }\end{array}$ & 2.5.1 & Lluvias abundantes. \\
\hline & $\begin{array}{l}3.1 \\
\text { Dependencias } \\
\text { del proyecto }\end{array}$ & $\begin{array}{l}\text { Riesgos asociados con } \\
\text { grupos de trabajo } \\
\text { necesarios para realizar } \\
\text { el proyecto }\end{array}$ & $\begin{array}{l}3.1 .1 \\
3.1 .2\end{array}$ & $\begin{array}{l}\text { Departamento de ventas no } \\
\text { sabe vender los servicios. } \\
\text { Mala selección del equipo de } \\
\text { trabajo (Equipo no idóneo). }\end{array}$ \\
\hline & 3.2 Recursos & $\begin{array}{l}\text { Riesgos asociados a la } \\
\text { asignación de recursos } \\
\text { necesarios para } \\
\text { actividades/tareas. }\end{array}$ & $\begin{array}{l}3.2 .1 \\
3.2 .2\end{array}$ & $\begin{array}{l}\text { Inadecuada asignación de } \\
\text { recursos. } \\
\text { Poca asignación de recursos. }\end{array}$ \\
\hline & $\begin{array}{l}3.3 \\
\text { Financiación }\end{array}$ & $\begin{array}{l}\text { Riesgos que } \\
\text { comprenden la falta de } \\
\text { financiación o } \\
\text { sobrecosto del } \\
\text { proyecto. }\end{array}$ & $\begin{array}{l}3.3 .1 \\
3.3 .2 \\
3.3 .3\end{array}$ & $\begin{array}{l}\text { Desinterés de los socios para el } \\
\text { financiamiento del proyecto. } \\
\text { Falta de financiamiento del } \\
\text { proyecto. } \\
\text { Devaluación de la moneda. }\end{array}$ \\
\hline & $\begin{array}{l}3.4 \\
\text { Priorización }\end{array}$ & $\begin{array}{l}\text { Riesgos asociados a las } \\
\text { entregas tempranas a } \\
\text { solicitud del } \\
\text { inversionista. }\end{array}$ & 3.4 .1 & $\begin{array}{l}\text { Retrasos en el comienzo de la } \\
\text { obra, actividades y entregas del } \\
\text { proyecto. }\end{array}$ \\
\hline & 4.1 Estimación & $\begin{array}{l}\text { Riesgos asociados a } \\
\text { con los supuestos de } \\
\text { gran significado en el } \\
\text { proyecto. }\end{array}$ & 4.1.1 & $\begin{array}{l}\text { Apretado calendario del } \\
\text { proyecto. }\end{array}$ \\
\hline & $\begin{array}{l}4.2 \\
\text { Planificación }\end{array}$ & $\begin{array}{l}\text { Riesgos asociados a la } \\
\text { forma en cómo se } \\
\text { coordinan las }\end{array}$ & $\begin{array}{l}4.2 .1 \\
4.2 .2\end{array}$ & $\begin{array}{l}\text { Procedimientos de trabajo mal } \\
\text { definidos o incorrectos. } \\
\text { Demora en la definición de }\end{array}$ \\
\hline
\end{tabular}




\begin{tabular}{|l|l|l|l|l|}
\hline & $\begin{array}{l}\text { actividades del } \\
\text { proyecto. }\end{array}$ & & procedimiento de trabajo. \\
\cline { 2 - 5 } & 4.3 Control & $\begin{array}{l}\text { Riesgos asociados al } \\
\text { control que se realiza } \\
\text { por parte de los altos } \\
\text { cargos. }\end{array}$ & $\begin{array}{l}4.3 .1 \\
4.3 .2\end{array}$ & $\begin{array}{l}\text { Normativa desactualizada. } \\
\text { Demora excesiva en los } \\
\text { procesos. }\end{array}$ \\
\cline { 2 - 5 } & $\begin{array}{l}\text { Riesgos asociados con } \\
\text { Comunicación } \\
\text { comunicación e } \\
\text { información a los fines } \\
\text { del proyecto. }\end{array}$ & 4.4 .1 & $\begin{array}{l}\text { Proceso de negociación } \\
\text { inadecuado; (No se plasma } \\
\text { correctamente la oportunidad). } \\
\text { Conflictos entre artes. }\end{array}$ \\
\hline
\end{tabular}

Plan de Acción para los riesgos

\begin{tabular}{|c|c|c|c|c|c|c|}
\hline $\begin{array}{l}\text { Códi } \\
\text { go }\end{array}$ & Riesgo & $\begin{array}{l}\text { Estrateg } \\
\text { ia }\end{array}$ & $\begin{array}{l}\text { Acción } \\
\text { Preventiva }\end{array}$ & $\begin{array}{l}\text { Contingencias y } \\
\text { respaldos }\end{array}$ & $\begin{array}{l}\text { Dispara } \\
\text { dor }\end{array}$ & $\begin{array}{l}\text { Responsa } \\
\text { ble }\end{array}$ \\
\hline 1.1 .1 & $\begin{array}{l}\text { Demora en la } \\
\text { autorización y } \\
\text { expedición de } \\
\text { los permisos } \\
\text { necesarios. }\end{array}$ & Evitar & $\begin{array}{l}\text { Iniciar los } \\
\text { trámites con } \\
\text { anterioridad. }\end{array}$ & $\begin{array}{l}\text { Revisión de } \\
\text { puntos álgidos en } \\
\text { estudios de pre } \\
\text { inversión, } \\
\text { específicamente } \\
\text { estudio legal. }\end{array}$ & $\begin{array}{l}\text { Informe } \\
\text { s de } \\
\text { Gerenci } \\
\text { a } \\
\text { General }\end{array}$ & $\begin{array}{l}\text { Asesor } \\
\text { Legal }\end{array}$ \\
\hline 1.1.2 & $\begin{array}{l}\text { Problemas en } \\
\text { contrato } \\
\text { fiduciario, se } \\
\text { presentan } \\
\text { observaciones } \\
\text { o } \\
\text { incongruencias } \\
\text { en la } \\
\text { elaboración del } \\
\text { contrato. }\end{array}$ & Mitigar & $\begin{array}{l}\text { Hacer } \\
\text { seguimiento al } \\
\text { avance del } \\
\text { contrato. }\end{array}$ & $\begin{array}{l}\text { Revisión de } \\
\text { puntos álgidos en } \\
\text { estudios de pre } \\
\text { inversión, } \\
\text { específicamente } \\
\text { estudio legal. }\end{array}$ & $\begin{array}{l}\text { Informe } \\
\text { s de } \\
\text { Gerenci } \\
\text { a } \\
\text { General }\end{array}$ & $\begin{array}{l}\text { Asesor } \\
\text { Legal }\end{array}$ \\
\hline 1.2 .1 & $\begin{array}{l}\text { Riesgos en } \\
\text { manejo de } \\
\text { medios } \\
\text { informáticos } \\
\text { (tecnología) } \\
\text { por parte de } \\
\text { personal de la } \\
\text { empresa. }\end{array}$ & Evitar & $\begin{array}{l}\text { Establecer } \\
\text { mecanismos de } \\
\text { asesoría } \\
\text { personalizada a } \\
\text { fin de atender } \\
\text { eventualidades } \\
\text { relacionadas. }\end{array}$ & $\begin{array}{l}\text { Dar capacitación } \\
\text { al personal } \\
\text { contratado y que } \\
\text { estén por debajo } \\
\text { del perfil } \\
\text { requerido. }\end{array}$ & $\begin{array}{l}\text { Informe } \\
\text { s de } \\
\text { Secretar } \\
\text { ia } \\
\text { General }\end{array}$ & $\begin{array}{l}\text { Jefe de } \\
\text { Servicios }\end{array}$ \\
\hline 1.2.2 & $\begin{array}{l}\text { Riesgos en } \\
\text { manejo de } \\
\text { medios } \\
\text { informáticos }\end{array}$ & Evitar & $\begin{array}{l}\text { Establecer } \\
\text { mecanismos de } \\
\text { asesoría } \\
\text { personalizada a }\end{array}$ & $\begin{array}{l}\text { Dar capacitación } \\
\text { al cliente } \\
\text { contratado y que } \\
\text { estén por debajo }\end{array}$ & $\begin{array}{l}\text { Informe } \\
\text { s de } \\
\text { Secretar } \\
\text { ia }\end{array}$ & $\begin{array}{l}\text { Jefe de } \\
\text { Servicios }\end{array}$ \\
\hline
\end{tabular}




\begin{tabular}{|c|c|c|c|c|c|c|}
\hline & $\begin{array}{l}\text { (tecnología) } \\
\text { por parte de } \\
\text { personal de los } \\
\text { usuarios } \\
\text { (clientes). }\end{array}$ & & $\begin{array}{l}\text { fin de atender } \\
\text { eventualidades } \\
\text { relacionadas. }\end{array}$ & $\begin{array}{l}\text { del perfil deseado, } \\
\text { sin afectar } \\
\text { económicamente } \\
\text { al proyecto. }\end{array}$ & General & \\
\hline 1.3 .1 & $\begin{array}{l}\text { Defectos en } \\
\text { elaboración de } \\
\text { contratos }\end{array}$ & Mitigar & $\begin{array}{l}\text { Establecer } \\
\text { mecanismos de } \\
\text { asesoría } \\
\text { personalizada a } \\
\text { fin de atender } \\
\text { eventualidades } \\
\text { relacionadas. }\end{array}$ & $\begin{array}{l}\text { Dar capacitación } \\
\text { al personal o } \\
\text { clientes y que } \\
\text { estén por debajo } \\
\text { del perfil } \\
\text { requerido. }\end{array}$ & $\begin{array}{l}\text { Informe } \\
\text { s de } \\
\text { Secretar } \\
\text { ia } \\
\text { General }\end{array}$ & $\begin{array}{l}\text { Jefe de } \\
\text { Servicios }\end{array}$ \\
\hline 1.3 .2 & $\begin{array}{l}\text { Problemas en } \\
\text { publicación de } \\
\text { actualización } \\
\text { en la web }\end{array}$ & Evitar & $\begin{array}{l}\text { Establecer } \\
\text { responsabilida } \\
\text { d en cada } \\
\text { asesor de } \\
\text { servicios. }\end{array}$ & $\begin{array}{l}\text { Elaborar listas de } \\
\text { chequeo. }\end{array}$ & $\begin{array}{l}\text { Informe } \\
\text { de Jefe } \\
\text { de } \\
\text { Servicio } \\
\text { s }\end{array}$ & $\begin{array}{l}\text { Asesor } \\
\text { de } \\
\text { Servicios }\end{array}$ \\
\hline 1.4 .1 & $\begin{array}{l}\text { Dificultad por } \\
\text { parte de los } \\
\text { usuarios } \\
\text { (clientes) en el } \\
\text { aprovechamien } \\
\text { to de } \\
\text { posibilidades } \\
\text { ofrecidas por } \\
\text { parte del } \\
\text { proyecto }\end{array}$ & Evitar & $\begin{array}{l}\text { Establecer } \\
\text { mecanismos de } \\
\text { asesoría } \\
\text { personalizada a } \\
\text { fin de atender } \\
\text { eventualidades } \\
\text { relacionadas. }\end{array}$ & $\begin{array}{l}\text { Dar capacitación } \\
\text { al cliente } \\
\text { contratado y que } \\
\text { estén por debajo } \\
\text { del perfil deseado, } \\
\text { sin afectar } \\
\text { económicamente } \\
\text { al proyecto. }\end{array}$ & $\begin{array}{l}\text { Informe } \\
\text { de Jefe } \\
\text { de } \\
\text { Servicio } \\
\text { s }\end{array}$ & $\begin{array}{l}\text { Asesor } \\
\text { de } \\
\text { Servicios }\end{array}$ \\
\hline 1.5 .1 & $\begin{array}{l}\text { Descontento } \\
\text { por parte de } \\
\text { usuarios } \\
\text { (clientes) }\end{array}$ & Mitigar & $\begin{array}{l}\text { Establecer } \\
\text { mecanismos de } \\
\text { asesoría } \\
\text { personalizada a } \\
\text { fin de atender } \\
\text { eventualidades } \\
\text { relacionadas. }\end{array}$ & $\begin{array}{l}\text { Elaborar listas de } \\
\text { chequeo. }\end{array}$ & $\begin{array}{l}\text { Informe } \\
\text { de Jefe } \\
\text { de } \\
\text { Servicio } \\
\text { s }\end{array}$ & $\begin{array}{l}\text { Asesor } \\
\text { de } \\
\text { Servicios }\end{array}$ \\
\hline 2.1 .1 & $\begin{array}{l}\text { Problemas con } \\
\text { el local } \\
\text { alquilado. }\end{array}$ & Evitar & $\begin{array}{l}\text { Iniciar revisión } \\
\text { y condiciones } \\
\text { con } \\
\text { anterioridad. }\end{array}$ & $\begin{array}{l}\text { Local propuesto } \\
\text { pertenece a la } \\
\text { familia de uno de } \\
\text { los dos } \\
\text { inversionistas, se } \\
\text { pueden conversar } \\
\text { posibles } \\
\text { problemáticas con } \\
\text { tiempo. }\end{array}$ & $\begin{array}{l}\text { Informe } \\
\text { s de } \\
\text { Secretar } \\
\text { ia } \\
\text { General }\end{array}$ & $\begin{array}{l}\text { Jefe de } \\
\text { Servicios }\end{array}$ \\
\hline 2.1 .2 & Problemas con & Evitar & Establecer & Determinar un & Informe & Asesor \\
\hline
\end{tabular}




\begin{tabular}{|c|c|c|c|c|c|c|}
\hline & $\begin{array}{l}\text { el software } \\
\text { web. }\end{array}$ & & $\begin{array}{l}\text { responsabilida } \\
\text { d en cada } \\
\text { asesor de } \\
\text { servicios, } \\
\text { reportando } \\
\text { incidentes. }\end{array}$ & $\begin{array}{l}\text { presupuesto de } \\
\text { mantenimiento } \\
\text { mensual. }\end{array}$ & $\begin{array}{l}\text { de Jefe } \\
\text { de } \\
\text { Servicio } \\
\text { s }\end{array}$ & $\begin{array}{l}\text { de } \\
\text { Servicios }\end{array}$ \\
\hline 2.1.3 & $\begin{array}{l}\text { Problemas en } \\
\text { el fideicomiso. }\end{array}$ & Evitar & $\begin{array}{l}\text { Revisión } \\
\text { constante de } \\
\text { condiciones. }\end{array}$ & $\begin{array}{l}\text { Determinar un } \\
\text { presupuesto de } \\
\text { mantenimiento } \\
\text { mensual. }\end{array}$ & $\begin{array}{l}\text { Informe } \\
\text { s de } \\
\text { Gerenci } \\
\text { a } \\
\text { General }\end{array}$ & $\begin{array}{l}\text { Asesor } \\
\text { Legal }\end{array}$ \\
\hline 2.2.1 & $\begin{array}{l}\text { Cambios en la } \\
\text { normativa local } \\
\text { en los } \\
\text { reglamentos } \\
\text { regulatorios del } \\
\text { medio. }\end{array}$ & Evitar & $\begin{array}{l}\text { Revisión } \\
\text { constante de } \\
\text { condiciones. }\end{array}$ & $\begin{array}{l}\text { Determinar un } \\
\text { presupuesto de } \\
\text { mantenimiento } \\
\text { mensual. }\end{array}$ & $\begin{array}{l}\text { Informe } \\
\text { s de } \\
\text { Gerenci } \\
\text { a } \\
\text { General }\end{array}$ & $\begin{array}{l}\text { Asesor } \\
\text { Legal }\end{array}$ \\
\hline 2.2.2 & $\begin{array}{l}\text { Uso de } \\
\text { reglamentacion } \\
\text { es o } \\
\text { documentación } \\
\text { obsoleta, no } \\
\text { actualizadas. }\end{array}$ & Evitar & $\begin{array}{l}\text { Revisión } \\
\text { constante de } \\
\text { condiciones. }\end{array}$ & $\begin{array}{l}\text { Determinar un } \\
\text { presupuesto de } \\
\text { mantenimiento } \\
\text { mensual. }\end{array}$ & $\begin{array}{l}\text { Informe } \\
\text { s de } \\
\text { Gerenci } \\
\text { a } \\
\text { General }\end{array}$ & $\begin{array}{l}\text { Asesor } \\
\text { Legal }\end{array}$ \\
\hline 2.2.3 & $\begin{array}{l}\text { Penalidades } \\
\text { contractuales } \\
\text { (por daño, } \\
\text { robos, desvío } \\
\text { de recursos, } \\
\text { etc.). }\end{array}$ & Aceptar & $\begin{array}{l}\text { Contratación } \\
\text { de seguros que } \\
\text { minimicen } \\
\text { riesgo }\end{array}$ & $\begin{array}{l}\text { Determinar un } \\
\text { presupuesto de } \\
\text { mantenimiento } \\
\text { mensual. }\end{array}$ & $\begin{array}{l}\text { Informe } \\
\text { s de } \\
\text { Asesor } \\
\text { Legal }\end{array}$ & $\begin{array}{l}\text { Secretari } \\
\text { a General }\end{array}$ \\
\hline 2.3.1 & $\begin{array}{l}\text { Disponibilidad } \\
\text { y accesibilidad } \\
\text { a recursos } \\
\text { necesarios. }\end{array}$ & Evitar & $\begin{array}{l}\text { Revisión } \\
\text { constante de } \\
\text { condiciones. }\end{array}$ & $\begin{array}{l}\text { Elaborar listas de } \\
\text { chequeo. }\end{array}$ & $\begin{array}{l}\text { Informe } \\
\text { s de } \\
\text { Secretar } \\
\text { 1́a } \\
\text { General }\end{array}$ & $\begin{array}{l}\text { Jefe de } \\
\text { Servicios }\end{array}$ \\
\hline 2.4.1 & $\begin{array}{l}\text { Exceso de } \\
\text { costos debido a } \\
\text { las } \\
\text { especificacione } \\
\text { s propuestas } \\
\text { (requeridas). }\end{array}$ & Evitar & $\begin{array}{l}\text { Revisión } \\
\text { constante de } \\
\text { condiciones. }\end{array}$ & $\begin{array}{l}\text { Elaborar listas de } \\
\text { chequeo. }\end{array}$ & $\begin{array}{l}\text { Informe } \\
\text { s de } \\
\text { Secretar } \\
\text { 1́a } \\
\text { General }\end{array}$ & $\begin{array}{l}\text { Jefe de } \\
\text { Servicios }\end{array}$ \\
\hline 2.5.1 & $\begin{array}{l}\text { Lluvias } \\
\text { abundantes }\end{array}$ & Aceptar & $\begin{array}{l}\text { Establecer } \\
\text { mecanismos de } \\
\text { asesoría } \\
\text { personalizada a }\end{array}$ & $\begin{array}{l}\text { Dar capacitación } \\
\text { al cliente } \\
\text { contratado y que } \\
\text { estén por debajo }\end{array}$ & $\begin{array}{l}\text { Informe } \\
\text { de Jefe } \\
\text { de } \\
\text { Servicio }\end{array}$ & $\begin{array}{l}\text { Asesor } \\
\text { de } \\
\text { Servicios }\end{array}$ \\
\hline
\end{tabular}




\begin{tabular}{|c|c|c|c|c|c|c|}
\hline & & & $\begin{array}{l}\text { fin de capacitar } \\
\text { respecto portal } \\
\text { web. }\end{array}$ & $\begin{array}{l}\text { del perfil deseado, } \\
\text { sin afectar } \\
\text { económicamente } \\
\text { al proyecto. }\end{array}$ & $\mathrm{s}$ & \\
\hline 3.1 .1 & $\begin{array}{l}\text { Departamento } \\
\text { de ventas no } \\
\text { sabe vender los } \\
\text { servicios. }\end{array}$ & Mitigar & $\begin{array}{l}\text { Revisión } \\
\text { constante de } \\
\text { metas } \\
\text { razonables. }\end{array}$ & $\begin{array}{l}\text { Dar capacitación } \\
\text { al personal o } \\
\text { clientes y que } \\
\text { estén por debajo } \\
\text { del perfil } \\
\text { requerido. }\end{array}$ & $\begin{array}{l}\text { Informe } \\
\text { s de } \\
\text { Secretar } \\
\text { ia } \\
\text { General }\end{array}$ & $\begin{array}{l}\text { Jefe de } \\
\text { Servicios }\end{array}$ \\
\hline 3.1 .2 & $\begin{array}{l}\text { Mala selección } \\
\text { del equipo de } \\
\text { trabajo (Equipo } \\
\text { no idóneo). }\end{array}$ & Mitigar & $\begin{array}{l}\text { Revisión } \\
\text { constante de } \\
\text { metas } \\
\text { razonables. }\end{array}$ & $\begin{array}{l}\text { Dar capacitación } \\
\text { al personal o } \\
\text { clientes y que } \\
\text { estén por debajo } \\
\text { del perfil } \\
\text { requerido. }\end{array}$ & $\begin{array}{l}\text { Informe } \\
\text { s de } \\
\text { Secretar } \\
\text { ia } \\
\text { General }\end{array}$ & $\begin{array}{l}\text { Jefe de } \\
\text { Servicios }\end{array}$ \\
\hline 3.2 .1 & $\begin{array}{l}\text { Inadecuada } \\
\text { asignación de } \\
\text { recursos. }\end{array}$ & Evitar & $\begin{array}{l}\text { Revisión } \\
\text { constante de } \\
\text { condiciones. }\end{array}$ & $\begin{array}{l}\text { Elaborar listas de } \\
\text { chequeo. }\end{array}$ & $\begin{array}{l}\text { Informe } \\
\text { s de } \\
\text { Secretar } \\
\text { ía } \\
\text { General }\end{array}$ & $\begin{array}{l}\text { Jefe de } \\
\text { Servicios }\end{array}$ \\
\hline 3.2 .2 & $\begin{array}{l}\text { Poca } \\
\text { asignación de } \\
\text { recursos. }\end{array}$ & Evitar & $\begin{array}{l}\text { Revisión } \\
\text { constante de } \\
\text { condiciones. }\end{array}$ & $\begin{array}{l}\text { Elaborar listas de } \\
\text { chequeo. }\end{array}$ & $\begin{array}{l}\text { Informe } \\
\text { s de } \\
\text { Secretar } \\
\text { ía } \\
\text { General }\end{array}$ & $\begin{array}{l}\text { Jefe de } \\
\text { Servicios }\end{array}$ \\
\hline 3.3 .1 & $\begin{array}{l}\text { Desinterés de } \\
\text { los socios para } \\
\text { el } \\
\text { financiamiento } \\
\text { del proyecto. }\end{array}$ & Evitar & $\begin{array}{l}\text { Revisión } \\
\text { constante de } \\
\text { necesidades de } \\
\text { financiación. }\end{array}$ & $\begin{array}{l}\text { Elaborar } \\
\text { cronograma de } \\
\text { desembolso con } \\
\text { tiempos } \\
\text { anticipados. }\end{array}$ & $\begin{array}{l}\text { Informe } \\
\text { s de } \\
\text { Gerenci } \\
\text { a } \\
\text { General }\end{array}$ & $\begin{array}{l}\text { Gerencia } \\
\text { General }\end{array}$ \\
\hline 3.3 .2 & $\begin{array}{l}\text { Falta de } \\
\text { financiamiento } \\
\text { del proyecto. }\end{array}$ & Evitar & $\begin{array}{l}\text { Revisión } \\
\text { constante de } \\
\text { necesidades de } \\
\text { financiación. }\end{array}$ & $\begin{array}{l}\text { Elaborar } \\
\text { cotizaciones de } \\
\text { crédito ante } \\
\text { alguna } \\
\text { emergencia. }\end{array}$ & $\begin{array}{l}\text { Informe } \\
\text { s de } \\
\text { Gerenci } \\
\text { a } \\
\text { General }\end{array}$ & $\begin{array}{l}\text { Gerencia } \\
\text { General }\end{array}$ \\
\hline 3.3.3 & $\begin{array}{l}\text { Devaluación de } \\
\text { la moneda. }\end{array}$ & Aceptar & $\begin{array}{l}\text { Fomento y } \\
\text { enfoque en } \\
\text { productos } \\
\text { financieros de } \\
\text { corto plazo. }\end{array}$ & $\begin{array}{l}\text { Revisión constante } \\
\text { de realidad } \\
\text { financiera. }\end{array}$ & $\begin{array}{l}\text { Informe } \\
\text { s de } \\
\text { Gerenci } \\
\text { a } \\
\text { General }\end{array}$ & $\begin{array}{l}\text { Secretari } \\
\text { a General }\end{array}$ \\
\hline 3.4 .1 & $\begin{array}{l}\text { Retrasos en el } \\
\text { comienzo de la }\end{array}$ & Evitar & $\begin{array}{l}\text { Revisión } \\
\text { constante de }\end{array}$ & $\begin{array}{l}\text { Elaborar listas de } \\
\text { chequeo. }\end{array}$ & $\begin{array}{l}\text { Informe } \\
\mathrm{s} \text { de }\end{array}$ & $\begin{array}{l}\text { Jefe de } \\
\text { Servicios }\end{array}$ \\
\hline
\end{tabular}




\begin{tabular}{|c|c|c|c|c|c|c|}
\hline & $\begin{array}{l}\text { obra, } \\
\text { actividades y } \\
\text { entregas del } \\
\text { proyecto. }\end{array}$ & & actividades. & & $\begin{array}{l}\text { Secretar } \\
\text { ia } \\
\text { General }\end{array}$ & \\
\hline 4.1.1 & $\begin{array}{l}\text { Apretado } \\
\text { calendario del } \\
\text { proyecto. }\end{array}$ & Evitar & $\begin{array}{l}\text { Revisión } \\
\text { constante de } \\
\text { tiempos en } \\
\text { actividades. }\end{array}$ & $\begin{array}{l}\text { Elaborar listas de } \\
\text { chequeo. }\end{array}$ & $\begin{array}{l}\text { Informe } \\
\text { s de } \\
\text { Secretar } \\
\text { ia } \\
\text { General }\end{array}$ & $\begin{array}{l}\text { Jefe de } \\
\text { Servicios }\end{array}$ \\
\hline 4.2.1 & $\begin{array}{l}\text { Procedimientos } \\
\text { de trabajo mal } \\
\text { definidos o } \\
\text { incorrectos. }\end{array}$ & Evitar & $\begin{array}{l}\text { Revisión } \\
\text { constante de } \\
\text { actividades. }\end{array}$ & Ninguna & $\begin{array}{l}\text { Informe } \\
\text { s de } \\
\text { Gerenci } \\
\text { a } \\
\text { General }\end{array}$ & $\begin{array}{l}\text { Secretari } \\
\text { a General }\end{array}$ \\
\hline 4.2 .2 & $\begin{array}{l}\text { Demora en la } \\
\text { definición de } \\
\text { procedimiento } \\
\text { de trabajo. }\end{array}$ & Evitar & $\begin{array}{l}\text { Revisión } \\
\text { constante de } \\
\text { tiempos en } \\
\text { actividades. }\end{array}$ & $\begin{array}{l}\text { Elaborar listas de } \\
\text { chequeo. }\end{array}$ & $\begin{array}{l}\text { Informe } \\
\text { s de } \\
\text { Gerenci } \\
\text { a } \\
\text { General }\end{array}$ & $\begin{array}{l}\text { Secretari } \\
\text { a General }\end{array}$ \\
\hline 4.3.1 & $\begin{array}{l}\text { Normativa } \\
\text { desactualizada. }\end{array}$ & Evitar & $\begin{array}{l}\text { Revisión } \\
\text { constante de } \\
\text { condiciones. }\end{array}$ & $\begin{array}{l}\text { Determinar un } \\
\text { presupuesto de } \\
\text { mantenimiento } \\
\text { mensual. }\end{array}$ & $\begin{array}{l}\text { Informe } \\
\text { s de } \\
\text { Gerenci } \\
\text { a } \\
\text { General }\end{array}$ & $\begin{array}{l}\text { Asesor } \\
\text { Legal }\end{array}$ \\
\hline 4.3.2 & $\begin{array}{l}\text { Demora } \\
\text { excesiva en los } \\
\text { procesos. }\end{array}$ & Evitar & $\begin{array}{l}\text { Revisión } \\
\text { constante de } \\
\text { tiempos en } \\
\text { actividades. }\end{array}$ & $\begin{array}{l}\text { Elaborar listas de } \\
\text { chequeo. }\end{array}$ & $\begin{array}{l}\text { Informe } \\
\text { s de } \\
\text { Secretar } \\
\text { ia } \\
\text { General }\end{array}$ & $\begin{array}{l}\text { Jefe de } \\
\text { Servicios }\end{array}$ \\
\hline 4.4.1 & $\begin{array}{l}\text { Proceso de } \\
\text { negociación } \\
\text { inadecuado; } \\
\text { (No se plasma } \\
\text { correctamente } \\
\text { la } \\
\text { oportunidad). }\end{array}$ & Mitigar & $\begin{array}{l}\text { Establecer } \\
\text { mecanismos de } \\
\text { asesoría } \\
\text { personalizada a } \\
\text { fin de atender } \\
\text { eventualidades } \\
\text { relacionadas. }\end{array}$ & $\begin{array}{l}\text { Elaborar } \\
\text { procedimientos de } \\
\text { revisión aleatoria. }\end{array}$ & $\begin{array}{l}\text { Informe } \\
\text { de Jefe } \\
\text { de } \\
\text { Servicio } \\
\text { s }\end{array}$ & $\begin{array}{l}\text { Asesor } \\
\text { de } \\
\text { Servicios }\end{array}$ \\
\hline 4.4 .2 & $\begin{array}{l}\text { Conflictos } \\
\text { entre partes. }\end{array}$ & Evitar & $\begin{array}{l}\text { Revisión } \\
\text { constante de } \\
\text { tiempos en } \\
\text { actividades. }\end{array}$ & $\begin{array}{l}\text { Elaborar } \\
\text { procedimientos de } \\
\text { revisión aleatoria. }\end{array}$ & $\begin{array}{l}\text { Informe } \\
\text { s de } \\
\text { Secretar } \\
\text { ia } \\
\text { General }\end{array}$ & $\begin{array}{l}\text { Jefe de } \\
\text { Servicios }\end{array}$ \\
\hline
\end{tabular}




\section{Prevención y Mitigación de Riesgos con especial consideración}

\section{- Prevención de Lavado de Activos}

IDeltas S.A.C para minimizar los riesgos por lavado de activos sólo admitirá personas que tengan cuentas en el sistema financiero peruano. Lo cual justificaría que los clientes han sido evaluados por las entidades financieras donde mantienen sus cuentas de acuerdo al reglamento de prevención del Lavado de Activos y Financiamiento del Terrorismo (LAFT).

\section{- Información no validada}

IDeltas S.A.C. realizará la validación y verificación de datos otorgados por los participantes, de existir información que revele incumplimientos de obligaciones o endeudamiento elevado respecto de sus ingresos, el cliente podrá no ser admitido para solicitar préstamos a través del sistema.

\section{- Riesgo de seguridad informática}

El proyecto tiene una guía detallada sobre la ley de protección de datos personales LEY Nro 29733, contemplando:

a) Se inscribirá ante la Autoridad correspondiente los Bancos de Datos Personales (BDP) que se obtengan y/o formen

b) Se procederá a obtener un consentimiento firmado informado de los titulares de los datos personales.

c) Aplicación de medidas de seguridad informática

d) Se permitirá mediante procedimiento atender derechos de personas naturales (Acceso, Rectificación, Cancelación, Oposición)

e) Se comunicara efectivamente el flujo transfronterizo (por migración de infraestructura, proveedor de servicios en "Cloud Computing", mudanza física de instalaciones a otro país ) 
El detalle de la norma la podemos encontrar en la referencia oficial del gobierno (El Peruano, 2011)

La metodología global que guía este ámbito de gobernabilidad y seguridad es la Norma Técnica Peruana “NTP ISO/SEC 27001:2014 Tecnología de la Información. Técnicas de Seguridad, Sistemas de Gestión de Seguridad de la Información. Requisitos, 2da Edición”

\section{- Riesgo legal}

Una vez que se formaliza una operación de préstamo, se genera de inmediato un contrato de mutuo entre las partes. Es muy importante que la redacción de éstos deba ser precisa y sin vacíos legales que pudieran perjudicar a cualquiera de las partes.

\section{- Riesgo de cambios regulatorios}

Contar con un asesor legal de reconocido prestigio dentro de los negocios de emprendimiento.

\section{- Riesgo de acceso a clientes que busquen préstamo}

Buscar medios de colaboración o formar alianzas, con las universidades de la ciudad, o instituciones de educación superior. Para incentivar a estos colaboradores se ha acordado brindar asesorías, promoción en cuanto a los costos de los productos que se ofrece, así como el uso de la plataforma para conseguir información.

\section{- Riesgo de acceso a clientes inversores}

Para mitigar este riesgo se ofrecerá promociones que van desde la participación en eventos de emprendimiento, foros de inversores, networking, apariciones en medios, así como reinvertir en marketing, evaluar si se puede aplicar el método bola de nieve, que es el de afiliar clientes por recomendación o invitación de otros clientes.

\section{- Riesgo de que un cliente se retrase en uno de sus pagos}

Ante posibles impagos o retrasos por parte de los prestatarios, IDeltas S.A.C. realizará el cobro de los intereses por la demora, lo cual queda pactado en el contrato. 


\section{- Riesgo involucrados con el tipo de financiamiento}

El proyecto, no intermedia ni afronta riesgos de restitución de fondos, tampoco de riesgo de incobrabilidad de financiamientos otorgados. El riesgo asociado por parte de los inversores está relacionado directamente a la cantidad de ganancia que los clientes esperan o desean.

El proyecto no capta recursos con la obligacion de restitucion como si lo hacen los bancos, esto, por que el proyecto no es depositario. El proyecto trabaja con fiduciantes quienes son inversores, no son depositantes tampoco acreedores, que invierten su dinero aceptando y entendiendo el riesgo que conlleva.

El inversor tiene diferentes modos de bajar el nivel de riesgo, solicitando hipotecas, garantías, elevando un contrato a registros públicos, etc. Todo esto lo puede realizar con los servicios especiales, asi como asesoria continua o por horas.

Con respecto a la movilidad del dinero, existe el "seguro multirriesgo", en el proyecto es considerado como un factor de menor riesgo para quienes solicitan financiamiento (prestatarios), o solicitantes de ventas por adelantado. 


\section{BIBLIOGRAFÍA}

Baca, Urbina. (2010). Evaluación de Proyectos. México D.F.: McGrawHill Education.

Chase, R., Jacobs, F. \& Aquilano, N., (2009).Administración de Operaciones Producción y Cadena de Suministros. México D.F.: McGrawHill Education.

Chiavenato, Idalberto (2011). Administración de Recursos Humanos. México D.F.: McGrawHill Interamericana.

David, Fred R. (2013). Conceptos de Administración Estratégica. Naucalpan de Juárez, México: Pearson Education.

Gitman, L. \& Zutter, C. (2012) Principios de Administración Financiera (12ma ed.). Naucalpan de Juárez, México: Pearson Education.

Gómez, N., Govea del Valle, A., Zagal, S. (2016). La Internacional Corredores de Seguros: Creación de un Bróker en Alianza con Prestigiosas Entidades Financieras (Tesis de MBA). Universidad Peruana de Ciencias Aplicadas, Lima, Perú.

Hair, J., Bush, R. \& Ortinau, D., (2010). Investigación de mercados en un ambiente de informacion digital. México D.F.: McGrawHill Education.

Hernandez, R., Fernandez, C. \& Baptista, P., (2010). Metodología de la Investigación. México D.F.: McGrawHill Education.

IOSCO (2014) Crowd-funding: An infant Industry Growing Fast. SWP3

Krajewski, L., Ritzman, L. \& Malhotra, M., (2008). Administración de Operaciones Procesos y cadenas de valor. Naucalpan de Juárez, Estado de México: Pearson Education.

Kotler, P. \& Armstrong, G. (2012). Marketing. Naucalpan de Juárez, México: Pearson Education. 
Mankiw, N.G. (2012). Principios de Economía. Santa Fe, México: Cengage Learning.

Sapag, N., (2011). Proyectos de Inversión. Formulación e inversion.. Macul, Santiago de Chile: Pearson

Schwienbacher, A. \& Larralde, B. (2012). Crowdfunding of Small Entrepreneurial Ventures. In Cumming, D. (Ed.), The Oxford Handbook of Entrepreneurial Finance. Oxford University Press.

Thompson, A., Gamble, J., Peteraf, M. \& Strickland, A. (2012). Administracion Estrategica. Mexico D.F.: The McGraw-Hill 


\section{REFERENCIAS ELECTRÓNICAS}

Acconcia (2015). Guía básica de crowdfunding \#4: El crowdfunding de recompensa.

Recuperado de https://vanacco.com/guia-crowdfunding-recompensa/

Actualidad Empresarial (2015). Costo de capital promedio ponderado (WACC). Recuperado de

http://aempresarial.com/servicios/revista/324_9_RNBMQJTOEZIOLSSMSWQOC DWMJRZXXBXPPYBFIUTNUCBFUTSNPI.pdf

Afluenta (2016). Afluenta, crédito humano. Recuperado de https://www.afluenta.pe/

Afluenta (2019). Testimonio Notarial de Fideicomiso de Administración Afluenta Perú 1.

Recuperado de

https://www.afluenta.pe/legales/testimonio_notarial_de_fideicomiso_de_administra cion_afluenta_peru1

ASBANC (2015). Balance de la banca peruana 2015. Recuperado de http://www.asbanc.com.pe/Paginas/Noticias/DetalleNoticia.aspx?ItemID=191

Asociación de Agentes de Aduana (2016). Nuestros Asociados. Recuperado de http://www.aaap.org.pe/

Aurum consultoria\&mercado (2015, Abril). Perspectivas Económicas 2015, Región Arequipa. Recuperado de http://ucsp.edu.pe/cegob/wpcontent/uploads/2015/04/AURUM_Informe-Perspectivas-Econ\%C3\%B3micas2015-Regi\%C3\%B3n-Arequipa_Abril-2015.pdf

Banco Central de Reserva. (2016). Reporte de estabilidad financiera Mayo 2016. Recuperado de http://www.bcrp.gob.pe/docs/Publicaciones/Reporte-Estabilidad-Financiera/refmayo-2016.pdf 
Banco Continental (2019). Multiriesgo Negocio. Recuperado de https://www.bbvacontinental.pe/negocios/seguros/multiriesgo-negocio/\#ficha$\underline{\text { content- } 0}$

Bolsa de Valores de Lima (2016). Educación Bursátil, Herramientas. Recuperado de http://www.bvl.com.pe/

Biblios - University of Pittsburgh (2016), Crowdsourcing en bibliotecas. Recuperado de http://biblios.pitt.edu/ojs/index.php/biblios/article/download/297/263

Caja Paita (2019). Seguro multiriesgo asociado al desembolso crédito. Recuperado de http://www.cajapaita.pe/seguros/seguro-multiriesgo-asociado-al-desembolso-credito/

Cámara de Comercio de Arequipa (2016), Informe de coyuntura: Junio 2016. La Dinámica de la PEA en Arequipa. Recuperado de http://www.camaraarequipa.org.pe/sites/default/files/publicaciones/informe_de_coyuntura__la_dinamica_de_la_pea_en_arequipa._junio_2016.pdf

Comisión Multisectorial de Inclusión Financiera (2015), Estrategia Nacional de Inclusión Financiera. Recuperado de https://mef.gob.pe/contenidos/archivosdescarga/ENIF.pdf

Correo (2014), PEA de Arequipa es de 660 mil. Recuperado de https://diariocorreo.pe/ciudad/pea-de-arequipa-es-de-660-mil-35401/

Dobrecky (2016), Crowdsourcing en bibliotecas. Recuperado de http://biblios.pitt.edu/ojs/index.php/biblios/article/view/297

El Comercio (2014). El 65\% de todas las empresas en el Perú son informales. Recuperado de https://elcomercio.pe/economia/peru/65-empresas-peru-son-informales-168604 
El Comercio (2015). Vender una vivienda en el Perú puede demorar hasta seis meses. Recuperado de http://elcomercio.pe/economia/peru/vender-vivienda-peru-puededemorar-hasta-seis-meses-noticia-1840737

El Comercio (2015). Estos son los retos que afrontan las microfinanzas en Perú. Recuperado de http://elcomercio.pe/economia/dia-1/estos-son-retos-que-afrontan-microfinanzasperu-noticia-1861734

El Comercio (2017). SBS usa fideicomiso para regular fintech mientras sopesa una ley para el sector. Afluenta es la primera fintech que forma fideicomiso para hacer más transparentes sus operaciones. Recuperado de https://elcomercio.pe/economia/negocios/sbs-fideicomiso-regular-fintech-sopesa-ley$\underline{\text { sector-425966 }}$

El Peruano (2011). Ley de protección de datos personales. Recuperado de http://www.pcm.gob.pe/transparencia/Resol_ministeriales/2011/ley-29733.pdf

Equilibrium Clasificadora de Riesgos S.A.(2016). Informe de Clasificación: Banco de Crédito del Perú. Recuperado de http://www.equilibrium.com.pe/Bcp.pdf

Equilibrium Clasificadora de Riesgos S.A.(2016). Informe de Clasificación: ICBC Perú Bank. Recuperado de http://www.equilibrium.com.pe/ICBC.pdf

Gestión (2013). IPE: El 20\% de los créditos informales cuesta más de $700 \%$ anual. Recuperado de https://gestion.pe/tu-dinero/ipe-20-creditos-informales-cuesta-700$\underline{\text { anual-39813 }}$

Gestión (2014). ¿Por qué no existen más opciones de financiamiento alternativo en el Perú?. Recuperado de http://gestion.pe/tu-dinero/que-no-existen-mas-opcionesfinanciamiento-alternativo-peru-2116509 
Gestión (2015). Cuatro razones por las que China golpeará a la economía peruana.

Recuperado de http://gestion.pe/economia/cuatro-razones-que-china-golpearaeconomia-peruana-2140908

Gestión (2016). Piura, Arequipa y Chiclayo con mayor proyección de crecimiento para el sector cobranzas. Recuperado de http://gestion.pe/tu-dinero/piura-arequipa-ychiclayo-mayor-proyeccion-crecimiento-sector-cobranzas-2169092

Gestión (2016). Perú Sotheby's amplía intermediación de bienes raíces en Lima. Recuperado de http://gestion.pe/empresas/peru-sothebys-amplia-intermediacion-bienes-raices$\underline{\text { lima-2156369 }}$

Gestión (2017). Fintech: Cuatro datos para saber si una fintech es confiable. Recuperado de https://gestion.pe/economia/mercados/fintech-cuatro-datos-fintech-confiable-144495

Gestiópolis (2014). Estrategias de promoción dentro de las 4 p. Recuperado de http://www.gestiopolis.com/estrategias-de-promocion-dentro-de-las-4-p/

Gestiópolis (2014). Estrategias de ventas desde la mercadotecnia. Recuperado de http://www.gestiopolis.com/estrategias-de-ventas-desde-la-mercadotecnia/

Grow.ly (2016). Plataforma Grow.ly. Recuperado de https://www.grow.ly/

Instituto Nacional de Estadística e Informática (2016), Clasificación Industrial Internacional Uniforme Rev. 4. Recuperado de http://proyectos.inei.gob.pe/ciiu/

Instituto Peruano de Economía (2012). El crédito informal en el Perú. Recuperado de http://ipe.org.pe/documentos/el-credito-informal-en-el-peru

Kapital Zocial (2016). Kapital Zocial. Recuperado de http://www.kapitalzocialperu.com/ 
Kickstarter (2016). Kickstarter. Recuperado de https://www.kickstarter.com/

Lara, T. (2014). Crowdsourcing: cultura compartida. En Acción Cultural Española. Anuario AC/E de Cultura Digital. Recuperado de http://www.accioncultural.es/es/publicacion_digital_anuario_ac_e_cultura_digital_f ocus_2014

Legislación Ambiental (2015). Manual de Legislación Ambiental. Recuperado de http://www.legislacionambientalspda.org.pe/

Lego (2016), Lego IDEAS. Recuperado de https://ideas.lego.com/

Ministerio de Economía y Finanzas (2016), Marco Macroeconómico Multianual 2017-2019. Recuperado de https://www.mef.gob.pe/contenidos/pol_econ/marco_macro/MMM_2017_2019_Rev isado.pdf

Müller, A. (2016). Análisis de Mercado. Recuperado de http://www.lamolinavirtual.org/campus2/pluginfile.php/11697/mod_folder/content/0 /IDEA\%20DE\%20NEGOCIO\%20Y\%20ESTUDIO\%20DE\%20MERCADO/estudio -de-mercado.pdf?forcedownload $=1$

Ministerio de la Producción (2014), Decreto Supremo No.003-2014-PRODUCE Programa Nacional de Innovación para la Competitividad y Productividad. http://www2.produce.gob.pe/dispositivos/publicaciones/ds003-2014-produce.pdf

NCFA (2015) Massolution Report Released: Crowdfunding Market Grows 167\% in 2014, Crowdfunding Platforms Raise \$16.2 Billion. Recuperado de: http://ncfacanada.org/2015-massolution-report-released-crowdfunding-marketgrows-167-in-2014-crowdfunding-platforms-raise-16-2-billion/

Peruanos Por el Kambio (2016), Plan de Gobierno 2016-2021. Recuperado de http://ppk.pe/documentos/plandegobierno.pdf 
Portal de Turismo (2016). Intermediación en la industria de viajes en Perú crece $10 \%$. Recuperado de http://portaldeturismo.pe/index.php/local/item/4551-intermediacionen-la-industria-de-viajes-en-peru-crece-10

Gleiser, S. (2014). El 65\% de todas las empresas en el Perú son informales. Recuperado de http://elcomercio.pe/economia/peru/65-todas-empresas-peru-son-informales-noticia$\underline{1720484}$

RIMAC (2015). Productos: Mayor flexibilidad para las PYMEs. Recuperado de https://www.rimac.com.pe/corredores/articulo/productos/Mayor-flexibilidad-para$\underline{\text { las-PYMEs }}$

Semana Económica (2015). La confianza del consumidor en Arequipa. Recuperado de http://semanaeconomica.com/desdeelsurperuano/2015/06/18/la-confianza-delconsumidor-arequipeno/

Smithsonian (2016). Smithsonian Digital Volunteers: Transcription Center. Recuperado de https://transcription.si.edu/

Superintendencia de Banca y Seguros y AFP (2015). Carpeta de Información del Sistema Financiero. Recuperado de http://www.sbs.gob.pe/app/stats/EstadisticaBoletinEstadistico.asp?p=14\#

Superintendencia Nacional de Aduanas y de Administración Tributaria (2018). Cuadro Resumen de otras rentas de segunda categoría. Recuperado de http://orientacion.sunat.gob.pe/index.php/personas-menu/impuesto-a-la-rentapersonas-ultimo/rentas-de-segunda-categoria-personas/otras-rentas-de-segunda$\underline{\text { categoria }}$

Unidad de Proyección Normativa y Estudios de Regulación Financiera (2016). Alternativas de regulación del crowdfunding. Recuperado de http://www.urf.gov.co/urf/ShowProperty?nodeId=\%2FOCS\%2FP_MHCP_WCC049581\%2F\%2FidcPrimaryFile\&revision=latestreleased

\section{COTIZACIONES}

